\title{
IUCN
}

\section{Shared Resources}

Issues of Governance

Sharelle Hart

Editor

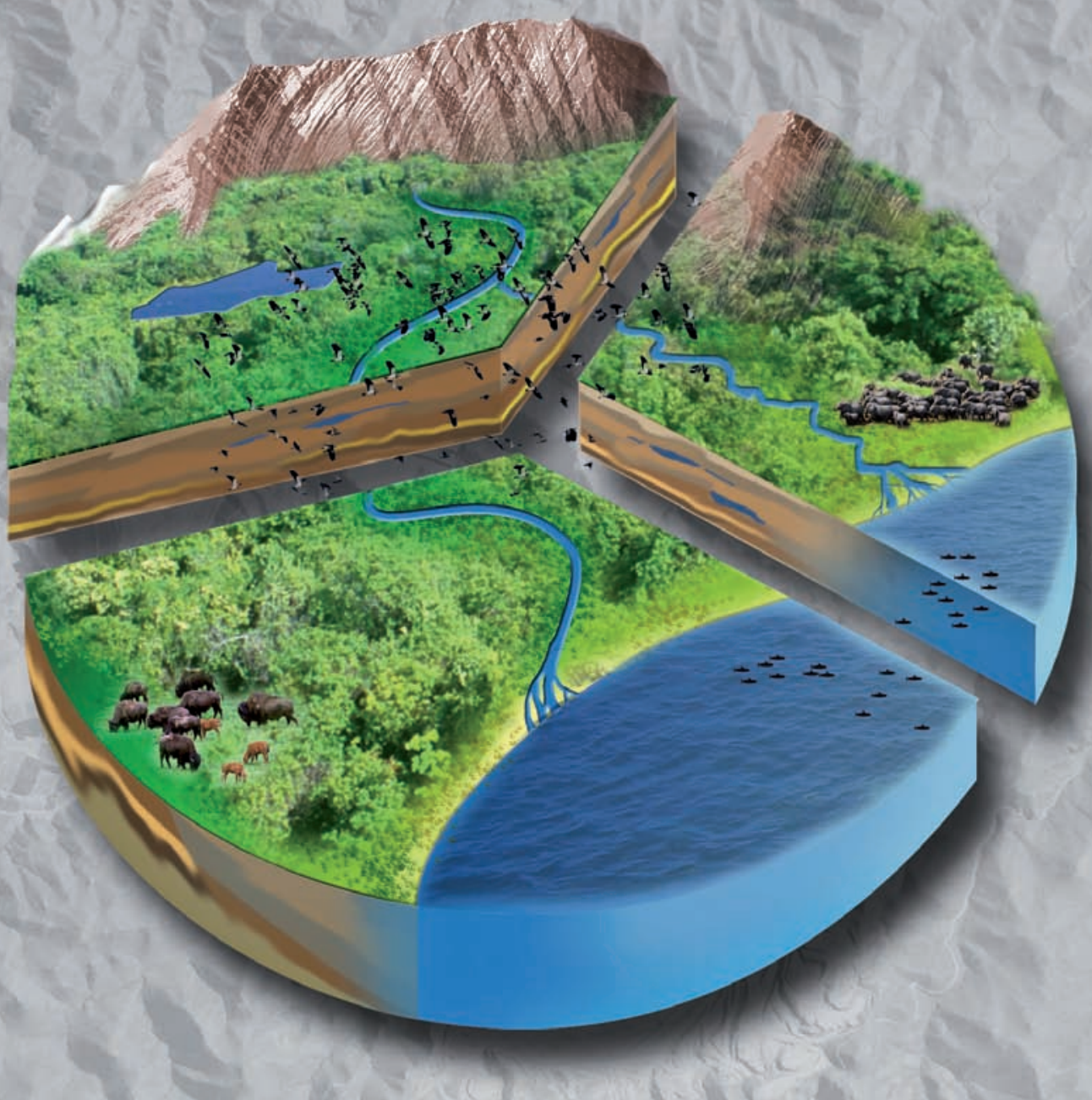



Shared Resources: Issues of Governance 


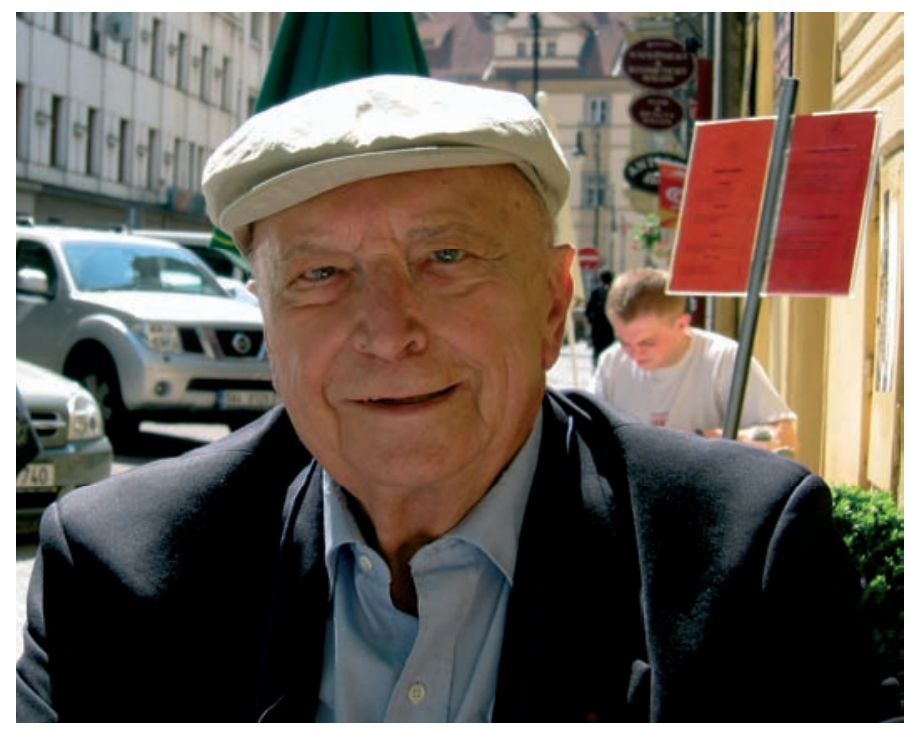

This publication is dedicated to the memory of Prof. Alexandre Kiss for the contribution he has made over the years to the Environmental Law Programme. 


\section{Shared Resources: Issues of Governance}

Sharelle Hart

Editor

IUCN Environmental Law and Policy Paper No. 72 
The designation of geographical entities in this book, and the presentation of the material, do not imply the expression of any opinion whatsoever on the part of IUCN or the German Federal Ministry for Economic Cooperation and Development (BMZ) concerning the legal status of any country, territory, or area, or of its authorities, or concerning the delimitation of its frontiers or boundaries.

The views expressed in this publication do not necessarily reflect those of IUCN or BMZ.

This publication has been made possible in part by funding from BMZ.

Published by: IUCN, Gland, Switzerland in collaboration with the IUCN Environmental Law Centre, Bonn, Germany

Copyright: $\quad$ (c) 2008 International Union for Conservation of Nature and Natural Resources

Reproduction of this publication for educational or other non-commercial purposes is authorized without prior written permission from the copyright holder provided the source is fully acknowledged.

Reproduction of this publication for resale or other commercial purposes is prohibited without prior written permission of the copyright holder.

Citation: $\quad$ Hart, Sharelle (editor) (2008). Shared Resources: Issues of Governance.

IUCN, Gland, Switzerland. xii + 249pp.

ISBN: $\quad 978-2-8317-1141-6$

Cover design by: IUCN Environmental Law Centre

Cover image: $\quad$ magoodesign $\bullet$ Markus Kahlenberg

Layout by: $\quad$ DCM Druck Center Meckenheim GmbH

Produced by: IUCN Environmental Law Centre

Printed by: $\quad$ DCM Druck Center Meckenheim GmbH

Available from: IUCN Publications Services

Rue Mauverney 28

1196 Gland

Switzerland

Tel +41229990000

Fax +41229990010

books@iucn.org

www.iucn.org/publications

A catalogue of IUCN publications is also available.

The text of this book is printed on Novatech $90 \mathrm{~g} / \mathrm{m}^{2}$ paper made from raw materials originating from responsibly managed forests. 


\section{Table of Contents}

\section{Preface}

1 International Cooperation on Shared Natural Resources.

Dinah Shelton

1.1 Shared resources management ....................................................................... 2

1.2 Transboundary protected areas and landscapes ................................................... 4

1.3 Ecosystem protection and management ........................................................... 5

1.3.1 The polar regions............................................................................ 5

1.3.2 Mountain ecosystems ........................................................................ 8

1.3.3 Coastal and marine ecosystems .......................................................... 10

1.4 Common principles and legal issues ............................................................ 12

2 Experiences in Negotiating Transboundary Agreements ........................................ 15

Dr Iwona Rummel-Bulska

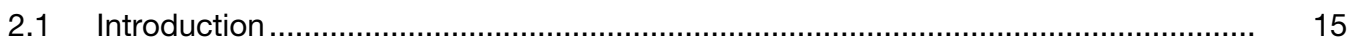

2.2 Negotiating transboundary agreements: general principles................................... 16

2.2.1 Approaches used in negotiating transboundary agreements ....................... 17

2.2.2 Different mechanisms used to avoid delays ............................................... 19

2.3 UNEP Principles on Shared Natural Resources ..................................................... 20

2.4 Specific examples of transboundary agreement negotiations .................................... 22

2.4.1 Transboundary aspects in the UNEP Provisions for Co-operation between States in Weather Modification .................................................................. 22

2.4.2 Offshore mining and drilling ............................................................... 23

2.4.3 Montreal Guidelines for the Protection of the Marine Environment against Pollution from Land-Based Sources ..................................................... 23

2.4.4 Environmental impact assessment .......................................................... 23

2.4.5 Management of Hazardous Waste.............................................................. 24

2.4.6 International Trade in Chemicals................................................................. 24

2.5 Negotiating agreements on management and use of regional seas .......................... 26

2.5.1 The Mediterranean Sea: a case study........................................................ 26

2.5.2 Negotiation of other Regional Seas Action Plans .......................................... 27

2.6 Negotiating binding regional regimes on shared freshwater resources ...................... 28

2.6.1 The Zambezi Action Plan for the Environmentally Sound Management of the Common Zambezi River System.......................................................... 29

2.6.2 Other shared water resources: Lake Chad and the River Nile...................... 31

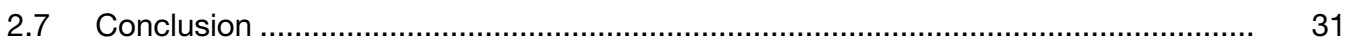


3 Transboundary Management of Natural Resources: A Brief Overview of World Bank Policies and Projects

Charles E. Di Leva

3.1 Introduction

3.2 Relevant Bank policies for the management of transboundary natural resources...... 35

3.2.1 International Waterways (OP 7.50) ...................................................... 35

3.2.2 Projects in Disputed Areas (OP 7.60) ..................................................... 37

3.2.3 Environmental Assessment (OP/BP 4.01) ................................................. 37

3.2.4 Other policies that promote sound resource protection, information sharing, and stakeholder participation ...................................................... 40

3.3 Instruments to support compliance ........................................................................ 42

3.4 Operational Policies in a transboundary resource context..................................... 43

3.4.1 Brazil-Bolivia Gas Pipeline Project (GASBOL) ....................................... 43

3.4.2 Yacyreta Hydroelectric Project............................................................... 43

3.4.3 Nam Theun 2 Project (NT2) ................................................................ 44

3.4.4 Mekong River Water Utilization Project.................................................... 44

3.4.5 Nile Basin Initiative (NBI) .......................................................................... 45

3.4.6 Red Sea - Dead Sea Water Conveyance Project ........................................ 46

3.5 New partnerships for managing natural resources............................................... 46

3.5.1 Transboundary protected areas .............................................................. 46

3.5.2 Partnerships to address global fishery and forest issues ............................ 47

3.5.3 Bank projects and their strategic alignment with a country's priorities......... 47

3.5.4 Role of Civil Society Organizations ...................................................... 48

3.6 Lessons learned ............................................................................................. 49

3.6.1 Bank's review of experience with the EA policies....................................... 49

3.6.2 Shared lake basins ........................................................................ 50

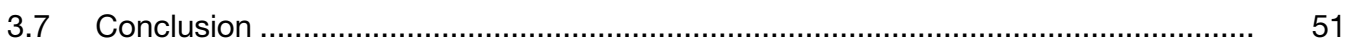

\section{The Southern African Development Community Experience in Shared Watercourse} Governance

Louis J. Kotzé

4.1 Introduction.

4.2 SADC: an overview

4.3 The need for shared watercourse governance in SADC ....................................... 59

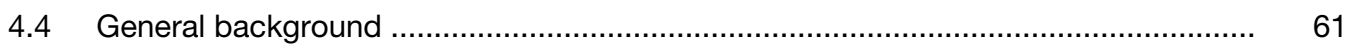

4.5 Legal nature of the 2000 Protocol........................................................................... 62

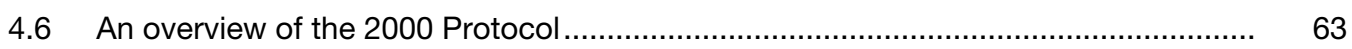

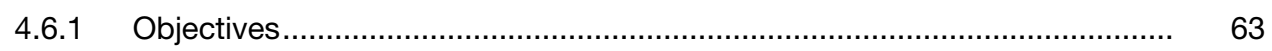

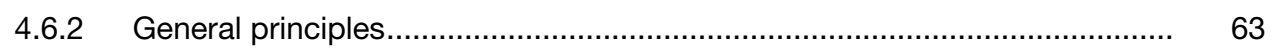

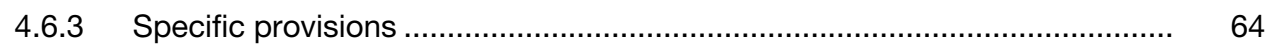

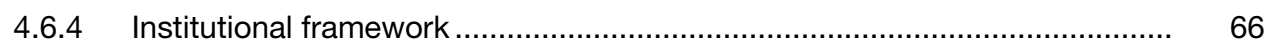

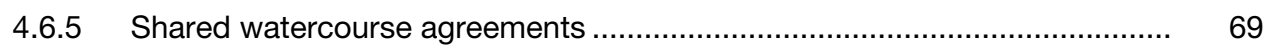


4.6.6 Dispute settlement ............................................................................ $\quad 70$

4.7 Application of the regime in domestic jurisdictions: a South African case study........ 71

4.8 Challenges and opportunities .......................................................................... 74

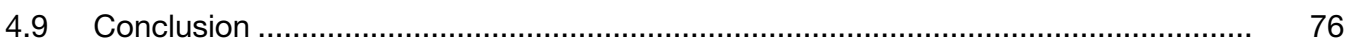

5 Gestion transfrontalière du Bassin du Lac Tchad : Enjeux, défis et opportunités ........ 77

Rémi Jiagho and Paul Noupa...................................................................................... 77

5.1 Presentation du Bassin du Lac Tchad ................................................................ 77

5.2 Description des caractéristiques biophysiques ...................................................... 77

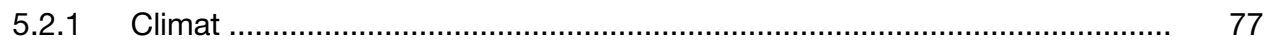

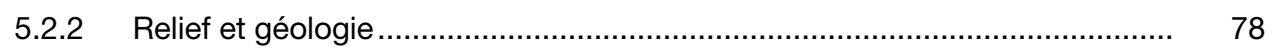

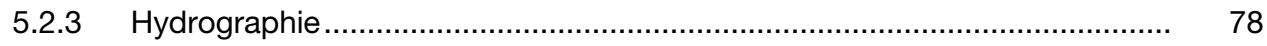

5.2.4 Eléments biologiques ............................................................................. 78

5.3 Les arrangements institutionnels mis en place pour la gestion transfrontalière dans le Bassin du Lac Tchad........................................................................................... $\quad 80$

5.3.1 Bref aperçu de la Commission du Bassin du Lac Tchad............................. 80

5.3.2 Forces et faiblesses des arrangements institutionnels au niveau de la gestion du Bassin du Lac Tchad ............................................................ 81

5.4 Opportunités \& défis ................................................................................... 82

5.4.1 Respecter les directives de la convention de Ramsar ................................ 82

5.4.2 Restructurer la CBLT pour la rendre plus efficace....................................... 83

5.4.3 Développement d'un processus de concertation nationale et sous régionale ....................................................................................... 84

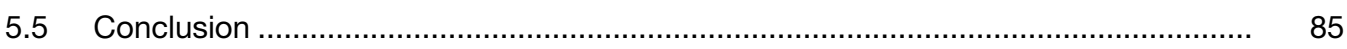

6 Transboundary Management of Natural Resources Neusiedler See / Fertö-Tó ............ 87 Katharina Diehl and Alois Lang

$6.1 \quad$ Introduction .............................................................................................. 87

6.2 The transboundary national park area .................................................................. 88

6.2.1 The geographical setting ................................................................ 88

6.2.2 Common history .......................................................................... 89

6.2.3 Protection status ........................................................................ 92

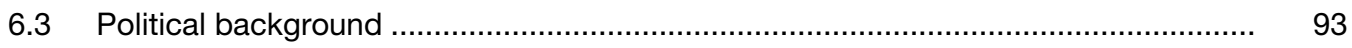

6.3.1 Co-operation in water management ...................................................... 93

6.3.2 Co-operation in nature conservation......................................................... 95

6.3.3 Co-operation in the establishment of the national parks .............................. 95

6.3.4 A long-term vision ......................................................................... 96

6.4 Treaties and institutional arrangements............................................................ 97

6.4.1 The nineteenth century ..................................................................... 97

6.4.2 Treaty on the regulation of water management ....................................... 97

6.4.3 Establishment of a national park ........................................................ 97 
6.4.4 Establishment of a World Heritage Site .................................................... 99

6.5 Lessons learned in transboundary co-operation ................................................... 100

6.6 Effect on nature conservation ................................................................... 101

6.7 Dispute resolution processes........................................................................ 101

6.8 Role of NGOs, international organizations, and funding bodies............................. 103

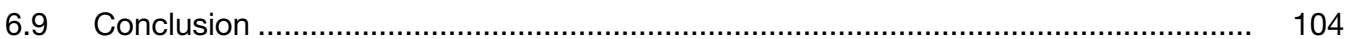

7 The Antarctic Protected Area Approach.................................................................. 105

Lyn Goldsworthy Alan D. Hemmings

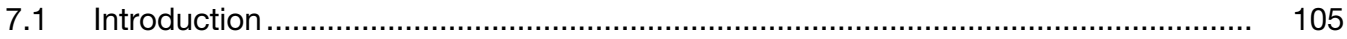

7.2 Broad-level management - the Antarctic Treaty System .......................................... 107

7.3 Development of specific area management and protection..................................... 112

7.3.1 Early concepts .................................................................................. 112

7.3.2 The arrival of the Madrid Protocol .................................................................. 114

7.3.3 The 'workshop' era.................................................................................... 116

7.3.4 Frameworks, Guidelines, and Reviews ................................................. 119

7.3.5 Marine Protected Areas........................................................................... 120

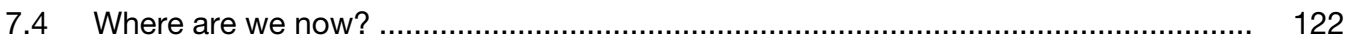

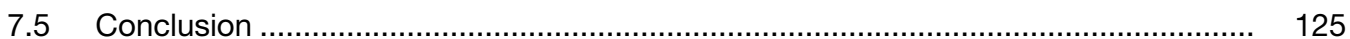

8 Efectos Ambientales Transfronterizos del Proyecto Minero Binacional Pascua Lama: el conflicto analizado desde la perspectiva internacional ............................................ 129 Marta Brunilda Rovere

8.1 Introducción

8.2 Efectos contaminantes sobre los recursos naturales: reclamos de los opositores al Proyecto

8.3 Situación de los glaciares: vacíos legales

8.4 Normativa nacional ambiental aplicable al Proyecto .............................................. 136

8.5 Carácter binacional del Proyecto: tratados ambientales multilaterales y principios del derecho internacional ambiental

8.5.1 Consideraciones generales. Los tratados ambientales multilaterales como creadores de obligaciones para las partes

8.5.2 Principios del derecho ambiental internacional: su consideración en los tratados ambientales multilaterales y en los acuerdos bilaterales

8.5.3 Instrumentos bilaterales comerciales y ambientales aplicables al conflicto .

9 Successfully Managing Marine Fisheries in the Benguela Current Large Marine Ecosystem

Shaheen Moolla

9.1 Introduction 
9.2 Establishment of the BCLME Programme ......................................................... 151

9.2.1 Phase 1: the Benguela Fisheries Interaction Training Programme ................ 151

9.2.2 Phase 2: establishment of the BCLME Programme.................................... 151

9.2.3 Implementation of the BCLME Programme, 2002 ................................... 152

9.3 Institutional arrangements......................................................................... 153

9.4 Evaluating the BCLME Programme: challenges and achievements........................ 158

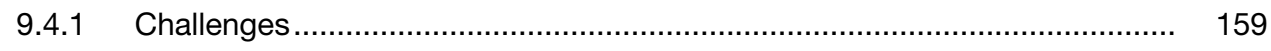

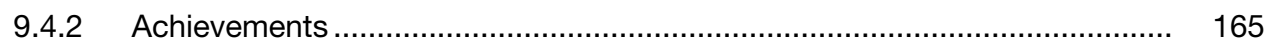

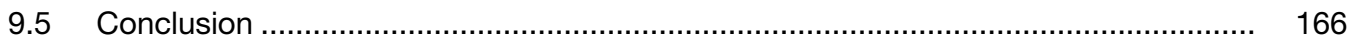

10 The North Atlantic Salmon Conservation Organization (NASCO): Nearing a 25 Year

Voyage in Transboundary Cooperation but Still Confronting a Sea of Challenges.......

David L. VanderZwaag and Emily Pudden

10.1 Introduction .................................................................................................... 169

10.2 The Salmon Convention and NASCO administration ............................................. 170

10.3 NASCO's voyage in transboundary co-operation ................................................ 173

10.3.1 Addressing fisheries management ......................................................... 173

10.3.2 Adopting the precautionary approach ............................................... 176

10.3.3 Broadening the scope of NASCO .................................................... 180

10.3.4 Encouraging scientific research .......................................................... 184

10.3.5 Reviewing NASCO's effectiveness..................................................... 186

10.4 Confronting a sea of challenges ......................................................................... 189

10.4.1 Putting precaution into practice .............................................................. 189

10.4.2 Embracing the ecosystem approach ...................................................... 190

10.4.3 Enhancing public participation .......................................................... 192

10.4.4 Considering indigenous participation and rights ................................... 192

10.4.5 Getting better grips on unreported catches.............................................. 193

10.4.6 Bringing the St. Pierre and Miquelon fishery into the NASCO fold................ 193

10.4.7 Preventing escape of farmed salmon........................................................ 194

10.4.8 Ensuring implementation of existing commitments ................................... 195

10.4.9 Reaching agreement on a performance review ....................................... 195

10.4.10 Addressing dispute resolution....................................................... 196

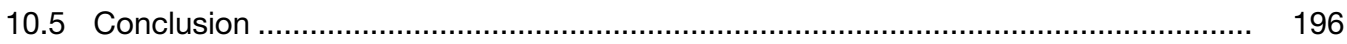

11 Management of Tuna Fisheries in the Western and Central Pacific ........................... 199

Pepe Clarke

11.1 Introduction .............................................................................................. 199

11.2 Regional overview .................................................................................... 200

11.3 Resource overview.............................................................................. 201

11.3.1 Conservation status............................................................................ 202

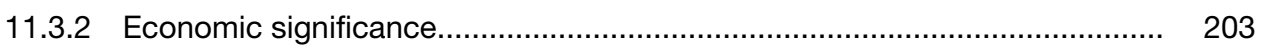




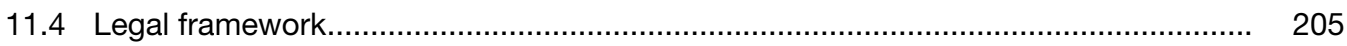

11.4.1 Global treaties ............................................................................... 205

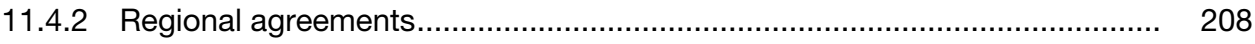

11.4.3 Bilateral agreements................................................................... 214

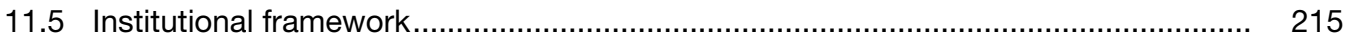

11.5.1 Forum Fisheries Agency ................................................................. 216

11.5.2 Western and Central Pacific Fisheries Commission ................................ 219

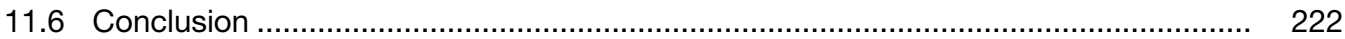

12 A Breakthrough in Solving the Indonesian Haze? ................................................... 225

Koh Kheng-Lian

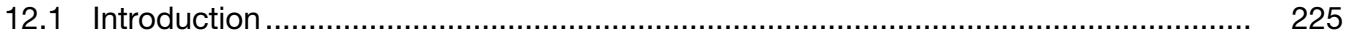

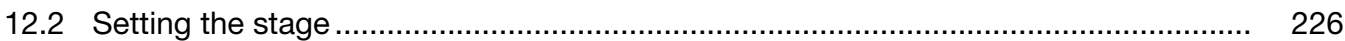

12.3 Evaluation of ASEAN's and Indonesia's roles in dealing with the haze from the 1990s to August 2006 ............................................................................................. 227

12.3.1 ASEAN soft law environmental instruments relating to the haze .................. 227

12.3.2 ASEAN Regional Haze Action Plan, 1997 ................................................ 230

12.3.3 ASEAN Agreement on Transboundary Haze Pollution, 2002 ...................... 231

12.4 An evaluation - the ASEAN and Indonesian levels ............................................ 232

12.5 Breakthrough in solving the haze: from August 2006? ....................................... 236

12.5.1 Cebu Resolution on Sustainable Development, 2006: Haze ....................... 237

12.5.2 Action plans for 'fire-prone' districts ........................................................... 238

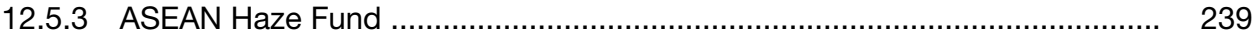

12.5.4 Establishment of an ASEAN Environmental Taskforce? ............................... 240

12.5.5 The 'Heart of Borneo Forests' transboundary collaboration: keeping the haze at bay ................................................................................... 240

12.5.6 A Turn of Events Affecting Solution of Haze? .......................................... 241

12.6 Conclusion ........................................................................................................... 244

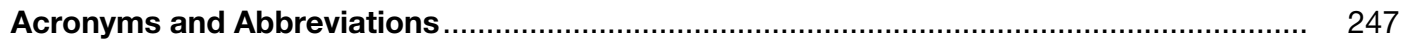




\title{
Preface
}

It is my pleasure to present ELP's new publication on "Shared Resources: Issues of Governance". This publication explores the range of transboundary governance structures that are in place to address shared resources and the environmental impacts on them.

As environmental impacts and effects know no boundaries, there has been an increasing recognition of the need for collective international action. This has led to the development of a range of instruments and tools to govern shared resources. In many cases, these instruments have overcome jurisdictional, policy and practical challenges to develop a framework for collaborative action to address regional environmental issues.

The publication contains a number of case studies that highlight different types of transboundary governance structures that address specific ecosystems. These case studies cover single ecosystems, such as the Antarctica, as well as shared watercourses under the jurisdiction of a number of States such as the projects in Southern Africa and Lake Chad, and fishery management issues from tuna management in the Pacific to the Benguela Current Large Marine Ecosystem.

While each case study presents its own unique circumstances, some common themes and challenges emerge. For example the need for a holistic approach, effective application on environmental impact assessments and for precaution. There is also common recognition of the need for continuing political will to make those structures effective.

I am grateful to the German Federal Ministry for Economic Cooperation and Development (BMZ) who have made this publication possible. I would also like to express my gratitude to Sharelle Hart, former Legal Officer at the ELC, who was the initial editor of the publication and coordinator of the project. My thanks also go to Andrea Düppen, Legal Consultant, who finalized the editing process.

\author{
Alejandro Iza \\ Head, Environmental Law Programme \\ Director, Environmental Law Centre
}





\section{International Cooperation on Shared Natural Resources}

\section{Dinah Shelton ${ }^{1}$}

New approaches to achieving effective environmental protection emerge with greater knowledge and understanding of the biosphere and its components. As the global and multidimensional character of environmental problems has become clear, most States now accept that holistic international efforts are required to address many aspects of environmental deterioration, including marine pollution and living resources, depletion of stratospheric ozone, and climate change. Each of these issues can be seen to involve a shared natural resource, a concept that has moved beyond the traditional scope of addressing transboundary resources to encompass areas beyond national jurisdiction as well as natural processes like climate change. An ecosystem approach that considers the totality of impacts, even when the ecosystem crosses national boundaries, is stressed in the current work of international bodies concerned with environmental protection. Early legal measures for the joint or common management of shared resources are thus being extended to large ecosystems.

Without international regulation, particularly for areas beyond national jurisdiction, shared natural resources are vulnerable to the 'tragedy of the commons', becoming depleted or exhausted as each State seeks to maximize its own benefit by exploiting the resource. International cooperation is required to prevent this result, and the general international obligation to cooperate in addressing international problems therefore must be applied to shared resources. States should cooperate in the conservation, management, and restoration of natural resources that occur in areas under the jurisdiction of more than one State or fully or partly in areas beyond the limits of national jurisdiction, treating the natural system as a single ecological unit. As Iwona Rummel-Bulska describes in Chapter 2, the process of achieving such cooperation through negotiating transboundary agreements can be difficult because of doctrines of sovereignty and the problems of national debt, technology transfer, and financial resources. The role of public pressure and nongovernmental organizations is critical to achieving a sound result.

Various treaties have long existed on some transboundary resources, such as migratory species $^{2}$. Others have addressed commons areas like Antarctica or regional seas like the Mediterranean and Baltic. More recently, the 1997 New York Watercourses Convention, discussed further below, created a framework for negotiating agreements on the critical issue of shared aquatic systems. Many of the case studies in this volume analyze particular watercourse agreements in the context of the 1997 convention. Despite the increasing number of subregional agreements, the only general instrument on shared resources is a nonbinding text drawn up under

1 Ahn Professor of International Law, The George Washington University Law School, Washington, DC.

2 Convention on Migratory Species (1979), Berne Convention on European Wildlife (1979), Birds Convention (1950), EC Council Directive on the Conservation of Wild Birds (1979), Polar Bear Agreement (1973), and the Convention on Biological Diversity (1992). 
the auspices of the United Nations Environment Programme (UNEP) in 1978: the Draft Principles of Conduct in the Field of the Environment for the Guidance of States in the Conservation and Harmonious Utilization of Natural Resources Shared by Two or More States. The principles have proved very influential in the development of many agreements, particularly those concerning transnational parks and protected areas, as seen in Chapter 6, by Katharina Diehl and Alois Lang, on the cross-border national park shared by Hungary and Austria.

\subsection{Shared resources management}

The concept of joint management of shared resources began with commercially exploited species and international watercourses. ${ }^{3}$ Establishment of permanent institutions or rules for joint management reflected the ecological reality of a shared resource. Common or joint management is not a new technique - it was used as early as the nineteenth century in the Convention on Navigation of the Rhine and later in the 1911 Conventoin Respecting Measures for the Preservation and Protection of the Fur Seals in the North Pacific Ocean - but it is increasingly applied to international watercourses and to shared ecosystems such as the Alps and the Arctic. Almost half the Earth's land surface lies within 263 international river basins - that is, those that traverse political boundaries. ${ }^{4}$ The Congo, Niger, Nile, Rhine, and Zambesi, for example, are each shared by more than nine countries. The essential need for water and the potential conflicts that can arise from competition over it makes it important that countries reach agreement on sharing water resources. State practice demonstrates awareness of this fact: the first known international water agreement dates back to the settlement of a water dispute over the Tigris River between the Sumerian city-states of Lagash and Umma (in 2500 BC). ${ }^{5}$ The Food and Agriculture Organization (FAO) has identified more than 3,600 international water treaties concluded between 805 and 1984. Since 1948, States have adopted 295 international water agreements. ${ }^{6}$

Early agreements mostly aimed to regulate navigation and demarcate boundaries, but the development of hydropower and large-scale irrigation development in the twentieth century shifted the focus to reconciling nonnavigational uses. Now better knowledge and understanding of ecosystems and their natural processes lead States to conclude more comprehensive agreements protecting freshwater resources as hydrographic units rather than as individual watercourses. These agreements recognize the difficult problem of balancing competing demands and differences between upstream and downstream States and their varied interests, including agriculture, industry, recreation, flood control, hydropower, environmental protection, and human health. The physical, economic, and social disparities between riparian nations can make management complex. An integrated approach offers a legal framework to reconcile differences

3 See United Nations Environment Programme (UNEP), Principles of Conduct in the Field of the Environment for the Guidance of States in the Conservation and Harmonious Utilization of Nature Resources Shared by Two or More States, Nairobi, May 9, 1978; A. Kiss, Can We Speak of the Protection and Management of Shared Natural Resources? Juridisk Tidskrift 1997-1998, IV 1.

4 A 'river basin' is the area that contributes hydrologically to surface and groundwater of a first order stream. The latter discharges into the ocean or a closed lake or inland sea. River basin is thus similar in concept to watershed or catchment area.

5 A. T. Wolf, Conflict and Cooperation Along International Waterways, Water Policy, vol. 1, no. 2 (1998), p. 251.

6 UNEP, Atlas of International Freshwater Agreements (Nairobi: 2002), p. 3. 
and make choices. When coupled with joint or shared management and monitoring, water basin agreements may provide the structure for effective environmental protection in the context of sustainable development.

The 1987 Agreement on the Action Plan for the Environmentally Sound Management of the Common Zambezi River System was one of the first to adopt a holistic approach to water resources management through an entire river system. Although the Action Plan is not legally binding, it provides the framework for action for the riparian States. The use of a 'soft law' instrument may reflect the fact that basin conditions and priorities may change considerably over time, necessitating flexibility in provisions and institutions. Water allocation, in particular, may vary according to availability, changing needs and values. In contrast to the approach of the Zambezi States, the newly independent countries around the Aral Sea adopted a series of binding agreements between 1993 and 1999 on water-related activities, improving the environment, and economic development of the region. ${ }^{7}$ Similarly, countries in the Southern African Development Community adopted a protocol on shared water systems on August 28, 1995, and revised it on August 7, 2000.

Despite the large number of positive developments, more than half the international water basins lack a cooperative management framework. ${ }^{8}$ In addition, many of the older agreements lack provisions on water quality management, monitoring, public participation, flexible allocation, and dispute resolution. Future agreements may be developed within the legal framework of the 1997 U.N. Convention on the Law of the Non-navigational Uses of International Watercourses, which includes the 'obligation not to cause significant harm'. Article 5 requires equitable and reasonable use. Watercourse States should use and develop the watercourse to obtain optimal and sustainable use thereof and benefits consistent with adequate protection of the watercourse. All watercourse States should participate in the use, sustainable development, and protection of an international watercourse in an equitable and reasonable manner, which includes both the right to use the watercourse and the duty to cooperate in the protection and development of it. These principles, together with an adaptable management structure and flexible criteria for maintaining water quality and quantity, can promote holistic water management.

In the context of international agreements, the environmental unity of international watercourses has led to recognition of the need for common management with the active participation of all concerned States. Article 24 of the 1997 treaty on international watercourses stops short of mandating the establishment of joint management, but it provides that watercourse States must enter into consultations concerning management, including possible creation of a joint management mechanism, at the request of any of the concerned States. In this regard,

7 For example, Agreement on Joint Activities in Addressing the Aral Sea and the Zone around the Sea Crisis, Improving the Environment, and Ensuring the Social and Economic Development of the Aral Sea Region (March 26, 1993); Agreement between the Government of the Republic of Kazakhstan, the Government of the Kyrgyz Republic, and the Government of the Republic of Uzbekistan on Cooperation in the Area of the Environment and Rational Nature Use (March 17, 1998); Agreement on the Use of Water and Energy Resources of the Sry Darya Basin (March 17, 1998); and Protocol to the Agreement on the Use of Water and Energy Resources of the Syr Darya Basin (May 7, 1999).

UNEP, supra note 6 , p. 7. 
management means planning the sustainable development of the watercourse and implementation of any plans adopted. It also means promoting the rational and optimal use and the protection and control of the watercourse. Such joint management has been adopted in many regions of the world. The Great Lakes, which contain one-fifth of the world's freshwaters, are jointly managed by the United States and Canada pursuant to a 1909 Boundary Waters Treaty through the International Joint Commission, an independent bilateral agency. The Commission today also addresses transboundary air pollution. Namibia and South Africa also have created a permanent water commission.

Agreements among interested States call for common management of, inter alia, the Niger, the Mekong, the Danube, the Meuse, the Scheldt, the Zambezi, the Mosel, the Mahakali (Nepal-India), the Ganges (India-Bangladesh), and the La Plata rivers as well as the Lake Chad basin. A declaration of principles between Jordan, the Palestine Liberation Organization, and the State of Israel seeks cooperation in regard to the Jordan River. The agreements on the rivers Meuse and Scheldt, signed in 1994, call for integrated management of the drainage area of the two rivers and agree on the need for measures of management and cooperation in regard to the sediments in the bed of the rivers. The agreements create an international commission to facilitate international cooperation.

The Convention on Co-operation for the Protection and Sustainable Use of the Danube River (Sofia, June 29, 1994) establishes an International Commission to coordinate consultation and joint activities for the sustainable and equitable management of surface and ground waters in the Danube catchment area. It looks to joint or harmonized programmes in part because its aim is regional and includes the reduction of the pollution loads of the Black Sea from sources in the catchment area. According to Article 4a, the States Parties should engage in consultations and joint activities in the framework of the International Commission. Other provisions call for harmonized domestic regulations for emission limits and standards (Article 7(5)(a)), harmonized monitoring and assessment methods (Article 9(1)), joint monitoring systems and programmes (Article 9), joint research (Article 15), and joint warning systems (Article 16).

\subsection{Transboundary protected areas and landscapes}

Transboundary protected areas are being created on a bilateral or even multilateral basis. Recently, the governments of Argentina, Paraguay, and Brazil agreed to link state and private reserves in the Parana jungle region, thus creating a green corridor. Since 1972, the Gran Paradiso National Park in the Italian Alps has been paired with the Vanoise National Park in France, nearly tripling the protected area and providing year-round protection to the ibex. On the regional level, the Waddenzee National Park covers all the natural range of seals along the tidal flats of Denmark, Germany, and the Netherlands. In 1987, the three coastal States entered into an administrative agreement on a common secretariat to set out their duties to cooperate in research and management of the Waddenzee ecosystem as a whole. Similarly, Spain and France coordinate signposts, visitor centres, and tourist information for the French Pyrenees Occidentales National Park and the Spanish Ordesa National Park. 
On November 30, 1999, Kenya, Tanzania, and Uganda signed in Arusha the Treaty for the Establishment of the East African Community. Chapter 19 of the treaty provides for cooperation in environment and natural resources management providing, in this framework inter alia, for irrigation and water catchment management, food security, and wildlife management (Articles 109, 110, and 116). It also advocates the integration of environmental management and conservation measures in all developmental activities such as trade, transport, agriculture, industrial development, mining, and tourism in the community (Article112, 1(e)).

The Council of Europe member States adopted the European Landscape Convention on October 20, 2000, with the objective of promoting landscape protection, management, and planning and to organize European cooperation on landscape issues. 'Landscape' is defined in the convention as an area, as perceived by people, whose character is the result of the action and interaction of natural and/or human factors. Landscape protection means action to conserve and maintain the significant or characteristic features of a landscape justified by its heritage value derived from its natural configuration and/or from human activity. These definitions place the treaty fully in the approach of integrated protection, reinforced by Article 2, which provides an extensive scope of application, including the entire territory - land, inland waters, and marine areas - of the Parties, and which covers natural, rural, urban, and peri-urban areas.

The general measures Parties should take include recognition of landscapes in law as an essential component of peoples' surroundings, an expression of the diversity of their shared cultural and natural heritage, and a foundation of their identity. This formulation indicates an understanding that humans throughout the world have altered the natural environment in diverse ways that today are part of the cultural identity of the group. This is expressed in the preamble, which notes that developments in agriculture, forestry, industrial and mineral production techniques, and the regional planning, town planning, transport, infrastructure, tourism, and recreation sectors and, at a more general level, changes in the world economy are in many cases accelerating the transformation of landscapes.

Specific obligations include identifying, assessing, and developing quality objectives for landscapes, with public participation. There should also be education and awareness raising of the general public. Article 9 calls on Parties to encourage transfrontier cooperation on local and regional levels and, whenever necessary, to prepare and implement joint landscape programmes.

\subsection{Ecosystem protection and management}

A holistic approach has come to be particularly important in protecting large transboundary ecosystems: the polar regions, mountains, and marine ecosystems.

\subsubsection{The polar regions}

The foundations of the Antarctica Treaty System emerged from the International Geophysical Year 1957-1958, proclaimed by the International Council of Scientific Unions, a nongovernmental organization supporting open scientific research. As discussed by Lyn Goldsworthy and Alan Hemmings in this volume, the 1959 Antarctic Treaty, concluded outside the auspices of the United Nations, demilitarized the continent and established that it be set aside for peaceful purposes in 
the interest of all humanity. The treaty guarantees freedom of scientific investigation and promotes the exchange of scientific information. State compliance with treaty obligations is ensured through a system of mutual inspections. The Antarctic Treaty Parties are also, according to Article X, to 'exert appropriate efforts consistent with the Charter of the United Nations, to the end that no one engages in any activity in Antarctica contrary to the principles or purposes of the ...Treaty'. The language of Article $X$ has given rise to many debates about whether it is intended to ensure that the activities of non-Parties conform to the treaty within Antarctica and its surrounding waters. ${ }^{9}$ Article IX foresees regular meetings of the Contracting Parties ${ }^{10}$ who are given authority to adopt measures regarding, inter alia, the preservation and conservation of living resources in Antarctica. Thus although the word environment does not appear in the treaty, there is a juridical base for considering and acting on environmental issues.

As Goldsworthy and Hemmings describe, the Antarctic Treaty has been progressively complemented by conservation measures and by two conventions, one adopted June 1, 1972, on the Conservation of Antarctic Seals and the second adopted May 20, 1980, on the Conservation of Antarctic Marine Living Resources (CCAMLR) in the area. CCAMLR is one of the first international agreements to adopt an ecosystem approach because it considers the interrelationship between all species and their particular physical environment. Its coverage is uniquely based upon a biological boundary, because it extends to ocean waters that are south of the 'Antarctic convergence', the cold waters favourable to nutrients and phytoplankton growth and to the proliferation of krill, one of the bases of the marine food chain. CCAMLR envisages the creation of a system to observe and supervise compliance with the treaty, including procedures relating to on-site visits to and inspections of ships operating within the treaty area. These inspections are undertaken by observers and inspectors designated by members of an international commission established by the convention. ${ }^{11}$ The major problem has been unreported and illegal catches, most of them made by non-Parties to the agreement. ${ }^{12}$ In order to strengthen its effectiveness, the CCAMLR Commission created a documentation scheme ${ }^{13}$ in 1999 and a monitoring system at the end of 2000.

In 1991, the Parties to the Antarctic Treaty negotiated a Protocol on Environmental Protection to the Antarctic Treaty that includes principles and rules concerning all activities in the Antarctic Treaty area. The Madrid Protocol designates Antarctica as 'a natural reserve, devoted to peace and science'. It invests the Antarctic Treaty System Consultative Meetings with the task of defining the

9 The provisions of the Antarctic Treaty and the Environmental Protocol apply to the area south of 60 degrees South Latitude, including all ice shelves. Article VI.

10 The Parties to the treaty do not all have the same rights of participation. Fully participating states, the Antarctic Treaty Consultative Parties (ATCP), are those that demonstrate their interest in Antarctica 'by conducting substantial scientific research activity there, such as the establishment of a scientific station or the dispatch of a scientific expedition'. The ATCP meet in the Consultative Meeting.

11 May 20, 1980, Art. 24, U.K.T.S. 48 (1982), Cmd. 8714, T.I.A.S. 10240, A.T.S. 3 (1982), 19 I.L.M. 837 (1980).

12 Greenpeace estimates that over half of the Patagonian toothfish catch is taken by illegal fishing conducted from countries that are not party to the Convention on the Conservation of Antarctic Marine Living Resources. See www.greenpeace.org

13 Although the Catch Documentation Scheme is intended to ensure that all toothfish are legally procured, in practice the captain of a vessel need only state that the fish were caught outside the convention area to circumvent the restrictions. 
general policy for the comprehensive protection of the Antarctic environment and creates a Committee for Environmental Protection to assist it in this task. The Committee provides advice and formulates recommendations to the Parties in connection with the implementation of the Protocol. In particular, it provides advice on the effectiveness of implementation measures, on the state of the Antarctic environment, and on the need for scientific research and procedures for situations requiring urgent action. The treaty foresees opening all areas of Antarctica, including stations, installations and equipment, and all ships and aircraft within this area, to inspection by observers designated by the Consultative Parties. The Committee for Environmental Protection provides advice on inspection measures, including formats for inspection reports and checklists for the conduct of inspections. The result has been the development of specific area management and protection, as well as marine protected areas. As the authors of the chapter indicate, however, there remain many issues and needs to develop effective environmental protection in the Antarctic Treaty area.

At the northern extreme of Earth, eight Arctic countries adopted in 1991 a detailed instrument on environmental protection. Called the Arctic Environmental Protection Strategy, it is based on the principle that management, planning, and development activities shall provide for the conservation, sustainable use, and protection of Arctic ecosystems and natural resources for the benefit and enjoyment of present and future generations, including indigenous peoples. Use and management of natural resources is based on an approach that considers the value and interdependent nature of ecosystem components. Management, planning, and development activities that may significantly affect the Arctic ecosystems must be based on informed assessments of their impact, including cumulative impact, on the Arctic environment; provide for the maintenance of the region's ecological system and biodiversity; respect the Arctic's significance for and influence on the global climate; be compatible with the sustainable use of Arctic ecosystems; take into account the results of scientific investigations and the traditional knowledge of indigenous peoples; and develop a network of protected areas. The Arctic Strategy identified six specific pollution issues that require attention: persistent organic contaminants, oil pollution, heavy metals, noise, radioactivity, and acidification. Unusually, disturbance from noise also is taken into account. The Strategy identified existing international mechanisms and proposed actions for each identified nuisance. Separate chapters relate to the protection of the Arctic marine environment, to emergency prevention, preparedness, and response, and to the conservation of Arctic fauna and flora.

A 1996 declaration, also a legally nonbinding text, created the Arctic Council as a multilateral forum in order to serve as a permanent high-level intergovernmental framework in which the eight Arctic nations can oversee existing Arctic multilateral activities as well as develop new initiatives. In addition to the eight member States, three organizations representing the majority of indigenous peoples in the circumpolar Arctic are Permanent Participants in the Council, which meets on a biennial basis. The Arctic Council oversees and coordinates programmes originally established under different instruments: the Arctic Environmental Protection Strategy; the Arctic Monitoring and Assessment Programme; the Conservation of Arctic Flora and Fauna; the Protection of the Arctic Marine Environment; and Emergency Prevention, Preparedness, and Response. Other developments include the adoption of an International Code of Safety for Ships in Polar Waters and a Circumpolar Protected Areas network. 


\subsubsection{Mountain ecosystems}

Mountains and uplands constitute about half of the terrestrial landmass of Earth and exist in over three-quarters of the world's countries. Mountain areas contain all the environmental milieu and human activities that have been part of international environmental regulation. They are places of unique and rich biodiversity, cultural diversity within largely traditional lifestyles, fresh water, pristine landscapes, tourism (eco- and industrial), and forest and mineral resources. They are also areas of poverty, erosion, natural disasters, desertification, and industrial development. They have a significant impact on other ecosystems and areas, being important water towers and sensitive indicators of global climatic and environmental change. Some of the activities most destructive to mountain areas, such as extractive mining and large-scale dams, have few or no international norms governing them.

No treaty for mountain areas exists at the global level; only Chapter 13 of Agenda 21 offers a blueprint for mountain resources. Chapter 13 - together with Commission on Sustainable Development progress reports, ECOSOC resolution 1997/45, and a 1997 FAO report on Chapter 13 - identifies the importance of law in the promotion of mountain conservation and development. ${ }^{14} \mathrm{~A}$ study by the Mountain Institute found that legal, regulatory, and enforcement structures are perhaps the most important contributing factors to promoting conservation and sustainable development, particularly when using the principle of subsidiarity to enhance local participation. ${ }^{15}$

The Convention Concerning the Protection of the World Cultural and Natural Heritage (of November 23, 1972) has more than 40 mountain areas around the world on the World Heritage list, including Virunga National Park (Democratic Republic of the Congo), Mount Kenya, Simen National Park (Ethiopia), Prinin National Park (Bulgaria), and Yosemite National Park (United States). In New Zealand, the sacred peaks of Tongariro National Park became the first national park to be created from a gift of land by an indigenous people and a World Heritage site in 1992, the first to be granted that status on both landscape and cultural grounds. Listing increases international recognition for the importance of the sites, but protection measures are largely left to national authorities.

The treaty system established for the protection of the Alps is the most extensive and explicit corpus concerning mountain areas. It aims at protecting one of the largest continuous and relatively unspoilt natural regions in Europe. A Convention Concerning the Protection of the Alps adopted on November 7, 1991, by seven countries of the region and the European Union ${ }^{16}$ proclaimed a set of principles addressing virtually every aspect of human activities that produce direct or indirect impacts on the mountain environment. The convention is a framework treaty that lists the main fields where specific protocols are to be drafted. It also establishes the foundations

14 FAO, Task Manager's Report on Chapter 13, Agenda 21, Report of the Secretary-General, E/CN.17/1997/2/Add.12, 22 January 1997. The report refers to the need for new or reinforced legal mechanisms (charters, conventions, national legislation, etc.) to protect fragile mountain ecosystems and promote sustainable development in mountain regions.

15 Lynelle Preston (ed.), Investing in Mountains: Innovative Practices and Promising Examples for Financing Conservation and Sustainable Development (Washington, DC: The Mountain Institute, 1997).

16 Salzburg, November 7, 1991, EMuT 991:83. 
of legal, scientific, economic, and technical cooperation and creates a Conference of Contracting Parties, called the Alpine Conference, charged with elaborating the protocols. The Conference also has established a Compliance Mechanism providing for reporting procedures.

The first protocol, adopted in 1994, aims to implement the Alpine Convention in the Field of Town and Country Planning and Sustainable Development. ${ }^{17}$ A second instrument, the Protocol for the Implementation of the Alpine Convention in the Field of Mountain Agriculture ${ }^{18}$ insists on the use of agricultural methods of production that are respectful of nature and environment. It also advocates the integration of agricultural considerations into other policies and has a particular importance for land conservation and management. The aim of the Protocol on Nature Protection and Landscape Conservation ${ }^{19}$ is not only to protect but also to manage and, if necessary, restore landscapes and nature in the Alpine region. It recommends cooperation - in particular, transboundary cooperation - in the preparation of inventories and the creation and the monitoring of protected areas. Here again, local communities should participate in the action. After this first series of protocols, the Alpine States adopted a further instrument in 1996, related to mountain forests. ${ }^{20}$ It insists on the main functions of the forests and on protecting them as well as urban areas and agricultural land, and on maintaining the productivity of forests and their social and ecological functions.

On October 16, 1998, Parties to the Alpine convention adopted three more protocols. The first of these is on the protection of soils. ${ }^{21}$ The Protocol Concerning Energy ${ }^{22}$ invites the Parties to harmonize their plans related to energy with their general management scheme for the Alpine region; to optimize energy production, transport, and distribution taking into account the needs of environmental protection; and to limit the impact of the uses of energy on the environment, including that of negative effects on the landscapes. The protocol also advocates energy conservation and the use of renewable sources of energy. Parties shall exchange information on the use and surveillance of nuclear energy sources. All new projects related to energy and all modification of existing installations should be submitted to an environmental impact assessment. The third protocol, adopted on the same day, ${ }^{23}$ aims to ensure sustainable development of the Alpine region through tourism that respects the environment. The influx of tourists should be controlled within the natural limits of the development of the region. This principle should be applied to different aspects of tourism: housing, transport, sports, use of aircraft, coordination of the dates of vacation, cooperation with agriculture, forestry, and local handcraft. Quiet areas should be created, and the use of ski lifts and of ski slopes should be in conformity with environmental requirements.

17 Chambéry, December 20, 1994, EMuT 991:83/B.

18 Chambéry, December 20, 1994, EMuT 991:83/C.

19 Chambéry, December 20, 1994, EmuT 991:83/D.

20 Protocol for the Implementation of the Alpine Convention in the Field of Mountain Forests, Brdo, February 27, 1996, EMuT 991:83/E.

21 Protocol for the Implementation of the Alpine Convention in the Field of Soil Protection, Bled, October 16, 1998, EMUT 991:83/F.

22 Bled, October 16, 1998, EMuT 991:83/G.

23 Protocol for the Implementation of the Alpine Convention in the Field of Tourism, October 16, 1998, EMuT, $991: 83 / \mathrm{H}$. 
The last two Protocols were adopted on October 31, 2000. The objective of the first, related to transport, ${ }^{24}$ is to adopt a sustainable policy in this field by reducing nuisances and risks, avoiding or minimizing danger for biodiversity, and using means of transport that respect as much as possible the environment and natural resources. Such objectives should also be taken into account in other policies. As with all the protocols, participation of the local populations is encouraged. The final protocol concerns dispute settlement ${ }^{25}$ and aims to reach such settlement by consultation and by arbitration.

In another region, the Framework Convention on the Protection and Sustainable Development of the Carpathians was adopted in Kiev on May 23, 2003, by the fifth ministerial conference 'Environment for Europe' and signed by Hungary, Romania, Serbia and Montenegro, Slovakia, and Ukraine. It follows the model of the Alpine conventional system and includes all aspects of protecting the mountain environment. Detailed provisions concern the conservation, sustainable use, and restoration of biological and landscape diversity including the protection of endangered species, endemic species, and large carnivores. It also aims at preventing the introduction of alien invasive species and the release of genetically modified organisms threatening ecosystems, habitats, or species and their control or eradication. A critically important Article 6 invites States Parties to ensure sustainable and integrated water/river management, including land-use planning. It also calls on them to adopt policies aimed at conserving natural watercourses, springs, lakes, and groundwater resources, recognizing the importance of pollution and flood management, prevention, and control. States Parties should also preserve and protect wetlands and wetland ecosystems. An early warning system for transboundary impacts on the water regime or flooding and accidental water pollution should be further developed.

Other provisions concern an integrated approach to land resource management, spatial planning, sustainable agriculture and forestry, sustainable transport and infrastructure, sustainable tourism, cultural heritage, and traditional knowledge. The Parties shall apply, where necessary, risk assessments and environmental impact assessments and shall consult on projects of transboundary character. Awareness raising, education, and public information and participation are also imposed by this convention. ${ }^{26}$ All the obligations of the convention are to be applied on the basis of general principles listed in Article 2(2): precaution and prevention, polluter pays, public participation and stakeholder involvement, transboundary cooperation, integrated planning and management of land and water resources, a programmatic approach, and the ecosystem approach.

\subsubsection{Coastal and marine ecosystems}

Efforts to protect the marine environment increasingly take an ecosystem approach, recognizing that coastal areas, mangroves, sea grasses, coral reefs, and other marine living and non-living resources combine to produce complex ecosystems demanding integrated management. There

24 Protocol for the Implementation of the Alpine Convention of 1991 in the Field of Transport, Lausanne, October 31, 2000, EMuT, 991:83/l..

25 Lausanne, October 31, 2000, EMuT, 991:83/J.

26 Parties to this agreement are also Parties to the June 24, 1998, Aarhus Convention on Information, Participation, and Access to Remedies in Environmental Matters. 
are several definitions of what integrated coastal and marine management means. Agenda 21, Chapter 17, defines integrated coastal management as a system that: (a) provides for an integrated policy and decision making process, including all involved sectors, to promote compatibility and a balance of uses; (b) identifies existing and projected uses of coastal areas and their interactions; (c) concentrates on well-defined issues concerning coastal management; (d) applies preventive and precautionary approaches in project planning and implementation, including prior assessment and systematic observation of the impacts of major projects; (e) promotes the development and application of methods, such as national resource and environmental accounting, that reflect changes in value resulting from uses of coastal and marine areas, including pollution, marine erosion, loss of resources, and habitat destruction; and ( $f$ ) provides access, as far as possible, for concerned individuals, groups, and organizations to relevant information and opportunities for consultation and participation in planning and decision making at appropriate levels.

The Ramsar States Parties have adopted principles and guidelines for incorporating wetland issues into Integrated Coastal Zone Management (ICZM). ${ }^{27}$ According to Appendix I of Recommendation VIII.4, integrated coastal zone management is a mechanism for bringing together the multiplicity of users, stakeholders, and decision makers in the coastal zone in order to secure more effective ecosystem management while achieving economic development and equity within and between generations through the application of sustainability principles. This, like most other definitions, recognizes that ICZM is a continuous, proactive, adaptive process of resource management for sustainable development of coastal zones. Its goals must be achieved within the constraints of physical, social, economic, and envirnmental conditions.

Integrated management generally serves as and aims to be a guide on uses in order to avoid exceeding the carrying capacity of the resource base; respect natural dynamic processes; to reduce risks to valuable resources; to ensure ecosystem biodiversity; to encourage complementary activities; to ensure that environmental, social, and economic objectives are achieved at an acceptable cost; to protect traditional uses and rights and equitable access to resources; and to resolve sectoral issues and conflicts. All of these goals require the full participation of local communities based upon a 'bottom-up' approach.

The Jakarta Mandate on Marine and Coastal Biological Diversity adopted by the second Conference of the Parties to the Convention on Biological Diversity in 1995 and supplemented by a programme of work adopted in $1998^{28}$ also addresses integrated marine and coastal area management, sustainable use of living resources, protected areas, mariculture, and alien species. The Jakarta Mandate looks to coordinate and collaborate with other organizations and experts. It calls integrated marine and coastal area management 'the most suitable framework' for addressing human impacts and promoting conservation and sustainable use of biodiversity. The basic principle of the Programme of Work is that ' [t]he ecosystem approach should be promoted at global, regional, national and local levels'. In addition, 'protected areas should be integrated into wider strategies for preventing adverse effects to marine and coastal ecosystems from external

27 Resolution VIII.4, Principles and Guidelines for Incorporating Wetland Issues into Integrated Coastal Zone Management, $8^{\text {th }}$ Meeting of the Conference of the Parties, Valencia, Spain, 18-26 November 2002. 
activities and take into consideration, inter alia, the provisions of Article 8 of the Convention [on Biological Diversity]'. The precautionary approach should be used as guidance for all activities, with science providing knowledge on key processes and influences in the marine and coastal ecosystems that are critical for the structure, function, and productivity of biological diversity.

Even in the absence of integrated management, marine resources are shared and require regulation. The three studies on regional fisheries contained in this volume illustrate the challenges and some of the successful approaches to achieving sustainable utilization and equitable allocation of such resources. Whether the area under consideration is the North Atlantic, the Western and Central Pacific, or Southwest Africa, the issues are the common ones of achieving regional agreement on basic principles, establishing effective monitoring of compliance, and enforcing regulations, as well as ensuring that vessels originating outside the region do not undermine the agreement reached.

\subsection{Common principles and legal issues}

An ecosystem approach is defined as the 'strategy for the integrated management of land, water and living resources that promote conservation and sustainable use in an equitable way'. The concept of adaptive management has become central to this approach to conservation of resources. Decision V/6 of the Convention on Biological Diversity emphasizes the role of adaptive management and stresses the necessity of flexibility of management systems of biological resources. The lack of knowledge about ecosystems requires that 'management must be adaptive in order to be able to respond to such uncertainties and contain elements of "learning-by-doing" or research feedback'. The decision recognizes the necessity of measures based on the precautionary principle. The latter is described as measures needed 'even when some cause-andeffect relationships are not yet fully established scientifically'. Monitoring is in fact a key to adaptive management because it helps reduce uncertainties and allows quick response to changes in the ecosystem.

An ecosystem approach to environmental protection still requires incorporation and balance with other societal goals, including economic and social development. The World Summit on Sustainable Development referred to the 'three pillars' of sustainable development: economic development, social development, and environmental protection. The participating States called for a collective responsibility to advance and strengthen these three interdependent and mutually reinforcing social goals at local, national, regional, and global levels. The problem remains to determine the bases and procedures for balancing the sometimes competing, although interdependent, aspects.

The developments described here represent the emergence of a holistic approach to environmental protection that corresponds to the nature of the environment but that also poses considerable legal difficulties. Concrete integrated action is effective but more difficult to achieve than the narrower sectoral or source-based approach of prior decades. Many international instruments contain vague directives calling for integrated participatory action, but the provisions lack specificity. This may be partly responsible for the proliferation of 'case studies' to illustrate best practices as a starting point for action, such as those contained in this volume. 
The studies identify many innovations used to address shared natural resources, many of which were developed in order to encourage the participation of sometimes reluctant States. The use of incentives and the principle of common but differentiated responsibilities, the adoption of nonconfrontational review and compliance mechanisms, and the leadership role of certain States have all be instrumental in concluding agreements on shared resources. In some instances the common goals and interests can be served by the adoption of nonbinding instruments, as the Arctic example shows.

Substantively, the agreements concluded reflect the UNEP principles on shared resources, in that they call for avoiding adverse transboundary environmental impacts, a fundamental principle also contained in Principle 21 of the Stockholm Declaration on the Human Environment and Principle 2 of the Rio Declaration on Environment and Development. Prior notification of plans that would significantly affect the resource, along with information about any emergency, are also now widely accepted principles. Indeed, as Charles Di Leva writes in Chapter 3, the operational guidelines of the World Bank require prior notification of Bank-funded projects to all potentially affected watercourse States, following completion of an environmental impact assessment that includes transboundary effects. The Bank policies generally can be seen to promote the sharing of information among relevant stakeholders. Beyond the legal requirement, many of the chapters that follow emphasize the importance of public participation and stakeholder involvement to the success of any common management programme.

The duty to cooperate and the principle of equitable use of shared resources also seem clearly established in international environmental law. Cooperation can be enhanced through using already existing regional or subregional organizations, as Louis Kotzé describes in his analysis of the Southern African Development Community (SADC). SADC, like many other organizations and States, bases much of its shared management of watercourses on the principle of equitable utilization. The many factors that determine whether a given use is reasonable and equitable are sometime conflicting, but they provide the basis for decision making consistent with another principle, that of prevention of significant harm. It is also worth noting that the principle of equitable utilization could be applied to the atmosphere, where it could have significant consequences in climate change negotiations. Already, the concept that the atmosphere is a shared natural resource has led to an ASEAN Agreement on Transboundary Haze Pollution, analyzed by Koh Kheng-Lian in Chapter 12.

One of the unresolved and most difficult issues that underlies legal developments with respect to shared natural resources is the determination of their legal status. Many States and scholars view transboundary resources as being within the sovereignty of each State, to the extent that the resource is located therein. There have been challenges to this notion for more than two centuries, however, by those who have claimed that no part of a shared resource can belong exclusively to the individual State if the entire resource extends over the territory of several States; instead, the resource must be considered the common property of all. This notion akin to common heritage has been applied thus far only to resources found outside the jurisdiction of any State and not to transboundary resources like international watercourses. It is certainly worth considering the extent to which the concept of a shared resource acts to limit State sovereignty in respect to the resource, 
even without an agreement between the relevant States. As many of the chapters and the comments here indicate, there are international legal obligations that arise from the fact that a resource is shared, whether or not the term 'common heritage' is applied to the resource.

Broader institutional and financial issues are highlighted in many of the case studies, because these factors are as important as political will in achieving agreement and arriving at effective implementation and compliance with agreed obligations. The challenges may be discouraging, but they may also provide opportunities for innovations and comprehensive developments to address the complex political, environmental, and governance issues raised by the need to achieve equitable and sustainable use of shared resources. 


\section{Experiences in Negotiating Transboundary Agreements}

\section{Dr Iwona Rummel-Bulska ${ }^{1}$}

\subsection{Introduction}

The global environment is complex, and those who attempt to formulate international environmental law related to shared natural resources must be specialists in several domains. The laws they negotiate, in particular transboundary agreements, require careful negotiation and skilful diplomacy to find compromise resolutions that satisfy the different political and economic interests of the States sharing natural resources. Often they are able to identify the real solution to the problem at hand, but the hard political and economic facts force adoption of a compromise measure, a half-solution that will be only the first step towards a final solution that may be years away.

When the development of environmental law proceeds slowly, it also slows the achievement of environmental goals. Nevertheless, progress in development of environmental law at national and international levels is considered the most valuable tool in policy implementation. Many governments, especially those from the developing world, continue to request assistance from United Nations agencies and foreign donors in formulating their own regulatory machinery related to environmental laws and policies.

One of the most important features of international environmental law as it develops has been its challenge to the doctrine of consent: the tradition that an agreement between two parties is binding only on them and not on third parties. As the transboundary nature of environmental threats has become clearer, a growing number of agreements have attempted to lay down norms and to offer incentives for other States to sign on, or at least to commit themselves to a similar course of action.

The 1973 Convention on the International Trade in Endangered Species of Wild Fauna and Flora (CITES) is an example. The parties to CITES may trade with nonparties only if the latter substantially conform to the terms of the convention. Although this seems to undermine the liberalization of trade (under the General Agreement on Tariffs and Trade and the World Trade Organization), it is justified by the realization that the internal activities of one country may have a material effect on others.

A clear paradigm is the fact that although North European countries produced insignificant amounts of sulphur dioxide and nitrogen oxide, they were had the worst acid rain problems in the world due to the activities of other countries in Europe. The modern reality, deriving from the general principles of international law, is that some countries, even in the absence of specific

1 Chief Lawyer and UNEP Legal Counsel at the Division of Environmental Law and Conventions, United Nations Environment Programme. 
regulations, have an obligation to refrain from causing harm to others. Similar examples were the concerns of some developed countries about ozone depletion due to Asia's use of chlorofluorocarbons and the danger that land in developing countries such as, for instance, Bangladesh and the Maldives, will be swamped by rising sea levels as a result of carbon emissions in the developed part of the world.

The 1972 Stockholm Declaration touched on these challenges to the absolute sovereignty principle when, in Principle 21, it declared:

States have, in accordance with the Charter of the United Nations and the principles of international law, the sovereign right to exploit their own resources pursuant to their own environmental policies, and the responsibility to ensure that activities within their jurisdiction or control do not cause damage to the environment of other States or areas beyond the limits of national jurisdiction.

The same principle was later reiterated by Principle 2 of the 1992 Rio Declaration on Environment and Development and Article 3 of the 1992 Convention on Biological Diversity (CBD), which was signed at the Rio Conference.

Also, in the World Charter for Nature of 1992, paragraph 16 called on States and other related institutions 'to ensure that activities within their jurisdictions or control do not cause damage to the natural systems located within other States or in the areas beyond the limits of national jurisdiction.' The Charter also called on States and other actors 'to safeguard and conserve nature in areas beyond national jurisdiction'.

\subsection{Negotiating transboundary agreements: general principles}

The agreements dealing with transboundary matters and the growing spirit of co-operation they seem to indicate have taken place against the background of issues of absolute national sovereignty, national debt, technology transfer, and financial resources - all of which vary widely between developing and developed countries. In the face of threats to the global environment, it is unfortunate that often the essential motivation of a country remains its self-interest. Governments will generally only negotiate if they believe the problem can be solved no other way. The decision to negotiate is strongly influenced by economic considerations, trade elements, pressure groups, and public opinion, all of which may be influenced by new scientific findings.

After it has been agreed that an environmental treaty is needed, the negotiation process itself presents further difficulties. As new developments in science, technology, or economics become known, views of the negotiators change, creating difficulties in drafting the proposed treaty so that it is both reactive and anticipatory as well as flexible enough to adapt to new developments. This makes it difficult to draft a treaty that will impose binding standards, as shown by the problems in negotiating the treaties on ozone, hazardous waste, climate change, and biodiversity.

During the negotiations, the conflict between economic necessity and ecological responsibility often becomes apparent, as the explanation is heard that 'important bureaucracies at home favour economic growth'. Public pressure is acknowledged to force governments into collective action for environmental protection and prevention of transboundary pollution, but the level of public concern 
does not explain policy inconsistencies among nations such as Nordic European and North American countries on sulphur emissions that caused acid rain. Though all these countries have experienced high levels of public pressure on this issue, their policies differed. It is considered that this is the result of whether the country in question is a net importer or exporter of pollution: if a net exporter and strong domestic groups oppose environmental protection regulations, public pressure will not be enough to shape a pro-environment policy.

A further problem, common to the processes of establishing all international law related to transboundary problems, is that the inherent delays mean it may be years before the treaty goes into effect. First the negotiators must agree on a framework; then more time is needed to negotiate protocols on issues covered only in general terms in the framework; and finally there are normally long delays in parliamentary ratification by the parties. Generally, multilateral treaties come into force several years after they have been agreed upon - the average is about five years. Remarkably - and a clear indication of their importance to the contracting parties - with few exceptions the environmental treaties concluded over the past two decades entered into force in less than three years.

An issue that is quite interesting in negotiating transboundary agreements is the role of nongovernmental organizations (NGOs). At first rather limited, NGOs' activities have expanded to gathering technical information, devising policies, and mobilizing public support. NGOs were and should continue to be fully involved in the negotiation process and given the opportunity to express their views. Their participation, however, should be and recently has been governed by procedural rules and their activities should be monitored. NGOs are often important in urging governments to act, but sometimes they are seeking maximum results rather than achievable provisions at a given time. Several NGOs have been active participants in negotiating transboundary environmental treaties.

Industry and business are also playing an increasing role in negotiations, especially where the subject of the treaty touches very closely on their activities.

The most active during the negotiation on transboundary movement of hazardous wastes and chemicals were the Chemical Manufacturers' Association, Conseil Europeen des Federations de I'Industrie Chimique, the International Chamber of Commerce, Imperial Chemical Industries, and DuPont.

NGOs and industry organizations have participated in a number of negotiations of transboundary agreements as observers. However, on some occasions, when negotiations were particularly difficult and tense, the observers were excluded (e.g., negotiations of the 1987 Montreal Protocol on Substances That Deplete the Ozone Layer and the 1989 Basel Convention on the Control of Transboundary Movements of Hazardous Wastes and Their Disposal).

\subsubsection{Approaches used in negotiating transboundary agreements}

A number of innovations have been devised to obtain agreement while negotating transboundary environmental issues among otherwise reluctant parties. These include 1) selective incentives, 2) differential obligations, 3) regionalization, and 4) promotion of overachievement by lead countries. 
In using selective incentives, additional benefits are offered to a party to the agreement to encourage participation in a programme it would otherwise find unacceptable. These may include access to funding, natural resources, markets, or technology. Examples are the 1972 Convention Concerning the Protection of the World Cultural and Natural Heritage, in which parties maintain sites on the World Heritage List and are thus eligible for financial assistance to support those sites; the Montreal Protocol, whose Multilateral Montreal Fund covers the incremental costs incurred by signatory developing countries in adhering to the control measures stipulated; the 1982 United Nations Convention on the Law of the Sea (UNCLOS), guaranteeing access of its parties to shared mineral resources; and CITES, which gives access to world markets for wildlife products in return for observing agreed-upon conservation standards. The Montreal Protocol, the Basel Convention, and the CBD are recent examples of treaties containing provisions for technology transfer in return for participation.

The second approach provides differential obligations for parties to transboundary agreements, acknowledging that treaty obligations must be adjusted to the circumstances of each Party. The Montreal Protocol offers a 10-year grace period for implementation to developing countries with less than 0.3 kilograms per capita consumption of the substances it controls. The European Council's 1988 (and later 2001/80/EC) Directive on the Limitation of Emissions of Certain Pollutants into the Air from Large Combustion Plants and the 1976 Convention for the Protection of the Rhine against Pollution by Chlorides both used the principle of differential obligations. This has also been used in arranging contributions to various trust funds established since the early 1970 s to finance joint programmes. ${ }^{2}$

In the third approach, a regional regime can be established, since countries of one region usually share the same problems. ${ }^{3}$ In January 1991 the Organization of African Unity adopted the Bamako Convention on the Ban of the Import into Africa and the Control of Transboundary Movement of Hazardous Wastes, which aligned a regional regime with a global regime, the Basel Convention. The Bamako Convention follows the basic principles of the Basel Convention but is more stringent. Significant financial and technical resources are required for its implementation. Non-African industrial States are not bound by the Bamako Convention, yet their co-operation is essential to the effectiveness of the regional agreement. Such co-operation can only be achieved when these States and the African States have become parties to the Basel Convention.

By achieving more than an environmental treaty requires, countries that participate in negotiating transboundary treaties encourage others to reach the treaty's goals. This is the philosophy behind the fourth approach, the promotion of overachievement by lead countries. Some

2 For example, those under CITES, the 1979 Convention on Long-range Transboundary Air Pollution (Geneva Convention), the 1985 Convention for the Protection of the Ozone Layer (Vienna Convention) and its Montreal Protocol, and the Basel Convention.

3 These include the 1974 Convention on the Protection of the Marine Environment of the Baltic Sea Area (Helsinki Convention), the 1974 Convention for the Prevention of Marine Pollution from Land-Based Sources (Paris Convention), the United Nations Environment Programme (UNEP) Regional Seas Agreements, and treaties for the management of shared freshwater resources such as the Zambezi River and Lake Chad Basins. 
environmental treaties, such as CITES, the Montreal Protocol, and the Geneva Convention and its Helsinki and Sofia Protocols, contain provisions recognizing this approach.

\subsubsection{Different mechanisms used to avoid delays}

There are a number of devices used in negotiating transboundary environmental agreements to avoid the delays inherent in the traditional treaty process. These include 1) provisional application, 2) 'soft-law' options, and 3) delegated law-making and supplemental provisions within the treatymaking amendments or adjustments binding on all signatories not specifically opposing them.

The first device, provisional application, is a procedure recognized by the 1969 Vienna Convention on the Law of Treaties and may be exemplified by the Geneva Convention, whose signatories decided to 'initiate, as soon as possible and on an interim basis, the provisional implementation of the convention' and to 'carry out the obligations arising from the convention to the maximum extent possible pending its entry into force'. This resulted in the establishment of an interim executive body, which held regular annual meetings and created subsidiary working groups well before the Convention took effect in 1983. This was also the case with the Basel Convention of 1989, whose plenipotentiary conference also resolved 'that until such time as the Convention comes into force, all states refrain from activities which are inconsistent with the objectives and purposes of the convention'. All States were called on to apply the provisions of the Basel Convention as soon as possible.

The second device employed to avoid implementation delays is the use of soft-law options. The term 'soft law' is used to distinguish informal agreements (such as codes of conduct, guidelines, and principles) from formal, legally binding agreements. Many such instruments have been formulated in the environmental field, covering shared natural resources, off-shore mining and drilling, the exchange of information on chemicals in international trade, environmentally sound management of hazardous waste, marine pollution from land-based sources, weather modification, and environmental impact assessment, as well as the (nonbinding) forestry principles adopted at the 1992 United Nations Conference on Environment and Development.

The great advantage of such legal instruments is that they do not require ratification and can be put into use immediately; this is, however, offset by their informality and lack of legal force. Softlaw agreements may eventually evolve into treaties. This was the case with the 1987 Cairo Guidelines and Principles for the Environmentally Sound Management of Hazardous Wastes, the basis of the binding Basel Convention, as well as with voluntary Prior Informed Consent procedures, as set out in the UNEP Amended London Guidelines for the Exchange of Information on Chemicals in International Trade, the basis for two binding Conventions: the 1987 Rotterdam Convention on the Prior Informed Consent Procedure for Certain Hazardous Chemicals and Pesticides in International Trade and the 2001 Stockholm Convention on Persistent Organic Pollutants.

In the case of treaties dealing with areas that are subject to frequent changes in technology and rapid advances in scientific knowledge, a third device, the delegated lawmaking approach, permits an intergovernmental body to revise the treaties without the need for ratification by the parties. An 
example is the control measures of the Montreal Protocol that lead to adoption of several amendments and adjustments.

As the protection of various components of the environment and transboundary management have moved from the scientific world to that of high politics, governments have taken a more flexible approach to the question of absolute national sovereignty and absolute national integrity. The principle of good neighbourliness in which all countries are real neighbours through the ozone layer, global warming, animal migrations, and transboundary movement of wastes or chemicals has prevailed. Negotiations of transboundary agreements related to environmental law have developed rapidly since the 1970s, with negotiations in the field being complicated by scientific uncertainties. This has led to the flexible, anticipatory nature of environmental agreements and to the use of techniques that will enhance their adoption, ratification, enforcement, and implementation.

\subsection{UNEP Principles on Shared Natural Resources}

In response to United Nations General Assembly Resolution 3129 (XIVIII) of 13 December 1973, a Working Group of legal experts was established by the United Nations Environment Programme (UNEP) and met several times between 1976 and 1978 to develop Principles on Shared Natural Resources.

The Principles were drawn up for the guidance of States with respect to conservation and harmonious utilization of natural resources shared by two or more States. They refer to such conduct of individual States as is considered conducive to the attainment of the said objective in a manner that does not adversely affect the environment. Moreover, the Principles aim to encourage States sharing a natural resource to co-operate in the field of the environment.

Negotiations began in 1976, and legal experts representing their various governments who were meeting under the auspices of UNEP found the negotiations to be as difficult as if they were working out a binding treaty.

When the draft Principles were presented to the UNEP Governing Council, the head of the Brazilian delegation led his delegates from the room in protest sparked by Brazil's conflict over La Plata River, which it shared with Argentina.

Eventually States, through the UNEP Governing Council Decision 6/14 of 19 May 1978, adopted the Principles of Conduct in the Field of the Environment for the Guidance of States in the Conservation and Harmonious Utilization of Natural Resources Shared by Two or More States. ${ }^{4}$ The Principles, together with the Working Group's Report (LJNEP.IG.12/2) and further Government comments on the draft Principles (UN document A/34/557 and Corr.l), were presented to the UN General Assembly. The General Assembly, by its Resolution 34/186 of 18 December 1979, requested all States:

to use the principles as guidelines and recommendations in the formulation of bilateral or multilateral conventions regarding natural resources shared by two or more States, on the basis of the principle of good faith and in the spirit of good neighbourliness and in such a

4 For further details, see www.unep.org/Law/PDF/UNEPEnvironmental-Law-Guidelines-and-Principles.pdf 
way as to enhance and not adversely affect development and the interests of all countries, in particular the developing countries.

This succinctly encompasses a number of significant concepts: It reconfirms Principle 21 of the Stockholm Declaration - namely, Principle 3 of the Principles on Shared Natural Resources highlights that nations have the sovereign right to exploit their own resources as well as the responsibility not to injure other States or areas beyond national jurisdiction. It is a reminder that the agreement contained only principles to be used as guidelines and recommendations by its Parties in a spirit of good faith and good neighbourliness. It also put special emphasis on the development and interests of developing countries while assuring that it would not adversely affect the interests of all countries.

These elements are still relevant for negotiations of transboundary environmental agreements. Each State should, as much as possible, avoid adverse environmental effects beyond its jurisdiction in the use of a shared natural resource, especially when such use might affect the use of the resource by a sharing State, threaten the conservation of a shared renewable resource, or endanger the health of another State's populace. This principle should be interpreted as taking into account the practical abilities of sharing States to abide by it.

Principle 6 sets out the requirement that every sharing State notify others in advance of any plans to begin or change its use or conservation of the resource if this will significantly affect other States' environment. Upon request, the State should enter into consultations regarding its plans and provide any additional information requested. If the State has not furnished such advance notice, it must upon request consult with States that may be affected.

In addition, Principle 9 states that States have an urgent duty to inform other States that may be affected by any emergency situation arising from use of a shared natural resource, or from sudden natural events related to the resource, that may cause harmful effects on their environment. Principle 13 requires that domestic environmental policy take into account the potential adverse environmental effects of the use of shared natural resources, whether the effects were in their jurisdiction or outside it. These two Principles constitute a significant erosion of the old rule of absolute sovereignty.

During negotiations on the Principles, an attempt was made to avoid language that might create the impression that it was intended to refer either to a specific legal obligation under international law or to the absence of such obligation.

The language used throughout the Principles did not seek to prejudice whether or to what extent the conduct envisaged in the Principles was already prescribed by existing rules of general international law. Nor did the formulation intend to express an opinion as to whether, to what extent, and in what manner the Principles should be incorporated into the body of general international law, in cases where they do not reflect already existing rules of general international law.

The Principles state that it is necessary for States to co-operate in the field of the environment concerning the conservation and harmonious utilization of natural resources shared by two or more States. Accordingly, it is necessary that consistent with the concept of equitable utilization of 
shared natural resources, States co-operate with a view to controlling, preventing, reducing, or eliminating adverse environmental effects that may result from the utilization of such resources. Such co-operation is to take place on an equal footing, taking into account the sovereignty, rights, and interests of the States concerned.

In order to ensure effective international co-operation concerning the conservation and harmonious utilization of natural resources shared by two or more States, States sharing such natural resources should endeavour to conclude bilateral or multilateral agreements between or among themselves in order to secure specific regulation of their conduct, applying as necessary the Principles in a legally binding manner, or should endeavour to enter into other arrangements, as appropriate, for this purpose. In entering into such agreements or arrangements, States should consider the establishment of institutional structures, such as joint international commissions, for consultations on environmental problems relating to the protection and use of shared natural resources.

While fully confirming States' sovereign right to exploit their own resources pursuant to their own environmental policies, the Principles also emphasized that it is necessary for each State to avoid to the maximum extent possible, and to reduce to the minimum extent possible, the adverse environmental effects beyond its jurisdiction of the utilization of a shared natural resource so as to protect the environment. It was further stipulated that the principle 'be interpreted taking into account, where appropriate, the practical capabilities of States sharing the natural resource'.

The Principles further emphasized that States should make environmental assessments before engaging in any activity with respect to a shared natural resource that may create a risk of significantly affecting the environment of another State or States sharing that resource. The expression 'significantly affect' was defined as referring to any appreciable effects on a shared natural resource and excludes 'de minimis' effects. The Principles refer to well-established principles of good faith and good neighbourliness.

After the adoption of the Principles, the UNEP Secretariat regularly sent out questionnaires on their use and application to all countries, and quite positive progress reports on implementation of the Principles were compiled by the UNEP Secretariat based on the replies. ${ }^{5}$

\subsection{Specific examples of transboundary agreement negotiations}

\subsubsection{Transboundary aspects in the UNEP Provisions for Co-operation between States in Weather Modification}

Weather modification guidelines, called 'Provisions', negotiated under UNEP auspices and adopted by the UNEP Governing Council in 1980 require early notification of any planned practices that might affect other States. The term environmental impact assessment (EIA) appeared for the first time in these guidelines, predating the Governing Council's 1987 Guidelines and Principles on Environmental Impact Assessment.

5 The compiled results were submitted to the General Assembly through the UNEP Governing Council in 1981 (UNEP/GC.9/5/Add.2) and in 1985 (UNEP/GC.13/9/Add.1). 
The Weather Modification Guidelines require that:

States should ensure that an assessment is made of the environmental consequences of prospective weather modification activities under their jurisdiction or control which are likely to have an effect on areas outside their national jurisdiction, and either directly or through the World Meteorological Organization, make the results of such assessments available to all concerned States.

States are also required to notify potentially affected States and enter into 'timely consultation' with them.

\subsubsection{Offshore mining and drilling}

In 1982, UNEP adopted guidelines on offshore mining and drilling, formally titled Conclusions of the Study of Legal Experts Concerning the Environment Related to Offshore Mining and Drilling within the Limits of National Jurisdiction. These guidelines again followed Principle 21 of the Stockholm Declaration and for the first time provided guidance on how to perform an EIA, as well as defining elements of liability and compensation in cases of environmental damage.

Adoption of these guidelines was a clear attempt to formalize management of offshore exploration and drilling for oil and other minerals so as to minimize pollution and other harmful results and to urge States to adopt laws regulating these activities. They include recommendations for the assessment of environmental effects, advance notice measures, assignment of liability, and payment of compensation for damages. Section E, on 'consideration of transfrontier environmental impact when authorizing operations; procedure for information and consultation' refers to Principle 21 of the Stockholm Declaration and stipulates that States within whose jurisdiction operations are carried out should take measures to avoid to the maximum extent possible, and reduce to the minimum level possible, pollution and other adverse effects on the environment beyond the limits of their jurisdiction and provide other States with information in a timely manner when the operations could have significant adverse effects on the environment of other States.

\subsubsection{Montreal Guidelines for the Protection of the Marine Environment against Pollution from Land-Based Sources}

In 1985 the UNEP Governing Council adopted the Montreal Guidelines for the Protection of the Marine Environment against Pollution from Land-Based Sources, which took almost two-and-a-half years to negotiate. Following the pattern of earlier guidelines, they include elements from Principle 21 of the Stockholm Declaration and continue to move away from the notion of absolute sovereignty. The Montreal Guidelines exemplify the use of nonbinding agreements to achieve cooperation in an area ripe for a legally binding global treaty.

\subsubsection{Environmental impact assessment}

The Goals and Principles on Environmental Impact Assessment were adopted by UNEP in 1987. These guidelines codify the processes that, beginning with Principle 21 of the Stockholm Conference, were developed throughout the history of the agreements described above. They were further used in the 1991 Convention on Environmental Impact Assessment in a Transboundary 
Context, which were elaborated under the auspices of the United Nations Economic Commission for Europe.

Some of the instruments identify the minimal content of an EIA, but few specify procedures or methods. The 1988 Convention on the Regulation of Antarctic Mineral Resource Activities speaks of the assessment of the possible impacts of such activities. As yet, there have been only a few cases in which rules have been made for procedural details or the activities for which an EIA should be carried out have been named; the exceptions are the 1991 Protocol on Environmental Protection to the Antarctic Treaty (Madrid Protocol) and the provisions dealing with EIAs of seabed activities under UNCLOS. The 1987 Action Plan for the Environmentally Sound Management of the Common Zambezi River System also addresses environmental assessment as one of its four elements, recognizing the need for continuing systematic assessment of water management and quality and describing the tasks required, but it does not specify the administrative procedures to be followed.

All the above show a clear move away from the old concept of national sovereignty. But in spite of this, attempts to develop the guidelines into an international treaty have failed. The next step should be global legislation that will protect the environment and will reduce conflicts and enhance peace by making each nation responsible for the damage its activities may inflict on its neighbours.

\subsubsection{Management of Hazardous Waste}

An example of how nonbinding guidelines and principles can help States deal with a common transboundary problem pending a later binding agreement is the Cairo Guidelines and Principles for the Environmentally Sound Management of Hazardous Wastes, adopted by the UNEP Governing Council in 1987, which became the basis for the Basel Convention. The Cairo Guidelines included four important principles governing the transfer of technology, capacity building, public access to information, and liability and compensation. The guidelines recognized developing countries' need for technical assistance from the industrialized world to ensure the environmentally sound management of hazardous waste, highlighting the need for the public to have access to all information concerning this activity and establishing a requirement for national laws governing liability and compensation for damages in case of accident or mismanagement.

\subsubsection{International Trade in Chemicals}

In 1972, the United Nations Conference on the Human Environment requested that the UN, governments, and scientific and international bodies:

develop plans for an International Registry of data on chemicals in the environment based on the environmental behaviour of the most important man-made chemicals, together with their pathways from factory via utilization to ultimate disposal or recirculation. ${ }^{6}$

This request resulted in the establishment of the International Register of Potentially Toxic Chemicals in 1976, a computerized data bank for the exchange of information on production and

61972 Stockholm Declaration, A. Pollution Generally Recommendation 74(e). 
consumption of these substances, their use, the treatment of poisoning, waste management, and control of hazards posed by them.

In the late 1970s, Kenya brought to the attention of the UNEP Governing Council the indiscriminate trade in toxic chemicals, particularly the trade carried out in the South by companies from the North. In 1977 the Council urged governments:

to take steps to ensure that potentially harmful chemicals ... which are unacceptable for domestic purposes in the exporting country, are not permitted to be exported without the knowledge and consent of appropriate authorities in the importing country.

In 1978, the Council further urged that such chemicals not be exported until their health and environmental effects had been tested and reported to the recipient countries, and called for adequate monitoring, evaluation, and protections to be instituted by both exporting and importing governments.

The Montevideo Programme, adopted by the Governing Council as its Programme of Action in Environmental Law for 1981-1991, included the preparation of principles or guidelines on the exchange of information relating to the trade in potentially harmful chemicals, particularly in pesticides. An ad hoc working group of experts met in the Netherlands in March 1984 and submitted to the next Governing Council session a Provisional Notification Scheme for Banned and Severely Restricted Chemicals, which the Council adopted, calling for it to go into effect as soon as possible and urging close co-operation with other UN bodies and specialized agencies in further elaboration of the draft guidelines. Among its provisions, the notification scheme called for a country that has acted to ban or severely restrict a chemical to notify other nations' authorities promptly and to provide the appropriate information at the time of the first export following such action.

In 1987 the UNEP Governing Council adopted the London Guidelines for the Exchange of Information on Chemicals in International Trade, which continued to be developed and two years later were adopted as amended. The 1987 guidelines were designed to complement existing instruments of other governments and intergovernmental organizations and of the UN and its specialized agencies, particularly the Food and Agriculture Organization's Code of Conduct on Distribution and Use of Pesticides. The guidelines stated that in using chemicals, nations should abide by Principle 21 of the Stockholm Declaration, and it flagged a potential conflict if the unilateral adoption of environmental regulations were to create obstacles to international trade agreements. They also specified that control requirements be normalized for all producers of the same chemical.

The 1987 guidelines were in negotiation for five years, and during that time the developing countries consistently invoked the principle of prior informed consent (PIC), while the industrialized nations resisted its inclusion in the formal guidelines. The working group of legal experts continued its efforts following adoption, and the principle of PIC was included in the amended London Guidelines, the first time it had been accepted in an agreed text negotiation by governments. It would later appear as part of legally binding treaties, together with the contents of Principle 21 of the Stockholm Declaration, in both the Basel Convention and the CBD. 


\subsection{Negotiating agreements on management and use of regional seas}

Environmental problems rarely affect one nation alone, especially when they involve coastal areas and the marine environment. Because regional fishing grounds are normally shared by several nations, each country's pollution and activities can degrade the shared environment and damage the resources of all. Therefore, protecting the coastal environment and the sea's resources depends on regional co-operation.

Historically, international marine agreements regulated navigation and fishing. It has only been recognized relatively recently that the world's oceans should be protected and managed as a shared natural resource. This important change from a user-oriented to a resource-oriented approach has come about only in the last four decades. Most legal regimes adopted after 1970 have included the protection, conservation, and management of the marine and coastal environment and their resources.

In the late 1960s and early 1970s, scientific findings were widely publicized that the Mediterranean was a dying sea, that the Caribbean Sea and the Arab Gulf were heavily polluted, and that the Pacific fishing grounds had been overexploited. Alarmed, governments in these areas co-operated to find durable solutions. With the UNEP acting as catalyst and coordinator, the Regional Seas Programme was launched in the mid-1970s with its basic strategy to deal with the causes, as well as the effects, of coastal environmental damage.

\subsubsection{The Mediterranean Sea: a case study}

The virtually enclosed waters of the Mediterranean Sea are shared by European, Asian, and African countries. In the early 1970s the Mediterranean Sea was so heavily polluted that many feared it might die. Efforts to save it began with an assessment of its condition, carried out by a team of technicians from all the relevant UN organizations.

The question then became, in the midst of wars and political tensions, to what extent Mediterranean countries would be willing to enter into an environmental agreement related to the management and protection of this vulnerable shared natural resource. This was a time when all the Arab States were at war with Israel, when Turkey and Greece were disputing ownership of Cyprus, when Algeria and Morocco were at odds over the Sahara, and when the Cold War was still shaping international relations. In spite of these difficulties, and in the face of the belief that the Mediterranean was beyond saving, UNEP decided to go forward. Spain offered to host meetings to negotiate regional co-operation in an effort to save the Mediterranean and, surprisingly, almost all of the basin States not only attended the negotiating sessions but in 1975 succeeded in adopting a joint action that would slow and ultimately reverse the threat.

A disagreement during the negotiations arose around the question of where to locate the coordination unit of the plan. Informal consultations and a straw ballot showed that Greece would win and Athens was formally chosen. Negotiations on the Mediterranean Action Plan were marked with some major political difficulties. In most cases difficulties related to matters other than the programme of management and protection of the environment of the Mediterranean Sea. For 
example, the Turkish delegation regularly submitted letters to the UNEP Secretariat protesting the Greek presence in Cyprus and Syria and, while ratifying the Convention, recorded that its ratification did not constitute recognition of Israel.

During the negotiations of the Convention, the delegates refrained from criticizing the pollution habits of others, in an implied recognition that all were responsible for the pollution of Mediterranean. This was also due to the nature of the negotiations, which were intended to save the Mediterranean rather than to assign blame. However, some political considerations prevailed over efforts to control pollution; delegates of most of the Mediterranean States, particularly the northern Mediterranean, were unwilling to admit an effective Soviet Union presence. For this purpose they defined the Mediterranean as the area between the Straits of Gibraltar and the southern limits of the Dardanelles, thus eliminating the Black Sea and rivers flowing into the Mediterranean and blocking participation of the Black Sea States of Bulgaria and Romania. Other non-littoral States with rivers emptying into the Mediterranean, such as Portugal, Switzerland, and the Sudan, were by this definition also excluded from the agreement. This reduced the effectiveness of the Convention, because it cannot deal with some major pollution sources, including the Gulf of Izmir and the Sea of Marmara.

In 1976, the Barcelona Convention for the Protection of the Mediterranean Sea against Pollution and two protocols, one to prevent pollution of the Mediterranean by dumping from ships and aircraft and the other to achieve co-operation in combating pollution by oil and other harmful substances, were signed. As the programme evolved, the participants were able to enlarge their understanding of the environment's role in development and began to see evidence that both developed and developing nations were prepared to put aside their political differences as they cooperated to protect their shared environment. Soon after the adoption of the 1976 Barcelona Convention, several action plans, conventions, and protocols were adopted. ${ }^{7}$ Now, through the Regional Seas Programme, some 140 countries are working together to improve the marine environment and make use of their shared natural resources.

\subsubsection{Negotiation of other Regional Seas Action Plans ${ }^{8}$}

Although the formal requirements for achieving each action plan would seem to be enough to occupy its negotiators, difficulties arising outside the agreement negotiations often postpone, delay, or distract the development process. The Kuwait Action Plan process provides an example of the knotty political problems that arise. The seven riparian Arab States and Iran, although agreeing that a convention was necessary to assure the use and ecological health of their shared waters, could not agree on the name of the waters. The Arabs insisted it should be called 'the Arab Gulf'; the Iranians were adamant that it would go under the UN term, 'the Persian Gulf'; suggestions for compromises such as 'Arab/Persian Gulf' or simply 'the Gulf' were rejected by both sides. In order to get on with the negotiations, it was finally agreed to call it 'the body of water surrounded by Bahrain, Iran, Iraq, Kuwait, Oman, Qatar, Saudi Arabia, and United Arab Emirates',

7 For an update on the environmental instruments governing the Mediterranean, see www.unep.org/ regionalseas/Programmes/UNEP_Administered_Programmes/Mediterranean_Region/default2.asp

8 See www.unep.org/regionalseas for information about the Regional Seas and Partner Programmes. 
and, since the meeting was to be held in Kuwait, to name the adopted convention the Kuwait Action Plan Convention.

Negotiations for the Caribbean Action Plan were also complicated by political matters. European countries having territorial claims in the Caribbean attended the meetings, and from time to time the Caribbean States would exclude them and hold their own meetings. However, patience and the common desire to protect the region prevailed, and the Caribbean Action Plan was followed by the negotiation and adoption of the 1983 Convention for the Protection and Development of the Marine Environment of the Wider Caribbean Region (the Cartagena Convention).

The negotiation of regional seas action plans and legally binding regional agreements has yielded useful information for future activities related to negotiations of transboundary environmental agreements. To begin with, when science speaks with authority, governments listen. Scientific reports that identified the cause of the Mediterranean's ills spurred the countries surrounding it to action; subsequent action plans and agreements have been preceded by scientific assessment of the regional sea in question. Governments have also shown themselves to be willing to put aside political differences and address a common threat, but such negotiations succeed only when they share certain features, and there must be strong leadership by at least one of the parties.

Dealing with shared environmental problems has inevitably led to an erosion of the old doctrine of absolute sovereignty, as governments have become willing both to give and to accept instructions as to how to modify environmentally damaging activities.

\subsection{Negotiating binding regional regimes on shared freshwater resources}

The difficulties encountered in negotiating the regional seas agreements were matched and sometimes exceeded by those seeking to reach agreement on management of shared freshwater resources (rivers, lakes, and aquifers), including their living aquatic resources. Fresh waster is one of the basic requirements of life, and in theory there is enough of it to meet the needs of all, but in practice it is often a scarce resource.

Some human settlements have grown up where there is ample fresh water, others where there is more water than they need or want but not in the right place or at the right time, still others where there is barely enough water, compelling them to exist in a perpetual state of drought. Some of this imbalance may be traced to changing global weather patterns, but some is due to the modification of water circulation and quality. Development has led to overexploitation of freshwater resources and to channelling and other regulation of river courses, as well as altered land use patterns that have led to changes in vegetation and soil cover that have affected the hydrological cycle.

The near destruction of Lake Erie by industrial pollution, the poisoning of more than 20,000 lakes in Scandinavia and Canada by acid rain, the siltation and oxygen depletion of thousands of lakes in developing countries by imprudent development and sanitation practices - all these merely hint at the extent of the problem. 
The joint use of international water courses has always depended on co-operation among the countries along their banks, regulated in some cases by international treaties and organizations. Historically, these treaties dealt with the allocation of water shares, regulation of navigation and fishing, and construction of dams and other public works. As early as 1792 the Provisional Executive Council of the French Republic stated, 'Streams that flow through the territory of several States do not belong exclusively to these States with respect to the particular portion traversing this territory, but represent the common and inalienable property of all riparian States'. This principle is echoed by the 1814 Treaty of Paris. More recently, agreements have focused on the cleanup of shared waters. The Great Lakes Water Quality Agreements of 1972 and 1978 focused respectively on traditional pollution sources, such as municipal sewers, that were causing severe oxygen depletion and toxic pollutants. Since 1980, countries along the Rhine have undertaken a joint programme for the rehabilitation of its waters and the management of its aquifer.

In other regions the shortage of freshwater resources may result in conflicts among the nations that share them. International tensions during the last decades have centred on the use of shared rivers. The United States and Mexico have clashed over the Colorado River; Iraq, Syria, and Turkey over the Euphrates; India and Pakistan over the Indus; Israel and Jordan over the Jordan River; and Brazil and Argentina over La Plata River. The scope for conflict rises with the growth of populations, and opportunities must be created for mutual co-operation, dialogue, and confidence building among States who must share the natural resource.

The experiences of UNEP in the Regional Seas Programme showed that international concern for environmental issues can overcome political and economic conflicts. The organization was therefore encouraged to enter the complex and problematic area of the management of shared freshwater resources (including their allocation, use, and conservation, as well as their protection against pollution), beginning in 1985 with the Zambezi Action Plan.

\subsubsection{The Zambezi Action Plan for the Environmentally Sound Management of the Common Zambezi River System}

Eight countries affect the waters of the Zambezi River. Arising near the extreme northern border of Zambia and Angola, this great river becomes the border between Zambia and Namibia; Zambia and Botswana; and Zambia and Zimbabwe. Fed by tributaries from Tanzania and Malawi, it then flows through Mozambique to the Indian Ocean. In its course, which leads it more than halfway across southern Africa, the Zambezi collects water that more than fulfils the needs of the riparian States. Nevertheless, negotiation of the Zambezi Action Plan and its accompanying agreement met a series of nearly insurmountable difficulties.

At the time the plan was initiated, the Southern African States had established the Southern African Development Co-ordination Conference, now called the Southern African Development Community. The political situation in South Africa had eroded confidence between some of the governments involved, which suspected others of intending to pass some of the Zambezi's water to Southern Africa. The Conference Secretariat was at best lukewarm to UNEP's proposal, and it became evident that to be effective the plan would have to have the support not only of the highest 
political levels of government but also of the donor community, because the riparian States were all poor.

Visits were arranged in which the Executive Director of UNEP met with the Heads of State in three of the major countries involved: Botswana, Zambia, and Zimbabwe. The concept of regional management of the Zambezi Basin was endorsed by them. With this important endorsement, UNEP approached Finland, Norway, Sweden, and Canada expressing interest. They provided highlevel experts who helped UNEP Senior Staff work with the national experts of the riparian States, and by the time the Action Plan had been drawn up the Nordic States had committed themselves to furnish the $\$ 10$ million that was the estimated cost to conduct the work.

Preparation of the Action Plan began with a diagnostic study of the river basin, including information on river flows, national water needs, development plans, and conservation requirements. Although this took a long time, as a straightforward collection of factual information it was clear and powerfully convincing to the riparian States involved, who agreed that co-operation was necessary.

Negotiations were difficult, mostly for reasons to do with national political interests and the various nations' attitudes towards events in southern Africa. It took from April 1985 to May 1987 to reach an agreement. Negotiations were held in Nairobi, Lusaka, Gaborone, and Harare in which each expert presented technical and scientific evidence of the need for common action by all riparian countries.

Even more difficult were the negotiations held at the ministerial level in Harare in May 1987, which would adopt the Action Plan and its implementing legal agreements. Of the eight riparian States, only six attended; governments lacked confidence in each other, and it was difficult even to establish the drafting and credentials committees. It took more than a full day of the three days allotted to the meeting to agree that five countries would sit on the drafting committee and all six on the credentials committee. The composition of the bureau of the ministerial conference was sensitive, and Zimbabwe, Zambia, and Botswana were chosen to ensure balanced views. During the ministerial meetings, the value of informal consultations once again proved itself. The agreement was signed in Harare on 28 May 1987 by Botswana, Mozambique, Tanzania, Zambia, and Zimbabwe.

It was evident during these meetings that since the late 1970s, when the UNEP Shared Natural Resources Guidelines were being negotiated, attitudes had changed. Instead of refusing to consider international control of shared waters, as Brazil had earlier done regarding the La Plata River, the riparian States of the Zambezi saw clearly that none could manage its part of the water alone and that all must co-operate. The Zambezi countries agreed that 'in view of the present utilization of the river system it is possible and highly desirable to deal with the water resources and environmental management problems of the river system in a coordinated manner to avoid possible future conflicts'.

The diagnostic study identified, inter alia, the following problems relating to the environmentally sound management of the river basin that should be dealt with through selected activities as part of the Zambezi Action Plan, namely inadequate co-ordination both at national and at river basin 
level and inadequate information on environmental impacts of water resources and related development projects, e.g., hydropower, irrigation, etc.

The objective of the Zambezi Action Plan was to overcome the problems listed in the study and to promote the development and implementation of environmentally sound water resources management of the whole river system. It was agreed that the activities in the Zambezi river basin should include solid and reliable environmental assessment. Such information would be related to socioeconomic developments that may adversely affect the environment, including the identification of favourable opportunities for river basin development in general, as well as the identification of human activities that could be affected by environmental degradation. The Action Plan provided for the gradual development and operation of a basin-wide unified monitoring system for water and water-related environment and for the development of a river basin planning process.

\subsubsection{Other shared water resources: Lake Chad and the River Nile}

The success of the Zambezi Basin negotiations led the governments surrounding Lake Chad (Chad, Niger, Nigeria, and Cameroon) to work on the development of a similar plan. The process began in 1988, again with a diagnostic study. At this time the lake had shrunk on one shore by 25 kilometres and on another by 40 kilometres, but the causes were controversial. Unfortunately the objectivity of the study was called into question and it had to be completely redone. This and other factors caused initial enthusiasm for the plan to fade.

While these efforts were under way UNEP stepped into the much more complicated situation of the Nile Basin. ${ }^{9}$ The early phases of the negotiations were marred by hypersensitivity on the part of some delegates, and it took two full years of concerted effort by both water experts and environmental law specialists for delegates to realize that collective management of the Nile Basin for the benefit of all was the best option. Ultimately, the delegates agreed to develop a diagnostic study and an Action Plan. The same slow progress is reported in achieving a joint Action Plan for the Rio Arauca, shared by Colombia and Venezuela.

Negotiations relating to the management of shared freshwater resources seem to be more difficult than management of regional seas, although it is encouraging that progress has been made towards agreeing to limit application of principles of absolute territorial sovereignty and absolute territorial integrity for the common good.

\subsection{Conclusion}

Major constraints in negotiating transboundary agreements are usually related to lack of cooperation among States sharing natural resources and the lack of mechanisms in the form of shared natural resources agreements that set out terms of co-operation. Failure in undertaking an EIA when activities are likely to affect the environment beyond national jurisdiction and lack of consultation and exchange of information often lead to exploitation of natural resources without

9 See Nile Basin Initiative, Nile Transboundary Environmental Action Project (part of the Shared Vision Program), at http://nteap.nilebasin.org/index.php 
regard to the effects on areas beyond national jurisdiction. This can be further aggravated by the lack of notification and consultations on plans for activities that may significantly affect another State, as well as by delays or failure to share information or to notify and consult in good faith and in a spirit of good neighbourliness.

There is no doubt that co-operation (including entering into agreements that articulate the terms of this co-operation), sharing information, notification, and consultations are very important in transboundary management of natural resources, as well as ensuring that activities undertaken in the country do not affect areas beyond national jurisdiction. All this can only be assured by having an impact assessment for major projects in shared, transboundary natural resources. The same applies to designing corridors where there is a cross-border national park used by migratory species in range States or where there is a natural resource that requires joint management of a river, lake basin, wetland, or catchment area cutting across two or more countries. 


\section{Transboundary Management of Natural Resources: A Brief Overview of World Bank Policies and Projects}

Charles E. Di Leva'

\subsection{Introduction}

The International Bank for Reconstruction and Development (the World Bank) was established in 1945. Since its inception, the World Bank has been at the forefront of international institutions that address complex transboundary natural resource management issues. With nearly universal membership, and as the world's largest development aid agency, the Bank has long been helping member States design and implement projects on international land and aquatic boundaries in a manner that is sensitive to neighbouring States and the international community.

Today, the World Bank membership consists of 186 governments. Members join with the understanding that projects implemented by the Bank must comply with the Bank's Articles of Agreement. ${ }^{2}$ Among many other aspects, these articles support the 'good neighbour' aspects of transboundary management of natural resources. They also require that the Bank conduct its operations with 'due regard' to the effect on business investment in other members of the Bank (Article 1 (5)). Moreover, under Article 3 (1), the resources of the Bank are to be used for the benefits of its members with 'equitable considerations to projects for development'. In addition, the Articles require that the Bank should 'act prudently in the interests both of [the borrower and other members] ${ }^{3}$ and that all loans 'should be for productive purposes'.

Over time, with the assent of its members, the Bank developed operational policies that also support efforts to help ensure that Bank-financed projects are in line with key internationally accepted principles. These operational policies therefore help ensure that projects will be sensitive to the interests of Bank members, including those interests that arise because of transboundary concerns.

As early as the 1950s, the Bank was taking measures to ensure that hydroelectric projects on international waterways were carried out with transboundary co-operation. The Bank was well aware of potential transboundary conflicts, especially between large riparian states facing competitive demands or concerns about water flows and quality. Later, the Bank became the first

1 Chief Counsel, Environmentally and Socially Sustainable Development and International Law, World Bank Legal Department. The views expressed in the paper are the author's in his individual capacity and should not be attributed to the World Bank. The author would like to express his gratitude to Sachiko Morita, Esq., for her excellent contribution to this chapter.

2 International Bank for Reconstruction and Development, Articles of Agreement (1945).

3 Ibid., Article III, Section 4(v). 
development institution to put in place an environmental assessment (EA) policy that also required the Bank to consider applicable transboundary issues when projects are developed.

Today, a range of factors make these considerations even more important. These factors include the scientific and political awareness of the stress being placed on shared natural resources. Modern scientific research demonstrates the urgency of managing our shared natural resources better. A prominent example of this research took place following a request for a study by the United Nations Secretary General on the state of the world's ecosystems. As a result of this request, 1,360 experts collaborated on the development of the Millennium Ecosystem Assessment, co-sponsored by the World Bank and released in $2005 .{ }^{4}$ The extensive report depicted the stress throughout our planet on our water supplies, our forests, and our fishery resources. Overabstraction and overuse of all these resources threaten conflict among those who depend upon their access, highlighting the need to implement scientifically sound shared approaches to these resources.

Political awareness of the increasing pressure for access to resources is also driving the need for better transboundary management. To this extent, governments and the United Nations system, including its specialized agencies such as the World Bank, have also supported the efforts to attain the UN Millennium Development Goals. ${ }^{5}$ These goals, including Goal Seven - to achieve environmental sustainability - are driven by factors such as the following: 1) populations are increasing and in many areas of the world, critical natural resources are becoming more scarce; 2) access to resources is accelerating due not only to demand but also from sophisticated technology that can cross borders, such as slant drilling; 3) climate change will affect resources to an increasing degree, often damaging crops and water supplies; and 4) unless managed well, the factors above may lead states towards conflict. Reports have been documented of conflicts between or within some World Bank member States that are connected to resource scarcities; given current environmental trends, there is no current reason to assume that this type of conflict will diminish. ${ }^{6}$

Against this background, this chapter discusses how certain World Bank operational policies, specifically certain environmental and social safeguard policies, ${ }^{7}$ are relevant for addressing transboundary management of resources in Bank-financed projects, and how these policies and instruments are implemented to assist with compliance. The chapter then provides project

4 Millennium Ecosystem Assessment, March 2005, at www.maweb.org/en/index.aspx

5 UN Millennium Development Goals, at www.un.org/millenniumgoals

6 Most recently, reports of conflict arising from water scarcities in Darfur have been frequently pointed to as examples of disputes brought about over water and with connections to climate change. See, e.g., Ban KiMoon, A Climate Culprit in Darfur, Washington Post, 16 June 2007; United Nations Environment Programme, Sudan Post-Conflict Environmental Assessment, available at www.unep.org/Sudan. Historically, there have been conflicts between Turkey and Syria over the Euphrates, between Egypt and the lower riparian States over the Nile, and between China and its riparian States of the Mekong River. See Eyal Benvenisti, Sharing Transboundary Resources: International Law and Optimal Resource Use (Cambridge, UK: Cambridge University Press, 2002).

7 Beginning in 1999, Bank management applied the term 'safeguard' to a set of 10 environmental, social, and international law policies whose primary objective is to ensure that Bank-funded operations are designed to protect those who might be adversely affected by such projects and that the projects do not cause unacceptable harm to the environment. 
examples where these policies have been effectively applied at different levels (local, national, regional, and international).

Next, it briefly discusses how the Bank is engaged with different partners to address transboundary resources and how it seeks to ensure that its projects, including those involving transboundary natural resources, are strategically aligned with the member countries' development and poverty reduction goals. It also discusses the role that civil society organizations (CSOs) have played in the Bank's operations to carry out these projects. The chapter concludes with lessons learned from the Bank's experience in implementing its environmental assessment policy and in managing transboundary lake basins. ${ }^{8}$

\subsection{Relevant Bank policies for the management of transboundary natural resources}

Since the 1950s, the Bank has promulgated and implemented operational policies, inter alia, to promote effective and co-operative management of transboundary resources. These policies have generally required borrowing States to assess the potential transboundary effects of their projects and to make this information available to other affected members and the public prior to proceeding with the projects.

As understanding about the potential adverse impact of large-scale infrastructure has grown, the Bank developed a suite of environmental and social impact policies referred to as 'safeguard policies'. These are designed so that Bank projects will 'do good and avoid harm'. Several of the 10 safeguard policies are particularly useful in addressing transboundary issues: Operational Policy (OP) 7.50 International Waterways, OP 7.60 Projects in Disputed Areas, and OP 4.01 Environmental Assessment. This section provides details on these safeguard policies and other Bank policies that also promote the sharing of information with relevant stakeholders.

\subsubsection{International Waterways (OP 7.50)}

\section{Brief history}

- With an increase in Bank-financed projects on international waterways, and in view of the Bank's pertinent Articles, the Bank adopted a policy on international waterways in $1956 .{ }^{9}$ The policy required the Bank's management to be informed of any project that involved the use of international inland waters.

- In 1964, the Bank revised this policy to expand the scope so that it would apply to all international waters bound by two or more States. The revised policy also extended the

8 This section looks at the Bank's experience with applying its policies on environmental assessment.

9 World Bank, Operational Memorandum for Projects on International Inland Waterways, Operational Memorandum No. 8 (1956). 
reporting requirement so that the Bank's Board of Executive Directors would be informed of such projects. ${ }^{10}$

- The policy was again revised in $1985 .{ }^{11}$ Building upon existing Bank practice and the emerging rules of international law, the revised policy adopted the principle of notification for all projects on an international waterway that are within a set of pre-identified activities. Under this requirement, a State proposing a project on an international waterway is required to inform its neighbouring riparian States of its potential effects in advance of the Bank's final appraisal of the project.

- The policy is referred to in current practice as OP 7.50 and was last revised in August $2004 .{ }^{12}$

\section{Information-sharing mechanism}

OP 7.50 requires that the beneficiary State formally notify the other riparian States of a proposed project and its project details if the project is on an international waterway. ${ }^{13}$ If the beneficiary does not wish to give notification, the Bank does so. If the beneficiary objects to the Bank's doing so, the Bank discontinues processing the project and informs the relevant Executive Directors accordingly.

These procedures enable riparians to engage in information sharing and understand the potential impact of projects. Potentially affected riparian States can seek additional information or register concerns or objections.

\section{Consistency with existing treaties and other instruments}

- OP 7.50 is drawn from generally recognized principles of international law, ${ }^{14}$ international arbitral awards, and the work of the Institute of International Law, International Law Association, and the UN International Law Commission. ${ }^{15}$

- The Bank attaches great importance to the existing agreements or arrangements among riparian States. For example, if two watercourse States have an agreement that details water allocation and use but does not impose a notification requirement upon the State carrying out the project, the Bank would generally respect the terms of such an agreement and, consequently, OP 7.50

10 Raj Krishna, The Evolution and Context of the Bank Policy for Projects on International Waterways, in Salman M.A. Salman and Laurence Boisson de Chazournes (eds.), International Watercourses: Enhancing Cooperation and Managing Conflict - Proceedings of a World Bank Seminar, World Bank Technical Paper No 414 (Washington, DC: World Bank, 1998).

11 Operational Manual Statement 2.32 (1985).

12 OP/BP 7.50 (August 2004).

13 Para.7 of OP 7.50 defines three categories of exceptions: 1) for any ongoing schemes, projects involving additions or alterations that will not adversely change the quality or quantity of water flows to other riparians; 2) water source surveys and feasibility studies; and 3) projects relating to a tributary of an international waterway where the tributary runs exclusively in one state and the state is the lowest downstream riparian.

14 These principles include the principle of equitable utilization and the obligation not to cause appreciable harm.

15 Krishna, supra note 10. 
would not require notification. ${ }^{16}$ Similarly, if the agreement sets out the terms of notification, the Bank would expect the States to comply with the terms of the agreement to which they agreed to be bound.

\subsubsection{Projects in Disputed Areas (OP 7.60)}

OP 7.60 requires that the Bank notify governments if a proposed project may have an impact on territory that is the subject of dispute between the States. ${ }^{17}$ The policy recognizes that projects may raise sensitive issues between governments, and in some cases a project should not proceed unless the governments concerned agree that it can do so in a way that is not harmful to the interests of relevant interested States. Increasingly, with technological advances such as slant drilling enabling resource extraction under or across borders, issues pertaining to appropriate notification and impact assessment will be even more important.

OP 7.60 also requires Bank staff to provide details of possible territorial disputes that could be relevant to project operations. Further, Bank staff must ensure that interested governments have an opportunity to fully detail the issues of the dispute. Thus, prior to proceeding, Bank staff must investigate whether such a project could harm the interest of the States. The Bank may proceed with a project where it determines that it will not prejudice the claims of the country that is not borrowing for the project. ${ }^{18}$

\subsubsection{Environmental Assessment (OP/BP 4.01)}

\section{Brief history}

- Since the late 1980s, the Bank has been carrying out various forms of environmental assessment as its standard procedure for ensuring satisfactory environmental quality in its project portfolio.

- In 1989, the Bank adopted Operational Directive 4.00 (amended as OD 4.01 in 1991) that obliged borrowing States to carry out environmental assessment if their projects were likely to have potential (adverse) environmental risks and impacts. In 1999, the OD was converted into OP/BP (Bank Procedure) 4.01. The latest revision was made in August 2004.

\section{Environmental assessment requirement}

OP/BP 4.01 requires that the borrower carry out environmental assessment, taking into account the natural environment (air, water, and land); human health and safety; social aspects (involuntary resettlement, indigenous peoples, and cultural property, socioeconomic considerations); and transboundary and global environmental aspects. ${ }^{19}$

16 Ibid.

17 OP 7.60 (June 2001).

18 Ibid., para. 2.

19 OP 4.01, para. 3 (August 2004). 
According to OP 4.01, Bank investment projects are classified as category $\mathrm{A}^{20} \mathrm{~B},{ }^{21} \mathrm{C},{ }^{22}$ or $\mathrm{Fl}^{23}$ according to the nature and magnitude of potential environmental impacts. For category $A$ and $B$ projects, the borrower prepares an environmental assessment report. For category $C$ projects, beyond screening, no further EA is required. For category FI projects, sub-borrowers or beneficiaries are required to carry out appropriate EA for each subproject.

For category A projects, the borrower is required to retain independent experts not affiliated with the project to carry out the EA. If a project in category $A$ is highly risky or contentious or involves serious and multidimensional environmental concerns, the borrower should normally also engage an advisory panel of independent, internationally recognized environmental specialists to advise on all aspects of the project relevant to the EA. ${ }^{24}$

To ensure good-quality EA and consistency with OP 4.01 requirements, the Bank reviews the findings and recommendations of the EA to determine whether they are adequate. If appropriate, the Bank requires additional EA work. ${ }^{25}$

\section{Public consultation and disclosure requirements ${ }^{26}$}

- For category A and B projects, the borrower is required to consult project-affected groups and local nongovernmental organizations (NGOs) about the project's environmental aspects and to take their views into account. The borrower is to initiate such consultations as early as possible.

- For category A projects, the borrower is required to consult these groups at least twice: (a) shortly after environmental screening and before the terms of reference for the EA are finalized and (b) once a draft EA report is prepared. In addition, the borrower consults with such groups throughout project implementation as necessary to address EA-related issues that affect them.

20 A proposed project is classified as Category A if it is likely to have significant adverse environmental impacts that are sensitive, diverse, or unprecedented. These impacts may affect an area broader than the sites or facilities subject to physical works. EA for a Category A project examines the project's potential negative and positive environmental impacts, compares them with those of feasible alternatives (including the 'without project' situation), and recommends any measures needed to prevent, minimize, mitigate, or compensate for adverse impacts and to improve environmental performance. Para. 8 (a).

21 A proposed project is classified as Category B if its potential adverse environmental impacts on human populations or environmentally important areas - including wetlands, forests, grasslands, and other natural habitats - are less adverse than those of Category A projects. These impacts are site-specific, few if any of them are irreversible, and in most cases mitigating measures can be designed more readily than for Category A projects. Like Category A, the EA examines the project's potential negative and positive environmental impacts and recommends any measures needed to prevent, minimize, mitigate, or compensate for adverse impacts and improve environmental performance. Para. 8 (b).

22 A proposed project is classified as Category $\mathrm{C}$ if it is likely to have minimal or no adverse environmental impacts. Para. 8 (c).

23 A proposed project is classified as Category Fl if it involves investment of Bank funds through a financial intermediary, in subprojects that may result in adverse environmental impacts. Para. 8 (d).

24 Para. 4.

25 Para. 5.

26 Paras. 14-18. While the EA policy contains disclosure, consultation, and public participation provisions, it is also important to be aware of the Bank Policy on Disclosure of Information. This is the Bank's umbrella policy for disclosure of information and contains provisions on disclosure related to the environment that are consistent with those set out in OP 4.01. 
- The borrower makes the draft EA (for category A projects) or any separate EA report (for category B projects) available in-country in a local language and at a public place accessible to project-affected groups and local NGOs prior to appraisal.

\section{Consistency with existing treaties and other instruments}

OP 4.01 and other safeguard policies provide the Bank with tools that support environmental and social principles that can be found in the 1992 Rio Declaration on Environment and Development, ${ }^{27}$ the 1991 Convention on Environmental Impact Assessment in the Transboundary Context (Espoo Convention), ${ }^{28}$ and the 1998 Convention on Access to Information, Public Participation in Decisionmaking and Access to Justice in Environmental Matters (Aarhus Convention), ${ }^{29}$ among other international environmental instruments.

Furthermore, many borrowing countries have internalized the EA requirement in their national law. A recent World Bank study, for example, found that 24 sub-Saharan countries have environmental impact assessment (EIA) legislation and that the majority of these have incorporated provisions that are consistent with the key requirements of the Bank policy on EA. ${ }^{30}$

Finally, to ensure that the Bank-financed projects take into account the borrower's policies and laws, OP 4.01 requires that the EA assess the country's national environmental action plans, the overall policy framework, national legislation, institutional capabilities related to the environment and social aspects, and the country's obligations under relevant international environmental treaties and agreements. The Bank does not finance project activities that would contravene

27 Rio Declaration on Environment and Development, www.unep.org/documents. Among these, Rio Principle 2 is probably the most often cited when it comes to transboundary use issues: 'States have, in accordance with the Charter of the United Nations and the principles of international law, the sovereign right to exploit their own resources pursuant to their own environmental and developmental policies, and the responsibility to ensure that activities within their jurisdiction or control do not cause damage to the environment of other States or of areas beyond the limits of national jurisdiction.' Nevertheless, a number of other principles reflect internationally accepted principles for addressing transboundary issues. Rio Principle 10 encourages States to involve stakeholders in environmental decision making. The precautionary principle set forth in Rio Principle 15 is reflected in the precautionary approach set forth in OP 4.01 (as well as OP 4.04 on Natural Habitats). In both cases the Bank requires an EA before an environmental project can proceed, and in OP 4.04 such an approach is required in determining whether a project can affect natural habitats. OP 4.01 is also in direct line with Principle 17, which declares that a State shall undertake an EIA for projects that are likely to have a significant adverse impact on the environment and are subject to a decision of a competent national authority. OP 4.01 and OP 7.50 contain many elements supportive of Rio Principle 19 that obliges States to provide prior and timely notification and relevant information to potentially affected States on activities that may have a significant adverse transboundary environmental effect and that they shall consult with those States at an early stage and in good faith.

28 See www.unece.org/env/eia. The convention requires States to carry out an EIA for all activities listed in Appendix I that are likely to have a 'significant adverse transboundary impact.' Art 2 (2).

29 At www.unece.org/env/pp/documents/cep43e.pdf, Article 5, para. 6 provides that 'Each Party shall encourage operators whose activities have a significant impact on the environment to inform the public regularly of the environmental impact of their activities and products, where appropriate within the framework of voluntary eco-labeling or eco-auditing schemes or by other means.'

30 These provisions include the consultation and disclosure requirements. Mohammed A. Bekechi and JeanRoger Mercier, The Legal and Regulatory Framework for Environmental Impact Assessments: A Study of Selected Countries in Sub-Saharan Africa (Washington, DC: World Bank, 2002). 
national or international environmental treaty obligations identified during the EA process. ${ }^{31}$ Taken together, these principles set forth in the Bank's environmental assessment policy, as with those addressing international waterways and disputed areas, provide strong support for ensuring that transboundary resources are managed or developed in ways that comport with sound international practice.

\subsubsection{Other policies that promote sound resource protection, information sharing, and stakeholder participation}

Several other Bank policies promote natural resource protection and information sharing with relevant stakeholders.

- Natural habitats (OP 4.04): Requires the borrower to seek to avoid damage to natural habitat and to take into account the views, roles, and rights of affected groups, including local NGOs, and involve them in planning, designing, implementing, monitoring, and evaluating such projects. The Bank encourages governments to provide affected people with appropriate information and incentives to protect natural habitats. ${ }^{32}$ This policy has also been applied in World Bank projects that support the establishment and maintenance of transboundary protected areas.

- Pest management (OP 4.09): The borrower addresses pest management issues in the context of the project's environmental assessment, and therefore the same public consultation and disclosure requirements as those required under OP 4.01 apply. This policy is supportive of the objectives of international environmental treaties that address chemicals management. ${ }^{33}$

- Indigenous peoples (OP 4.10): The Bank requires the borrower to engage in a process of free, prior, and informed consultation with affected indigenous peoples. ${ }^{34}$ Furthermore, OP 4.10 requires that the borrower make the social assessment report and draft Indigenous Peoples Plan or Indigenous Peoples Planning Framework available to the affected indigenous peoples' communities in an appropriate form, manner, and language. ${ }^{35}$ The policy also requires the review and analysis of the relation of indigenous peoples and the lands that they traditionally use, own, or occupy. In doing so, the policy takes special note of indigenous peoples' stewardship of natural resources.

- Physical cultural resources (OP 4.11): The borrower consults relevant stakeholders as part of the overall consultation process for the EA, including project-affected groups, concerned government authorities, and relevant NGOs, in documenting the presence and significance of physical cultural resources, assessing potential impacts, and exploring avoidance and mitigation options. ${ }^{36}$ The findings of the cultural resources component of the EA are normally disclosed to the public, as per OP 4.01, except where the borrower, in consultation with the Bank,

31 Para. 3.

32 OP 4.04, para. 10 (August 2004).

33 OP 4.09, para. 1 (August 2004); World Bank, Safeguard Policies, Draft Matrices, Tools for Learning, World Bank (updated on 1 June 2006).

34 OP 4.10, paras. 1 and 10 (July 2005).

35 Para. 15.

36 OP 4.11, para. 11. 
determines that such disclosure would jeopardize the safety or integrity of the physical cultural resources involved or of the source of information on the physical cultural resources. ${ }^{37}$ This policy has also been critical in supporting international treaties on cultural heritage.

- Involuntary resettlement (OP 4.12): The Bank requires that displaced persons and their communities, and any host communities receiving them, are provided timely and relevant information, consulted on resettlement options, and offered opportunities to participate in the planning, implementation, and monitoring of resettlement. Also, appropriate and accessible grievance mechanisms should be established for these groups. ${ }^{38}$ The disclosure requirements are similar to those required under OP $4.01 .^{39}$

- Forests (OP 4.36): The Bank requires borrowers to identify and consult the groups interested in forest areas likely to be affected by Bank-financed projects in and beyond the forest sector. ${ }^{40}$ The disclosure requirements as set out in OP 4.01 apply to all projects that affect forests. ${ }^{41}$

- Disclosure of information: The Bank has a presumption in favour of disclosure and is committed to making information available to the public. The documents now available to the public under this policy range from project and policy documents to strategy and evaluation documents. ${ }^{42}$

- Human rights: The Bank does not have a policy per se on human rights. However, the Bank has recognized the importance of, and the need to, address human rights issues in diverse and multiple ways. The Bank supports human rights through a wide range of its activities. Explicit reference to the importance of human rights is set forth in OP4.10 (Indigenous Peoples). ${ }^{43}$ The Bank is currently working on a manual on human rights indicators, which was due to be finalized in 2007. The Bank has also recently established a trust fund that will be used for analytical work on human rights and to promote collaboration with other development partners. ${ }^{44}$

37 Para. 12.

38 OP 4.12, para. 13(a) (April 2004).

39 Draft Matrices, supra note 33.

40 OP 4.36, paras. 11 and 12 (August 2004).

41 Draft Matrices, supra note 33.

42 World Bank Policy on Disclosure of Information, Information Disclosure Web site, at http://www1.worldbank.org/operations/disclosure

43 Para. 1 provides that OP 4.10 'contributes to the Bank's mission of poverty reduction and sustainable development by ensuring that the development process fully respects the dignity, human rights, economies, and cultures of Indigenous Peoples.' (emphasis added)

44 Examples of activities funded through this trust fund include: Studies and pilot projects to provide empirical documentation on the links between human rights, development, and poverty reduction; analytical work on the impacts of human rights on economic growth, sustainable human development, and good governance; development of justice/rule of law/human rights analysis that might be useful in the preparation of Poverty Reduction Strategy Papers or other national development strategies; coordination in the field between the Bank-supported justice reform programmes and human rights programmes supported by other development partners; and development of methodologies and mechanisms to monitor and measure justice and human rights, including design of indicators and assisting with their implementation in countries, building on existing research in this field. JHRTF Concept Note, World Bank (draft 12 July 2006). 


\subsection{Instruments to support compliance}

World Bank Operational Policies define the rules applicable to Bank operations in the design, preparation, implementation, and supervision of Bank-financed projects. Each OP, in turn, has a binding Bank Procedure that spells out how the Policy should be carried out. ${ }^{45}$ To ensure consistency and quality of safeguard application and implementation, the BPs set out details for required procedures and documentation.

The Bank has also established a central Quality Assurance and Compliance Unit, which provides support to the operational staff responsible for implementing safeguard policies and promotes harmonization of safeguard issues across regions. ${ }^{46}$

To ease the implementation of and remain consistent with the evolving safeguard issues, these policies regularly undergo revision. The revisions do not alter the objectives and principles of the policies, but rather are intended to clarify ambiguities in the existing policy statements, codify current practice based on evolving standards, and reflect recommendations of evaluations carried out by the Bank's independent Operations Evaluation Department. ${ }^{47}$

In 1993, following a number of concerns expressed by the impact of large infrastructure projects (including hydroelectric facilities on international waterways), the Bank established an independent inspection mechanism known as the Inspection Panel. The panel's primary purpose is to address the concerns of people who may be adversely affected by Bank projects and to ensure that the Bank adheres to its operational policies and procedures during the design, preparation, and implementation phases of projects. ${ }^{48}$ An investigation can be requested by any group of private individuals who believe they have been, or might be, harmed by a Bank-financed project and who believe that the harm stems from the Bank's failure to abide by its own policies and procedures. ${ }^{49}$

The Panel is the first body of its kind within an international financial institution to give voice to private citizens in an international development context. ${ }^{50}$ Since its inception in September 1993, the Panel had received 43 formal requests for inspection as of this writing, most of which have concerned the Bank's safeguard policies, with a number involving alleged noncompliance with

45 Definitions, Operational Manual, at

http://intranet.worldbank.org/WBSITE/INTRANET/OPSMANUAL/0,,contentMDK:20122392 menuPK:60000 691 pagePK:60001219 piPK:60000961 theSitePK:210385,00.html

46 Each of the Regional Vice Presidencies has a Regional Safeguard Director and a Coordinator. See Issues Brief: The World Bank's Environmental and Social Safeguard Policies, World Bank Safeguard Policies, at http://intranet.worldbank.org/WBSITE/INTRANET/UNITS/ESSDNETWORK/INTSAFEPOL/0,,contentMDK:2 0446525 hIPK:971249 menuPK:613214 pagePK:64168332 piPK:64168299 theSitePK:584402,00.html; Kenneth M. Green and Alison Raphael, Third Environmental Assessment Review (FY 96-00) (Washington, DC: World Bank, 2002); David Freestone, The Environmental and Social Safeguard Policies of the World Bank and the Evolving Role of the Inspection Panel, in A. Kiss, D. Shelton, and K. Ishibashi (eds.), Economic Globalization and Compliance with International Environmental Agreements (London: Kluwer Law International, 2003).

47 Issue Brief, supra note 46.

48 World Bank, Accountability at the World Bank, The Inspection Panel 10 Years On (Washington, DC: 2003). See also, Charles Di Leva, in Carl E. Bruch (ed.), Public Participation in the Governance of International Freshwater Resources (Tokyo: United Nations University, 2005).

49 World Bank, supra note 48.

50 Ibid. 
polices on project supervision and disclosure of information. A number of these requests have concerned transboundary resource management, especially concerning large dams and pipelines. ${ }^{51}$ Many other international financial institutions have now established similar dispute settlement mechanisms

\subsection{Operational Policies in a transboundary resource context}

The safeguard policies are applied at the local, national, regional, and international levels. The following are a few examples in several Bank regions where these policies have been applied in a transboundary context.

\subsubsection{Brazil-Bolivia Gas Pipeline Project (GASBOL)}

GASBOL is South America's largest gas transport project to date. The primary purpose of the project is to transport natural gas produced from Bolivian gas reserves to major industrial centres in Brazil. ${ }^{52}$ To ensure that environmental and social impacts are properly considered, a number of environmental studies were conducted to analyze medium, long-term, and cumulative impacts of the project. $^{53}$ In addition, the governments concerned set up an institutional framework for environmental management and supervision. ${ }^{54}$ With respect to public consultation and participation, the project established community-based organizations and committees to engage the public regarding the draft regulations and the project's environmental assessment. The Brazilian government also made extensive use of the media to publicize the results of the EIA, and the Bolivian government conducted outreach activities to channel appropriate information to local communities that were affected by the project. Meetings were also held with NGOs. ${ }^{55}$

\subsubsection{Yacyreta Hydroelectric Project}

This project was designed to produce least-cost baseload electric supply, to improve navigation along the Parana River located between Argentina and Paraguay, and to improve opportunities for fisheries. To manage this transboundary resource, the two governments established a bi-national entity, the Entidad Bi-Nacional de Yacyreta, to administer the facility, with the support of the World Bank. The project has succeeded in providing an increasing amount of electricity, though it has also been the subject of some controversy and was investigated by the World Bank Inspection Panel following the complaint of some citizens that, among other things, the resettlement of affected people on both sides of the river had not been carried out appropriately. Similar to the Nam Theun 2 hydroelectric project discussed below, under the design of the Yacyreta facility the operation would supply power principally to one riparian State (Argentina) with royalties directed towards the other State (Paraguay).

51 A complete listing and description of the Requests for Inspection, along with Panel Reports and related documentation, are available at the Inspection Panel Web site, at www.inspectionpanel.org

52 Green and Raphael, supra note 45; World Bank, Integrating Environmental Safeguards into Oil and Gas Pipeline Projects: A Best Practices Case Study of the Bolivia-Brazil Pipeline Project (Washington, DC: 2005).

53 Green and Raphael, supra note 46.

54 Ibid.

55 Ibid. 


\subsubsection{Nam Theun 2 Project (NT2)}

The hydroelectric project on the Nam Theun River in Lao PDR provides for the export of 996 megawatts of electricity-generating capacity and electrical energy to Thailand. ${ }^{56}$ To ensure that the project complies with the Bank's safeguard policies, including OP 4.01, several environmental and social impact assessments, studies, and evaluations were conducted by the sponsors, the government of Lao PDR, domestic and international NGOs, independent consultants, and multilateral development institutions, including the Bank. ${ }^{57}$ The Bank also decided to finance the NT2 Social and Environment Project to mitigate some of the environmental and social impacts of the proposed hydroelectric project. 58

Moreover, the government and the sponsors placed a high priority on public consultations and disclosure to ensure that all affected people were fully informed of the project and that the views of the affected population were taken into consideration. ${ }^{59}$ For example, the project design was amended to reflect the stakeholders' concerns related to the choice of location for the resettlement area $^{60}$ The project also engaged local villagers in its preparatory work as well as the implementation process of mitigation measures in their area. In addition, more than 200 local, national, and international consultations and workshops about the project and project-related issues have been conducted since $1997 .{ }^{61}$ To ensure that the project was developed and operated in accordance with all applicable standards, three internationally recognized and fully independent panels were also established to closely monitor the project. ${ }^{62}$

\subsubsection{Mekong River Water Utilization Project}

Launched in 2000, with a closing date scheduled for 2008, this transboundary management project seeks to assist the Mekong River Commission and its Secretariat to address water quality and management issues along the Mekong River for the four riparian countries that are members of the

56 Integrated Safeguards Data Sheet, Report No. AC 293 (8 March 2004).

57 The project was also developed to ensure consistency with the International Finance Corporation's environmental and social policies. The suite of safeguard documents for the project includes the Environmental Assessment and Management Plan, the Social Development Plan, the Social and Environmental Management Framework and Operational Plan, and the Social and Environmental Impact Assessment. See Nam Theun 2 Hydroelectric Project Web site, at www.namtheun2.com; NT2 Safeguard Documents, Environmental Assessment and Management Plan, at http://web.worldbank.org/WBSITE/EXTERNAL/COUNTRIES/EASTASIAPACIFICEXT/LAOPRDEXTN/ 0,,contentMDK:20330022 pagePK:141137 piPK:141127 theSitePK:293684,00.html

58 Ibid.

59 Prior to this project, the Laotian government had little experience with open, inclusive public consultation. However, as the project progressed the government adopted a consultation strategy with four levels: international, national, provincial, and local, with the greatest emphasis placed at the local level. Green and Raphael, supra note 46.

60 Nam Theun 2 Hydroelectric Project Web site, supra note 57.

61 Ibid.

62 The Panels are the Panel of Environmental and Social Experts, commissioned by the Government of the Lao PDR in conjunction with the World Bank; the International Advisory Group, responsible for advising the World Bank in its handling of the social and environmental issues on the project; and the Dam Safety Panel of Experts, appointed by the Government of the Lao PDR in conjunction with the World Bank. Nam Theun 2 Hydroelectric Project Web site, supra note 57. 
Commission - Cambodia, Lao PDR, Thailand, and Vietnam. Discussions are also taking place with China and Myanmar to seek the collaboration of all riparian States.

The transboundary issues to address within the Mekong Basin include fisheries, forestry and watershed management, wetlands, salinity, acid-sulfate soils, soil erosion and sedimentation, and floodplain management. The project activities will place increasing emphasis on the collection of data and conduct of related research on linkages between such issues and the flow and hydrologic regime. According to the project design, "[a]ssessing each problem area with all available data, determining which problems are of regional and global significance, and identifying specific needs for additional data are the key steps in launching this process' ${ }^{63}$

The project also seeks to implement the Mekong River Agreement of 1995 by helping address the Rules of the Agreement that sought to have the countries agree on equitable utilization of the Mekong's waters. This was very challenging and therefore is a key element of the project. Article 26 of the Mekong Agreement mandates the Joint Committee to prepare Rules for Water Utilization and Inter-Basin Diversions pursuant to Articles 5 and 6 of the Mekong Agreement. Article 5 contains the general principle of 'reasonable and equitable utilization' of the waters of the Mekong system and outlines the conditions for notification, consultation, and agreement on proposed water uses. Article 6 calls for the maintenance of flows on the mainstream with respect to i) natural dry season flows; ii) wet season flows sufficient to enable the acceptable natural reverse flow of the Tonle Sap; and iii) peak flood flows. In order to implement Articles 5 and 6 of the Mekong Agreement and adhere to the principles of Article 3: Protection of the Environment and Ecological Balance and Article 7: Prevention and Cessation of Harmful Effects, additional rules on water use monitoring, information and data exchange protocols, and water quality are needed. In summary, rules for water utilization anticipated to be formulated under the Project are: i) Procedural Rules protocols for information exchange, for monitoring water use and diversions in the Mekong Basin, and for the notification and consultation on proposed water use, and ii) Physical Rules maintenance of flows on the mainstream and water quality rules.

\subsubsection{Nile Basin Initiative (NBI)}

The Nile Basin Initiative provides a unique forum for the riparian countries of the Nile to cooperatively manage the resources of the basin. ${ }^{64}$ These resources are critical for energy, drinking water, and irrigation supply. The Initiative has eight co-operative projects in the basin that are intended to provide a strategic environmental framework to manage the transboundary waters and

63 Project Appraisal Document on a Proposed Grant from the Global Environmental Facility in the Amount of 8 million SDR (\$11 million) to the Mekong River Commission for a Water Utilization Project (Washington, DC: World Bank, 10 January 2000).

64 Ten countries share the Nile - Burundi, Democratic Republic of Congo, Egypt, Eritrea, Ethiopia, Kenya, Rwanda, Sudan, Tanzania, and Uganda. The Nile River Basin serves as home to an estimated 160 million people within the boundaries of the Basin, and about 300 million live within the 10 countries that share the waters. Nile Basin Initiative, at www.worldbank.org/afr/nilebasin/overview.htm 
environmental challenges there. ${ }^{65}$ The Nile Transboundary Environmental Action Project, for example, aims to improve the co-operation among the riparian States through: i) enhanced communication and knowledge exchange; ii) support of community-level land, forest, and water conservation approaches; and iii) increased public awareness and understanding of communities within the basin about, inter alia, basin-wide environmental issues. The Bank, at the request of the Nile Council of Ministers, has supported and facilitated the development of the $\mathrm{NBI}$ and is coordinating international support for NBI projects. ${ }^{66}$

\subsubsection{Red Sea - Dead Sea Water Conveyance Project}

The World Bank has been involved in transboundary water management issues in the Middle East for decades. One example of a recent effort is World Bank support for a study on the feasibility of transferring water from the Red Sea to the Dead Sea as a solution to stop the rapidly declining level of the Dead Sea.67 This study was announced on May 22, 2005, at the annual World Economic Forum by the Hashemite Kingdom of Jordan, the State of Israel, and the Palestinian Authority. The declining water level of the Dead Sea has far-reaching environmental, social, and economic consequences for the Dead Sea region and beyond. The water level of the Dead Sea has fallen more than 20 metres in less than 50 years. The current rate of decline is approximately one metre per year. The consequent impacts on the region of the shrinking sea are varied and numerous, and they may soon become irreversible. The World Bank was asked to co-ordinate donor support and to manage the study. The Bank will manage the study in accordance with the policies discussed in this chapter as well as other relevant policies.

While the collaboration marks an important opportunity to bring together political entities that have not always been able to work together, the studies are being conducted against a backdrop of concerns voiced by environmental groups. They have expressed concern about the feasibility of the mixing of waters of different densities, as well as the feasibility of conveying the water upgrade. For these reasons, the accepted international practice of the World Bank assessment and analytical tools may be crucial to finding the right way to address this complicated issue. ${ }^{68}$

\subsection{New partnerships for managing natural resources}

\subsubsection{Transboundary protected areas}

The World Bank has been engaged with the World Conservation Union-IUCN and other agencies in supporting a range of protected area initiatives spanning a number of borders. ${ }^{69}$ These include the

65 A review of information and projects under Nile Basin Initiative Shared Vision Program is available at http://web.worldbank.org/WBSITE/EXTERNAL/COUNTRIES/AFRICAEXT/EXTREGINI/EXTAFRNILEBASINI/ 0,,contentMDK:21175378 menuPK:3427090 pagePK:64168445 piPK:64168309 theSitePK:2959951,00. html; see Nile Basin Initiative Home Page, at www.nilebasin.org

66 Nile Basin Initiative Home Page, supra note 65.

67 http://web.worldbank.org/WBSITE/EXTERNAL/COUNTRIES/MENAEXT/0,,contentMDK:20664264 page PK:146736 piPK:146830 theSitePK:256299,00.html

68 The Economist, 16 March 2007.

69 The Global Transboundary Protected Area Network (IUCN, and IUCN World Commission on Protected Areas), at www.tbpa.net/case_07.htm 
Mesoamerica Biological Diversity Corridor; the Mesoamerican Barrier Reef Project; the project to enhance the trilateral co-operation between Kazakhstan, the Kyrgyz Republic, and Uzbekistan in the West Tine Shan Mountain Range; and the Eastern Carpathian Mountains.

These efforts have included working on the legal arrangements between the bordering States to help launch collaborative arrangements for managing the shared resources and for sharing knowledge.

\subsubsection{Partnerships to address global fishery and forest issues}

Two recent partnerships launched by the Bank in collaboration with other development partners may also support regional and country-based approaches for the management of fishery and forest resources. The World Bank has established a new Global Program on Fisheries (PROFISH) in association with key donors and stakeholders to meet the challenge of this growing crisis. ${ }^{70}$ PROFISH is supported with a multidonor trust fund and includes among its objectives ways to improve the unregulated and unsustainable harvesting of fish beyond territorial waters.

PROFOR is another multidonor trust fund administered by the World Bank that sits within the Environmentally and Socially Sustainable Development's Forests Team. ${ }^{71}$ PROFOR is funded by the Department for International Development of the United Kingdom, the Finnish Department for International Development Cooperation, the Japanese International Forestry Cooperation Office, and the Swiss Development Cooperation. The German government is an in-kind contributor. PROFOR was initially established at the United Nations Development Programme and was relocated to the World Bank in 2002. PROFOR's objectives are consistent with those of the World Bank's Forest Strategy and Policy approved in October 2002. PROFOR collaborates closely with the Bank in implementing the Bank's strategy, which is built on three pillars: harnessing the potential of forests to reduce poverty, integrating forests in sustainable economic development, and protecting global forest values.

\subsubsection{Bank projects and their strategic alignment with a country's priorities}

A country assistance strategy (CAS) ensures that Bank projects are strategically aligned with a country's development priorities. The CAS's primary purpose is to analyze the country's development situation and to identify the key areas in which the Bank can best assist the country to achieve its development and poverty reduction goals. ${ }^{72}$ Although a CAS is normally prepared for a single member country, a regional strategy may also be prepared for a group of countries to analyze issues relevant for the entire region (e.g., the Eastern Caribbean subregion, the Pacific

70 http://web.worldbank.org/WBSITE/EXTERNAL/TOPICS/EXTARD/0,,contentMDK:20663260 page PK:210058 piPK:210062 theSitePK:336682,00.html

71 See www.profor.info/about.html

72 A CAS is prepared in consultation with the government, civil society organizations, development partners, and other stakeholders. 
Islands, West Africa). ${ }^{73}$ Furthermore, many CASs explicitly discuss the management of transboundary resources. ${ }^{74}$

\subsubsection{Role of Civil Society Organizations}

CSOs have been playing a critical role in the Bank's operation, including project identification, design, implementation, and monitoring and evaluation. ${ }^{75}$ Examples of CSOs' contributions include: ${ }^{76}$

- Increased stakeholder participation particularly by poor and marginalized populations - CSOs can also help ensure that these views are properly considered in policy and programme decisions;

- Improved and enhanced public sector transparency and accountability, enabling an environment for good governance;

- Increased public consensus and local ownership of reforms, national poverty reduction and development strategies, and promotion of public-private co-operation;

- Innovative ideas and solutions and participatory approaches to solve local problems;

- Assistance with strengthening development programmes through the incorporation of local knowledge, targeted assistance, and the generation of social capital at the community level; and

- Provision of professional expertise and capacity building assistance for effective service delivery.

The Bank has also consulted CSOs on the revision, application, and monitoring of major Bank policies, including the safeguards on forest management, information disclosure, indigenous peoples, and resettlement. ${ }^{77}$ For example, when applying the safeguards on natural habitats, the Bank often refers to the categories to determine the type of natural habitats at issue as established by IUCN. The Bank also consults numerous international associations and NGOs, including the International Association for Impact Assessment and IUCN, for reliable scientific information to be applied on projects with transboundary considerations.

73 Additional information on CAS, including BP 2.11 (June 2005), available at http://web.worldbank.org/ WBSITE/EXTERNAL/PROJECTS/0,,contentMDK:20120746 menuPK:51551 pagePK:41367 piPK:51533 theSitePK:40941,00.html

74 For example, Kenyan and Ugandan CASs discuss the management of Lake Victoria and the Nile Basin, and Albanian CAS discusses the management of Lake Ohrid. Kenya CAS (2004); Uganda CAS (2000); Albania CAS (2006).

75 A document review of loans approved in fiscal year 2004 found that 194 projects, or 74 per cent of the 262 projects approved by the Bank's Board, had some form of civil society participation. World Bank, World Bank - Civil Society Engagement: Review of Fiscal Years 2002-2004 (Washington, DC: 2005).

76 Approach to the World Bank's Engagement with Civil Society, available at http://web.worldbank.org/ WBSITE/EXTERNAL/TOPICS/CSO/0,,contentMDK:20093200 menUPK:220424 pagePK:220503 piPK:220 476 theSitePK:228717,00.html

77 At least 15 Bank operational policies or directives for staff, recent IDA Replenishment reports, and the 2000 World Development Report on Attacking Poverty also discuss the need to engage civil society. Civil Society Background, at http://web.worldbank.org/WBSITE/EXTERNAL/TOPICS/CSO/0,,contentMDK:20093161 menuPK:220423 pagePK:220503 piPK:220476 theSitePK:228717,00.html 


\subsection{Lessons learned}

\subsubsection{Bank's review of experience with the EA policies}

The Bank's environmental assessment policy has been applicable in all the Bank's projects that affect transboundary natural resources. Its implementation is critical to the success of development finance of such projects. Given the critical importance of this policy, the Bank has on three occasions reviewed application of the EA policy since its adoption of OD 4.01 in 1989: the first review was in 1992 (covering the period 1989-1992), the second in 1996 (1993-1995) and the third in 2002 (1996-2000).

The latest review found that the Bank has made tangible progress in many areas of EA performance (see Annex 3.1). The following are some key findings from the review:

- The recent supervision assessment (QSA4), which was carried out in FY2000 and covered 103 Bank projects (14 Category A, 56 Category B, and 33 Category C), found that there were no projects rated 'unsatisfactory' for environmental aspects and that there were no Category $A$ projects rated lower than 'satisfactory' for overall supervision quality. ${ }^{78}$

- With respect to the public consultation (PC) requirement, the review found that the Bank has made important progress in planning (notably recruiting experienced participation experts, conducting good social assessments, and disseminating information), participation (through greater inclusion of vulnerable populations such as women and the poor), and improving local capacity. ${ }^{79}$

- Approximately 87 per cent of the projects held PC during the scoping phase of the EA, and again about 87 per cent held PC on the draft EA. Some of these PCs influenced project design and improved project quality. For example, in the case of Lithuania Klaipeda Port Project, the PC process allowed the Bank to learn about the history of dredging spoils by the client, which was in conflict with the client's international obligations to protect the Baltic Sea. As a result, the scope of the mitigation plan was enlarged to accommodate the construction of an inland containment facility. ${ }^{80}$

- About 90 per cent of projects reviewed were considered to have excellent informationdissemination strategies and had been successful in sharing information in appropriate languages and through appropriate venues. ${ }^{81}$

The report recommended more analysis of alternatives and potential long-term negative impacts beyond the project-specific areas, as well as increased attention to the monitoring and supervision of projects to help improve compliance and application of the Bank's EA policies. As the scope of EA increases, its reach to address transboundary considerations will also increase. These factors should build on and take into account the lessons learned in the context of shared lake basins.

78 Green and Raphael, supra note 46, p. 48.

79 lbid., p. 65.

80 lbid., pp. 65-67.

81 lbid., p. 65. 


\subsubsection{Shared lake basins}

In 2002, the Global Environmental Facility (GEF) approved a study that was published as 'Towards a Lake Basin Management Initiative: Sharing Lessons and Experiences from GEF and Non-GEF Lake Basin Management Projects'. The study analyzed the experiences gained and lessons learned from the management of 28 lake basins, of which 16 were transboundary lakes. ${ }^{82}$ Although the study focused on the management of lake basins, many of the findings shed some light on the management of other transboundary natural resources.

Some of the lessons learned are the following:

- Internationally funded projects should use existing, agreed regional and national plans, programmes, and institutions rather than starting afresh. This approach helps to minimize disruption to and repetition of existing mechanisms (e.g., Lake Malawi/Nyasa). ${ }^{83}$

- Generating a common understanding of the issues affecting a transboundary lake basin and potential management actions through joint diagnosis helps advance co-operation between countries (e.g., Lake Victoria, Lake Ohrid). ${ }^{84}$ The Transboundary Diagnostic Analysis process devised by the GEF has helped riparian countries exchange information and work together to develop common lake basin goals. ${ }^{85}$

- Success of transboundary lake basin management depends principally on member States' longterm political will, commitment, and fulfilment of obligations rather than just the particular form of institution or its legal status. ${ }^{86}$

- Lake basin management requires the trust of sectoral institutions and the public to succeed. It should build on effective communications, a common set of data and methodology for analysis, and transparent decision making (e.g., Lake Peipsi/Chudskoe). ${ }^{87}$

- Public participation and stakeholder involvement are essential for lake basin management, and these can be improved by increasing access to reliable scientific information and providing necessary assistance to all relevant stakeholders (e.g., Lakes Victoria and Tanganika). ${ }^{88}$ NGOs and CSOs often play critical catalytic roles in engaging stakeholders who are often marginalized, but their assistance needs to be better co-ordinated (e.g., Tonle Sap). ${ }^{89}$

- Key provisions in the rules governing the management of transboundary resources should be harmonized. Such provisions may include rules of access and rules governing exploitation and use of the resource. In the case of Lake Ohrid, for example, Albania and the Former Yugoslav

82 International Lake Environment Committee Foundation (ILEC), Managing Lakes and Their Basins for Sustainable Use: A Report for Lake Basin Managers and Stakeholders (Shiga, Japan: 2005).

83 lbid., p. 34.

84 World Bank, Lessons for Managing Lake Basins for Sustainable Use (Washington, DC: 2005), p. 85.

85 ILEC, supra note 82, p. 74.

86 Ibid., p. 34.

87 Ibid., p. 35.

88 lbid., p. 48.

89 World Bank, Elements of Good Lake Basin Governance, Presentation (Washington, DC: 2005); Rafik Hirji, Lake Basin Management Initiative Lessons from Asian Lake Basins, Presentation (Washington, DC: World Bank, 2005). 
Republic of Macedonia had different fishing regulations due to the differences in fishing pressures in the two countries. ${ }^{90}$ The inconsistencies in the rules led to the vastly different level of catchments in the two countries, especially in the 1980s and early 1990s (see Figure 3.1).

\subsection{Conclusion}

Despite the lessons learned during 60 years of World Bank transboundary resource engagement, the sensitive issues addressed in this chapter are likely to increase in complexity and frequency. Climate change impacts alone will likely increase tensions among shared resource users due to shifting water access and arable land. In addition, the demand for hydroelectric power and for reservoirs of shared groundwater and energy sources will place stress on transboundary relations. In the pursuit of access and development, international institutions will need to provide the scientific, economic, legal, and financial support necessary for sound management and development. In light of these factors, it is essential that we use unflagging efforts to apply the valid international rules with due process and integrity for all stakeholders.

Figure 3.1. Fish Catches in Lake Ohrid Showing the Effects of Different Rules in Two Riparian Countries

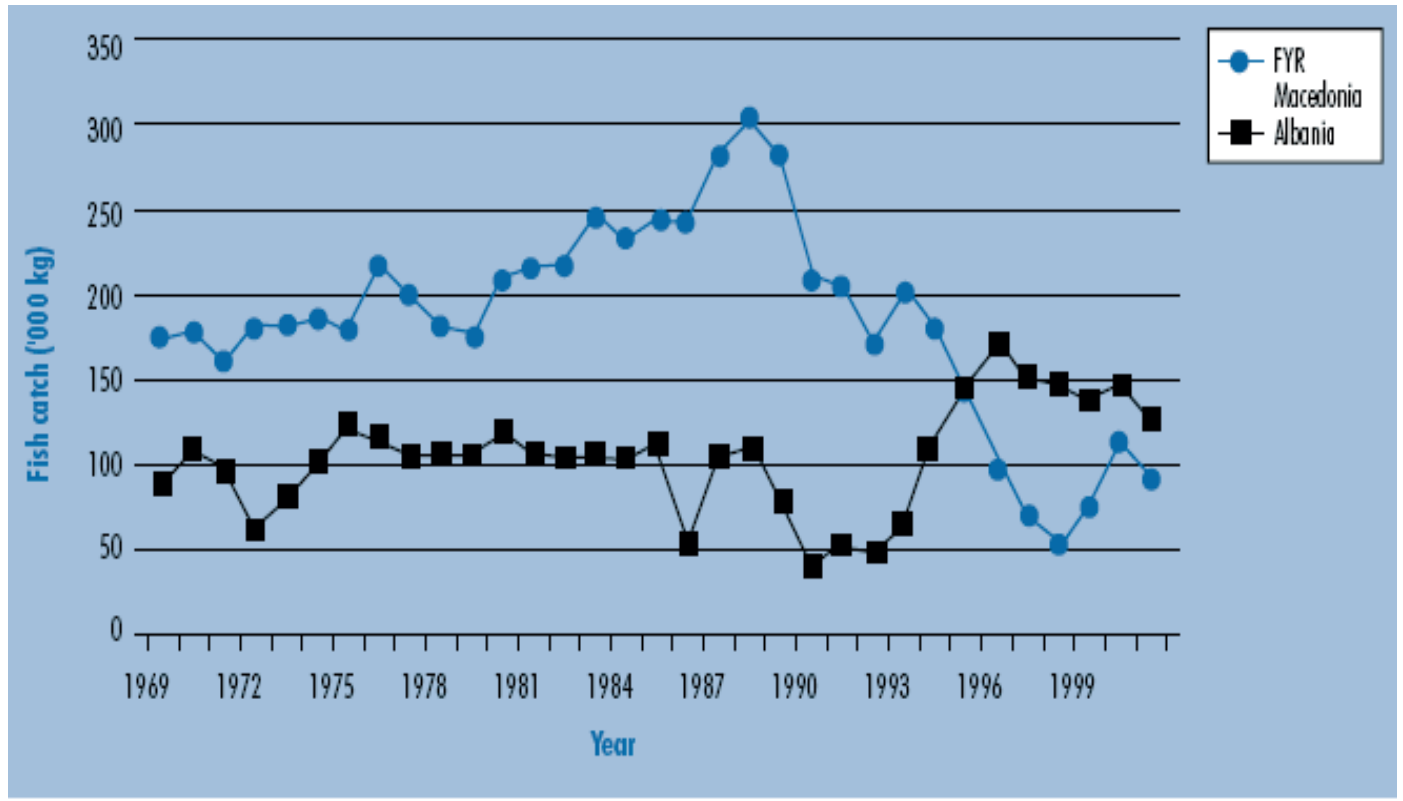

Source: The World Bank (2005).

90 For example, while there are limits on the catch in FYR Macedonia through concessions and licenses, there are no such restrictions in Albania nor are there any restrictions on the number of boats allowed on the lake or the number of nets a fisherman can employ. World Bank, supra note 84, p. 61. 


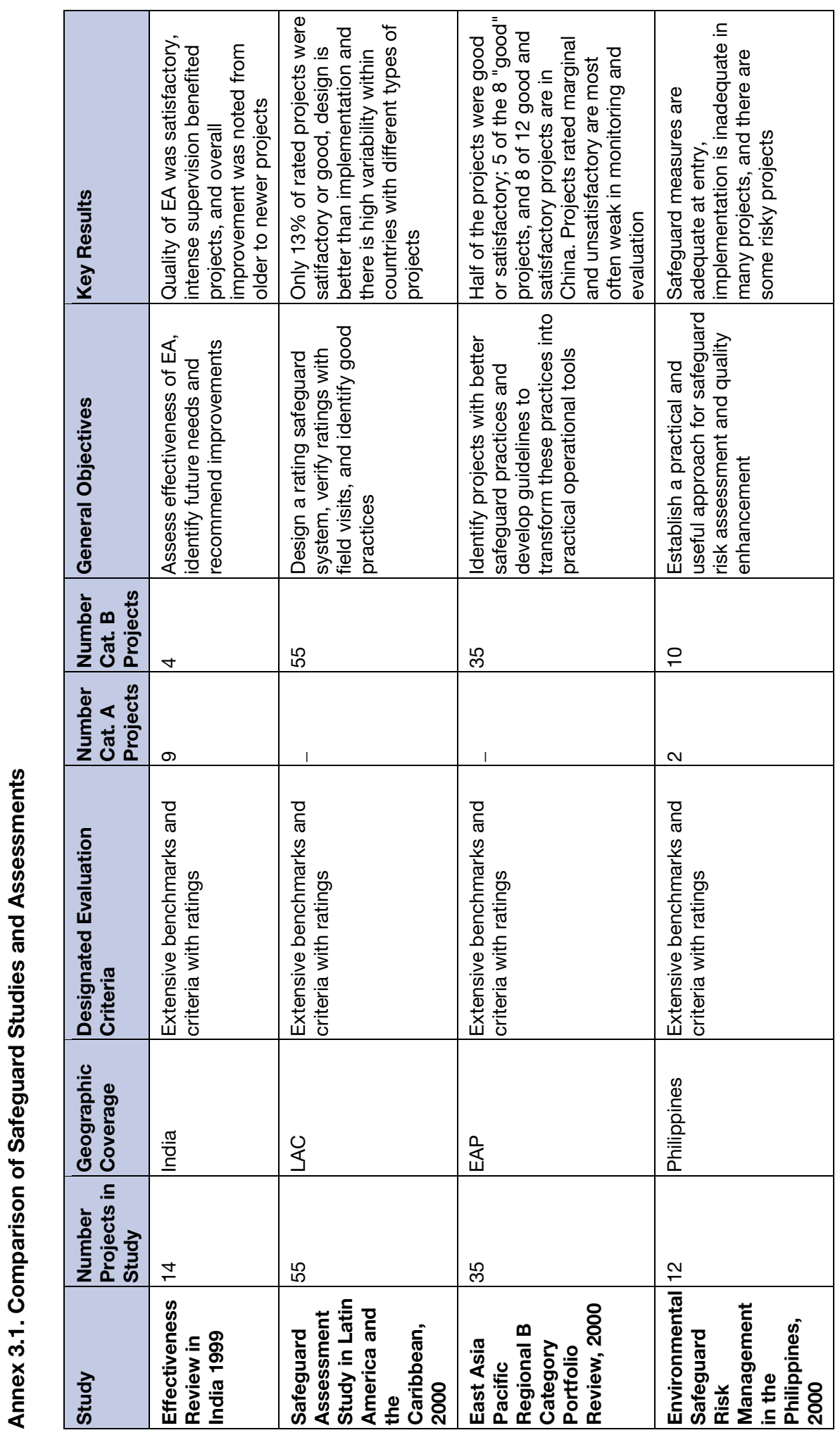




\begin{tabular}{|c|c|c|c|c|c|}
\hline 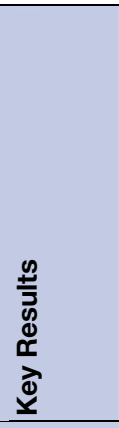 & 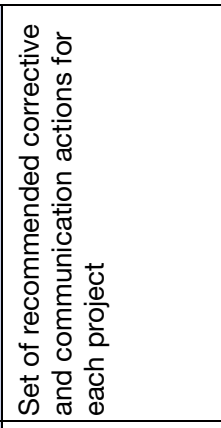 & 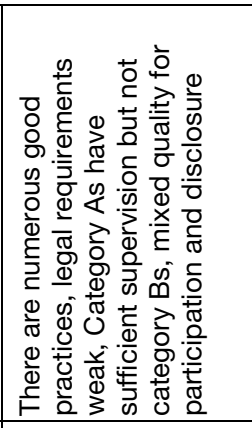 & 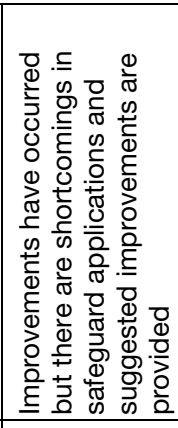 & 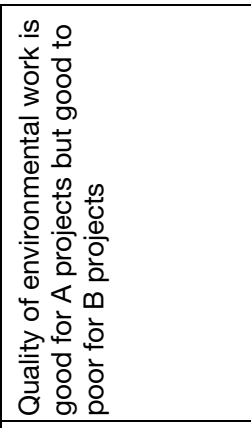 & 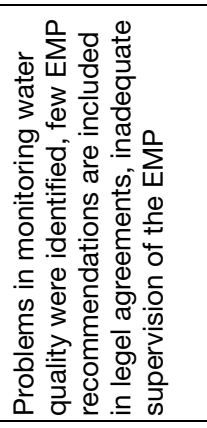 \\
\hline 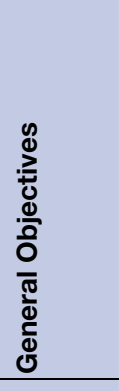 & 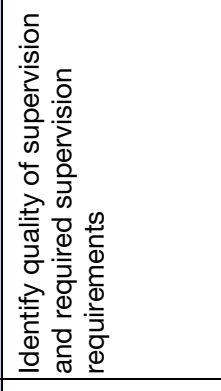 & 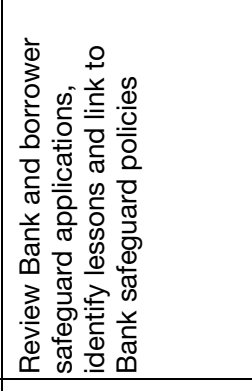 & 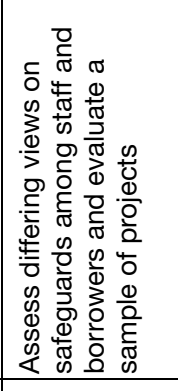 & 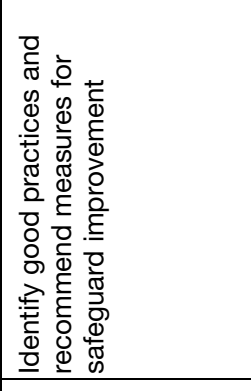 & 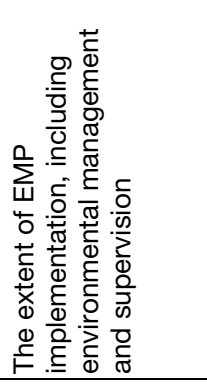 \\
\hline 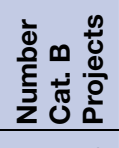 & r & $\infty$ & $\tilde{ल}$ & 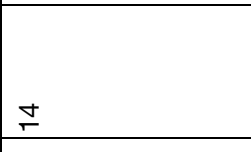 & \\
\hline 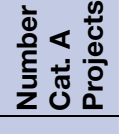 & 0 & $F$ & $\mp$ & $m$ & $\nabla$ \\
\hline 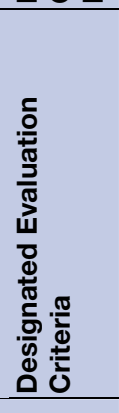 & 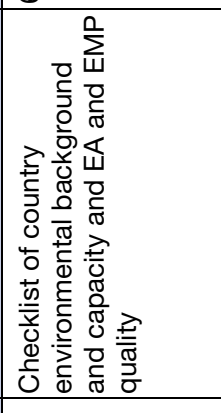 & 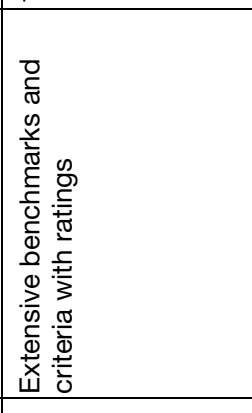 & 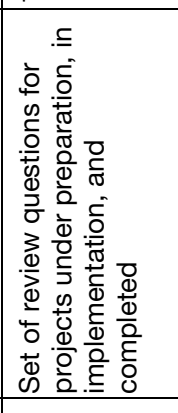 & 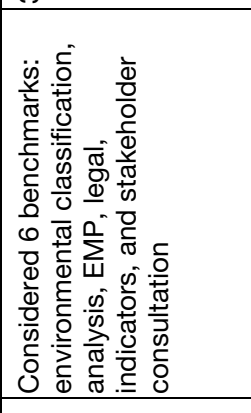 & 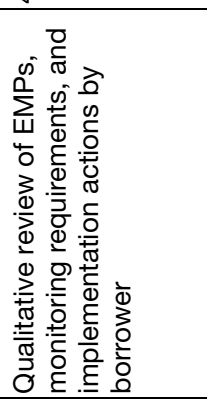 \\
\hline 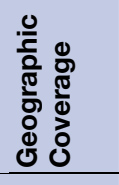 & 采 & 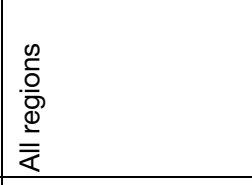 & 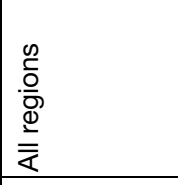 & 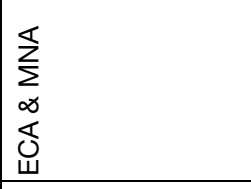 & $\begin{array}{l}\stackrel{0}{\bar{J}} \\
\end{array}$ \\
\hline 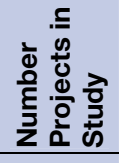 & 우 & $\stackrel{9}{\leftarrow}$ & 尺 & $\stackrel{\wedge}{ᄃ}$ & $\nabla$ \\
\hline$\stackrel{\text { ते }}{\vec{\partial}}$ & 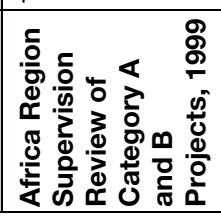 & 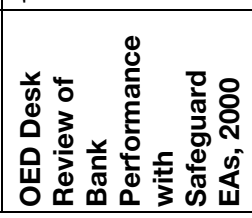 & 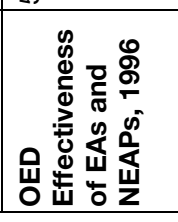 & 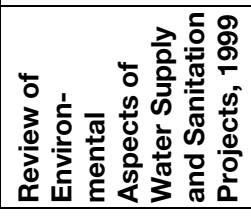 & 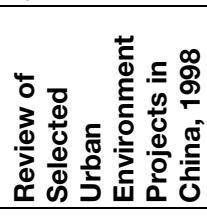 \\
\hline
\end{tabular}




\begin{tabular}{|c|c|c|c|c|c|}
\hline 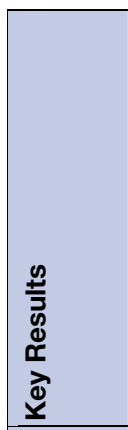 & 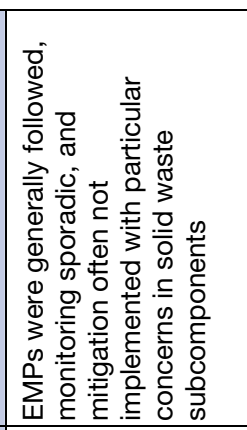 & 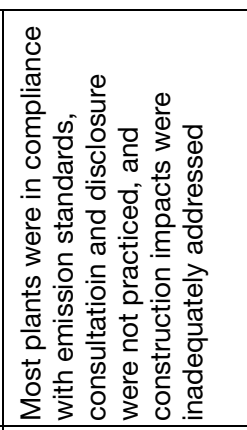 & 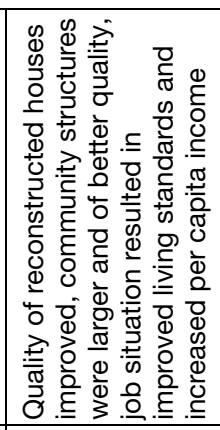 & 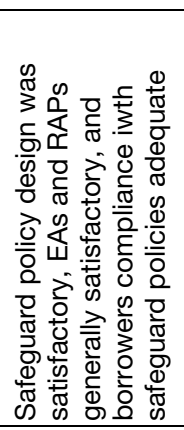 & 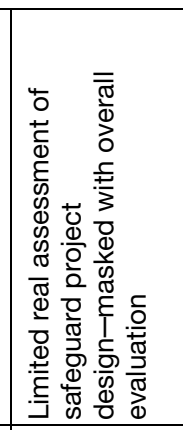 \\
\hline 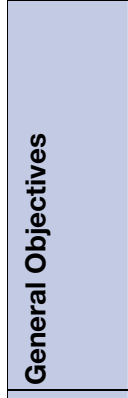 & 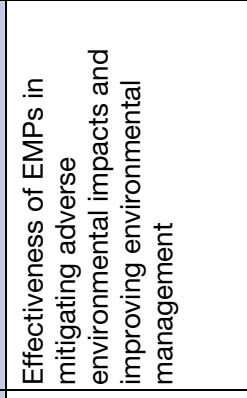 & 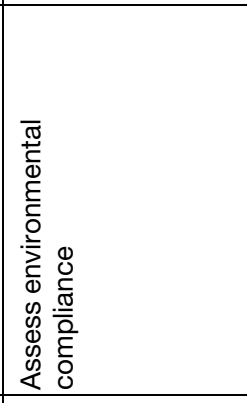 & 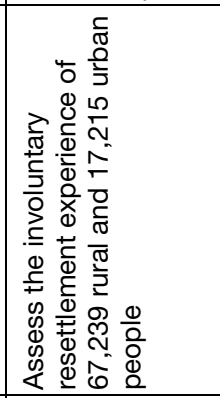 & 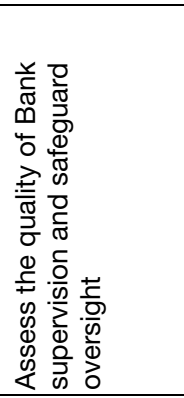 & 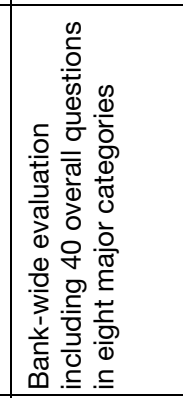 \\
\hline 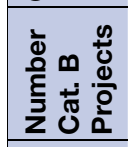 & & & & - & \\
\hline 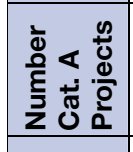 & + & 0 & $r$ & ம & \\
\hline 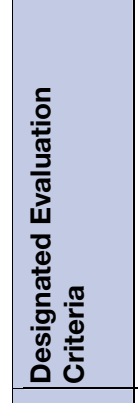 & 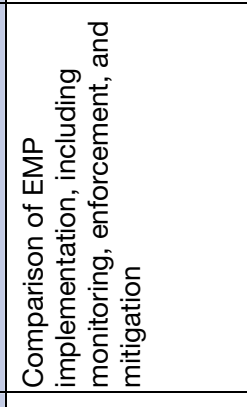 & 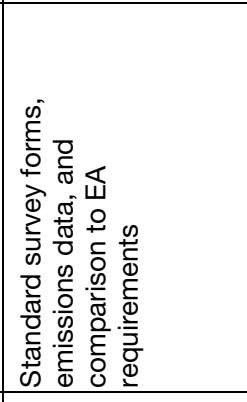 & 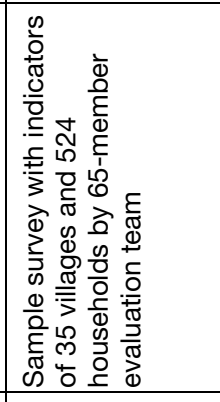 & 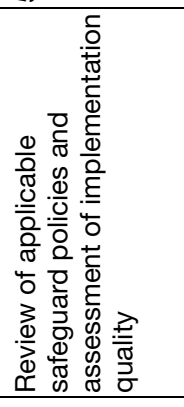 & 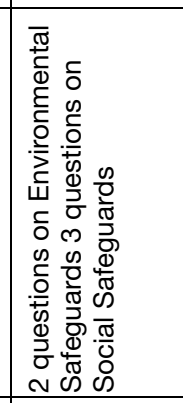 \\
\hline 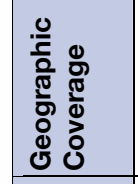 & 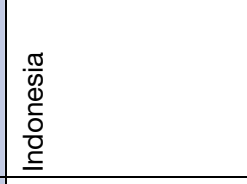 & \begin{tabular}{|l}
$\frac{\pi}{\tilde{\epsilon}}$ \\
\\
\end{tabular} & $\begin{array}{l}\frac{\pi}{\tilde{\Xi}} \\
\\
\end{array}$ & $\begin{array}{l}\frac{\pi}{\tilde{c}} \\
\text { d }\end{array}$ & \begin{tabular}{|l}
$\frac{0}{2}$ \\
$\frac{0}{0}$ \\
$\frac{0}{\overline{0}}$ \\
$\bar{c}$ \\
\end{tabular} \\
\hline 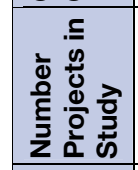 & 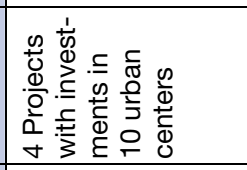 & & 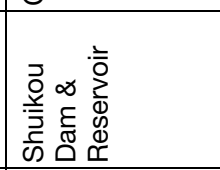 & 0 & 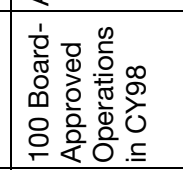 \\
\hline-40 & 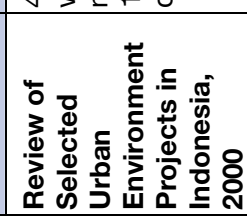 & 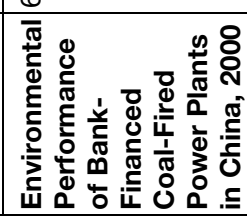 & 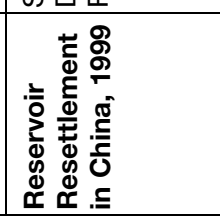 & 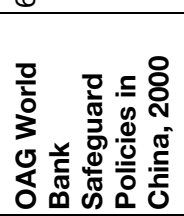 & 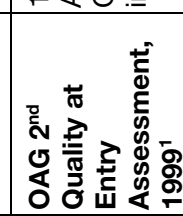 \\
\hline
\end{tabular}




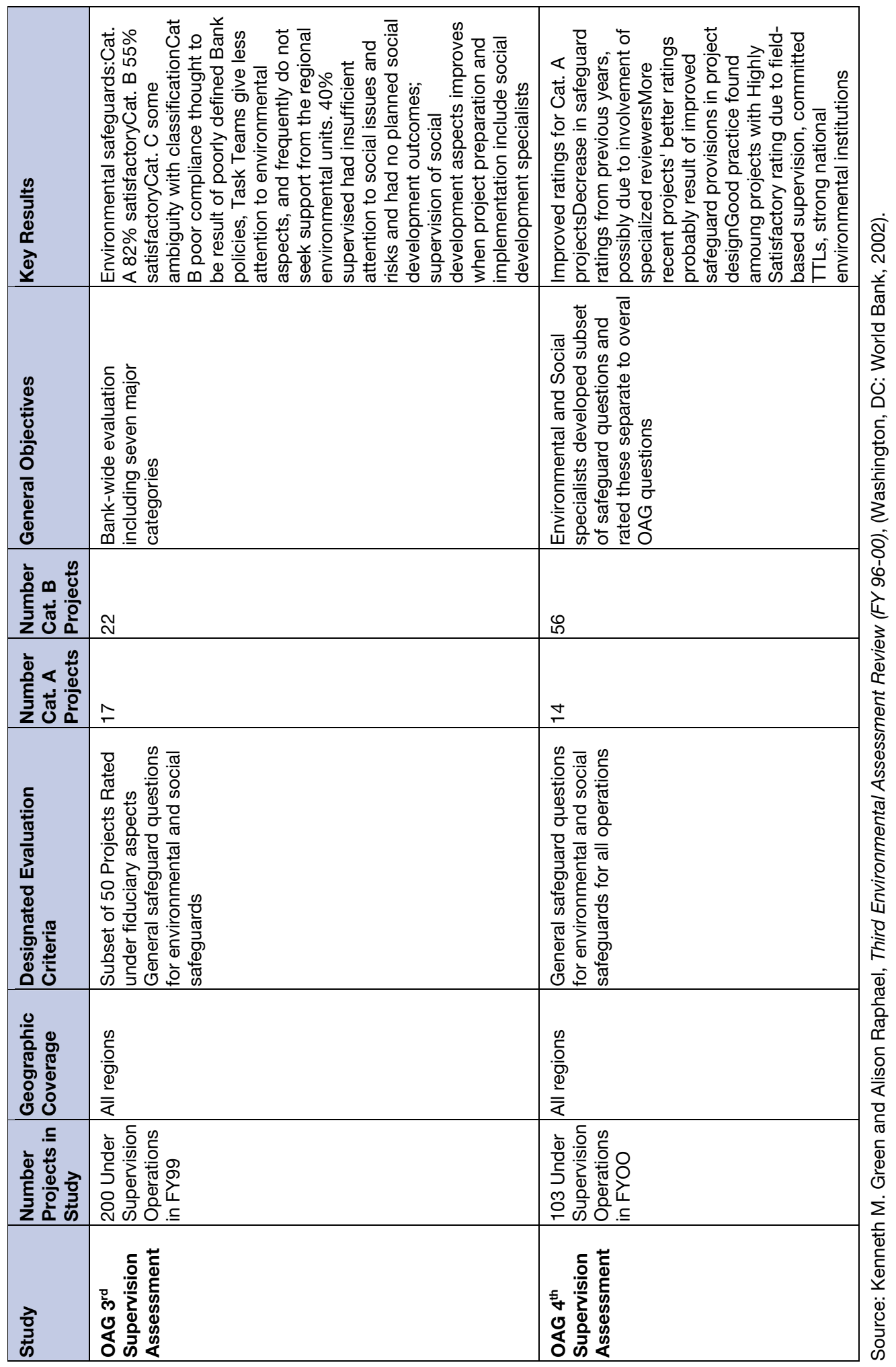





\title{
The Southern African Development Community Experience in Shared Watercourse Governance
}

\author{
Louis J. Kotzé
}

\subsection{Introduction}

Various shared watercourses exist throughout the world. These watercourses require governance regimes to optimize sustainable utilization. ${ }^{2}$ This is also the case in the Southern African Development Community (SADC), where shared watercourses were for some years governed by the SADC Protocol on Shared Watercourse Systems, 1995. ${ }^{3}$ This has been replaced by the Protocol on Shared Watercourse Systems in the Southern African Development Community (SADC) Region, 2000, ${ }^{4}$ which has been developed as a response to the increased need for regulating State interests, rights, and obligations with regards to shared watercourses in the Southern African region. ${ }^{5}$ The 2000 Protocol entered into force on 22 September 2003 and is currently the principal instrument for shared watercourse governance in the region. This chapter considers the current SADC shared watercourse governance regime with specific reference to:

- SADC as a regional organization;

- The rationale behind the establishment of a shared watercourse governance regime in the region;

- General background to the 1995 and 2000 Protocols;

- The legal nature of the 2000 Protocol;

1 Associate Professor, North West University, Potchefstroom Campus, South Africa. B.Com, LLB, LLM (PUCHE), LLD (NWU). Part of this research was conducted during a visit to the Max Planck Institut für Ausländisches Öffentliches Recht und Völkerrecht, Heidelberg, Germany. My sincerest thanks to the Institute and its personnel (in particular, Prof. Ulrich Beyerlin) for their assistance.

2 For some comparative perspectives in other regions, see A. Nollkaemper, The Evolution of the Regime for the Rhine River, in S.P. Subedi (ed.), International Watercourses Law for the $21^{\text {st }}$ Century: The Case of the River Ganges Basin (Aldershot, Hamps., UK: Ashgate Publishing, 2005), pp. 151-166; B. Pichyakorn, International Water Courses Law: The Experience of the Mekong River Basin, in ibid., pp. 167-192; and, generally, I. Al Baz, V. Hartje, and W. Scheumann (eds.), Co-operation on Transboundary Rivers (BadenBaden. Germany: Nomos Verlagsgesellschaft, 2002).

3 See, for the full text, www.sadc.int/english/documents/legal/protocols/shared_watercourse.php

4 See, for the full text, www.sadc.int/english/documents/legal/protocols/shared_watercourse_revised.php

5 For some interesting historical perspectives on the development of a legal framework for shared watercourse governance in the Zambezi Drainage Basin (which constitutes a significant part of SADC countries), see T. Maluwa, Towards an Internationalisation of the Zambezi River Regime: the Role of International Law in the Common Management of an International Watercourse, The Comparative and International Law Journal of Southern Africa, vol. 24, no. 1 (1992), pp. 20-43. The Zambezi Drainage Basin legal framework that the author describes would later develop into the more general 1995 and 2000 SADC Protocols that are applicable to all shared watercourses, not just the Zambezi. 
- A detailed discussion of the 2000 Protocol with specific reference to objectives, general principles, specific provisions, institutional framework, shared watercourse agreements, and dispute resolution;

- Application in domestic jurisdictions; and

- Challenges and opportunities.

\subsection{SADC: an overview}

The catalyst for the establishment of SADC was the creation of the Southern African Development Coordination Conference, which was formed in Lusaka in 1980. On 17 August 1992, the Coordinating Conference was transformed into the Development Community as it is known today. ${ }^{6}$ Member States of SADC currently include Angola, Botswana, the Democratic Republic of Congo (DRC), Lesotho, Madagascar, Malawi, Mauritius, Mozambique, Namibia, South Africa, Swaziland, the United Republic of Tanzania, Zambia, and Zimbabwe.

The objectives of SADC include, among others, to:

- achieve development and economic growth, alleviate poverty, enhance the standard and quality of life of the people of Southern Africa, and support the socially disadvantaged through regional integration;

- promote common political values, systems, and institutions;

- promote self-sustaining development on the basis of collective self-reliance and the interdependence of member States;

- achieve complementarities between national and regional strategies and programmes;

- promote and maximize productive employment and utilization of resources of the region; and

- achieve sustainable utilization of natural resources and effective environmental protection. ${ }^{7}$

The activities of the Community cover various sectors, including, inter alia, energy, tourism, mining, employment and labour, culture, information, sport, and transport and communications. Other sectors are finance and investment, human resource development, food, legal affairs, and health. One of the specific focus points of SADC is the environment, including land management, agriculture, and natural resources management - plus, decidedly important and relevant for the present discussion, water governance. ${ }^{8}$ The SADC Programme of Action (SPA) was designed to realize the overall goals and objectives of the programmes emanating from the above sectors. The

6 See further on the history and development of SADC at www.sadc.int/english/about/history/index.php. SADC was officially established through the Declaration and Treaty Establishing the Southern African Development Community, 17 August 1992.

7 See www.sadc.int/english/about/history/index.php. For a more general discussion of environmental concerns and African legal responses thereto, see M. Van der Linde, African Responses to Environmental Protection, The Comparative and International Law Journal of Southern Africa, vol. 34, no. 1 (2002), pp. 99-113. See also, generally, the discussion on the promotion of sustainable development in SADC in L. Louw, Die Bevordering van Volhoubare Ontwikkeling in die Suider-Afrikaanse Ontwikkelingsgemeenskap: 'n Regsvergelykende Ondersoek (LLM Dissertation, NWU, 2005). www.sadc.int/english/about/history/index.php 
1995 and 2000 protocols were created under the auspices and benefit of the SPA. The 2000 protocol currently constitutes the primary mechanism in the region for shared watercourse governance.

\subsection{The need for shared watercourse governance in SADC}

There are several motivations for the establishment of the current shared watercourse governance regime in SADC.

First, Africa has 60 internationally shared river basins and comes only second to Europe (which has 72) in this regard. ${ }^{9}$ However, Africa still remains the continent with the most rivers (watercourses) shared between more than two countries, totalling $30 .{ }^{10}$ In Southern Africa, inter alia, the Limpopo Basin is shared by 4 States (South Africa, Mozambique, Botswana, Zimbabwe); the Orange Basin by 4 States (South Africa, Namibia, Botswana, Lesotho); the Zambezi Basin by 9 States (Zambia, Angola, Zimbabwe, Mozambique, Malawi, Tanzania, Botswana, Namibia, DRC); and the Congo Basin by 11 States (DRC, Central African Republic, Angola, Republic of Congo, Zambia, Tanzania, Cameroon, Burundi, Rwanda, Gabon, Malawi). ${ }^{11}$ The sheer number of States and different jurisdictions that need to co-exist and to share watercourses in a mutually beneficial way emphasizes the need for a protocol to facilitate a harmonious and co-operative strategy towards sustainable use.

Second, Thomashausen ${ }^{12}$ indicates that legal plurality (or legal fragmentation) in SADC is particularly severe. The author notes various legal systems applicable in the 14 different SADC countries. These include, inter alia, domicile and national countries; common law, Belgian, Portuguese, and Roman-Dutch law orientated legal systems; and countries that have followed socialist law reforms. Different legal systems arguably lead to different approaches to sustainable water resource management, be it domestic or transboundary water resources. One clearly desires, in this maze of legal plurality, a uniform and consistent legal approach to regulate water resources that traverse borders, to induce some form of legal certainty. In fact, 'it is common cause that these goals ${ }^{13}$ [of SADC] cannot be achieved without improved forms of legal interaction, legal cooperation, and ultimately legal harmonisation'. ${ }^{14}$

Interaction, co-operation, and harmonization are usually achieved, especially in the international arena, by way of international law instruments such as treaties and protocols, of which the SADC protocols are examples. As such, the protocols may provide an opportunity to address inadequate

9 I. Dombrowsky and D. Grey, The Status of River Management in Africa, in Al Baz, Hartje, and Scheumann, supra note 2, p. 83. See also, for some historical perspectives on shared watercourse governance in Africa, generally, B.A. Godana, Africa's Shared Water Resources: Legal and Institutional Aspects of the Nile, Niger and Senegal River Systems (London: Frances Pinter, 1985).

10 Dombrowsky and Grey, supra note 9, p. 83.

11 Ibid., pp. 85-86, for a comprehensive discussion.

12 See generally, A. Thomashausen, The Enforcement and Recognition of Judgments and other Forms of Legal Cooperation in the SADC, The Comparative and International Law Journal of Southern Africa, vol. 34, no. 1 (2002), pp. 26-37.

13 See also paragraph 1 above.

14 Thomashausen supra note12, p. 29. Own emphasis. 
co-operation, outright conflict between riparian States, and negative impacts, as a result, on other basin States. ${ }^{15}$

Third, geographical fragmentation may also increase the need for cross-border co-operation, unification, and certainty in shared watercourse approaches. It is noted that:

African water resources are uniquely characterized by an abundance of transboundary basins, in large part due to the relatively recent drawing of many international boundaries by colonial powers. Most countries in the [African] region lack significant alternatives to the development of international basins, which are increasingly under pressure to fulfil the sum of demands claimed by riparian countries. ${ }^{16}$

Fourth, ever-increasing demands on shared watercourses by agricultural, urban, and industrial activities would require a strategy (which is acceptable to all interested and affected parties) that may be used to achieve sustainable resource utilization, principally by not allowing unequal utilization and overexploitation of these resources by different riparian countries. ${ }^{17}$

Fifth, an integrated and uniform set of legal rules for shared watercourse governance may be successfully employed as a conflict resolution mechanism in the event that conflict arises between States over the use of shared watercourses, as it inevitably does. This aspect is further explored below. ${ }^{18}$

Sixth, environmental, social, and economic characteristics (notably all those considerations postulated by the concept of sustainability) that are unique to a specific region will also determine to a large extent the need for and the nature of a regional instrument to govern shared watercourse. In the case of SADC, Hirji and Grey ${ }^{19}$ observe that:

Southern Africa is a water scarce region with numerous transboundary river basins and complex international water rights issues. The region is characterised by: extreme temporal and spatial rainfall variability, resulting in endemic drought and occasional floods; rapidly growing and urbanizing populations, leading to growing water scarcity and water pollution; low coverage of the urban and rural poor with water and sanitation services and consequently high incidence of water-borne diseases and, again, water pollution; heavy dependence on extensive agriculture, with generally very low water use efficiency; degraded watersheds and deteriorating water quality; and a growing importance of hydropower. ${ }^{20}$

Add to this various other emerging regional stresses, including, amongst others, water scarcity, drought, watershed degradation, and aquatic ecosystem degradation, ${ }^{21}$ which are the concern of

15 See, generally, S. Salman and L. Boisson de Chazournes (eds.), International Watercourses: Enhancing Cooperation and Managing Conflict - Proceedings of a World Bank Seminar, World Bank Technical Paper No. 414 (Washington, DC: World Bank, 1998).

16 R. Hirji and D. Grey, Managing International Waters in Africa: Process and Progress, in Salman and Boisson de Chazournes, supra note 15, p. 77; Dombrowsky and Grey, supra note 9, pp. 83-84.

17 See, further, Hirji and Grey, supra note 16, p. 78.

18 See paragraph 6.6 below.

19 Hirji and Grey, supra note 16, p. 80.

20 See also similar comments in Dombrowsky and Grey, supra note 9, pp. 83-84.

21 Hirji and Grey, supra note 16, pp. 81-86. 
all or at least of most countries in the region, and one clearly comes to appreciate the need for a mechanism to address shared watercourse governance in SADC.

\subsection{General background}

The original 1995 Protocol was signed and adopted by the SADC countries during a summit in 1995. It is governed mainly by the SADC Water Sector, which is currently based in Lesotho. The 1995 Protocol was extensively revised in 2000, partly because of the necessity to include the provisions of the United Nations Convention of the Law of Non-navigational Uses of International Watercourses. ${ }^{22}$ Both the 1995 and 2000 protocols indicate a move from State interests towards that of common interests (community of interests) insofar as sustainable, reasonable, and equitable utilization ${ }^{23}$ of shared watercourses is concerned. ${ }^{24}$

The 2000 Protocol reiterates the principles of the UN Convention and emphasizes the need and importance of environmental sustainability and equity in the riparian context. It also provides a framework for specific basin activities in an attempt to realize the aims and objectives of the UN Convention and the protocol itself. ${ }^{25}$ In this sense, 'riparian countries will move away from merely national water resources development programmes to basin programmes which will enhance integrated water resources management and increase co-operation between the riparian countries'.26

What we observe in terms of the projected outcomes of the 2000 Protocol, is thus a progressive shift from a national orientated focus to a more international/regional focus, where co-operation is of the utmost importance. This is, however, only one side of the coin, since it also holds true that the governance framework at the regional level (SADC) must guide and inform national approaches that must at the very least be conducive to achieving the overall objectives of the 2000 Protocol.

There are, apart from the 2000 Protocol, also other initiatives aimed at shared watercourse governance in the SADC region. Although this chapter only focuses on the 2000 Protocol, it may be worthwhile to point out that the Lesotho Highlands Water Project (referred to further below) and the Southern African Power Pool are two examples of such initiatives. ${ }^{27}$

22 For a discussion on the international regime generally, see M. Reimann, Die Nicht-navigatorische Nutzung Internationaler Süßwasserressourcen im Umweltvölkerrecht (Frankfurt: Peter Lang, 1999).

23 For a discussion on equitable ad reasonable use in respect of international watercourses, see A. RieuClarke, International Law and Sustainable Development: Lessons from the Law of International Water Courses (London: IWA Publishing, 2005), pp. 100-132.

24 See further, A. Hildering, International Law, Sustainable Development and Water Management (Delft, Netherlands: Eburon Publishers, 2004), p. 67.

25 See further, Dombrowsky and Grey, supra note 9, p. 92.

26 M.J. Tumbare, Co-operation in the Zambezi River Basin, in Al Baz, Hartje, and Scheumann, supra note 2, p. 103.

27 The Southern African Power Pool, which was concluded by way of a memorandum of understanding between seven SADC member States, does not focus exclusively on water. It does, however, consider the role of international rivers and the effect of drought on the region in endeavours to establish and enhance transnational electricity supply. See further Dombrowsky and Grey, supra note 9, pp. 92-94. 


\subsection{Legal nature of the 2000 Protocol}

SADC employs various legal instruments to facilitate governance of its affairs and achievement of its goals. These include, amongst others, treaties, protocols, memoranda of understanding, declarations, and charters.

Shared watercourses are principally governed by way of protocols in SADC. As a result, the entire governance regime resorts under the broader legal discipline of international water law, ${ }^{28}$ which has evolved mainly as a result of treaty practice, and more specifically transboundary water law (or shared watercourse law), which is an all but crystallized and completely codified legal subdiscipline. Sievers ${ }^{29}$ states in this regard that:

streaty and custom are continuing to mould an increasingly standardized set of rules to regulate disputes over and to direct management of transboundary watercourses. Today, the state of transboundary watercourse law lies somewhere along a continuum between unrestrained state discretion, a customary rule against any inequitable utilization that infringes on co-riparian interests, and, at the outer fringes, an erga omnes prohibition, based on the concept of common heritage, against degradation of riparian ecosystems.

Such practice includes a comprehensive range of mechanisms, such as general agreements, contractual-type legal and technical arrangements, and regional co-operation agreements, of which the 2000 Protocol is an example. ${ }^{30}$ The protocol binds all member States of SADC and may thus be considered, insofar as its legal status is concerned, a binding regional mechanism of international law, albeit only applicable in regional context. This is also evident from the fact that the instrument is a protocol to a regional treaty, legally concluded between 14 member States.

This protocol is also the primary mechanism for achieving sustainable governance of shared watercourses in the region. According to Mbuende, ${ }^{31}$ 'SADC aims to build regional structures which promote the peaceful resolution of differences and which foster a sense of common interests and shared responsibility for the sub-region's future'. Sustainable water provision, utilization, and

28 T. Maluwa, Towards an Internationalisation of the Zambezi River Regime: The Role of International Law in the Common Management of an International Watercourse, The Comparative and International Law Journal of Southern Africa, vol. 24, no. 1 (1992), p. 22, opts for the term 'international fluvial law'. S. Upadhye, The International Water Course: An Exploitable Resource for the Developing Nation under International Law, Cardozo Journal of International and Comparative Law vol. 8, no. 1 (2000), pp. 62-63, further states on the issue of international law and governance of shared watercourses: 'Today, the most effective regulation of the use of an international watercourse will only occur through the creation of a joint commission between the nations affected or by an affirmative declaration that watercourse use is squarely within the scope of established international law.'

29 E.W. Sievers, Transboundary Jurisdiction and Watercourse Law: China, Kazakhstan and the Irtysh, Texas International Law Journal, vol. 37, no. 1 (2002), p. 14.

30 P. Wouters, The Legal Response to International Water Conflicts: The UN Watercourse Convention and Beyond, German Yearbook of International Law, vol. 42 (1999), pp. 301-302.

31 K.M. Mbuende, Conflict Prevention and Resolution in the South African Development Community (SADC), International Journal on Minority and Group Rights, vol. 8, no. 1 (2001), p. 45. 
benefit-sharing are some of the issues that can lead to international conflicts. ${ }^{32}$ As such, the Protocol may play a vital role in achieving these paramount objectives of SADC.

\subsection{An overview of the 2000 Protocol}

\subsubsection{Objectives}

The protocol aims to address most of the concerns that may arise in the context of transboundary resources management. ${ }^{33}$ The overall objectives of the transboundary management effort centre around co-operation and co-ordination, the achievement of sustainability and sustainable use, resource protection, poverty alleviation, and regional integration. ${ }^{34}$ In achieving these objectives, the protocol proposes shared watercourse agreements and institutions; harmonization and monitoring of legislation and policies; and promotion of research and technology development, information exchange, capacity building, and the application of appropriate technologies in shared watercourses management. ${ }^{35}$

\subsubsection{General principles}

Various broad principles are formulated in which shared watercourse governance in SADC should be facilitated. Principles, by their very nature, are generic and are meant to provide a general guiding framework that should direct decision making and actions, to ultimately realize certain specific objectives. Most of these principles mirror the general principles espoused by international law; arguably some of these principles have already attained the status of international environmental law. ${ }^{36}$

Watercourse States are first required to recognize the unity and coherence of each shared watercourse. In other words, they are to recognize the indivisible, transboundary, and integrated nature unique to shared watercourses, which of course requires unique approaches to governance, notably that of harmonization and integration in a plural milieu. ${ }^{37}$

Second, the principle of equal and equitable use,${ }^{38}$ and arguably also that of State sovereignty, is provided in that:

32 For an example of such conflicts in the Nile Basin generally, see K. Wiebe, The Nile River: Potential for Conflict and Cooperation in the Face of Water Degradation, Natural Resources Journal, vol. 41, no. 3 (2001), pp. 731-754.

33 See paragraph 3 above.

34 Article 2.

35 Articles 2(a)-2(e).

36 Whether or not a principle can in fact be considered a rule of international environmental law (customary international law) falls outside the scope of this chapter.

37 Article 3(1). Co-operation is essential for achievement of integration and harmonization. Article 3(5) provides in this regard that: 'State Parties undertake to pursue and establish close cooperation with regard to the study and execution of all projects likely to have an effect on the regime of the shared watercourse.' Co-operation should also be facilitated by way of information exchange as regards shared watercourse governance. See article 3(6).

38 See also articles $7(a)-7$ (b), which specifically provide for equitable and reasonable use. 
[T] he utilisation of shared watercourses within the SADC Region shall be open to each Watercourse State, in respect of the watercourses within its territory and without prejudice to its sovereign rights, in accordance with the principles contained in this Protocol. The utilisation of the resources of the watercourses shall include agricultural, domestic, industrial, navigational and environmental uses. ${ }^{39}$

The principle of State sovereignty is underlined by the requirement that watercourse States shall respect existing rules of customary or general international law that may be applicable to shared watercourse governance. ${ }^{40}$

Third, the ideal of sustainability is provided in that watercourse States shall maintain a 'proper balance between resource development for a higher standard of living for their people and conservation and enhancement of the environment to promote sustainable development'. ${ }^{41}$ Sustainability thus requires integration of social, economic, and environmental concerns in all shared watercourse governance efforts.

Fourth, equitable and reasonable use should be determined by taking into account various considerations typically associated with the more general aspects related to water governance. These include: geographical, hydrographical, hydrological, climatic, ecological, and other factors of a natural character; the social, economic, and environmental needs of the watercourse States concerned; the population dependent on the shared watercourse in each watercourse State; the effects of the use or uses of a shared watercourse in one watercourse State on other watercourse States; existing and potential uses of the watercourse; conservation, protection, development, and economy of use of the water resources of the shared watercourse and the costs of measures taken to that effect; and the availability of alternatives, of comparable value, to a particular planned or existing use. ${ }^{42}$

Fifth, Article 10(a) provides for the preventive principle in that all appropriate measures should be taken to prevent the causing of significant harm to other watercourse States. In applying the preventive approach, States should also adhere to the principle of nondiscrimination, especially insofar as access to appropriate legal mechanisms and procedures are concerned, in the event that harm is caused. ${ }^{43}$

\subsubsection{Specific provisions}

Article 4 sets out various provisions related to specific governance issues. These provisions are more detailed and issue-specific than the general principles provided by Article 3 and, as such, arguably require more detailed and specific implementation strategies by watercourse States. Most of the specific provisions centre around exchange of information and procedures for notification.

Watercourse States are required to adopt in this respect, what Article 4(1) terms, 'planned measures'. These measures are not defined in Article 1 and arguably include all those measures 
agreed on by States that may be required to achieve the objectives of the protocol or that may have an adverse effect on either the resources or the interests of other watercourse States. States are first required in this regard to exchange information on planned measures and to notify each other in the event that such measures may have a significant adverse effect on other watercourse States. $^{44}$

It is here that we observe the first tangible mechanism available for shared watercourse governance, namely environmental impact assessment (EIA). Article 4(b) provides in this respect that notification should be accompanied by 'available technical data and information, including the results of any environmental impact assessment, in order to enable the notified States to evaluate the possible effects of the planned measures'. This provision does not require an EIA as per the protocol. It rather presupposes that an EIA will be conducted in the event that an activity may affect a shared watercourse in accordance with, inter alia, established international environmental law. The relevant provisions of the 1991 Convention on Environmental Impact Assessment in the Transboundary Context (the Espoo Convention) and those legal provisions as provided by domestic legal systems will thus arguably be applicable.

The remainder of this part of Article 4 deals with the period of notification; obligations of States during the notification procedure; obligations in respect of replies on notifications; absence of a reply to notification; consultations and negotiations relating to planned measures and notifications; procedures in the absence of notifications; and measures for the urgent implementation of planned measures. $^{45}$

Article 4(2) contains resource-directed measures that provide for 'environmental protection and preservation'. More specifically, it provides for the obligation and measures for protection and preservation of ecosystems; prevention, reduction, and control of pollution; ${ }^{46}$ control of alien or new species, which may affect watercourses; and measures for the protection and preservation of the aquatic environment.

Management of shared watercourses are unfortunately but understandably (given the legal nature of the protocol) described very generally. 'Management of shared watercourses' is defined in Article 1 as: '(i) planning the sustainable development of a shared watercourse and providing for the implementation of any plans adopted; and (ii) otherwise promoting the rational, equitable and optimal utilisation, protection, and control of the watercourse'.

Article 4(3) sets out various provisions to achieve these objectives. Watercourse States must, for example, consult with one another; enter into joint management mechanisms (which are neither explicitly defined nor provided for by the Protocol); implement measures for the regulation of the

44 Articles 4(1)(a)-4(1)(b).

45 Articles 4(1)(d)-4(1)(i).

46 These include measures to prevent transboundary pollution of watercourses, harmonize policies and legislation, and consult with a view to arriving at mutually agreeable measures and methods to prevent, reduce, and control pollution of a shared watercourse. The latter should be realized by setting joint water quality objectives and criteria, establishing techniques and practices to address pollution from point and non-point sources, and establishing lists of substances whose introduction into the waters of a shared watercourse is to be prohibited, limited, investigated, or monitored. Article 4(2)(b). 
flow of the waters of a shared watercourse; and employ efforts to maintain and protect installations, facilities, and other works related to a shared watercourse. ${ }^{47}$

As far as specific provisions are concerned, Articles 4(4)-4(5) provide for prevention and mitigation of harmful conditions, including emergency incidents.

\subsubsection{Institutional framework}

One of the major differences between the 1995 and 2000 protocols is the range and detail of institutional mechanisms available for implementation and governance of the agreement. Wouters ${ }^{48}$ states in this regard that these institutional mechanisms of the 2000 Protocol, 'are not only more numerous than those established under the 1995 Protocol, but more powerful as well'.

Article 5 provides for various institutional mechanisms to be responsible for governing shared watercourses as per the 2000 Protocol and, more specifically, for implementation of the provisions of the protocol. These include: SADC Water Sector Organs; the Committee of Water Ministers; the Committee of Water Senior Officials; the Water Sector Coordinating Unit; the Water Resources Technical Committee and subcommittees; and shared watercourse institutions.

Article 5(2) stipulates the various detailed functions for the SADC Water Sector Organs, which are set out in Table 1.

Watercourse States are furthermore required to establish appropriate institutions such as watercourse commissions and water authorities or boards. ${ }^{49}$ The functions of these shared watercourse institutions are less detailed and are supposedly left to the discretion of States and in accordance with any specific needs that may arise. The responsibilities of such institutions are largely to be determined by the nature of their objectives, which must be in conformity with the principles set out in the protocol. More specifically, they must provide on a regular basis or as required by the Water Sector Coordinating Unit all the information necessary to assess progress on the implementation of the provisions of the Protocol, including development of their respective agreements. $^{50}$

47 Articles 4(3)(a)-4(3)(c).

48 P. Wouters, Universal and Regional Approaches to Resolving International Water Disputes: What Lessons Learned from State Practice? in International Bureau of the Permanent Court of Arbitration, The Permanent Court of Arbitration-Peace Palace Papers: Resolution of International Water Disputes (The Hague: Kluwer Law International, 2003), p. 129.

49 Article 5(3)(a).

50 Article 5(3). 


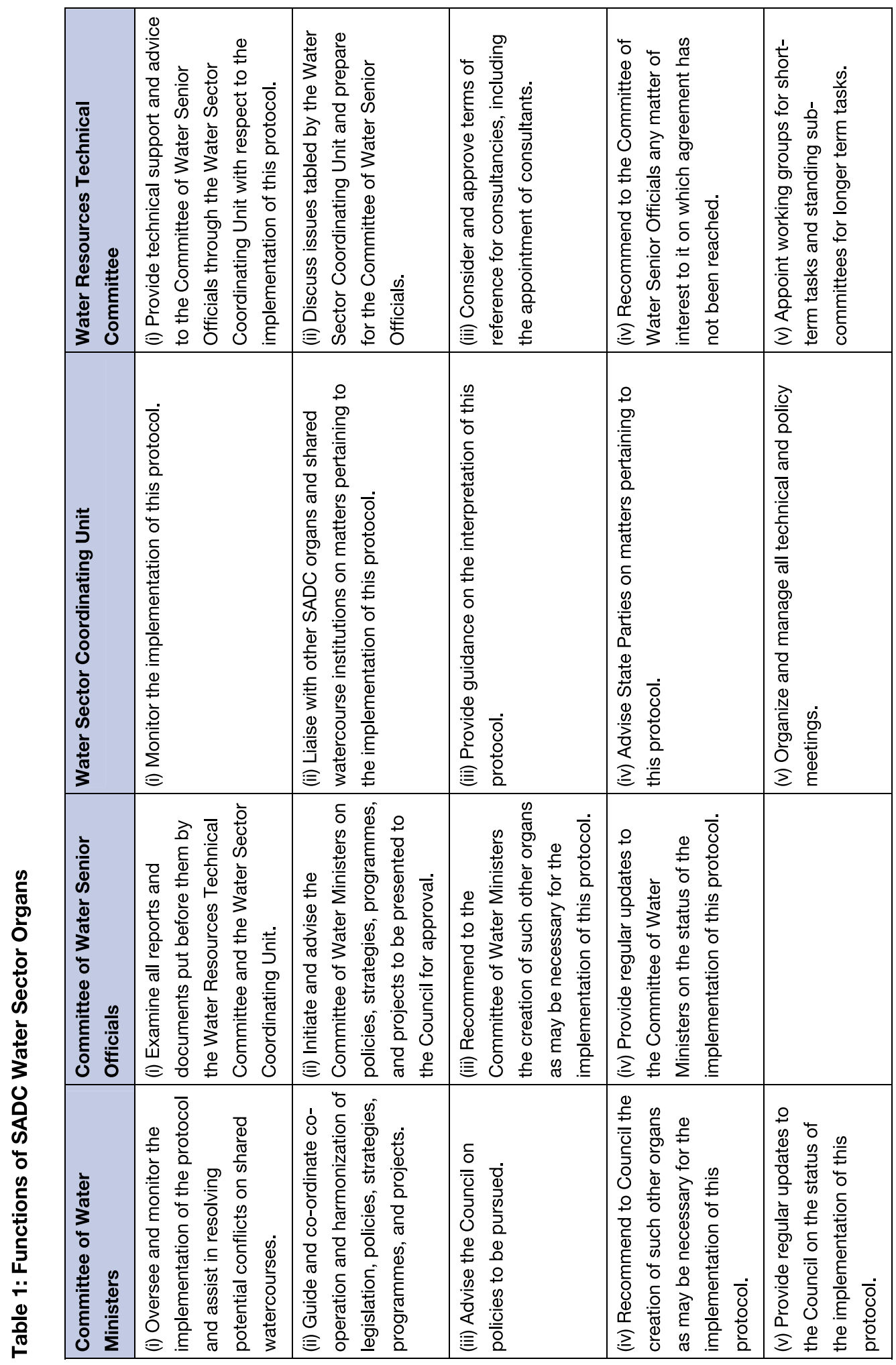




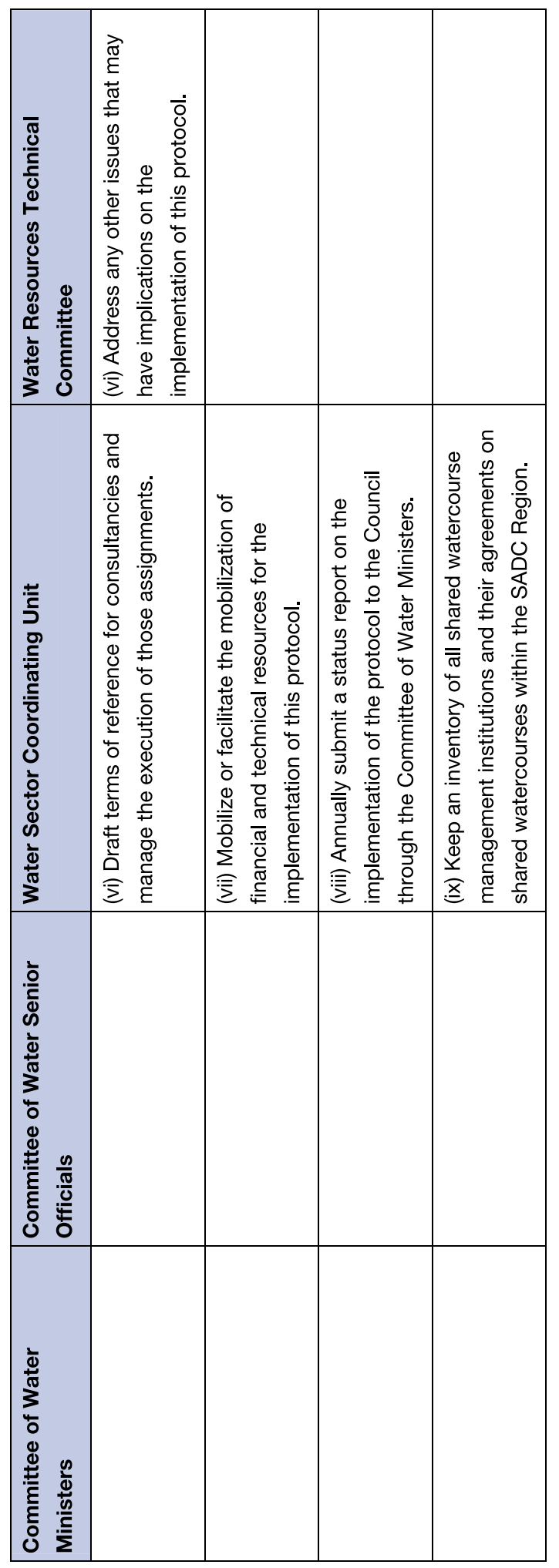




\subsubsection{Shared watercourse agreements}

The protocol, commendably so, envisages that effective and sustainable governance of shared watercourses need not necessarily be confined to the provisions, mechanisms, structures, and procedures of the protocol, thereby providing opportunities for a more comprehensive, and arguably more effective, governance effort. Article 6, in this respect, provides the possibility for Shared Watercourse Agreements (SWA) to co-exist with, and supplement, the provisions of the 2000 Protocol. This may be inferred from Articles 6(1) and 6(3) which state respectively that:

In the absence of any agreement to the contrary, nothing in this Protocol shall affect the rights or obligations of a Watercourse State arising from agreements in force for it on the date on which it became a party to the Protocol

and

Watercourse States may enter into agreements, which apply the provision of this Protocol to the characteristics and uses of a particular shared watercourse or part thereof.

The remainder of Article 6 more or less provides a carte blanche to watercourse States to establish SWAs insofar as it is deemed necessary to regulate any specific aspects of any specific shared watercourse. ${ }^{51}$

Examples of SWAs (albeit in the South African context and not necessarily concluded in terms of this provision of the Protocol) include:

- the Lesotho Highlands Water Project (South Africa and Lesotho) which was established by the Treaty on the Lesotho Highlands Water Project between the Government of the Republic of South Africa and the Government of the Kingdom of Lesotho, 24 October 1986;

- the Agreement on Establishment and Operation of a Common Works Area at the Caledon River for the Purpose of the Implementation of the Lesotho Highlands Water Project, 12 December 1989 (South Africa and Lesotho);

- the Agreement on Rivers of Mutual Interest and Cunene River Scheme, 13 October 1964 (South Africa and Mozambique);

- the Agreement on Establishment and Functioning of the Joint Water Commission, 26 July 1996 (South Africa and Mozambique);

- the Co-operation Agreement Relating to the Control, Development and Use of Water from the Orange River, 13 November 1987 (South Africa and Namibia); and

- the Agreement on Establishment of a Permanent Water Commission, 14 September 1992 (South Africa and Namibia).

Even though these are not SWAs as per the Protocol, it is argued that SWAs will probably resemble agreements of this nature. It is further argued that such agreements may ultimately optimize governance efforts in terms of the 2000 Protocol, aid in conflict resolution (as is

51 Articles 6(4)-6(7). 
demonstrated below), and provide tailor-made solutions for effective governance of shared watercourse issues not provided for by the more general provisions of the Protocol.

\subsubsection{Dispute settlement}

Conflicts over shared watercourses will always be imminent as long as these resources are shared by different States. Hirji and $\mathrm{Grey}^{52}$ state in this regard that:

Where water is becoming scarce [as is the case in SADC], access to and control over freshwater resources is diminishing and conflicts between sectoral users [different riparian states] are emerging and intensifying. Such conflicts become more complex and difficult to address when they concern waters shared by more than one nation. The complexity and management challenges increase as more riparian countries become involved.

Appropriate conflict resolution mechanisms are thus vital for any international law instrument aimed at the sustainable governance of shared watercourses to be successful.

When compared with the 1995 Protocol, the 2000 Protocol significantly reshapes the provisions on dispute settlement. ${ }^{53}$ Like its 1995 predecessor, the 2000 Protocol refers all disputes to the SADC Tribunal for settlement. All Parties are, however, required to strive to resolve all disputes amicably before resorting to the Tribunal. Article 4 contains various principles that are meant to guide disputing parties in this regard. ${ }^{54}$ Dispute settlement in terms of the 2000 Protocol is closely tied with the provisions of the SADC Treaty, which requires Member States to first resolve their disputes by way of negotiations and then, in the event that this is unsuccessful, to refer it to the SADC Tribunal. The Tribunal has jurisdiction over all disputes related to the Treaty and its accompanying Protocols and all its decisions are final and binding. ${ }^{55}$

Rieu-Clarke ${ }^{56}$ states that '[J]oint institutions are the most appropriate and common institutional structure for States to cooperate over their international watercourses', especially with the view to avoiding any possible conflict in this regard. The 2000 Protocol obliges Member States, in Article 4(2), to 'enter into consultations concerning the management of a shared watercourse, which may include the establishment of a joint management mechanism', which should, arguably, also be aimed at resolving any potential or existing conflicts regarding shared watercourses.

Avoidance of conflicts stands in very close relationship with the customary international law duty to give prior notification and consultation. This notion is also expressed in the purpose of the duty, which is, namely:

to give prior notification and consultation...to prevent a scenario where State $A$ alters its existing use of an international watercourse in a way that threatens State B's right to an

52 Hirji and Grey, supra note 16, p. 77.

53 Wouters, supra note 48, p. 129.

54 See paragraph 6.2 above.

55 Wouters, supra note 48, p. 131.

56 A. Rieu-Clarke, International Law and Sustainable Development: Lessons from the Law of International Water Courses (London: IWA Publishing, 2005), p. 135. 
equitable and reasonable use of the same watercourse, without State B having the opportunity to consider the change. ${ }^{57}$

EIA is one of the mechanisms that may be employed to realize this duty and may thus play an important role in conflict avoidance in the SADC region, especially insofar as it may be utilized to provide interested and affected riparian States with adequate information to guide decision making and action. ${ }^{58}$

Conflicts can also be resolved by way of, what Wouters ${ }^{59}$ terms, 'swapping of other beneficial use'. An example in this regard is the Lesotho Highlands Water Project. ${ }^{60}$ Whilst South Africa is a water-scarce country and in need of adequate water supply, Lesotho requires a sufficient and sustainable supply of electricity and water infrastructure. South Africa has agreed, in terms of this project, to cover most of the costs of constructing dams in Lesotho. The benefit to South Africa is increased security in access to water resources, whilst Lesotho is provided with hydroelectric power. ${ }^{61}$

The remainder of the 2000 Protocol deals with matters of a procedural nature as regards the implementation of the Protocol's provisions, including signature of the Protocol, ratification, entry into force, accession, amendment, withdrawal, termination, and the depository. ${ }^{62}$

\subsection{Application of the regime in domestic jurisdictions: a South African case study}

Wouters ${ }^{63}$ opines that: '[W]hat is often forgotten is that it is in every watercourse State's best interest to have a generally accepted and balanced legal framework rather than to rely upon unilateral acts or conflicting interpretation of international custom'. The author underlines the important requirement that watercourse States should, for any international environmental law instrument (such as the 2000 Protocol) to be effective, at the very least possess a legal regime that is conducive to the reception of the instrument's provisions. Moreover, domestic legal regimes must not only be receptive but arguably must also enhance, strengthen, and compliment the provisions of these international instruments.

This postulation is further explored hereafter by briefly turning to the domestic legal framework of South Africa that applies to international environmental, and more specifically water, law.

In order to introduce a comprehensive environmental legal protection regime in domestic law, the ratification and implementation of international environmental law instruments, as well as

57 lbid., p. 138.

58 See also the discussion in paragraph 6.3 above.

59 Wouters, supra note 30, pp. 322-323.

60 Established by the Treaty on the Lesotho Highlands Water Project between the Government of the Republic of South Africa and the Government of the Kingdom of Lesotho, 24 October 1986.

61 See further, Wouters, supra note 30, pp. 322-323; Dombrowsky and Grey, supra note 9, p. 93; and H.L. Beach et al., Transboundary Freshwater Dispute Resolution: Theory, Practice and Annotated References (Tokyo: United Nations University Press, 2000) pp. 129-131.

62 Articles 8-15.

63 Wouters, supra note 30, pp. 336. 
consideration of the legal principles of international customary law and soft law, are regarded as high priorities of the South African government. ${ }^{64}$ International law, which includes international environmental and water law as subdisciplines, is traditionally described as a body of rules and principles that are binding upon States in their relations with one another. ${ }^{65}$

Conventions, their protocols, and customary law arguably represent the main sources of international environmental law. Express consent by means of signing and ratification of a convention is necessary to make it binding on the State Party involved. This also applies to South African law, since any bilateral or multinational agreement needs to be incorporated into domestic law in one form or another in order to have force and effect within the jurisdiction of South Africa.

South Africa follows the dualist approach with regard to the incorporation of international law into domestic law. This approach proposes that, due to the differences between international and municipal law, domestic courts can only apply international law once it has been transformed into local law by means of legislation. ${ }^{66}$ According to this approach, the 2000 Protocol would require domestic legislation that specifically incorporates its provisions into South African law. South Africa currently has no specific act that expressly deals with governance of shared watercourses and hence no specific act that incorporates the 2000 Protocol into the domestic legal regime.

Water resources in South Africa are, however, regulated by the 1998 National Water Act 36 (NWA). Chapter 10 of this act deals with international water management with the objective of implementing international agreements in South Africa in respect of shared watercourses. It is stated in this regard that:

Under this Chapter the Minister may establish bodies to implement international agreements in respect of the management and development of water resources shared with neighbouring countries, and on regional co-operation over water resources. The governance, powers and duties of these bodies are determined by the Minister in accordance with the relevant international agreement, but they may also be given additional functions, and they may perform their functions outside the Republic. Certain existing international bodies are deemed to be bodies established under this Act.

The provisions of Chapter 10 provide the Minister of Water Affairs and Forestry with wideranging powers to implement international or regional agreements. The Minister may, for example, establish bodies in relation to investigating, managing, monitoring, and protecting water resources; regional co-operation on water resources; acquiring, constructing, altering, operating, or maintaining a waterwork; or the allocation, use, and supply of water in the international or regional context. ${ }^{67}$ The remainder of Chapter 10 provides, amongst others, for governance measures for these bodies, powers, and reporting obligations. ${ }^{68}$

64 L.J. Kotzé and L. Jansen van Rensburg, Legislative Protection of Cultural Heritage Resources: A South African Perspective, Queensland University of Technology Law and Justice Journal, vol. 3, no. 1 (2003), pp. 125-127.

65 J. Dugard, International Law: A South African Perspective (Cape Town, South Africa: Juta \& Co., 2005), p. 1.

66 Ibid., p. 47.

67 Section 102.

68 See section 103-107. 
There are, apart from these specific provisions, several other provisions that oblige the government to implement the 2000 Protocol. First, section 231 of the 1996 Constitution of the Republic of South Africa specifically deals with international agreements and the signing, ratification, and transformation thereof. ${ }^{69}$ This section provides, inter alia, that any international agreement becomes law in the Republic when it is enacted into law by national legislation.

Second, section 232 of the Constitution grants legal force to customary international environmental law in South Africa. ${ }^{70} \mathrm{~A}$ common law presumption exists that requires a court to interpret legislation in accordance with established international law. ${ }^{71}$ This common law presumption is given effect by section 233 of the Constitution, which provides that when interpreting any legislation, a court must prefer any reasonable interpretation of the legislation that is consistent with international law over any alternative interpretation that is inconsistent with international law. ${ }^{72}$

Third, even in those instances where South Africa is not legally bound by obligations under a treaty, section 39(1)(b) of the Constitution compels adversarial bodies, when interpreting the Bill of Rights, including the section 24 environmental right ${ }^{73}$ and the section 27 right of access to water, ${ }^{74}$

69 Section 231 states that:

(1) The negotiating and signing of all international agreements is the responsibility of the national executive.

(2) An international agreement binds the Republic only after it has been approved by resolution in both the National Assembly and the National Council of Provinces, unless it is an agreement referred to in subsection

(3) An international agreement of a technical, administrative or executive nature, or an agreement which does not require either ratification or accession, entered into by the national executive, binds the Republic without approval by the National Assembly and the National Council of Provinces, but must be tabled in the Assembly and the Council within a reasonable time.

(4) Any international agreement becomes law in the Republic when it is enacted into law by national legislation; but a self-executing provision of an agreement that has been approved by Parliament is law in the Republic unless it is inconsistent with the Constitution or an Act of Parliament.

(5) The Republic is bound by international agreements which were binding on the Republic when this Constitution took effect.

70 Section 232 provides that customary international law is law in South Africa unless it is inconsistent with the Constitution or an Act of Parliament.

71 See The Government of the Republic of South Africa and Others v Grootboom and Others [2000] 11 BCLR 1169 CC.

72 See also The Azanian Peoples Organization (AZAPO) and Others $v$ The President of the Republic of South Africa [1996] 4 SA 671 CC.

73 Section 24 states that:

Everyone has the right -

(a) to an environment that is not harmful to their health or well-being; and

(b) to have the environment protected, for the benefit of present and future generations, through reasonable legislative and other measures that -

(i) prevent pollution and ecological degradation;

(ii) promote conservation; and

(iii) secure ecologically sustainable development and use of natural resources while promoting justifiable economic and social development.

74 Section 27 states, inter alia, that:

(1) Everyone has the right to have access to

(a) health care services, including reproductive health care;

(b) sufficient food and water... 
to consider international law. ${ }^{75}$ According to the Constitutional Court decision in $S v$ Makwanyane and Another, ${ }^{76}$ public international law includes nonbinding (soft law), as well as binding law, which must be considered when interpreting any provisions of the Bill of Rights. International agreements and customary international law thus provide a framework within which the Bill of Rights may be evaluated and understood. ${ }^{77}$ It can be inferred that the Constitution provides a constitutional imperative for the implementation of the 2000 Protocol, albeit in more general terms.

Chapter 6 of the National Environmental Management Act 107 of 1998 (NEMA) further contains provisions that specifically deal with the incorporation of international environmental law into the domestic environmental law regime. It is provided in this regard that where South Africa is not yet bound by an international environmental instrument, the Minister of the Department of Environmental Affairs and Tourism may make a recommendation to Cabinet and Parliament regarding accession to and ratification of such an instrument. ${ }^{78}$ Where South Africa is a party to an international environmental instrument, the Minister, after compliance with the provisions of sections $231(2)$ and $231(3)$ of the Constitution, may publish the provisions of the international environmental instrument in the Government Gazette. ${ }^{79}$ The Minister may further introduce legislation in Parliament or make such regulations as may be necessary in order to give effect to an international environmental instrument to which South Africa is a party. ${ }^{80}$

It may be derived from the foregoing that international environmental law, which includes regional instruments such as the 2000 Protocol, play an important role in the South African environmental law regime. It is also apparent that South African law provides an enabling framework for the incorporation and application of such regional instruments. Whilst the Constitution sets out general provisions for the application of international environmental law, NEMA and the NWA further support endeavours to incorporate and apply regional shared watercourse governance mechanisms in South Africa.

\subsection{Challenges and opportunities}

Wouters ${ }^{81}$ states that 'despite adopting model regional and basin agreements, States continue to face conflicts of water use, ineffective institutional mechanisms and insufficient technical and economic capacity to manage their shared waters'. Any lack of success of sustainable shared

75 See, for example: $S$ v Williams [1995] 3 SA 632 CC; Ferreira $v$ Levin NO [1996] 1 SA 984 CC; $S$ v Rens [1996] 1 SA 1218 CC; Coetzee v Government of South Africa [1995] 4 SA 631 CC; Bernstein v Bester [1996] 2 SA 751 CC; In re Gauteng School Education Bill 1995 [1996] 3 SA 165 CC; The Government of the Republic of South Africa and Others $v$ Grootboom and Others [2000] 11 BCLR 1169 CC.

76 S v Makwanyane and Another [1995] 3 SA 391 CC; S v Makwanyane and Another [1995] 6 BCLR 665 CC.

77 For this purpose, decisions of tribunals dealing with comparable instruments, such as the United Nations Committee on Human Rights, the Inter-American Commission on Human Rights, the Inter-American Court of Human Rights, the European Commission on Human Rights, and the European Court of Human Rights, and, in appropriate cases, reports of specialized agencies such as the International Labour Organization, may provide guidance as to the correct interpretation of particular provisions of the Bill of Rights.

78 Section 25(1).

79 Section 25(2).

80 Section 25(3). According to section 26, there is also an obligation on the Minister to report to Parliament once a year regarding international environmental instruments for which he or she is responsible.

81 Wouters, supra note 30 , p. 300. 
watercourse governance in SADC should thus not necessarily be attributed to the lack of a legal mechanism in this regard. The main challenges, it would seem, are the lack of enforcement, institutional issues, and the lack of capacity. Furthermore there is a lack of 'ownership' with regards to, amongst other things, the mechanisms, issues, and strategies inherent to the protocol. Moreover, professionals responsible for executing governance mandates in terms of mechanisms such as the protocol are more often than not overburdened, under-resourced, and poorly compensated..$^{82}$

Another challenge is the lack of finances for investment in projects to further and facilitate the objectives of the 2000 Protocol. There has been a steady decline in the gross domestic product per capita in sub-Saharan Africa over the past three decades. Countries therefore have to make difficult decisions regarding priorities when financing projects (which, in the cadre of, for example, creating water infrastructure such as dams is usually extremely expensive and beyond the reach of most countries in the region). One of the opportunities in this regard, however, may be for countries to all contribute to a pool of funds that may be used to fund larger projects instead of leaving one country to borrow the money for this purpose. ${ }^{83}$

The African region, including Southern Africa, is also confronted by, inter alia, frequent political conflicts, economic instability, extreme poverty, and challenges posed by diseases such as HIV/AIDS. ${ }^{84}$ These challenges do not create an environment that is conducive to optimizing sustainable shared watercourse governance. Notwithstanding the comprehensiveness and effectiveness of a governance mechanism such as the 2000 Protocol, these challenges may significantly inhibit the achievement of sustainable governance results. However, most of these challenges can be linked, either directly or indirectly, to some of the issues that sustainable shared watercourse governance aims to address. For example, provision and sustainable use of fresh water (which can be achieved by way of, inter alia, the mechanisms of the 2000 Protocol) would enable subsistence farmers to practice sustainable farming, to provide food, to ensure an income, and to enhance people's health, livelihoods, and well-being. These challenges should thus not only be considered as being all negative but also as opportunities and catalysts to motivate riparian countries to comprehensively employ the mechanisms of the 2000 Protocol in order to address the challenges and to secure a sustainable future.

Opportunities further present themselves in terms of initiatives that are secondary to the protocol but that run consecutively and in support of it. One of these initiatives is the so-called ZACPLAN, which is a SADC-led programme for co-operative water governance in the Zambezi Basin. ${ }^{85}$ This

82 See more generally, Hirji and Grey, supra note 16, pp. 89-90.

83 See further, Dombrowsky and Grey, supra note 9, p. 88.

84 Dombrowsky and Grey (supra note 9, p. 86) state in this regard that: 'The sound management of international rivers is never a straight forward undertaking. In the anarchic system of international relations, it requires sovereign states to engage and to create mechanisms and institutions for this purpose. In Africa, the challenge of international water management is even greater, given poverty, limited human and institutional capacity and weak international relations.'

85 See also, for a more detailed discussion generally, T. Matiza, S. Crafter, and P. Dale (eds.), Water Resource Use in the Zambezi Basin: Proceedings of a Workshop Held at Kasane, Botswana, 28 April-2 May 1993 (Gland, Switzerland: IUCN, 1995), and Tumbare, supra note 26, pp. 101-112. 
project was launched in 1987 and aims to develop regional legislation and to establish a river basin commission and an integrated water resources management plan. ${ }^{86}$

Hirji and Grey ${ }^{87}$ list various other opportunities for improving governance of shared watercourses in the region. These include the following:

- Building national capacity and identifying and executing national priorities;

- Establishing, improving, and sustaining information systems;

- Developing dialogue between riparian states;

- Addressing simpler governance issues first before progressing to more complex issues;

- Establishing trust between riparian States;

- Recognizing that progress on complex water systems may be slow but that it is important to establish and maintain dialogue; and

- Seeking opportunities for mutually beneficial programmes and projects that support the overall governance effort.

\subsection{Conclusion}

Given current climate flux, increasingly unpredictable patterns of rainfall all over the world, and increasingly limited access to water, it is reasonable to assume that water resource conservation will become (or may even already be) one of the most profound concerns of the current environmental law discourse. Many of these watercourses are shared between various countries, some of which are situated in water-stressed areas. Moreover, equitable and sustainable use of shared watercourses gives rise to complex political, environmental, and governance issues. This chapter endeavoured to demonstrate that this is certainly also the case in SADC.

Sustainable governance of shared watercourses will remain a challenge unless it is executed alongside parameters set by regional legal instruments that are specifically designed for shared watercourse governance. The 2000 SADC Protocol is, in the context of the aforementioned legal instruments, the primary mechanism to facilitate shared watercourse governance in Southern Africa. The protocol certainly has the potential to address many of the concerns usually akin to shared watercourse governance. However, the success of this mechanism in achieving sustainable and equitable use of shared watercourses depends to a large extent on the manner in which its provisions are respected and implemented. Despite the many challenges (such as poverty, armed conflict, and HIV/AIDS) that may bedevil the effective implementation of the protocol's provisions, it can be considered a comprehensive regional instrument that, if implemented properly, will contribute to sustainable shared watercourse governance in the region.

86 Hirji and Grey, supra note 16, pp. 93-94.

87 Ibid., pp. 96-98. 


\section{Gestion transfrontalière du Bassin du Lac Tchad : Enjeux, défis et opportunités}

Rémi Jiagho and Paul Noupa ${ }^{1}$

\subsection{Presentation du Bassin du Lac Tchad}

Le bassin du lac Tchad est le plus vaste bassin endoréique du monde avec $2.381 .635 \mathrm{~km}^{2}$, soit $8 \%$ de la superficie du continent africain. Les pays concernés sont : l'Algérie, le Cameroun, le Niger, le Nigeria, la République Centrafricaine, le Soudan et le Tchad. Cependant la zone d'intervention de la Commission du Bassin du Lac Tchad ici désignée 'Bassin conventionnel' couvre après son extension en 1985 (5 $5^{\text {ème }}$ Sommet de la Commission du Bassin du Lac Tchad (CBLT)), une superficie de 967000 km². II représente le bassin hydrographique actif.

Le Bassin du Lac Tchad est une cuvette qui se subdivise en plusieurs unités naturelles plus ou moins tranchées: la région septentrionale désertique, les bassins alluviaux et les massifs. Le bassin hydrologiquement actif ne concerne que la partie sud. Le réseau hydrographique est constitué essentiellement du système Logone-Chari, des Mayo des monts Mandara et du Komadougou Yobe.

Le Bassin du Lac Tchad est une zone présentant des spécificités qui lui sont propres:

- Une diversité culturelle ;

- Une diversité linguistique (présence des pays francophones - Cameroun, République Centrafricaine (RCA), Tchad, Niger et anglophone -Nigeria)

\subsection{Description des caractéristiques biophysiques}

\subsubsection{Climat}

Le climat du bassin du Lac Tchad est globalement de type tropical; il appartient à la zone sahélienne. Localement, il est classé dans quatre sous-types, ${ }^{2}$ à savoir (en allant du Nord au Sud):

- Le climat saharien caractérisé par moins de 200 mm de pluies par an ;

- Le climat sahélo-saharien avec une précipitation moyenne annuelle comprise entre $200 \mathrm{~mm}$ et $400 \mathrm{~mm}$;

1 Rémi Jiagho (Technical Assistant) and Paul Noupa (Coordinator), Bureau Régional pour l'Afrique Centrale de Union Mondiale pour la Nature (I'UICN), Yaoundé, Cameroun

2 CBLT (1992) Plan Directeur pour le Développement et la Gestion écologiquement rationnelle des ressources naturelles du Bassin conventionnel du Lac Tchad. N'djamena, Tchad, 48 p. + annexes. 
- Le climat sahélo-soudanien, plus humide avec une précipitation moyenne annuelle comprise entre $400 \mathrm{~mm}$ à $600 \mathrm{~mm}$;

- Le climat soudano-guinéen avec une précipitation moyenne annuelle comprise entre $600 \mathrm{~mm}$ à $900 \mathrm{~mm}$, voire un plus par endroits.

L'écart de température y est important, la température est basse au cours de la saison des pluies et les nuits pendant la saison sèche. Les saisons sèches y sont généralement longues, environ 8 mois. Les précipitations sont peu élevées et sont réparties en peu de jours.

On admet avec ERE DEVELOPPEMENT ${ }^{3}$ que les écarts pluviométriques sont importants à l'intérieur des zones géographiques couplées au nombre de jours de pluies limité et aux fluctuations ponctuelles et locales de la durée de la saison sèche, rendant plus complexe la gestion des ressources de base (eau, sols, flore et pâturages, faune et ressources atmosphériques). L'humidité relative est assez basse et varie inversement avec l'altitude. Dans l'Extrême-Nord du Cameroun, elle est d'environ $30 \%$ sur les Monts Mandara et $35 \%$ dans les plaines. Elle est plus élevée en fin de saison des pluies et plus faible en fin de saison sèche. L'évaporation potentielle est assez élevée. En considérant toute chose égale par ailleurs, on constate qu'elle est de loin supérieure à la pluviométrie et ainsi peut justifier le déficit en eau dans cette partie du territoire.

\subsubsection{Relief et géologie}

Le relief du bassin est en grande partie plat. II est composé d'une pénéplaine dont les altitudes varient entre $500 \mathrm{~m}$ et $300 \mathrm{~m}$ entourée de hauts reliefs $(1.900 \mathrm{~m}-1.300 \mathrm{~m})$ au centre Nord nigérian, à l'Adamaoua camerounais et au Nord centrafricain d'où prennent source les différents cours d'eau dont le profil d'équilibre est atteint dans le lac Tchad $(280 \mathrm{~m})$.

Sur le plan géologique, le bassin est essentiellement occupé par des formations alluvionnaires. On note par endroits des argiles fines, des sables argileux et des sables des dunes.

\subsubsection{Hydrographie}

L'ensemble des apports hydriques du Lac Tchad (46 à 50 milliards de $\mathrm{m}^{3}$ ) provient en grande partie (environ 39 milliards de $\mathrm{m}^{3}$ ) du Logone et du Chari qui prennent leurs sources au Cameroun et en République Centrafricaine. L'autre partie provient des précipitations tombant directement dans le lac (6 milliards de $\mathrm{m}^{3}$ ) et des cours d'eau du Nigeria (Komadougou).

\subsubsection{Eléments biologiques}

\section{Végétation et flore}

Le bassin du Lac Tchad se caractérise par sa faible couverture végétale. On y distingue des savanes (boisées, arbustives et herbeuses), la steppe et le désert. La végétation est fortement modifiée par les activités anthropiques (agriculture, pâturage, collecte du bois de feu, activités industrielles, etc.). Ce qui rend assez vulnérable l'environnement. Cependant, il faut observer que les activités humaines ne constituent pas seulement un danger pour la végétation, elles participent

3 ERE DEVELOPPEMENT (2001a) Schéma directeur régional d'aménagement et de développement durable du territoire de la province de l'Extrême-Nord. Rapport $\mathrm{N}^{\circ} 1$ : Bilan diagnostic. 
aussi parfois à son développement grâce à la plantation des arbres utiles comme le Faideherbia albida.

Au Tchad, il est noté que la végétation des oasis a connu une profonde modification dans sa composition floristique. Elle est de nos jours constituée essentiellement de dattier (Phoenix dactilifera) et autres plantes cultivées. ${ }^{4}$

La spécificité observée dans le bassin, c'est la présence des arbres le long des lits des cours d'eau saisonniers appelés 'Mayo' au Cameroun et 'Ouadis' au Tchad. Ce type de végétation est considéré par certains auteurs comme des forêts galeries. ${ }^{5}$

\section{Faune}

II ressort des données sur la littérature que:

- les connaissances sur la faune dans le bassin du Lac Tchad restent parcellaires et les données des pays ne sont pas comparables ;

- la faune du bassin est riche et diversifiée et compte des espèces ayant un grand intérêt international dont les éléphants, les lions, les Elands de Derby, les gazelles (dorcas, aux cornes élancées), le lamantin du Lac Léré et de nombreux oiseaux migrateurs ;

- la zone constitue un grand intérêt pour la conservation des zones humides grâce à la présence des espèces phares et migratrices. Fosi-Mbantenkhu et Mahamat (2005) rapporte qu'environ 70 espèces migratoires viennent dans le Bassin du Lac Tchad; ${ }^{6}$

- le bassin a un fort potentiel faunique pour contribuer au développement local notamment à travers la pêche, et le tourisme de vision et cynégétique. En effet, Le bassin du Lac Tchad est l'une des régions les plus productrices de poissons d'eau douce en Afrique. ${ }^{7}$ La pêche représentait avant la grande sécheresse, la deuxième source de revenu dans l'économie du bassin.

Plusieurs espèces comme l'Addax, l'Oryx et les gazelles Dama ont presque disparu du bassin. ${ }^{8}$ Il en serait de même pour le rhinocéros noir.

4 Dolmia, M. (2005) Etude de la diversité biologique dans la partie tchadienne de Bassin du Lac Tchad. Rapport final de Consultation. Projet FEM/CBLT RAF/00/G31/P070252, N'Djamena.

5 Cf. note 4.

6 Fosi-Mbantenkhu, M. et Mahamat, H. (2005) Etude de la biodiversité dans le Bassin du Lac Tchad : Cas du bassin conventionnel du Cameroun. Rapport final de Consultation. Projet FEM/CBLT RAF/00/G31/P070252, Maroua.

7 Cf. note 2.

8 Cf. note 2. 


\subsection{Les arrangements institutionnels mis en place pour la gestion transfrontalière dans le Bassin du Lac Tchad}

\subsubsection{Bref aperçu de la Commission du Bassin du Lac Tchad}

L'instance institutionnelle légale dans le Bassin du Lac Tchad est la Commission du Bassin du Lac Tchad (CBLT). Elle a été créée au lendemain des indépendances africaines par les premiers dirigeants des jeunes Etats qui éprouvaient le besoin de se regrouper dans le but de résoudre des problèmes communs. La CBLT, naît le 22 mai 1964 par la Convention de Fort Lamy à N'Djamena, signée par les Chefs d'Etat du Cameroun, du Niger, du Nigeria et du Tchad.

Dès sa création, la CBLT a été un organisme de coordination et de promotion de la coopération sous-régionale. En effet, la Convention qui la crée fait référence dans son préambule à la Charte des Nations Unies et notamment à la résolution du Conseil Economique et Social relative à la coopération internationale dans le contrôle et la mise en valeur des ressources en eau. De ce fait, la CBLT est une institution bien organisée au plan du droit, et qui a des attributions régulatrices et régionales. Au regard de sa convention et de ses statuts, la CBLT a la responsabilité de réguler et de contrôler l'exploitation de l'eau et d'autres ressources naturelles du bassin, d'initier, de promouvoir et de coordonner les projets de développement des ressources naturelles et la recherche dans le bassin, d'examiner les plaintes et de promouvoir la coopération régionale par le règlement des différends.

La CBLT est composée de trois organes :

- un organe politique, le Conseil des Commissaires ou le sommet des Chefs d'Etat. II a pour mission l'élaboration des politiques et les orientations stratégiques. II se réunit tous les deux ans ;

- Un comité technique, le Conseil des ministres. C'est un comité qui comprend les spécialistes originaires de chaque Etat membre. Son but est de contribuer à l'harmonisation de la gestion des ressources en eau. Entre autre, II prépare les documents techniques pour les réunions du Conseil des commissaires et facilite la mise en œuvre des recommandations de la CBLT dans les institutions des Etats membres. II se tient une fois l'an ;

- Un organe exécutif, le Secrétariat Exécutif. Ses missions essentielles sont de :

- s'assurer de l'application des principes définis dans la Convention ;

- assembler, examiner et ventiler les données relatives aux projets préparés par les Etats membres et recommander un plan d'action pour le développement du bassin ;

- maintenir le contact entre les Etats membres afin de faciliter l'exploitation harmonieuse et efficiente des eaux du bassin ;

- mener les études et les travaux de base dans le bassin et en informer les Etats membres ;

- promouvoir la coopération régionale et le règlement des différends ;

- planifier, coordonner et exécuter les projets à l'échelle régionale. 
Le Sommet des Chefs d'Etat et le Conseil des Commissaires sont les deux autorités dont découlent les pouvoirs de la CBLT. Le Plan Directeur pour le Développement et la Gestion Ecologiquement rationnelle des Ressources naturelles du Bassin Conventionnel du Lac Tchad vient corriger les politiques ayant précédé les années 70 , à l'origine tournées vers la sécurité alimentaire, puis vers les projets hydro agricoles. La CBLT ne peut véritablement agir en matière de gestion des ressources en eau et des autres ressources que si les préalables suivants sont acquis:

- il y a un engagement ferme du Sommet des Chefs d'Etats, sur proposition du Conseil des Commissaires,

- tous les états acceptent le principe de la «gestion intégrée des ressources en eau » pour l'ensemble du bassin et se donnent les moyens d'appliquer ces principes.

A l'analyse, la CBLT devrait fonctionner comme une organisation politique chargée de l'information, de la consultation et du dialogue avec les Etats membres. La Convention de Fort Lamy, renforce cette position car elle « reconnaît les droits souverains des Etats membres sur les ressources du bassin, mais interdit une exploitation unilatérale des ressources en eau du Lac ", spécialement lorsqu'une telle utilisation affecte négativement les intérêts des autres Etats. Elle reconnaît également le droit des Etats membres de planifier des projets à condition de consulter au préalable la Commission. Finalement, les Etats membres doivent informer la commission de tous les projets qui sont envisagés sur le « bassin conventionnel ».

\subsubsection{Forces et faiblesses des arrangements institutionnels au niveau de la gestion du Bassin du Lac Tchad}

La disposition précédente sur la Convention de Fort Lamy fragilise cependant la CBLT sur la gestion des ressources en eau. En effet, elle ne lui donne aucun pouvoir coercitif contre un Etat qui violerait cet accord puisque chaque Etat garde sa souveraineté, d'une part et d'autre part elle ne crée aucune obligation individuelle de mise en œuvre commune de la gestion partagée des ressources du Bassin. Pour preuve les politiques nationales des Etats membres en matière de gestion d'eau restent encore très faibles voire inexistants pour certains. II y a une absence de normes et directives régionales et nationales pour réguler les mécanismes de partage des coûts de l'eau, ce qui contribue à la dégradation de l'environnement autour du bassin et ne favorise pas l'accès aux populations à certains aux dérivés tels l'électricité.

D'autre part, il n'existe pas de textes règlementaires communs de gestion spécifiques des ressources du bassin. Au moment de la mise en œuvre des dispositions réglementaires, les Etats membres conservent leur souveraineté. Chaque Etat membre crée sur le plan national conformément à sa propre vision, une structure de gestion de l'Eau. Par exemple, le Cameroun dispose d'un Comité technique de coordination et de suivi du projet de transfert d'eau interbassins et le Tchad quant à lui de la Société de Développement du Lac Tchad (SODELAC) qui sont des structures nationales intervenant directement dans la gestion des ressources en eau du Bassin.

II faut ajouter à ces spécificités nationales le droit traditionnel ou coutumier propre à chaque Etat membre qui prévaut en matière des eaux et des terres. 
La CBLT avec le concours de L'Organisation des Nations Unies pour l'alimentation et l'agriculture (FAO) a élaboré un projet de réglementation sur l'exploitation et la conservation de l'eau. Trois accords ont été signés, un entre le Cameroun et le Tchad, un autre entre le Nigeria et le Niger et un troisième entre certains Etats fédérés du Nigeria. Mais la bonne volonté des membres fondateurs n'a pas suivi pour l'application de la réglementation en matière d'eau.

\subsection{Opportunités et défis}

\subsubsection{Respecter les directives de la convention de Ramsar}

La Convention de Ramsar sur les zones humides s'applique au Bassin du Lac Tchad qui est la $2^{\text {ème }}$ plus grande zone humide d'Afrique grâce aux zones humides qu'on retrouve au Cameroun et au Tchad. L'article 5 de la Convention de Ramsar offre un mécanisme bien établi de coopération internationale, en particulier en ce qui concerne la gestion de l'eau douce: "Les Parties contractantes se consultent sur l'exécution des obligations découlant de la Convention, particulièrement dans le cas d'une zone humide s'étendant sur les territoires de plus d'une Partie contractante ou lorsqu'un bassin hydrographique est partagé entre plusieurs Parties contractantes. Elles s'efforcent en même temps de coordonner et de soutenir leurs politiques et réglementations présentes et futures relatives à la conservation des zones humides, de leur flore et de leur faune.»

La Convention dans les Nouvelles lignes directrices relatives aux plans de gestion des sites Ramsar et autres zones humides, donne les grandes orientations de gestion des zones humides et stipule en son article 29 que « La gestion des zones humides et en particulier le processus de planification doit être aussi intégrée que possible ».

Prenant conscience de l'importance des Directives de la Convention de Ramsar, la CBLT s'est engagée dans un processus de coopération avec le bureau de la Convention. C'est ainsi qu'un Mémorandum de coopération a été signé en novembre 2002 entre le bureau de la Convention sur les Zones humides et la CBLT et fixe les objectifs donc celui de renforcer, au niveau national et du bassin, les partenariats organisationnels entre toutes les parties prenantes, les entités étatiques, les organisations intergouvernementales, les Organisation non gouvernementale (ONG) et d'autres partenaires intéressés par la conservation et l'exploitation durable des zones humides.

Les mesures de la Convention de Ramsar sur les zones humides sont en effet très incitatives pour une démarche intégrée de la gestion des ressources du bassin qui prennent en compte les intérêts de toutes les parties prenantes avec un accent sur les approches transversales que sont le genre et la cogestion.

Toutefois, les missions et l'organisation actuelle de la CBLT ne lui permettent pas une mise en œuvre efficace des engagements pris au niveau de la signature du Mémorandum de coopération pour la mise en œuvre de la Convention de Ramsar. Aucun cadre n'est prévu pour la concertation des autres parties prenantes. Toute la vision, même dans la nouvelle restructuration est tournée vers les Etats. II serait souhaitable pour la CBLT de prendre des dispositions utiles et efficaces pour la mise en œuvre des engagements de ce Mémorandum. Les axes d'intervention de ce processus de collaboration sont à ce titre assez révélateur et concerne: 
- L'utilisation rationnelle de toutes les zones humides du bassin du lac Tchad;

- La mobilisation de ressources financières pour la conservation et l'utilisation durable des zones humides à l'échelle du bassin ;

- L'inscription et gestion de zones humides d'importance internationale (sites Ramsar) ;

- La coopération internationale et gestion transfrontière de systèmes aquatiques partagés.

Ce Mémorandum est un exemple patent de l'engagement de la CBLT au processus de gestion transfrontalière des ressources du Bassin du lac Tchad. Toutefois, les mesures courageuses doivent être prises pour faciliter la mise en œuvre de cet important accord.

\subsubsection{Restructurer la CBLT pour la rendre plus efficace}

La restructuration du Secrétariat de la Commission du Bassin du Lac Tchad a fait l'objet de plusieurs délibérations du Conseil des Ministres au cours des cinq dernières années. A cet égard, il est nécessaire de rappeler les Résolutions suivantes :

a. La 49ème Session du Conseil des Ministres de la CBLT, tenue à Yaoundé au Cameroun, du 14 au 15 janvier 2002, a adopté la Résolution №1 instituant un Comité ad hoc pour réviser le Statut du Personnel et les Procédures Financières. Dans cette Résolution les Commissaires de la CBLT ont décidé qu'une restructuration de la CBLT devrait être entreprise.

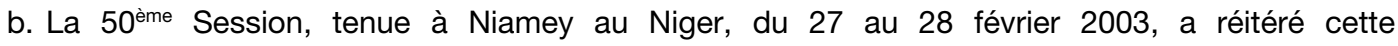
préoccupation à travers l'adoption de la Résolution $N^{\circ} 1$ sur la révision du Statut du Personnel, des Procédures Financières et la restructuration du Secrétariat Exécutif.

c. La résolution $N^{\circ} 8$ de la $52^{\text {ème }}$ Session tenue à N'djamena au Tchad du 15 au 16 Juin 2005 a approuvé les termes de référence présentés par le Secrétariat Exécutif et la Banque Mondiale concernant une revue institutionnelle de la CBLT.

Depuis la $52^{\text {ème }}$ Session, la CBLT a été en mesure d'appliquer ces Résolutions grâce au concours financier du Projet CBLT/FEM, financé par le Fonds pour l'Environnement Mondial sur L'Inversion des Tendances à la Dégradation des Terres et des Eaux dans l'Ecosystème du Bassin du Lac Tchad.

C'est dans cet esprit que la Commission du Bassin du Lac Tchad et ses partenaires ont convenu de s'engager dans le processus d'analyse et d'amélioration des capacités de la CBLT à remplir sa mission.

Le premier objectif de l'évaluation est de clarifier les caractéristiques fondamentales de la CBLT, y compris son mandat, les dispositions institutionnelles et financières correspondantes, les principales forces et faiblesses historiques et administratives de l'organisation.

Le second objectif est de proposer des changements permettant de résorber toutes faiblesses, entre autres les changements de mandat juridique, les fonctions, la structure, les sources de financement, l'administration et le fonctionnement, y compris le processus d'exercice de l'autorité, de prise de décisions et des responsabilités. L'évaluation doit également étudier l'implication de ses membres et des principaux acteurs dans les activités du bassin et le processus de prise de décision. 
II s'agit en réalité d'évaluer les fonctions et les responsabilités actuelles de la CBLT en vue de renforcer et d'améliorer ses capacités fonctionnelles, son efficacité régionale et d'assurer un niveau suffisant de finances pour ses opérations. L'évaluation ne doit pas être concentrée uniquement sur le Secrétariat Exécutif mais également sur les structures nationales et régionales de la Commission et doit se réaliser à travers un processus participatif qui impliquera les parties prenantes, les structures de la CBLT et les communautés locales.

Au regard de ce qui précède, et sur la base des missions de la CBLT, il s'avère nécessaire de restructurer la CBLT pour la permettre d'assurer son leadership en matière de gestion durable des ressources naturelles du bassin du Lac Tchad. Les responsabilités, prérogatives et ressources doivent être évalués en prenant en compte les besoins réels de l'institution. Les acteurs clés, en particulier les structures nationales et sous régionales de la CBLT ont besoin des capacités institutionnelles, techniques et matérielles requises pour assurer pleinement leur rôle.

\subsubsection{Développement d'un processus de concertation nationale et sous régionale}

L'objectif à long terme du Projet FEM/CBLT est de contribuer à l'amélioration des conditions environnementales mondiales à travers une gestion concertée des ressources naturellement intégrées en terres en eaux du Bassin du Lac Tchad. L'objectif spécifique du projet est de surmonter les obstacles qui s'opposent à la gestion concertée du bassin par une coopération bien orchestrée et accrue entre les Etats riverains et les parties prenantes et par le renforcement de leurs capacités. Ceci suppose une orchestration des activités tant nationales que régionales à travers un système de travail sur la gouvernance du bassin.

Avec l'aide du Programme des Nations Unies pour le Développement (PNUD) et de la Banque Mondiale comme agences de mise en oeuvre, le Fonds pour l'Environnement Mondial (FEM) est en train d'appuyer un projet qui implique l'achèvement de l'Analyse Diagnostique Transfrontalière (ADT) et qui a débouché sur la formulation du Programme d'Action Stratégique (PAS) chargé de résoudre les problèmes prioritaires transfrontaliers relatifs à l'environnement dans le bassin. L'exécution réussie du PAS adopté au Conseil des Ministres d'Abuja en juin 2008 suppose qu'un système efficace de gouvernance du bassin soit mis en place et que les acteurs clés au sein du système, particulièrement les structures nationales et régionales de la CBLT fassent preuve d'une capacité suffisante et disposent des ressources adéquates pour entreprendre une telle activité.

Le Programme pour l'Afrique Centrale et Occidentale de I'Union Internationale pour la Conservation de la Nature (UICN-PACO) travaille dans le cadre du Projet FEM/CBLT en encourageant la mise en place d'un processus de concertation des acteurs nationaux pour la réflexion autour des problèmes de gestion des ressources du Bassin du Lac Tchad. Au niveau de chaque pays, les acteurs clés ont été identifiés, en collaboration avec les points focaux nationaux pour participer au processus de concertation pour le diagnostic des ressources, le choix et la sélection des initiatives locales prioritaires à appuyer. L'ensemble des idées et préoccupations saillantes des acteurs a été rassemblé pour l'élaboration d'un plan de gestion du rivage du Lac Tchad et ses tributaires. Un processus de validation a été entrepris et a regroupé les représentants de chaque pays en vue compléter le document produit. Au cours de l'atelier de validation, des 
expériences et les préoccupations nationales ont été échangées et ont permis à tous les pays de se familiariser à une gestion concertée au niveau transfrontalière.

L'UICN voudrait dans cette approche inciter la mise en place d'un mécanisme de concertation permanent au niveau sous régional : le Processus de Gestion Concerté des ressources naturelles du Bassin du Lac (PGC/BLT). C'est un cadre, qui à l'instar de la Conférence sur les Ecosystèmes Denses et Humides d'Afrique Centrale (CEFDHAC) regroupera tous les acteurs y compris la société civile, les chercheurs, les groupes d'utilisateurs des ressources, les autorités traditionnelles et municipales.

Ce cadre vise à encourager tous les acteurs (Acteurs politiques, Administrations sectorielles, Municipalités, Autorités traditionnelles, ONG internationales, régionales et nationales, Groupes d'utilisateurs de la ressource, Acteurs de la société civile, etc.) à conserver les écosystèmes et à utiliser durablement les ressources naturelles dans le Bassin du Lac Tchad. Le PGC/BLT sera chargé entre autre de :

- Favoriser la cohérence des interventions ;

- Rendre disponible l'information ;

- Proposer les programmes et initiatives nationaux et régionaux cohérents ;

- Disséminer les idées et expériences novatrices ;

- Organiser les fora nationaux et régionaux et les ouvrir à tous les acteurs ;

- Contribuer à l'harmonisation des politiques et législations nationales et transfrontalières ;

- Nourrir les orientations politiques de la Commission du Bassin du Lac Tchad en informations techniques ;

- Développer et mettre en œuvre les mécanismes de gestion des conflits entre groupes d'utilisateurs des ressources naturelles dans le Bassin du Lac Tchad, etc.

II pourra se positionner comme un organe technique de gestion des ressources et aider la CBLT (organe politique) à atteindre ses missions. II devra par une implication de l'ensemble des acteurs, les aider à contribuer aux débats et nourrir les orientations politiques. L'analyse institutionnelle de la CBLT, dont le processus de finalisation est en cours, a relevé des gaps en matière de renforcement des capacités, d'information et de communication. Ce cadre devra permettre de dissiper ces gaps.

\subsection{Conclusion}

La prise de conscience de la gestion transfrontalière a été effective entre les Etats depuis le lendemain des indépendances des Etats africains. Cette prise de conscience s'est concrétisée avec la création d'un organe politique, la Commission du Bassin du Lac Tchad, dont les missions ambitieuses se heurtent à une insuffisance de capacités institutionnelles, techniques et matérielles. Des opportunités existent cependant. Le projet FEM/CBLT est l'exemple d'un processus dont la mise en œuvre effective et efficiente peut permettre de relever certains défis. Mais, le défi le plus important est celui de la mise en place d'un cadre de concertation permanent de tous acteurs, 
agissant comme organe technique, et ayant pour principale mission de nourrir l'organe politique, la CBLT, des connaissances et leçons apprises des expériences des acteurs nationaux. 


\title{
Transboundary Management of Natural Resources Neusiedler See / Fertő-Tó
}

\author{
Katharina Diehl and Alois Lang ${ }^{1}$
}

\subsection{Introduction}

The cross border national park Fertö-Hanság or Neusiedler See covers a wetland area of approximately 300 square kilometres $\left(\mathrm{km}^{2}\right)$ shared by Hungary and Austria. (See Figure 6.1.) It is located in the western-most part of the Carpathian Basin, east of the mountain formations of the Austrian Alps. The site has been divided by a State border since 1918. However, the joint pursuit of integration of culture with nature and the many links and interactions between the civilizations on both sides of the border has resulted in a geographically and historically uniform cultural landscape. ${ }^{2}$

The national park was founded on the Hungarian side in 1991. The opportunity to establish the park came with the radical political changes in $1989,{ }^{3}$ and the plans for developing a transboundary park were made under the former socialistic government in Hungary in 1988. The Austrian part of the park was established in 1993, according to the country's national park law that was approved in 1992. The two parks were symbolically joined by a ceremony on April 24, 1994.

While the methods that needed to be implemented for preserving or restoring valuable ecosystems turned out to be the same in both parts of the national park, the logistical, legal, and structural background was and still is very different. The situation today is one of successful collaboration between the two park directorates and also between most of the local communities. The EUROPARC award for successful transboundary co-operation in nature conservation, handed over in 2003 to both Directors, gave credit to the efforts that have been undertaken in this field since the foundation of the national park. ${ }^{4}$

1 Katharina Diehl (Assistant to European Green Belt Coordinator) and Alois Lang (European Green Belt Coordinator), World Conservation Union-IUCN (IUCN) Programme Office for South-Eastern Europe, Hungary.

2 Stadtland/AVL - Vienna and VATI KHT - Budapest (compilers), World Heritage Ferto / Neusiedlersee Cultural Landscape Management Plan (Budapest and Vienna: Eisenstadt, Fertöd, 2003).

3 B. Kohler, The Development of a Joint Education Strategy for the Neusiedler See Seewinkel/Fertö-Hanság Region - Introduction and Background, in Proceedings of Management of Transboundary Ramsar Sites Changes and Challenges Conference, Illmitz, Austria, 18-19 November 2004 (CD-Rom) (WWF Austria: 2004).

4 Natur \& Land, Schritt für Schritt zum Nationalpark Neusiedler See - Seewinkel, Eine Festschrift des ÖNB zur Gründung des Nationalparkes Neusiedler See - Seewinkel; Natur \& Land, 79. Jahrgang, Sonderheft zu 3-4/1993 (Salzburg: 1993). 


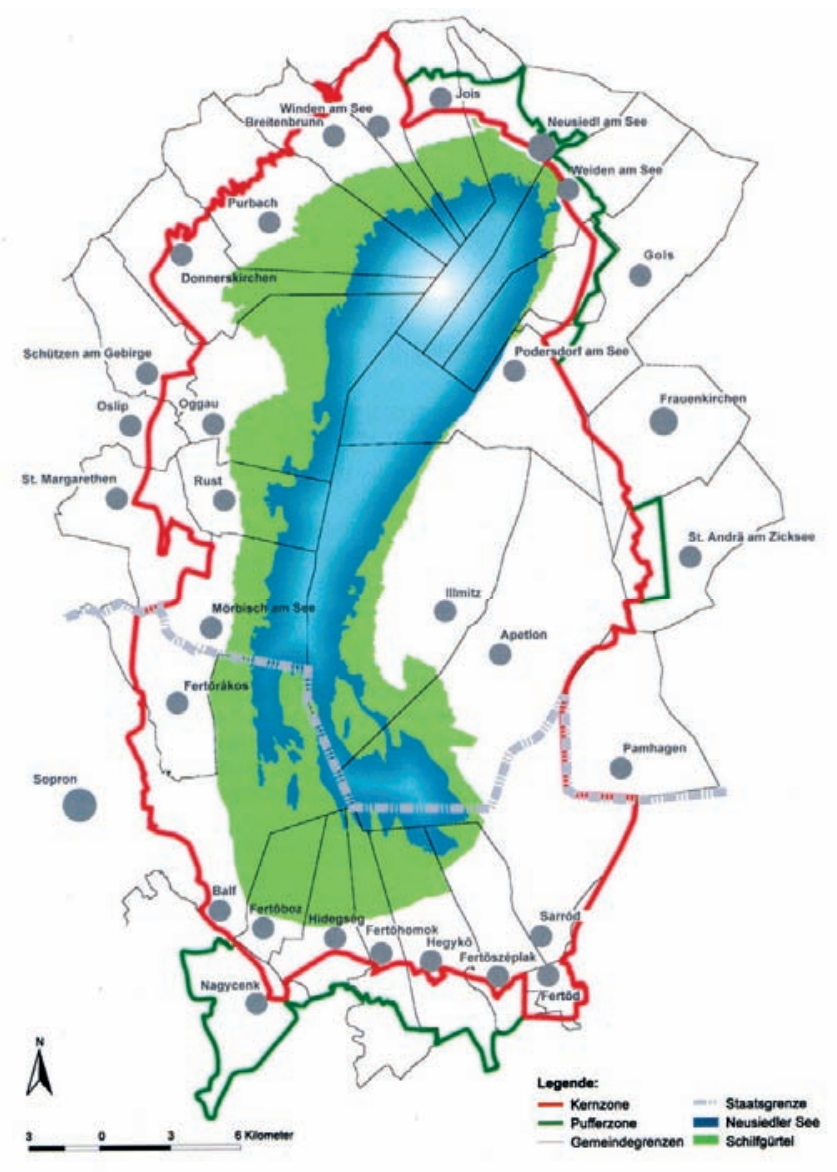

\subsection{The transboundary national park area}

\subsubsection{The geographical setting}

The Fertő-Neusiedler See ecosystem is the most westerly in a string of saline steppe-lakes across Eurasia. The shallow (up to 1.8 metres [m] deep) steppe lake is the largest saline water body in Europe, covering about $315 \mathrm{~km}^{2}$. It is about 13,000 years old, at a late stage of succession. ${ }^{5}$

In former times, the Fertö-Neusiedler See was in hydrological contact with the Danube and Raab River systems. Following intensive drainage of the Hanság basins in the twentieth century, greater floods of the rivers reached the Fertö-Neusiedler Lake through the Mosoni-Danube and Rábca, which contributed to major fluctuations in the lake's water level: at some times the lake flooded the

5 A. Herzig and M. Dokulil, Neusiedler See - Ein Steppensee in Europa, in M. Dokulil, A. Hamm, and J-G. Kohl (Hg), Ökologie und Schutz von Seen (Facultas UTB: 2001). 
surrounding area; at other times it dried out completely. Its water level is now subject to artificial control - at least in terms of flood prevention. ${ }^{6}$

\section{Figure 6.2. Transition zone from the steppes to the Alps}

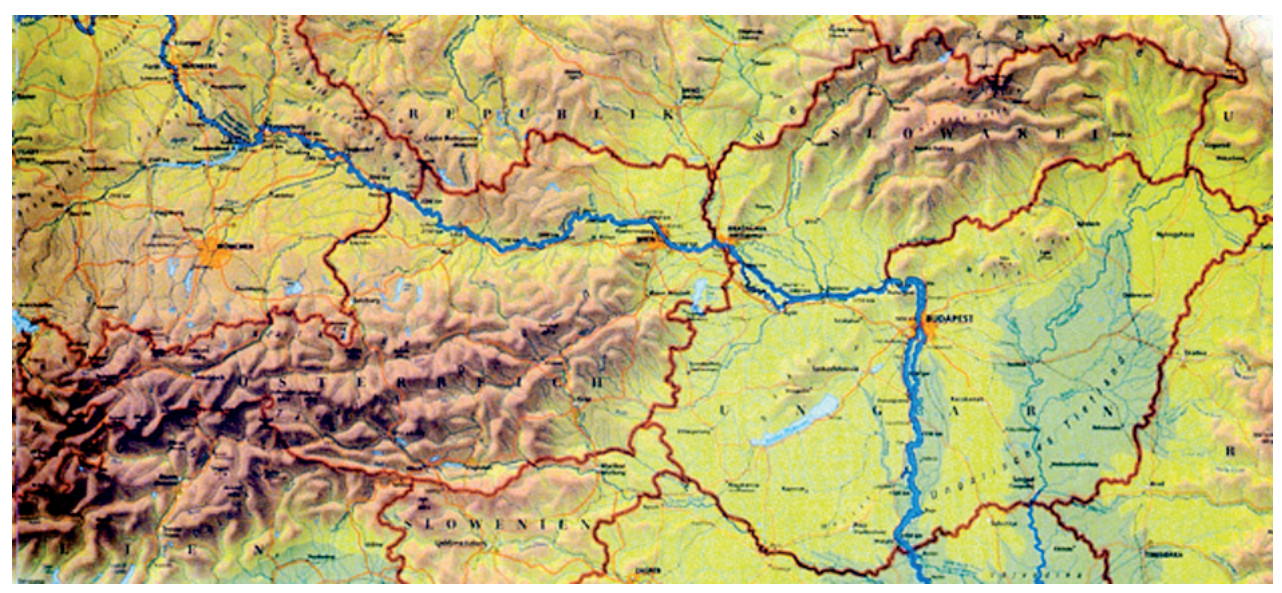

The region has always been a typical border region, due to its geographical and geological settting as a transition zone between the Carpathian Plains and the Alpine Mountains. (See Figure 6.2.) Because of the various climatic effects - continental, sub-Mediterranean, alpine - it is a meeting point also of floral and faunal borders. The ethnic composition of the human population shows a similar diversity, consisting of German, Slav (Croat), and Finno-Ugrian-Altaic (Hungarian) ethnic elements.

\subsubsection{Common history}

Findings from the Stone and Bronze Ages inform us that the region surrounding Lake Neusiedl was inhabitated 8,000 years ago. Archaeological findings prove that the successive civilizations had cultural and trading connections via trade routes crossing the south-west region of the lake, such as the Amber Route, which connected the Adriatic to the Baltic Sea and passed on the west side of the lake. There was also the main road connecting the plain of north-western Hungary to the Vienna basin from the east, with one of its tracks following the southern shore of Fertö-Neusiedler See.

Hundreds of years of continuous land use formed a landscape that is exceptionally diverse in its appearance. This diversity is caused by the gradual differences in altitude and by the numerous traditional forms of land use. The different elements, such as grazing and cattle herding (carried out both by the local inhabitants and by migrating cattle farmers), can be traced back to their historical context. Vineyards had been already established in Celtic and Roman times. From the 1950s to the 1970s, the area under vineyards reached its greatest extent and, particularly in the Seewinkel area,

6 A. Fersch and A. Lang, Between the Alps and the Puszta: A Trans-boundary National Park Shared by Hungary and Austria, in A. Terry, K. Ullrich, and U. Riecken (eds), The Green Belt of Europe: From Vision to Reality (Gland, Switzerland: IUCN, 2006), pp. 26-33. 
extended to parts of the landscape traditionally dominated by large pastures, dry meadows, and arable fields. The reed cutting is the most recent form of traditional land use (see Figure 6.3) - as the reed started spreading only after the sixteenth century, reaching its extensive area supporting economic use and natural values during the last 150 years. ${ }^{7}$

\section{Figure 6.3. Reed beds on Fertő-Neusiedl Lake, Schneeberg}

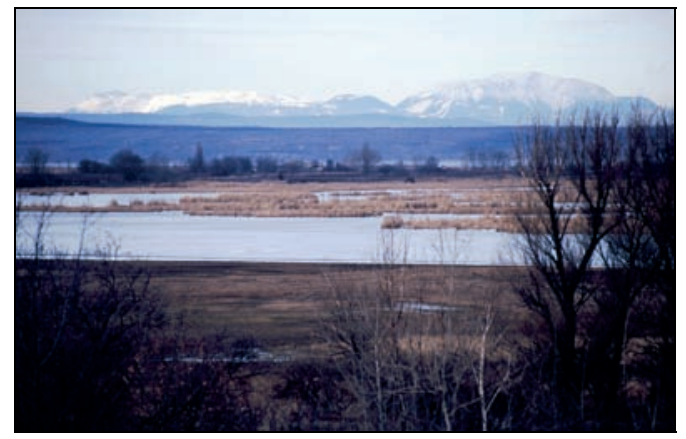

The Lake is surrounded by an inner ring of 16 settlements and an outer ring of 20 more. Unlike other protected areas that are characterized by one or more large objects, the Neusiedler Lake area is interrupted almost exclusively by rigidly defined settlements that were built closely together for security reasons in a flat land that was exposed not only to severe weather conditions but also to all kinds of hostile attacks. ${ }^{8}$

During the wars of the Turkish siege of Vienna, Lake Neusiedl was a besieged and hard-fought territory for more than 200 years. During the time that actually shaped today's cultural landscape (beginning in the second half of the seventeenth century) the region was mainly in the hands of the Austro-Hungarian nobility - i.e., the Esterházy, Széchenyi and Habsburg families. Smaller portions were owned by the Roman Catholic Church. ${ }^{9}$ (See Figure 6.4.) Overall, large estates dominated the land outside towns and villages. The stability of landownership greatly contributed to the continuity of land-use patterns. Even the sociopolitical upheavals after 1918 and 1945, when the nobility was in part succeeded by the public sector, has not really changed this pattern. The basic social structures defining the land in terms of ownership and source of subsistence for the population have largely remained the same. This has definitely had an impact on the cultural landscape, as it has helped to maintain the traditional socioeconomic structures and thus the balance between land use and the natural environment.

7 Stadtland/AVL and VATI KHT, supra note 2.

8 Ibid.

9 lbid. 
Figure 6.4. Kartenausschnitt Komitat Moson, 1886

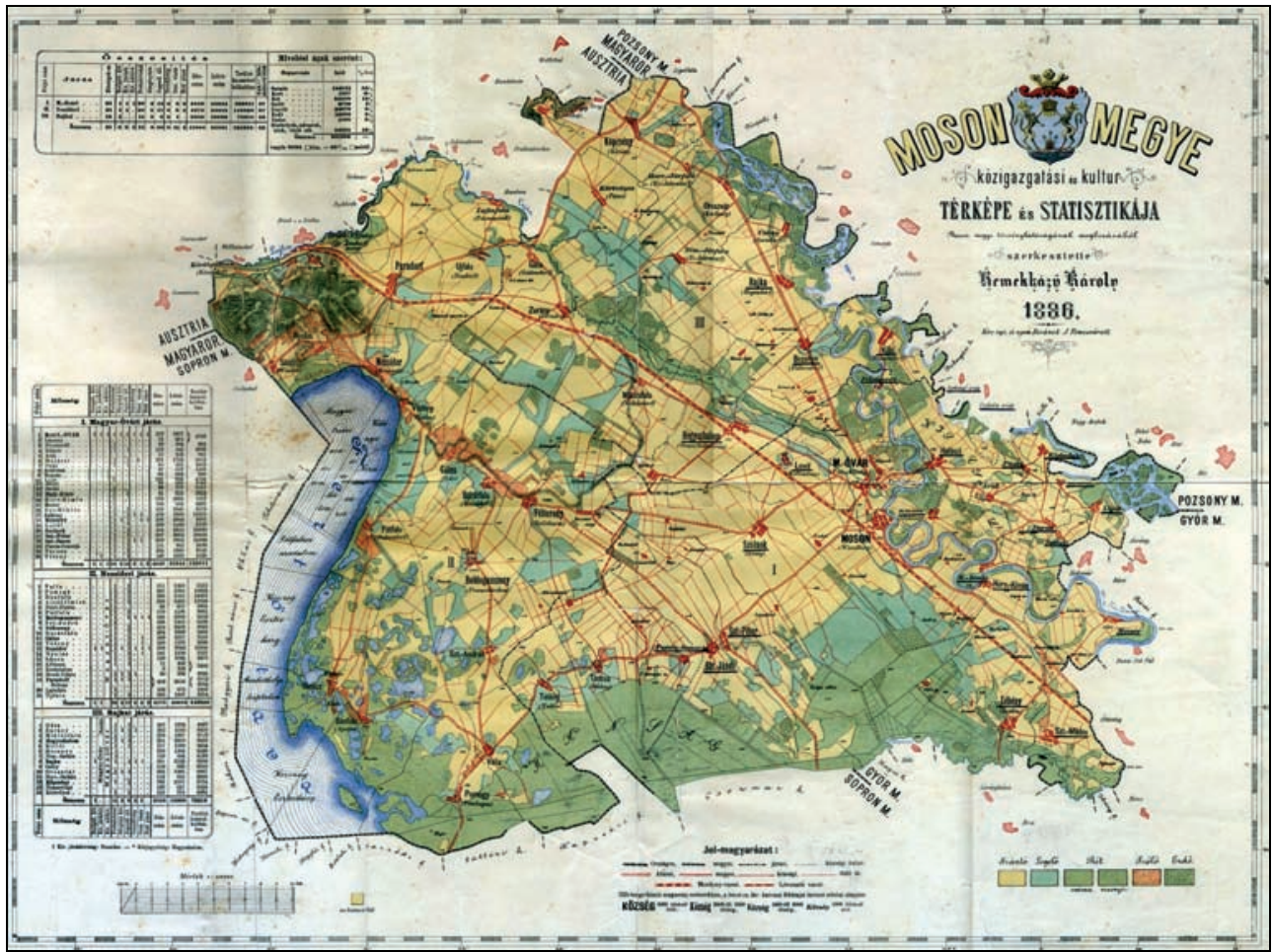

Until 1920 the Neusiedler See and the Burgenland belonged to the territory of the Hungarian Kingdom. After World War I, the Deutsch-Westungarn territory was attributed to Austria (Trianon, Saint-Germain, 1919). Since then, the national border introduced between Austria and Hungary has divided the region into two halves. Politically and administratively, the Austrian part of the lake belongs to the province ('Land') of Burgenland.

During World War II the area was again an arena for armed hostilities, this time between the German Wehrmacht and the Russian Red Army.

The water, the extensive reed beds cut into segments by a labyrinth of channels, the saline meadows once periodically flooded, and the row of hills enclosing the lake from the west with forests and vineyards on top represent not only the natural-geographical component features but also hundreds of years of identical land-use impacts. ${ }^{10}$ Around the lake, viticulture is the most important land use, but there are other manmade or seminatural habitats of ecological and landscape importance.

True isolation started with the establishment of the Communists' 'Iron Curtain' after World War II. During the Hungarian revolution in 1956, many Hungarians used the reed beds and the shallow lake to try a perilous escape to the west, before the border area was heavily secured for long years.

10 Ibid. 
But it was on the south-western part of the lake shore, between Fertörákos (Kroisbach) and St. Margarethen, that hundreds of participants in a Pan-European Picnic spontaneously tore down the barbed wire and reopened the border in August 1989. The population on the Austrian side had supported this change and welcomed hundreds of people trespassing across the border. ${ }^{11}$

\subsubsection{Protection status}

The lake at the base of the Alps is internationally important for migratory birds as a resting and feeding place. The reeds that cover between half and two-thirds of the lake are an important habitat for many nesting bird species, such as the Great White Egret (Ardea alba). To the east of the lake, the Seewinkel area complements the reed beds with some 40 shallow saline ponds as well as with remnant salt meadows, where thousands of geese arrive in late autumn. ${ }^{12}$ (See Figure 6.5.)

\section{Figure 6.5. Saltwater pans (Lacken)}

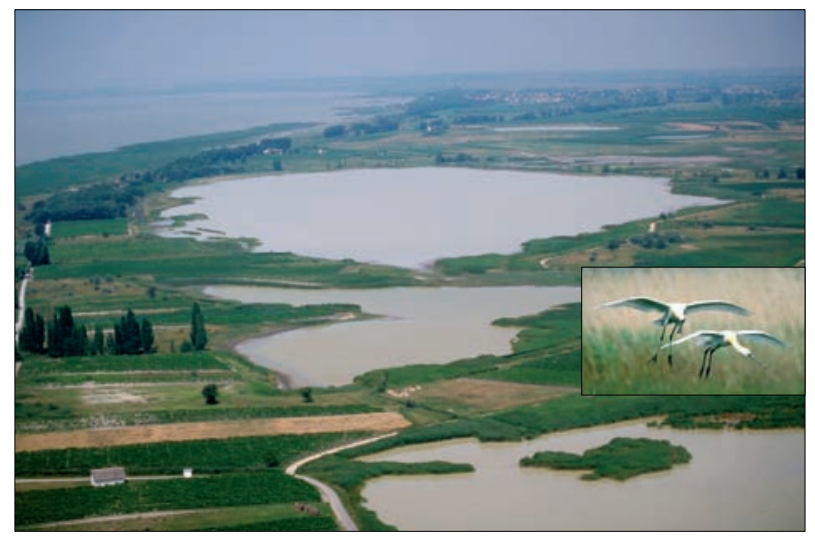

The basic fauna of the lakeshore is of European or Central European origin, including a few endemic species and a specifically prairie type fauna. The landscape setting of the lake, the bird populations, and the existence of so many biotope types in a relatively small area are the most important natural values of the site.

On the Austrian side of the border, the whole area has been a nature and landscape protection area since 1965, and the protection area has been classified a reserve under the Ramsar Convention since 1983. UNESCO proclaimed a Biosphere Reserve covering the basin of the lake in 1977. The Hungarian part of the lake and its surrounding wetlands has been a landscape protection area since 1977 and a Ramsar Area and a UNESCO Biosphere Reserve since 1989. ${ }^{13}$

The Austrian National Park Neusiedler See-Seewinkel was established in 1993. Today it covers 9,673 hectares (ha), of which 4,329 ha are designated as a core zone and 4,734 ha as a

11 Natur \& Land, supra note 4.

12 G. Dick et al., Vogelparadies mit Zukunft? Ramsar-Gebiet Neusiedler See-Seewinkel (Vienna: Umweltbundesamt, 1994).

13 Natur \& Land, supra note 4. 
conservation zone. Both zones have been taken out of private economic use. The important areas on the Austrian side of the national park are the reed beds, meadows, and grasslands as well as the salt pan meadows. The Hungarian national park, which was established in 1991, in a first phase comprised 6,400 ha of reed beds, 1,100 ha of water surface, and 670 ha of meadows and salt pans. It was significantly enlarged with the Hanság area in 1994 - today the components of the Fertő-Hanság Nemzeti Park cover more than 20,000 ha. ${ }^{14}$

In December 2001, the Fertő tó-Neusiedl See area was declared a UNESCO World Heritage Site under criterion with the justification that:

the Fertö-Neusiedler See has been the meeting place of different cultures for eight millennia, and this is graphically demonstrated by its varied landscape, the result of an evolutionary and symbiotic process of human interaction with the physical environment. ${ }^{15}$

\subsection{Political background}

The procedure of establishing a national park on both sides of the border cannot be seen as only the administrative process but has to include many years of development and negotiations that were necessary to form the park as it can be seen today. On the Austrian side, the idea had appeared now and again since the 1930s, when the Neusiedler See had been discovered as a tourist site and the natural assets were therefore seen from a new point of view. ${ }^{16}$ Between the wars, joint nature conservation efforts were not an issue, and a co-operation on the scientific level was established on a regular basis only much later, in the 1960 s. ${ }^{17}$

\subsubsection{Co-operation in water management}

Transboundary co-operation in nature conservation and water management started as early as the 1950s. ${ }^{18}$ The necessity for co-operation was as a result of the natural dynamics of the steppe lake. The lake has a size of $315 \mathrm{~km}^{2}$ but a catchment area of only $1,300 \mathrm{~km}^{2}$, which is spread across both countries. Rainfall, snow, and evaporation are the dominant factors affecting the water level in the lake, whereas small rivers, groundwater, and minor springs do not play a significant role. ${ }^{19}$ Transboundary water management turned out to be crucial for regional development in terms of flood prevention, agriculture, settlement development, and tourism. ${ }^{20}$

Before the eighteenth century the water level was subject to very high fluctuations of up to $3 \mathrm{~m}$ during only one year, which caused the flooding of vast areas of land - thus forming the salt meadows in the surrounding area. Things changed in the seventeenth century, when severe

14 Ibid.

15 International Council on Monuments and Sites, Fertö-Neusiedler Lake (Austria/Hungary), No 772rev., 2001, at http://whc.unesco.org/archive/advisory_body_evaluation/772rev.pdf (13.11.2006).

$16 \mathrm{~K}$. Hubacek and W. Bauer, Der Einsatz ökonomischer Anreizmassnahmen bei der Errichtung des Nationalparks Neusiedler See-Seewinkel, Reports R-142 (Vienna: Bundesministerium für Umwelt, Jugend und Famili, 1997).

17 Natur \& Land, supra note 4.

18 Fersch and Lang, supra note 6.

19 Herzig and Dokulil, supra note 5.

20 Fersch and Lang, supra note 6. 
interventions in form of an area-wide system of channels - built to gain more arable land - changed the water balance and the natural water flow almost completely. ${ }^{21}$

\section{Figure 6.6. Sluice of the Hanság-Channel}

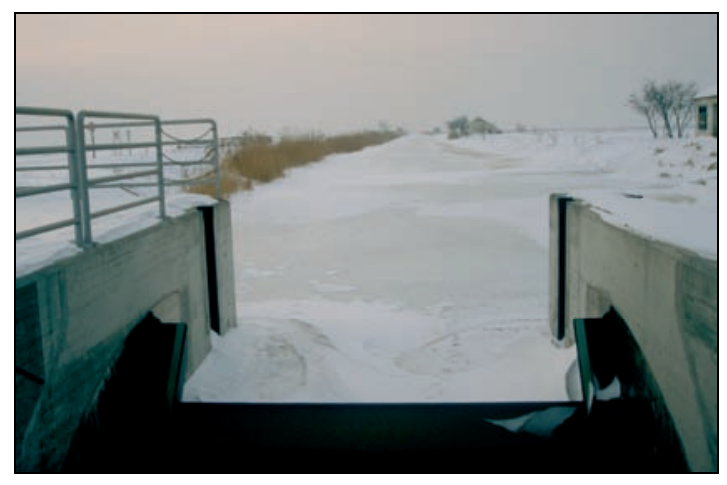

The first The first attempts to control the water level in a large scale to reduce the seasonal fluctuations were made around 1900, by constructing a long channel, the so-called Einserkanal (Fö csatorna). This channel stretches from the southeastern shore of the lake to the River Raab (Raba), some $36 \mathrm{~km}$ away. Since it is connected to deep canals that were dug especially between 1958 and 1967 (see Figure 6.6), major damage caused by floods could be avoided. A sluice was built in 1956, allowing a natural fluctuation of the water level of about 50 centimetres.

Transboundary co-operation became more essential because the sluice gate as well as the channel remained in the Hungarian part of the area, whereas some 80 per cent of the lake basin became part of Austria after World War I. From 1956 onwards, a bilateral water management commission for Lake Neusiedl was established. One of its tasks is the regulation of the sluice that was jointly renovated in $1992 .^{22}$

Although co-operation was necessary to manage the water resources of the lake, nature conservation was not considered grounds for closer co-operation for a long time. However, since the first Biologische Station on the Austrian side of the lake was opened in 1950, the outcomes of scientific research have been exchanged between Hungarian and Austrian institutions. During the years, this exchange process clearly gave an insight into the needs for active nature conservation in this sensitive area. In general, the loss of rare habitats in the cultural landscape and the threats to endangered species showed a similar need for action in both countries, including changes in traditional land-use practices, such as the abandonment of meadows and pastures, unrestricted

21 Ibid.

22 A brochure on the commissions work was published at the 40 year anniversary: Österreichisch-Ungarische Gewässerkommission, 40 Jahre Österreichisch-Ungarische Gewässerkommission zum Wohle der Wasserwirtschaftlichen Entwicklung des Grenzraums am Beispiel des Neusiedler Sees (Vienna and Budapest: Jubiläumsschrift, Bundesministerium für Land- und Forstwirtschaft, and Ministerium für Nachrichtenwesen, Verkehr-, und Wasserwirtschaft, 1996). 
growth of reeds along the shores of the lake and the soda lakes, as well as a fishery focused on introduced species, like the eel (Anguilla anguilla). ${ }^{23}$

\subsubsection{Co-operation in nature conservation}

Around the same time, Austrian nongovernmental organizations (NGOs) began to engage in activities to actively protect habitats in the meadows and around the soda lakes. ${ }^{24}$ The scope of activities ranged from the purchases of land to the reintroduction of cattle grazing. ${ }^{25}$

While calls for a national park were voiced on the Austrian side, the first attempt to co-operate across borders happened in the late 1970s. The Austrian Nature Conservation Association or Österreichischer Naturschutzbund (ÖNB) had established contacts with the Hungarian president of the regional authority for nature conservation, Zoltán Rakonczay and his colleagues. One result of this exchange of ideas was the establishment of the landscape protection area on the Hungarian side in December 1977, touching the landscape protection area on the Austrian side of the border that had been established in 1965.

On the twenty-sixth Austrian Conservation Day, in 1978, an event was organized by the ÖNB together with participants from the Hungarian side, where the ÖNB presented their manifest (Mattersburger Manifest) for transboundary co-operation for nature conservation together with documents containing concrete suggestions for a national park. These documents included key issues like area, boundaries, zonation, threats, and management plans - and they were regarded as a sound basis for the establishment of the national park in the course of the actual process in later years. ${ }^{26}$

Other attempts for a transboundary national park had been made in 1973 and 1987. In 1973, a concept had been drafted for a transboundary Europarc by the ninth European Conference for Nature and National Parks. In 1987, distinctive plans for a transboundary national park were voiced in the course of the two countries' plans to jointly run for an EXPO in 1995 that would be held in both capitals, Vienna and Budapest. ${ }^{27}$

The actual process of a transboundary national park had then been initiated in 1988 and 1989 , when the political changes created a setting for a new attempt and both the Austrian and the Hungarian Parliaments articulated their wish for realizing these plans.

\subsubsection{Co-operation in the establishment of the national parks}

The planning process of the national park was started by a bilateral commission consisting of experts from both sides and involving all stakeholders on the local level. In Austria, this meant an integration of more than a thousand families in seven villages, who were - and still are - the landowners of about $100 \mathrm{~km}^{2}$ of national park area. An evaluation of all proposed sites was undertaken on the basis of the current agricultural value of the land. These negotiations lasted

23 Stadtland/AVL and VATI KHT, supra note 2.

24 Namely, the Austrian Nature Conservation Association, WWF Austria, and BirdLife Austria (Österreichische Gesellschaft für Vogelkunde).

25 Natur \& Land, supra note 4.

26 lbid.

27 Kohler, supra note 3. 
almost four years, and they were constructively supported by the agricultural chamber. In 1992, contracts regulating compensation payments for the landowners were finally signed. ${ }^{28}$

In Hungary, the first phase of the national park was established on State land and through State law in 1991. To demonstrate the transboundary character of this protected wetland area, a joint opening ceremony was held in April 1994. The Prime Ministers of both Hungary and Austria, Boross and Vranitzky, stated their will to intensify co-operation in nature conservation - the event took place on the state border near the joint core zone of the new national park. ${ }^{29}$

When the Austro-Hungarian Planning Commission had achieved its goals in the establishment of the national park, it was agreed by both sides to continue the close co-operation in further developing transboundary park and its management plans. The Commission exists to this day, and it is active in discussing essential next steps and in taking care of using synergies in research, management, and ecotourism. The two national park directors, Laszlo Kárpáti and Kurt Kirchberger, are the heads of this Commission.

Today, knowledge, experience, and even infrastructure are shared wherever possible. Elements of the visitors' and educational programme are jointly developed on and for both sides. The mutual support during international conferences, press trips, or study trips hosted by one of the national park centres (IIImitz, Sarród) clearly indicates that these two national parks are part of one and the same wetland area.

\subsubsection{A long-term vision}

Concrete plans for a transboundary national park were voiced in 1987 when - still under the socialist system in Hungary - both countries decided to jointly run for an EXPO in 1995 that would be held in Vienna and Budapest. In the planning phase of the EXPO, the idea of a national park covering an area in two States with different political systems was considered an attractive part of the concept. Although the EXPO itself was never realized, the idea of the transboundary park was one of the very few parts of the concept that survived to become reality (Laszlo Karpati, Soproner Universität). On August 23, 1989, Hungary removed its border restrictions with Austria, so the time was ripe for realizing the dream of the transboundary national park.

The vision of the joint national park contributed to the forming of expectations. The open border allows for guests from either side of the national park to visit the other. One important method to enhance visitor interest in the park was to jointly prepare a map (for hikers and bikers) showing the whole park and providing information in German, Hungarian, and English.

When the Neusiedler Lake was declared a World Heritage Site in 2001, the value of the cultural landscape around the steppe lake was strongly underlined. Since then, the conservation activities in both national parks have been communicated to an even wider audience. This contributed significantly to a better understanding of today's nature conservation tasks.

28 Natur \& Land, supra note 4.

29 lbid. 
Due to the many natural and cultural assets of the region, the communities and businesses can attract tourism target groups outside the summer high season of July and August. This increases the sustainability of the small-scale tourism industry.

In general, it can be said that the influence of this long-term vision today is rather low, due to the short-term perspective used by decision makers - especially on the local and regional level - in terms of regional planning and nature conservation.

\subsection{Treaties and institutional arrangements}

\subsubsection{The nineteenth century}

Lake Neusiedl and all its surroundings were subject to the Hungarian monarchy until 1921. Until then, laws concerning nature had been mainly established out of agroeconomical interests, such as regulations for the conservation of birds relevant for agriculture. ${ }^{30}$ The first nature conservation law for the province of Burgenland on the Austrian side of the border was developed in 1926. ${ }^{31}$

\subsubsection{Treaty on the regulation of water management}

After World War II, the first cross-border management in the Neusiedler See region between Austria and Hungary began in 1955 with the first bilateral meetings on the management of water supply and distribution. These meetings led to joint signature of the 'treaty on the regulation of water management in the border area' and the establishment of a bilateral water management commission for Lake Neusiedl.

The treaty basically obliges both States to not negatively change, manipulate, or affect the water, the water quality, and the river channel or lakebed in any way. Changes need to be jointly agreed by the Commission in advance.

The Commission consists of four members for each country. Their tasks consist of solving problems in water supply and distribution, controlling the implementation of the joint resolutions, carrying out scientific research and hydrological monitoring programmes, and keeping the governments of both countries informed of their work. ${ }^{32}$

\subsubsection{Establishment of a national park}

Before the beginning of the planning phase for the national park, joint management through any other bilaterally agreed Codes of Conduct or agreements in nature conservation did not exist for either the Man and Biosphere Reserve or the Ramsar Site. Nevertheless, from the 1970s onwards the international nature conservation designations, such as Man and Biosphere Reserve and Ramsar Site for both sides of the Lake Neusiedl / Fertő tó, led to a certain need for homogenization of spatial plans in the area, based on an exchange of scientific data.

30 W. Hicke, Naturschutz im Burgenland. Teil II. Herausgegeben vom Amt der Burgenländischen Landesregierung Abteilung IV - Natur und Landschaftsschutz (Eisenstadt: 1996).

31 Hubacek and Bauer, supra note 16.

32 Österreichisch-Ungarische Gewässerkommission, supra note 22. 
The regular exchange of scientific data had already been established in the 1960s. Bi-annual scientific conferences (Neusiedler See Tagungen) were the first agreed and official instruments for transboundary co-operation. This not only showed clear similarities in landscape changes on both sides of the border, it also allowed for exchange on the needs for active nature conservation and protection of the environment. This had the effect that even before the national parks were established, similar methods for preservation or restoration of valuable habitats were used. ${ }^{33}$

The start of the joint planning for the national park, 1988, saw the establishment of a bilateral planning commission, consisting of experts from the local as well as the national level.

Today, the logistical, legal, and structural settings in the two national parks are still very different, which is mainly a result of fundamental differences between the countries concerning landownership patterns, involvement of the public, institutional arrangements, and administrative traditions. ${ }^{34}$ On both sides of the border, habitat management was prominent on the parks' agenda during the first decade of its existence. Much attention was given to the step-wise enlargement of protected areas, the creation of buffer zones, contractual arrangements regarding fishery and hunting, and the establishment of visitor facilities and programmes. ${ }^{35}$ Although there is little direct co-operation and no specific contract between the two parks, they act co-operatively in a spirit of 'good neighbourliness', with mutual consultation, and all activities were, and are, largely run in parallel on both sides of the border.

In Austria, the national park is subject to the 1992 National Park Neusiedler See - Seewinkel Act (NPG 1992, LGBI. Nr. 28/1993), including the modifications of 2000 (LGBI. Nr. 82/1993) that followed the enlargement of the national park's area. Although the National Park Neusiedler SeeSeewinkel/Lake Fertö tó is a transboundary national park, each country manages its protected area according to its relevant national legislation. ${ }^{36}$

The 1992 National Park Act includes the establishment of a joint Austro-Hungarian National Park Commission (Article 25) in order to harmonize the development of the parks. This Commission existed in the planning phase of the national park since 1988, and once it had achieved its function in the establishment of the national park, it could have been disbanded. However, it was agreed on both sides to continue the close co-operation and to keep the Commission for discussing essential steps and future synergies. The Commission operates under the National Park Act in Austria and the National Park's Directive of the Ministry of Environment in Hungary. It is led by both national park Directors and includes local representatives from both countries. ${ }^{37}$

The task of the Commission is the co-ordination of the planning, the creation, the establishment, and the maintenance of the national park in both States along with the handling of all affairs that are of a common interest and the information and public relations work for the transboundary national park. ${ }^{38}$

33 Fersch and Lang, supra note 6.

34 Kohler, supra note 3.

35 Ibid.

36 Hicke, supra note 30.

37 Fersch and Lang, supra note 6.

38 Hicke, supra note 30. 
The Commission on the Austrian side consists of a representative of the Federal Minister for Environment, one representative of the Federal Environmental Agency, two representatives from the provincial government, the national park Director, and the Head of the Scientific Advisory Board of the national park association Neusiedler See-Seewinkel. The Hungarian side provides four representatives of the State nature conservation agency, the national park Director, and the Head of the Scientific Advisory Board of the Hungarian Fertő-Hanság Nemzeti Park.

The members of the Commission have to determine the rules of procedure unanimously. The rules of procedure must include the terms for the extent and manner of the joint counselling sessions. The constituent meeting has to be summoned by the provincial government. The Federal Minister of Environment must be heard in all meetings. The administrative work of the Commission is to be done by the responsible department in the environmenal agency of the provincial government (Article 25 NPG 1992). ${ }^{39}$

Instead of a joint management plan, it was established that there was to be close permanent cooperation of the national park's staff in all sectors that were of common interest, such as management of the cultural landscape in the conservation zone, visitor management, nature education, and public relations as well as data exchange in research studies and inventories.

\subsubsection{Establishment of a World Heritage Site}

For the World Heritage Site, a joint management plan was published in 2004. The Management Plan is implemented by the two World Heritage management organizations in Austria and in Hungary. The review is organized and directed by the Austrian and Hungarian World Heritage Fertő / Neusiedler See management organizations that constitute the Management Forum. Transparent, readily available indicators with a high informative value are used for the monitoring process. As a methodological tool, the Criteria Catalogue for Ecologically Particularly Sensitive Areas is recommended in the management plan and has already been successfully tested for the Neusiedler See region on both the Austrian and Hungarian sides of the border.

The implementation process is monitored according to an Action Plan (integrated into the management plan), which has short- and medium-term objectives for sustainable nature and landscape protection, protection of cultural assets, sustainable agriculture, regional development, and environmental protection. Successfully implemented measures and any shortcomings relating to the implementation of the Plan are to be brought to the attention of the General Assembly of the World Heritage management organizations (held annually). There is a close co-operation of the World Heritage Site officers of both countries.

The management plan must be subjected to a review every six years. Broadly based dissemination of information about the plan via schools and other educational establishments, public information events, publications, the media, and the Internet is thus a major task of the World Heritage management organizations. On the Hungarian side the research projects, studies,

39 Ibid. 
and monitoring are supported by ad hoc subsidies from the Hungarian National Committee of World Heritage. ${ }^{40}$

\subsection{Lessons learned in transboundary co-operation}

In the national park, joint decisions on key steps for planning on the local level have led to sound conservation management. In general, more emphasis had been put on the integration of local stakeholders and less on national legal framework, especially at the beginning of decision-making processes. Avoiding monosectoral activities - e.g., by nature conservation NGOs - during the planning period led to broader participation of stakeholders.

The planning of the transboundary World Heritage Site built on the previously established relationships and co-operation. Working groups including all relevant stakeholders were established for developing the joint management plan. A well-moderated series of conferences for the presentation on the agreed objectives communicated the results to the general public. To date, the stakeholders in the World Heritage area are organized in both countries separately in World Heritage associations.

The mutual support in media work and public relations on both sides of the border must not be underestimated in its role in facilitating transboundary co-operation. In the case of the Neusiedler Lake, interest in transboundary issues and media relations was facilitated by the foundation of an EUREGIO co-operation of the Austrian district of Burgenland and the Hungarian counties of GyörMoson-Sopron, Vas, and Zala in 1998. Since then, the regional media has intensified its cross border co-operation, and expert working groups from both sides meet regularly within the joint EUREGIO. This has resulted in a much higher interest by the media in national park topics and transboundary co-operation projects. ${ }^{41}$

Very often, media reports on the region are written or produced by outsiders, who do not have the insight into the development process and the real obstacles in the region - which leads to the wrong messages being communicated. To avoid this, local public relations and media work are of high importance. Nevertheless, transboundary co-operation does not so much depend on joint or harmonized public relations, if the political and socioeconomic frameworks are too different. The national parks have made it their task to foster a new transboundary regional identity, based on natural assets, which can only be reached if all sectors of society are - at least partly - involved in the general process on the local level. In this context, the language barrier is still underestimated.

Both partners are proactive partners in the matter of fundraising for transboundary projects, such as the European Union co-funded project on traffic development in sensitive areas, which was driven by the respective Ministries in Vienna and Budapest. One output of this project was a solar boat for a maximum of 25 passengers that serves as an excursion boat on the lake for educational and public relations purposes.

Nature conservation proves to be a good mechanism for initiating and intensifying transboundary co-operation: compared with other sectors, there is almost no risk of

40 Stadtland/AVL and VATI KHT, supra note 2.

41 Fersch and Lang, supra note 6. 
misunderstanding, and the key actors are not suspected of being focused on personal economic advantages.

\subsection{Effect on nature conservation}

Intensification of transboundary co-operation in the 1980s mitigated the risks of unsustainable development in tourism, settlement extension, agriculture, and traffic infrastructure. Since then, remarkable progress has been made in environmental protection on the Hungarian side (e.g., in wastewater treatment), based on the experience of the Austrian side.

The removal of the core areas from economic use was carried out effectively on both sides of the border, with each national park following its own administrative process. On the Hungarian side, ecosystem restoration figured prominently among the management tasks. ${ }^{42}$ Keeping the socalled conservation zones intact is more challenging, as they are largely made up of ancient cultural landscapes, which means that they have to be maintained through the continuation of traditional forms of land use. The revival of these methods is a major task for the park authorities.

On the Hungarian side, national park staff are responsible for tending the land according to conservation management objectives. The national park on the Austrian side lets out land for use on a contractual basis but strictly enforces that such land use is beneficial for conservation.

In terms of economic development, the protective effect of the border persisted into the 1990s, since Austria joined the Schengen-countries within the European Union in 1995 and the borders were again more restrictively protected. ${ }^{43}$

Ongoing information exchange on the EUREGIO level, among the national park's authorities, and the World Heritage Site preclude problematic developments that could threaten the natural assets on one side of the border. Examples of this include information through the EUREGIO working group on a planned mining project in Hungary, which led to protests on the Austrian side in 2003; the demands for a crossborder cycle trail close to the national park's nature zone, which was jointly rejected by both directorates in 2004; and plans for a waste treatment plant in the southern part of the region on the Austrian side in 2006, which caused protests on both sides of the border.

\subsection{Dispute resolution processes}

The question of dispute resolution has to be treated separately for the Hungarian and the Austrian sides, since there has been virtually no public involvement or participation on the Hungarian side before or during the process of establishing the national park; the same is true for the World Heritage Site application. This is mainly due to the fact that no private landowners were involved on the Hungarian side. Whereas no human use had been tolerated within the military zone along the shore of the lake, the other land had been, and for the largest part still is, owned by the State. Only

42 Kohler, supra note 3.

43 Ibid. 
those local families who had stayed landowners until 1948 were in a position to claim back their former property. ${ }^{44}$

Quite to the contrary, the population surrounding the Lake Neusiedl on the Austrian side had been very much involved in the process of nature conservation and had actively articulated their opinions for or against a national park whenever challenged. Strong disputes arose on the Austrian side between 1988 and 1992, especially concerning the zoning system of the national park. ${ }^{45}$ The establishment of the national park, for example, meant the prohibition of converting meadows to fields. Due to the fact that livestock was a diminishing generator of income, the designation of land for a national park was considered a loss-making business.

This attitude changed in the 1980s, when farmers realized they were competing with the development of agro-industrial business. ${ }^{46}$ The dispute was finally solved by the co-operation of the planning authority with the chamber of agriculture. The planning authority began negotiations with the stakeholders about existing and future contracts concerning the property rights of the land that was designated for the national park. The Chamber of Agriculture agreed on financial compensation based on the outcome of these negotiations.

The authorities suggested establishing local stakeholder associations of landowners in the Austrian part of the Neusiedler Lake as a constructive counterpart in further disputes. Soon after, a local association of landowners was founded, and a Committee for further negotiations was nominated. The association of landowners and the planning authority could then agree on renting contracts offered to the landowners based on free will.

In addition, the park's administration successfully pointed out the economic advantages of preserving nature for ecotourists. The plans for building a Visitors Centre and for developing infrastructure along the cycling and hiking roads were presented at an early stage of the process.

The importance of independent and rigorous environmental impact assessment as well as scientific studies for dispute resolution has been found to be very high in general, especially on the management level. For the public discussion of sensitive issues, the scientific studies have to be carefully and soundly 'translated' in order to avoid misunderstandings.

In Austria, the role of public participation on the local level is naturally very high in the national park area, since the park is established on the land of private landowners. This assures a strong interest in the happenings in the national park and the activities of its authority, and it triggers discussions and participative involvement in the whole surrounding area. The national park management fostered this participation in environmental education issues by including freelancers and inhabitants into the tour programmes, which are up to 90 per cent covered by non-national park staff. Moreover, all (tourist) services that are offered by local family enterprises are not in competition with the national park authority (e.g., bike rental, commercial boat trips, horse coach

44 K. Kirchberger and L. Karpati, The Development of Cooperation and Land Use around Lake Neusiedl/Fertö, in Terry, Ullrich, and Riecken, supra note 6, pp. 101-109.

45 Hubacek and Bauer, supra note 16.

46 Kohler, supra note 3. 
tours). This approach clearly supported the acceptance of the national park in the surrounding villages.

This strategy has proved successful in the last years, and step by step it is regarded as a good example in management planning on the Hungarian side as well.

\subsection{Role of NGOs, international organizations, and funding bodies}

Private initiatives as well as the efforts of nongovernmental organizations laid the foundations for the national park not only in the political sense. It can be said that without the efforts of many people who secured areas by keeping them from the intensification of land use, the national park area would not have been as extensive and valuable as it is today. Many meadow areas in the vicinity of the salt pans were protected by private funds. These areas form large parts of the national park area today.

This is especially true on the Austrian side, where the ÖNB played a major role in conservation in the Neusiedler Lake region. The ÖNB was founded in 1913, and the establishment of national parks was a central point on its agenda. Long before the foundation of national parks was on any political agenda, Dr. Lothar Machura, a zoologist, promoted the idea of a national park. The ÖNB took up this idea in 1936, when they rented 200 ha of land in the surroundings of the village of Illmitz for the duration of 10 years. This initiative was supported by another project, which included the establishment of a scientific centre close to the lake in 1938. The ÖNB provided not only the impetus for both these initiatives but also a significant amount of financial aid to realize the attempt. ${ }^{47}$ During World War II, many conservation efforts were interrupted, but they resumed in the late 1940s.

In the late 1970s, the ÖNB established contacts with Hungarian conservationists, mainly based in the University of Sopron. The idea of a transboundary national park was put on a political agenda in the course of planning an Austro-Hungarian EXPO for 1995.

In order to reduce irrational fears of a national park, the Austrian ÖNB had organized an information trip to already existing national parks in Luxembourg, France, and Germany in 1979. Authorities from the district and the village level went on the trip, which also included an official conference in Strasbourg on questions concerning a national park. The trip led to an understanding that nature conservation does not necessarily harm tourism interests. ${ }^{48}$ Other significant events included a symposium for nature conservation held in Apetlon 1979 and a day for nature conservation in the Burgenland district. ${ }^{49}$

In 1961, the World Wildlife Fund (WWF) was founded, with an Austrian branch established in 1963. The efforts to protect the Neusiedler Lake region were in the centre of the organization's efforts for nature protection. A foundation was established, and international funds were obtained in order to rent land for conservation. The Lange Lacke, a big salt pan, was the focus of a longterm project. A meadow area of 420 ha was leased for 20 years (1965-1985). When funding had to

47 Natur \& Land, supra note 4.

48 lbid.

49 lbid. 
be raised on the national level over the years, this approach became more and more difficult to sustain. But WWF managed to join efforts with other conservation projects and organizations that were established in the region. The area of the national park today includes many of the areas that were formerly rented by WWF. Today WWF has found its role in the environmental education sector, which began by concentrating on tourists and site visitors, but has now become rooted in the education of local inhabitants, adults as well as youth and children. The strategy for the coming years includes strengthening the transboundary co-operation in environmental education. ${ }^{50}$

Both organizations were involved in the heated discussions that took place between farmers, landowners, nature conservationists, and the authorities, which may have sometimes been counterproductive for negotiations on the local level. But they also played a big role in mitigating threats to the Neusiedler Lake in the form of proposed infrastructure projects in the 1960s and 1970 s, such as a concrete bridge across the middle of the lake, or the efforts of private landowners to extend the land used as agricultural fields. In addition, ÖNB and WWF have achieved a change in attitude through their long years of continuous awareness raising and public relations work. ${ }^{51}$

International organizations were important especially in the administrative process of establishing the national park with respect to their influence on the criteria for protected areas categories, which pressured the authorities to take zonation and management models as a basis for implementation.

\subsection{Conclusion}

It can be said that this transboundary national park was planned and established from the bottom up. The support of key stakeholders on the local level for the national park led to a visible and stable co-operation of the local politicians on both sides. This co-operation on the ground has turned out to be a precondition for successful lobbying on the national level.

The interplay between national interests and transboundary governance to date has not created difficulties, since both countries follow their own administration and legal framework for the implementation of the aims of the national park. The past 10 years of co-operation have shown that different legal frameworks can be overcome if both sides have a clear will for constructive teamwork in everyday working life.

50 Kohler, supra note 3.

51 Natur \& Land, supra note 4. 


\section{The Antarctic Protected Area Approach}

\section{Lyn Goldsworthy ${ }^{1}$}

\section{Alan D. Hemmings ${ }^{2,3}$}

There are few places in the world where there has never been war, where the environment is fully protected and where scientific research has priority. But there is a whole continent like this - it is the land the Antarctic Treaty parties call ' a natural reserve, devoted to peace and science.' At the southern end of our world, those who share the challenges of distance and cold to visit the ice-bound continent have developed a tradition of warm cooperation. Such cooperation, unique on this scale, is cemented by the Antarctic Treaty.

XXIII Antarctic Treaty Consultative Meeting, Peru, May/June 1999

\subsection{Introduction}

'Antarctica' can mean many things and several areas. For this chapter we take it to mean the entire area south of the Antarctic Convergence, including the continent, surrounding islands, and the 'Southern Ocean'. We take a traditional view of the Southern Ocean as the body of water south of the Antarctic Convergence, rather than the technical definition of it as comprising only those waters south of 60 degrees South latitude, which was adopted by the International Hydrographic Office in 2000.

This is a huge area, some 10 per cent of the planet, and a great engine that drives global circulatory systems. The continent at its heart is around 14 million square kilometres in area and claims a raft of superlatives - the coldest, driest, windiest continent on earth, with the harshest climate, the highest average elevation, is technically our largest desert, contains 70 per cent of the world's fresh water (primarily locked up as ice), and has no permanent human residents. It is also the least polluted (but sadly not unpolluted) continent. The Southern Ocean as we define it covers

1 Lyn Goldsworthy is a consultant providing advocacy, strategic planning, and policy advice to nongovernmental organizations. She is a Senior Advisor to the Antarctic and Southern Ocean Coalition (ASOC) and has a long history of involvement in Antarctic issues. Goldsworthy has attended most Antarctic Treaty Meetings since 1985 as the nongovernmental representative on the Australian delegation, served four terms on the Australian Government's Antarctic Science Advisory Committee between 1988 and 2004, and has visited Antarctica three times to undertake environmental assessments. She was awarded an Order of Australia (Member) in 1993 and given the New Zealand Antarctic Society Trophy in 1991.

2 Dr Alan D. Hemmings is a consultant on environmental policy and governance in the polar regions, Senior Fellow at Gateway Antarctica Centre for Antarctic Studies and Research at the University of Canterbury, Christchurch, New Zealand, and Research Associate at the Institute of Antarctic and Southern Ocean Studies at the University of Tasmania, Hobart, Australia. He is a Senior Adviser to ASOC and a former Chair of IUCN's Antarctic Advisory Committee. He has attended Antarctic Treaty Consultative Meetings and meetings of the Convention for the Conservation of Antarctic Marine Living Resources since 1989 and currently serves on the Australian Government's Antarctic Science Advisory Committee.

The authors would like to acknowledge the contribution of their ASOC colleagues over many years. 
some 20 million square kilometres of cold, stormy, and very deep ocean, separated from northern oceans by the Antarctic Convergence and supporting historically vast populations of marine life from phytoplankton, krill, squid, and finfish to seabirds (including charismatic groups such as the penguins and albatross), seals, and whales.

The Antarctic has attracted an unprecedented range of broad-level and specific protection and management measures. Although differing from the more familiar examples of multilateral transboundary co-operation, these measures, collectively coordinated through the Antarctic Treaty system (ATS), can still properly be considered 'transboundary'. Rival territorial claims have been contained under the terms of the Antarctic Treaty and the wider Antarctic Treaty system, which have prohibited mining and military activity on the continent, declared the region a 'natural reserve devoted to peace and science', encouraged co-operative scientific programmes and the sharing of scientific data, and provided mechanisms for environmental management, which from its first iterations included particular attention to area protection. It is far from perfect of course, but there are foundations here if the will can be found.

This great realm is many things, but it is still - despite the historic and current assaults upon it from both local and global phenomena - the greatest wilderness on our planet. It is also one of the very few places on our common earth where humans have not butchered each other. The region faces many difficulties, but there is more reason for hope in relation to human engagement with Antarctica than in many other places.

The first known proposal for special area protection for a part of the Antarctic is that of Sir Douglas Mawson's efforts in 1915 to gain designation of the sub-Antarctic Macquarie Island as a wildlife sanctuary. ${ }^{4}$ However, it was not until 1960 that the first formal proposals were put forward. ${ }^{5}$

In 1950, at the height of cold war tensions, a group of American and British scientists proposed an international scientific collaboration centred around the polar regions, building on the success of two previous international scientific polar initiatives. ${ }^{6}$ From their efforts emerged the International Geophysical Year from July 1957 to December 1958, involving 12 States participating in an unprecedented co-operative scientific programme across the Antarctic. The desire to maintain and build on the international co-operation established during this programme prompted those 12 States $^{7}$ to negotiate a treaty.

The Antarctic Treaty came into force in 1961 and put aside political and legal differences to ensure 'in the interests of all mankind that Antarctica shall continue forever to be used exclusively

4 P.M. Selkirk, R.D. Seppelt, and D.R. Selkirk, Sub-Antarctic Macquarie Island: Environment and Biology (Cambridge, UK: Cambridge University Press, 1990).

5 Scientific Committee for Antarctic Research, SCAR Bulletin, vol. 6 (1960), pp. 66-75.

6 D.O. Belanger, Deep Freeze: The United States, the International Geophysical Year, and the Origins of Antarctica's Age of Science (Boulder, CO: University Press of Colorado, 2006), p. 30. The first International Polar Year (or IPY) was a collaborative, international research programme focused on the polar regions in 1882-1883. It was initiated by Karl Weyprecht, an Austro-Hungarian navy officer who unfortunately died before it occurred. Fifty years later - in 1932-1933 - a second IPY was held.

7 The Treaty was adopted by the seven states who have asserted territorial claims to parts of the continent Argentina, Australia, Chile, France, New Zealand, Norway, and the United Kingdom - and five others: Belgium, Japan, South Africa, the Soviet Union, and the United States (the last two maintaining a basis to claim). These were the original 12 'Consultative Parties'. 
for peaceful purposes and shall not become the scene or object of international discord'. ${ }^{8}$ The Treaty applies to the area south of 60 degrees $S$ and covers the Antarctic continent and its islands.

The differing views of States with respect to the scope of the Treaty in relation to the marine area south of 60 degrees $S$ led to the adoption of a separate legal instrument, the Convention for the Conservation of Antarctic Seals (CCAS), to manage any resumed sealing industry in the Antarctic marine environment, and later to the adoption of the Convention for the Conservation of Antarctic Marine Living Resources (CCAMLR) to regulate marine harvesting. A Convention on the Regulation of Antarctic Mineral Resource Activities (CRAMRA), adopted in 1988, was subsequently abandoned. ${ }^{9}$ Most recently, in 1991, Antarctic States adopted the Protocol on Environmental Protection to the Antarctic Treaty (the Madrid Protocol). The cluster of Antarctic instruments and the institutions and subsidiary agreements resulting from these have been termed the Antarctic Treaty system.

The Antarctic Treaty enables States that have conducted 'substantial scientific research activity there, such as the establishment of a scientific station or the dispatch of a scientific expedition'10 to become decision-making Consultative Parties. There are currently 46 Parties to the Antarctic Treaty, of which 28 are Antarctic Treaty Consultative Parties (ATCPs). ${ }^{11}$ The ATCPs set policy by adopting, by consensus, Measures, Decisions and Resolutions at their annual meetings (Antarctic Treaty Consultative Meetings, or ATCMs).

This chapter seeks to show that the Parties to the Antarctic Treaty, Madrid Protocol, and CCAMLR have embraced a broad-level management approach for protection of natural resources within the Antarctic area. However, despite considerable effort and energy in discussing theoretical frameworks and approaches, it suggests that the Parties have struggled to ensure effective implementation of their various measures and have yet to translate effective specific area and value protection into 'on-ground' representation in any substantive manner.

\subsection{Broad-level management - the Antarctic Treaty System}

The ATS provides, at least in a declaratory sense, a level of protection that generally exceeds that existing for other continents or regions. This is perhaps not surprising, since it is the only substantial part of the planet that is governed collectively and since human activity there is recent and until 20 years ago slight by comparison with other areas. ${ }^{12}$

8 Preamble to the Antarctic Treaty.

9 New Zealand, which led the negotiations and would have become the depository state, says it is 'unlikely to enter into force as superseded by the Environmental Protocol'; see www.mfat.govt.nz/ForeignRelations/1-Global-Issues/Antarctica/1-New-Zealand-Relationship-with-Antarctica/antarctictreatysyst.php, accessed 16 January 2008.

10 Article IX para 2, Antarctic Treaty.

11 Report of the Depository Government of the Antarctic Treaty and its Protocol (USA) in accordance with Recommendation XIII-2. Annex F, Final Report of the Antarctic Treaty Consultative Meeting, 2007.

12 This has now changed, see: A.D. Hemmings, Globalisation's Cold Genius and the Ending of Antarctic isolation, in L.K. Kriwoken, J. Jabour, and A.D. Hemmings (eds), Looking South: Australia's Antarctic Agenda (Annandale, Australia: Federation Press, 2007). 
The keystone for broad-level management is the Antarctic Treaty. Article I declares that Antarctica shall be used for peaceful purposes only. It prohibits military activities (other than logistic support for peaceful scientific research) and weapons testing. Article II enshrines freedom of scientific investigation and co-operation, Article III encourages exchange of scientific data and scientists, and Article IV 'freezes' positions in relation to territorial sovereignty and denies validity to the declaration of new claims or enlargement of existing claims for the duration of the Treaty. Article $\mathrm{V}$ bans nuclear explosions and disposal of radioactive wastes (at least pending the conclusion of any international agreements that allow these). Building on the pre-existing territorial claim boundaries, Article VI designates the area of application of the treaty (and as a consequence all subsequent ATS treaties, with the exception of CCAMLR) as the area south of 60 degrees south latitude. Article VII establishes freedom of access to all parts of Antarctica and allows on-the-spot inspections of stations and facilities, including ships and aircraft, by observers designated by any Consultative Party, and it requires advance notice of Antarctic expeditions. Jurisdiction over observers and exchange personnel is addressed in Article VIII by making them subject only to the jurisdiction of the Party of which they are nationals. Article IX establishes the mechanisms whereby Parties may meet to consider issues and further measures, and the remaining article address generic instrument issues.

Subsequent instruments of the ATS have developed the practical management tools for specific types of activity. These instruments can be seen as responses to emerging resource access issues, sequentially concerning seals (CCAS), fishing (CCAMLR), and minerals (CRAMRA) before resolving the last and establishing generic environmental standards through the Protocol.

The ATS operates largely on the basis of two annual two-week meetings: an Antarctic Treaty Consultative Meeting, where obligations under the Antarctic Treaty and Protocol (and reporting under CCAS) are addressed, and a meeting of the Commission for the Conservation of Antarctic Marine Living Resources (CCAMLR Commission). The former is hosted sequentially by Antarctic Treaty Consultative Parties and supported by an Antarctic Treaty Secretariat based in Buenos Aires; the latter is always held in Hobart, Tasmania, where a dedicated CCAMLR Secretariat is based.

Decisions are taken by consensus. This has the advantage of delivering broad ownership of decisions and provides reassurance for Parties (perhaps particularly the claimants) that national interest can, in the final resort, be guaranteed in the face of unwelcome proposals. But of course it has both raised the bar in terms of getting agreement and sometimes risks lowest-commondenominator outcomes. Critically, it poses difficulties in those instances where one of the States whose agreement is required is actually the source of the concern. ${ }^{13}$ In these instances, a self-

13 On problems in relation to Commission members seen as regularly breaching CCAMLR obligations, see A.D. Hemmings, Managing the Southern Ocean - The 2003 Meeting of the Commission for the Conservation of Antarctic Marine Living Resources, New Zealand Yearbook of International Law, no. 1 (2004), pp. 202-203. 
serving veto is provided. The 20 -year process of agreeing on an Antarctic Treaty Secretariat was in large part due to problems getting a couple of States to join consensus. ${ }^{14}$

The Antarctic Treaty is essentially a geopolitical instrument designed to address the tensions related to territorial claims in Antarctica and the broader tensions of the cold war. As such, there are no specific provisions in the treaty relating to protection of the environment per se, although clearly the prohibitions of military measures and nuclear activities were significant both environmentally and in shaping the character of the evolving regime in a manner that would be more favourable to environmental protection.

The roots of modern environmental protection in Antarctica appeared in an early ATCM Recommendation, the Agreed Measures for the Conservation of Antarctic Fauna and Flora. ${ }^{15}$ The Agreed Measures declared the Antarctic Treaty area a Special Conservation Area, set down general rules concerning the minimization of harmful interference with fauna and flora, and established the new category of Specially Protected Species, to which the Ross Seal Ommatophoca rossii and fur Seals of the genus Arctocephalus were assigned, and the area category of Specially Protected Areas (SPAs). ${ }^{16}$ The Agreed Measures were subsequently updated and then, again amended and absorbed into the Protocol in 1991, where they form Annex II Conservation of Antarctic Fauna and Flora.

The Convention for the Conservation of Antarctic Seals was adopted in 1972 by the 12 ATCP members at the time when it was thought that a commercial seal harvest might be resumed in the Antarctic. It came into force in 1978. CCAS established sealing zones and seasons, set limits on the number of seals to be taken, prohibited the killing of the southern fur seal species - Ross and Southern Elephant seals (Mirounga leonina) - and designated reserves where no sealing was permitted. Enforcement of the agreed conservation measures relies on self-policing by the now 16 Contracting Parties. ${ }^{17}$ No commercial seal harvesting has been held since the CCAS was adopted.

CCAMLR was adopted in 1980 in response to depletion of some fish stocks as a consequence of heavy fishing and an increasing concern about the impact of the growing unregulated krill fishery on the entire food web of the Antarctic. ${ }^{18}$ It aimed to provide a management system that allowed

14 See P. Vigni, The Secretariat of the Antarctic Treaty: Achievements and Weaknesses Three Years after Its Establishment, in G. Triggs and A. Riddell (eds.), Antarctica: Legal and Environmental Challenges for the Future (London: British Institute of International and Comparative Law, 2007).

15 Recommendation III-VIII adopted at the Third Antarctic Treaty Consultative Meeting, Brussels, 1964. Available at: www.ats.aq/dev/AS/info_measures_listitem.aspx?lang=e\&id=35, accessed 1 February 2008.

16 This allowed for the designation of important biological sites as Specially Protected Areas (SPAs), Sites of Special Scientific Interest (SSSIs), and Historic Sites and Monuments (HSMs). Other protected area concepts were proposed by the Treaty Parties - Specially Reserved Areas (SRAs), Multiple Use Planning Areas (MPAs), Marine SSSIs (MSSSIs), and Areas of Special Tourist Interest (ASTIs), but none of these were adopted at that time.

17 Argentina, Australia, Belgium, Brazil, Canada, Chile, France, Germany, Italy, Japan, Norway, Poland, Russian Federation, South Africa, United Kingdom, and United States. New Zealand signed the convention but has not ratified it.

18 The Antarctic food web is extremely short and most species depend either directly or indirectly on krill. See for instance I. Everson, Role of Krill in Marine Food Webs, the Southern Ocean, in I. Everson (ed.), Krill: Biology, Ecology and Fisheries, Fisheries and Aquatic Resources, Series 6 (Oxford: Blackwell Science, 2000). 
fishing activities within a holistic ecosystem-approach, taking into account the effects of fishing on dependent and related species as well as the ecosystem as a whole. The term 'conservation' was taken to include 'rational use'. The Commission to the Convention was further charged with conserving marine life, preventing decreases in populations of harvested species to levels below stable replacement, and restoring depleted populations to stable recruitment levels. Since its entry into force, CCAMLR has attracted interest from fishing States not necessarily interested in the Antarctic continent, and it now has a slightly different membership to that of the Antarctic Treaty, including the European Community. ${ }^{19}$ The opportunity for regional economic integration organizations, such as the European Community, to join CCAMLR is a significant departure from previous and subsequent ATS instrument arrangements. ${ }^{20}$

There is, as a result, something of a 'disconnect' in the focus of conservation management on the continent and on the surrounding oceans, and this has particularly hindered the development of protected areas with oceans and land components.

With growing interest in the potential mineral wealth of the continent in the 1980s, Antarctic Treaty States turned their attention to the regulation of minerals activities. Believing that mining was inevitable and that agreement on regulation prior to commencement of such activity was necessary, Treaty Parties negotiated the Convention on the Regulation of Antarctic Mineral Resource Activity. This was a time of considerable membership growth for the Antarctic Treaty, with many States joining so that they could be part of the perceived mineral grab. ${ }^{21}$ The text was completed in 1988, but following intense pressure from environmental groups to place the wilderness, scientific, and international collaboration values of the region above any benefits that may arise from mineral extraction, public pressure and key ATCPs forced the abandonment of the Convention in favour of a more overtly environmental focus for the Antarctic region.

The Protocol was adopted on October 4, 1991, and entered into force on January 14, $1998 .{ }^{22}$ It provides the framework for an integrated comprehensive environmental regime for the Antarctic continent and forms the basis for all current protection measures for the continent and for some

19 CCAMLR members include Namibia, the European Union in its own right, and Antarctic Treaty Consultative Parties (ATCPs) Argentina, Australia, Belgium, Brazil, Chile, China, France, Germany, India, Italy, Japan, New Zealand, Norway, Republic of Korea, Poland, Russia, South Africa, Spain, Sweden, United Kingdom, Ukraine, United States, and Uruguay. Signatories include ATCPs Finland, Bulgaria, Netherlands, and Peru, non-Consultative Parties Greece and Canada, and Vanuatu, Mauritius, and Cook Islands, which is currently applying for Commission status.

20 It is not possible with the Protocol, nor would it have been with CRAMRA, both of which post-date CCAMLR.

21 At the June 1988 signing of the Convention for the Regulation of Antarctic Mineral Resources, there were 19 Antarctic Treaty Consultative Parties, with Brazil, China, Germany, India, Italy, and Uruguay all joining between 1982 and 1988. Prior to this time, Poland was the only additional nation to seek consultative status, achieving this status in 1977. Between mid-1988 and the end of 1990, a further seven nations become Consultative Parties: Finland, Ecuador, Republic of Korea, Netherlands, Peru, Spain, and Sweden.

22 Twenty-six ATCPs negotiated the Madrid Protocol - Argentina, Australia, Belgium, Brazil, Bulgaria, Chile, China, Ecuador, Finland, France, Germany, India, Italy, Japan, Netherlands, New Zealand, Norway, Peru, Russia, Republic of Korea, Spain, South Africa, Sweden, United Kingdom, Uruguay, and United States. Many had joined in order to participate in the expected mining rush on the continent. 
measures in the marine environment. The Protocol designates Antarctica as a 'natural reserve devoted to peace and science'.

It aims to build on and strengthen the Antarctic Treaty's effectiveness in protecting the Antarctic Treaty area. It outlines binding environmental principles to be applied to all human activities in the region, while giving priority to scientific research. It draws heavily from the Agreed Measures and elements of the abandoned CRAMRA regime. ${ }^{23}$ The Protocol specifically bans mineral resource activities, other than for scientific research, for at least 50 years, unless the Consultative Parties involved in the negotiation of the Protocol unanimously agree otherwise and have also adopted a binding legal regime governing mining activities. Beyond 50 years, at least two-thirds of the Consultative Parties who negotiated the Protocol must agree to lift the ban.

The Madrid Protocol and its six Annexes provide a legally binding set of conservation measures applicable to most activities in the Antarctic Treaty area:

Annex I - Environmental Impact Assessment (EIA) - requires prior EIA for any proposed activity subject to the advance notification provisions of Article VII(5) of the Antarctic Treaty. Three levels of assessment are established, hinging on the concept of 'minor or transitory impact'. A preliminarystage evaluation (termed in some implementing legislation a Preliminary Assessment or Preliminary Evaluation) suffices if it is determined that the proposed activity will have less than a minor or transitory impact. If some greater impact is indicated - either through the Preliminary Stage, or a priori - then an Initial Environmental Evaluation or, if more than a minor or transitory impact is seen as possible, a Comprehensive Environmental Evaluation is required. ${ }^{24}$

Annex II - Conservation of Fauna and Flora - replaces and strengthens the Agreed Measures and includes regulations for protecting native fauna and flora and for restricting entry of non-native plants and animals.

Annex III - Waste Disposal and Waste Management - updates existing recommendations and specifies methods for the disposal and/or removal from the Treaty area of all kinds of waste from both expeditions and station activities. Importantly, it increases reliance on recycling and reduces the waste stream by decreasing the amount of packaging that is brought into the Antarctic. Parties are required to remove all waste materials regularly.

Annex IV - Prevention of Marine Pollution - drawing heavily from the International Convention for the Prevention of Pollution from Ships, as amended in the Protocol of 1978 (MARPOL 73/78), addresses ship discharges of oil, noxious liquid substances, garbage, and sewage and sets out guidelines for vessel retention capacity and for emergency response and preparedness.

Annex V - Area Protection and Management - provides for the designation of an area as an Antarctic Specially Protected Area (ASPA), a category into which pre-Protocol protected areas

23 CRAMRA saw, inter alia, the first consideration of intrinsic, wilderness, and aesthetic values, concepts now found in the Protocol - see A.D. Hemmings, Cumulative Impact on Antarctic Intrinsic, Wilderness and Aesthetic Values, in M. De Poorter and J.C. Dalziell (eds.), Cumulative Environmental Impacts in Antarctica: Minimisation and Management (Gland, Switzerland: IUCN, 1996).

24 For a more substantial explanation of the EIA system under the Protocol, see A.D Hemmings and R. Roura. A Square Peg in a Round Hole: Fitting Impact Assessment under the Antarctic Environmental Protocol to Antarctic Tourism. Impact Assessment and Project Appraisal, vol. 21 (2003), pp. 13-24. 
have been systematically converted and which, critically, allows the designation of 'any marine area' or an 'Antarctic Specially Managed Area' (ASMA), along with associated management plans.

Annex VI - Liability Arising from Environmental Emergencies - lays out preventive measures, contingency plans, response actions, and liability schemes to assist in addressing any accidental event that threatens the Antarctic environment.

Annexes I to IV entered into force with the Protocol in 1998. Annex V entered into force in May 2002, and thus the case history of actual practice is more limited than with the rest of the Protocol. The sixth Annex, dealing with liability arising from environmental emergencies, was adopted by the 28th ATCM in June 2005 and is not yet in force.

\subsection{Development of specific area management and protection}

\subsubsection{Early concepts}

Antarctic Treaty Parties initially met once every two years (since 1991, they have met every year) at Antarctic Treaty Consultative Meetings to exchange information and take decisions. All decisions are taken by consensus, as noted earlier. (Decisions were called 'Recommendations' until 1995, when three separate categories were introduced: Measures, which provide legally binding commitments (such as designation of protected areas and their management plans); Decisions, which cover administrative matters such as Rules of Procedure; and Resolutions, which are hortatory (guidelines are generally adopted in this manner).

The first recorded formal discussion of the application of conservation management measures within the Antarctic Treaty area for the purpose of protecting native species and setting aside specific areas was within the Scientific Committee on Antarctic Research (SCAR) ${ }^{25}$ at its third meeting in 1959. That meeting concluded that protection of native mammals and birds and the declaration of representative areas of natural environments was an urgent need and that 'the impact of man' and introduced animals on the Antarctic environment should be assessed'. ${ }^{26}$ The seventh General Assembly of the International Union for Conservation of Nature and Natural Resources (IUCN), ${ }^{27}$ held the following year in Warsaw, also discussed protected areas for the Antarctic region and urged that the proposed Antarctic Treaty should set aside protected areas for the conservation of fauna and flora and their natural environment. ${ }^{28}$

In 1961, SCAR presented the Parties of the newly formed Treaty with a number of recommendations that included the recognition of 'all areas of land and fresh water, including fast ice and ice shelves, and all coastal waters south of $60^{\circ} \mathrm{S} . .$. as a nature reserve' and 'designation

25 SCAR is a committee of ICSU, the International Council of Scientific Unions, and is charged with the initiation, promotion, and co-ordination of scientific research in Antarctica.

26 III Meeting Scientific Committee Antarctic Research, Canberra, Australia, 2-6 March 1959.

27 Note: The organization changed its name to World Conservation Union in 1990, but the full name and the acronym are often used together as many people still know it as IUCN. The organization was founded in October 1948 as the International Union for the Protection of Nature (or IUPN) following an international conference in Fontainebleau, France. The organization changed its name to the International Union for Conservation of Nature and Natural Resources in 1956. (See www.iucn.org/en/about)

IUCN, Proceedings: Seventh General Assembly. Warsaw, 15-24 June 1960. 
of selected areas as sanctuaries within which no form of disturbance should be permitted' so as to protect especially important or vulnerable species or habitats. ${ }^{29}$ These recommendations were subsequently utilised by the parties to develop the Agreed Measures, the provisions of which aimed to 'prohibit ... the killing, wounding, capturing or molesting of any native mammal or native bird or any attempt at any such act, except in accordance with a permit', 'to minimize harmful interference ... with the normal living conditions of any native mammal or bird, or any attempt at such harmful interference', to provide special protection to native mammals and birds designated as 'Specially Protected Species', and to provide special protection for 'areas of outstanding scientific interest ... in order to preserve their unique natural ecosystem system[s]' as Specially Protected Areas.

The adoption of the Agreed Measures placed the Antarctic at the forefront of conservation management in the 1960s. Unlike many Recommendations of the ATCMs, the Measures were mandatory, generating binding obligations on the Party once the Measure had come into force. ${ }^{30}$

However, while the permit system provided protection for identified species and some level of protection for other native mammals and birds, the development and approval of permits at the national level led to a range of interpretations and applications of the Agreed Measures. In addition, area protection under the Agreed Measures proceeded in a largely ad hoc manner, with little thought to the development of any systematic or structured approach to protecting representative examples of ecosystems, habitats, or species ${ }^{31}$ or to the development of area protection for comparable areas, species, communities, and habitats outside of the Antarctic Treaty area. Nonbiological sites were excluded, and management plans were not considered necessary. And with designated areas generally small and restricted to areas ashore (albeit with near-shore waters subsequently included in some areas), the system may have provided selective protection for sites of particular scientific interest, but this has hardly constituted the basis for a coherent and systematic protection of environmental values.

In 1972, SCAR raised its concern ${ }^{32}$ about the lack of representation of many major Antarctic land and freshwater ecological systems within designated SPAs, while noting that other systems seemed overrepresented, particularly coastal bird breeding sites. The Treaty Parties agreed and responded by adopting a Recommendation ${ }^{33}$ identifying the need to include examples of areas with values not adequately represented, such as major Antarctic land and freshwater ecological systems, areas with unique complexes of species and 'especially interesting breeding colonies of birds or mammals', as well as 'areas which should be kept inviolate so that in the future they may be used for purposes of comparison with localities that have been disturbed by man'. However, the Recommendation stressed that the number of SPAs should be kept to the minimum that would

29 Scientific Committee for Antarctic Research, SCAR Bulletin, vol. 8 (1961), pp. 103-115.

30 A practical limitation was however the protracted period between adoption and entry into force, due to the slowness of domestic process in some ATCPs (all of whom were required to ratify the Measure before it could become effective).

31 J. Valencia (ed.), Second Antarctic Protected Areas Workshop, Ministerio de Relaciones Exteriores and Instituto Antartico Chileno, Santiago, 2000.

32 Scientific Committee for Antarctic Research, Purposes and Designation of Special Areas. Report of SCAR Working Group on Biology, 1972.

33 VII ATCM, Rec 2. Wellington 30 October-10 November 1972. 
meet the criteria of representative examples and that the size of each SPA should be the minimum required to serve the purpose for which the area has been designated. Non-biological sites were also explicitly excluded from SPA criteria. $^{34}$

One of the original criteria for permitting entry into SPAs was to facilitate a scientific purpose 'which cannot be served elsewhere'. ${ }^{35}$ This led to the prioritization of scientific investigation at the expense of protection of fauna, flora, and/or ecosystems in the declaration of and approved activities within each Specially Protected Area. Consequently, the Treaty Parties established Sites of Special Scientific Interest (SSSIs) to permit protection of both scientific study sites and habitat and/or species sites. ${ }^{36}$

In 1989 the Treaty Parties adopted the concept of management plans for Antarctic SPAs in acknowledgment of the use of such plans in comparable protected sites elsewhere in the world. ${ }^{37}$ It was a further 12 years before the concept of marine SSSIs was approved. ${ }^{38}$

The 1989 Treaty Meeting also addressed the omission of non-biological features or values from the Agreed Measures by agreeing to the concept of Specially Reserved Areas to provide a specific mechanism for protection of areas of outstanding geological, glaciological, geomorphological, aesthetic, scenic, or wilderness values. ${ }^{39}$ One site was proposed at the following Treaty Meeting the North side of Dufek Massif - but was never designated by the Treaty. Multiple Use Planning Areas, designed to minimize the impact of different activities and activities from several nations within a single area, were also proposed at XV ATCM, and again one site was proposed but never designated - Southwest Anvers Island and vicinity. This area is currently under consideration for ASMA status.

Provisions to protect historic sites were taken at the very first ATCM in Canberra, Australia, in 1961, and monuments were added in 1968. ${ }^{40}$ While there are currently around 80 Historic Sites and Monuments, ${ }^{41}$ most are of national relevance rather than international importance.

\subsubsection{The arrival of the Madrid Protocol}

At the time of the negotiation of the Madrid Protocol there were a total of 19 SPAs, covering a land area of 102.5 square kilometres $\left(\mathrm{km}^{2}\right)$ and a sea area of $30 \mathrm{~km}^{2}$. A further 35 areas had been designated SSSIs, covering a total area of $2,685 \mathrm{~km}^{2}\left(675 \mathrm{~km}^{2}\right.$ land and $2010 \mathrm{~km}^{2}$ sea). Thus a total area of 2,817.5 square kilometres within the Antarctic tTreaty area was in some formal protected

34 While this was not specifically stated in III ATCM Rec. 8 (Agreed Measures) Article VIII (SPAs), it was spelt out in the preamble to VII ATCM Rec. 3 (Sites of Special Scientific Interest): 'sites of non-biological interest cannot be designated Specially Protected Areas'.

35 Article VIII (4)a of Agreed Measures for the Conservation of Antarctic Fauna and Flora, adopted at the 3rd Antarctic Treat Consultative Meeting, Brussels, June 1964.

36 VIII ATCM, Rec 3. Oslo, 9-20 June 1975.

37 XV ATCM, Rec 9. Paris, 9-20 October 1989.

38 XIV ATCM, Rec 6. Rio de Janeiro, 6-16 October 1987.

39 XV ATCM, Rec 10. Paris, 9-20 October 1989.

40 I ATCM, Rec 9. Canberra, 10-24 July 1961, and Rec 4. V ATCM, Paris, 18-29 November 1968.

41 A consolidated list of all Historic Sites and Monuments was annexed to Decision 3 (2003), appended to the Final Report of ATCM XXVI, Madrid, and subsequent additions are found in the texts of Measure 3 (2004), Measure 5 (2005), Measure 3 (2006), and Measure 3 (2007). 
area. This equated to considerably less than 1 per cent of the continent under special area protection. Most SPAs and SSSIs were located in the Antarctic Peninsula area or around McMurdo Sound.

The Madrid Protocol introduced a level of simplicity to protected area management, replacing the growing number of categories within the Antarctic Treaty with just two: ASPAs and ASMAs.

Article 2 of the Protocol outlines the objectives of Annex V (Area Protection and Management) as 'any area, including any marine area, [that] may be designated as an Antarctic Specially Protected Area or an Antarctic Specially Managed Area. Activities in those Areas shall be prohibited, restricted or managed in accordance with Management Plans adopted under the provisions of this Annex'.

ASPAs provide specific protection for discrete areas that have some identified special value by requiring permits for entry and an associated management plan, which provides information on the reason for designation, identification of any restricted zones, conditions under which permits may be granted, conditions applying to access, and activities that are permitted within the area. The Protocol makes it an offence to enter a protected area without a permit and the permit must not authorise any activity that has not been authorised by the management plan.

Article 3 outlines the types of areas that should be set aside as ASPAs. These include areas to be kept inviolate from human interference for use as monitoring or comparison zones; representative examples of major terrestrial ecosystems (including glacial and aquatic systems) and marine ecosystems; areas with important or unusual assemblages of species (including major colonies of breeding native birds or mammals); sites of the only known habitat of any species; areas of particular interest to ongoing or planned scientific research; examples of outstanding geological, glaciological, or geomorphological features; areas of outstanding aesthetic and wilderness value; sites or monuments of recognized historic value; and such other areas as may be appropriate to protect the values set out in the objectives.

The development of the Protocol gave the Treaty nations an opportunity to revise and update the management plans for existing protected sites. Some sites had irregular or inaccurately described boundaries, others had vague designations. All existing SPAs and SSSIs were redesignated and renumbered as ASPAs, and the Treaty nations developed new guidelines for preparing the required management plans. These are required to be submitted by the proposing nation to the Committee for Environmental Protection and approved at an ATCM. Thus far, 67 ASPAs have been designated. ${ }^{42}$

Annex $\mathrm{V}$ also provides for the creation of a new concept of protected area, ASMAs, which are intended to facilitate co-operation between nations operating in close proximity to each other, with a view to minimizing environmental impacts or mutual interference. While ASMAs do not need an entry permit, they do require a management plan and may contain zones where more restriction and permits might apply, including ASPAs and sites or monuments of recognized historic value,

42 Details of the ASPAs, including site information, location maps, detailed management plans and maps, site photographs, and permit information can be found on the Antarctic Protected Areas Information Archive, at http://cep.ats.aq/cep/apa/index.html 
and the activities within ASMAs are governed by a code of conduct. Thus far six ASMAs have been adopted..$^{43}$

\subsubsection{The 'workshop' era}

In 1992, SCAR and IUCN hosted a workshop to discuss the practical application of the Madrid Protocol provisions relating to protected areas. ${ }^{44}$ One example of the need for such a discussion was that Annex $V$ lists a number of values to be protected within a network of ASPAs but provides little guidance on methods for site identification or prioritization. The SCAR-IUCN workshop also aimed to draw from the application of best practices in conservation planning and management from elsewhere in the world.

The workshop highlighted the exclusion of consideration of protected area development from comparable areas, species, communities, and habitats outside the Antarctic Treaty area. One consequence of this is the absence of a clear and agreed standard or understanding of the concepts applied, which has led to a multitude of interpretations and applications by the Treaty nations. The workshop considered this to be particularly problematic when the Treaty Parties come to consider area protection for wilderness value, and particularly geographically large areas, perceived by many to unnecessarily impede national plans for station location, transport and scientific activities. Indeed, 15 years on, Treaty Parties continue to have difficulties in declaring any significant wilderness sites for ASPA level protection, and have also balked at restrictive protection for any large geographic areas.

The lack of understanding of the extent, diversity, and abundance of species' populations, communities, habitats, ecosystems, and biomes within the Treaty area was also identified as a major weakness in the selection of protected area sites. The resultant workshop proposal that a detailed biogeographical framework be developed - extending work already done by SCAR to classify a range of Antarctic terrestrial, inland water, and inshore marine ecosystems - generated an excellent pathway forward for the Treaty Parties. ${ }^{45}$

SCAR-IUCN went on to present 22 recommendations to the XVII ATCM in Venice, in November 1992. ${ }^{46}$ These included a call for work to start on the development of the protected area system immediately - prior to ratification of the Madrid Protocol and its Annexes; for proposals for new protected and managed areas in areas not yet fully represented to be encouraged; for the development of a more comprehensive selection of criteria for assessment of proposals; and for a standard methodology for site surveillance and monitoring to be established to ensure consistency in development of management plans. SCAR-IUCN also noted the absence of specific reference to

43 Details of ASMAs, including site information, location maps, detailed management plans and maps, site photographs, and permit information can be found on the Antarctic Protected Areas Information Archive, at http://cep.ats.aq/cep/apa/index.html

44 R.I. Lewis-Smith, D.W.H. Walton, and P.R. Dingwall, Developing the Antarctic Protected Area System, Proceedings of the SCAR/IUCN Workshop on Antarctic Protected Areas, Cambridge, UK, 29 June-2 July 1992.

45 L.K. Kriwoken and P.L. Keage, Identification and Selection of Protected Areas, in R.I. Lewis-Smith et al. (eds.), Proceedings of the SCAR/IUCN Workshop on Antarctic Protected Areas, Cambridge, UK, 29 June2 July 1992.

46 Ibid. 
the management of tourism in the Protocol and called upon Treaty Parties to address this through conservation principles for assessment and management of all tourist operations as well as research into and monitoring of tourist activities and their impacts.

The SCAR-IUCN workshop report specifically named a number of regions where new ASPAs might be designated to minimize human impact or to improve geographical representation of protected areas, particularly wilderness, paleontology, lakes/streams, geomorphology, glaciated terrain, and limnological features). ${ }^{47}$ While several of these areas and values remain underrepresented to this day, the Treaty nations have designated some from the list, including:

1) Deception Island as an ASMA (notable for its volcanology, bird biology, geology, and cartography) to better manage and minimize the impact of an ever growing number of scientists and tourists on its special volcanic and geological sites, unique bird colonies, and historically significant sites;

2) As an ASMA, the Larseman Hills notable for its wilderness, lakes, and vegetation values; and

3) An important nunatak ${ }^{48}$ area of Victoria Land, also as an ASMA.

It was not for another six years, however, that the Treaty Parties began to work on the issue in any formal or significant way. In 1998, they held a workshop in Tromsø, Norway, prior to the XXII ATCM, to specifically identify gaps between the current designated protected areas and the categories identified in Annex $\mathrm{V}$ of the Madrid Protocol and to identify new areas that might fill those gaps. ${ }^{49}$

The Troms $\varnothing$ Workshop noted a number of major concerns with (lack of) progress towards full implementation of an effective protected area system for the Antarctic region, including the urgent need for Annex $V$ to be ratified by all the ATCPs; the absence of a strategy to develop a network of protected areas; and an urgent need for the development and updating of management plans for existing SPAs and SSSIs in accordance with Annex V. While many at the workshop felt that area protection in Antarctica had fallen behind efforts made elsewhere in the world, ${ }^{50}$ others felt that the special status given to all of Antarctica under the Madrid Protocol was equivalent to (without implying sovereign status) Category II (National Park: protected area managed mainly for ecosystem protection and recreation) of the widely accepted 1993 United Nations Protected Area List $^{51}$ and thus placed the region at the leading edge of global area protection and management.

While this fundamental difference of view was not resolved, the workshop fleshed out a basic framework for the systematic development of a representative protected areas system, based on the Protocol and Annex V, and recommended that the ATCPs consider this and other systems for

47 Lewis-Smith, Walton, and Dingwall, supra note 46, p. 33.

48 Exposed summits that are not covered with ice or snow within an icefield or glacier.

49 See M. Prebble and A.D. Hemmings. The identification of Possible New Protected Areas. In B. Njåstad (ed.), Antarctic Protected Areas Workshop. Report No. 110 (Tromsø, Norway: Norwegian Polar Institute, 1998).

50 M. Holdgate, The Antarctic Protected Areas System in the New Millennium. Keynote Address to the Antarctic Protected Areas Workshop, 23 May 1998. In Njåstad, supra note 51.

51 IUCN, 1993 United Nations List of National Parks and Protected Areas (Cambridge, UK, and Gland, Switzerland: 1994). 
classifying protected areas in Antarctica and also take urgent steps to identify possible new protected areas, particularly for representative examples of ecosystems and areas to be kept inviolate from human interference. ${ }^{52}$

By this stage, the Madrid Protocol had entered into force and the Committee for Environmental Protection (CEP), created under Article 11 of the Madrid Protocol to provide advice and recommendations on the implementation of the Protocol, had been formally established. Parties were also hopeful of the imminent ratification of Annex V. From its inception, the CEP has faced many challenges with respect to the development of the protected area system -the orderly aggregation of SPAs, SSSIs, and HSMs into the new single category of ASPA; the development and application of the concept of active management; the development of criteria for site selection; marine protected areas (MPAs); and protected area size and representativeness. Further, there continue to be new potential impacts, including increasing tourism activities and fisheries.

The newly constituted CEP decided on a second protected area workshop to develop an overall Antarctic protected areas framework as envisioned in Article 3(2) of Annex V. This workshop, held in Lima, Peru, in June 1999 immediately prior to the Antarctic Treaty Meeting, was also tasked with considering systems for categorizing protected areas in Antarctica, with undertaking a gap analysis based on the values for site protection identified in Article 3 of Annex $\mathrm{V},{ }^{53}$ with preparing possible recommendations for new protected areas, and with providing suggestions on how the CEP could best review draft management plans for ASPAs.

The Lima workshop proposed a protected areas framework based on a schema that combines the values identified in Article 3 of Annex V, six identified protection categories (ecosystems, habitat, species, landscape, environmental features, and cultural/historic features), and five identified use categories (science, conservation, economic, recreation/tourism, and intrinsic) for the CEP to adopt. It further recommended that the CEP elaborate a conservation strategy to deal with gaps in current protected area categories and coverage, and it identified a range of existing tools such as environmental risk analysis and complementarity analysis to assist in selecting new protected areas. $^{54}$

Both workshops were limited in their terms of reference to ASPAs and thus in their capacity to provide broader recommendations to the Treaty Parties. For example, ASPAs have consistently been extremely limited in size, and the only option available for management or protection of larger areas is through the application of ASMAs.

This limitation in focus also restricted opportunities for a broader debate beyond that of existing protection mechanisms. For example, this is starkly illustrated by the proposed Lake Vostok drilling programme, which highlighted the capacity - and willingness - of Parties to choose scientific research over protection and process over outcome. Lake Vostok has significant intrinsic value as possibly the most pristine body of water on the planet. Buried under nearly 4 kilometres of ice, it is

52 XXII ATCM, Summary Report of the Antarctic Protected Areas Workshop, held 23rd May, Troms $ø$ (XXII ATCM/WP26), Tromsø, 25 May-5 June 1998.

53 See J. Acero, New Areas, Gap Analysis and Conservation Values. In Valencia, supra note 33.

54 XXIII ATCM, Report of the Second Workshop On Antarctic Protected Areas, 22-23 May 1999, Lima (XXIII ATCM/WP37), Lima , 24 May-4 June 1999. 
one of the world's biggest freshwater lakes and home to possibly unique flora and fauna, yet the Parties have expressed no interest or willingness to designate the lake as an ASPA.

\subsubsection{Frameworks, Guidelines, and Reviews}

In 2000, the Treaty Parties adopted a detailed Resolution entitled Guidelines for the Implementation of Article 3, Annex $\mathrm{V}^{55}$ which aimed to provide guidance on criteria and procedures for identifying and proposing new ASPAs, drawing from the concept of environmental risk. The Resolution describes itself as 'a set of tools to enable more systematic assessment, selection, definition and proposal of areas that might require greater protection in accordance with the provisions of Annex $\mathrm{V}$ of the Environmental Protocol'. While a significant advance in encouraging Parties to consider ASPA designations, the guidelines have no legal status and do not extend to ASMAs.

Five years later, no significant changes were evident. In 2005, New Zealand conducted a review of the status of the Antarctic protected areas system. They reported 62 ASPAs, protecting approximately a total of $2,741 \mathrm{~km}^{2}$ of Antarctica $\left(1,780 \mathrm{~km}^{2}\right.$ of sea area and $960 \mathrm{~km}^{2}$ of land area), representing 0.008 per cent of the total Antarctic Treaty area. ${ }^{56}$ The study notes that despite significant attention to upgrading and updating of management plans for ASPAs, four plans still needed to be updated into the accepted Annex $V$ format and 13 plans were overdue for their five yearly reviews. Little progress appeared to have been made in extending the representative coverage of underrepresented categories.

The New Zealand study also notes that sites appear to be nominated because they harbour a number of 'values' rather than for a single significant 'value'. For instance, while birds are the most protected fauna, few sites have been established primarily or exclusively to protect birds or a particular bird species. Similarly few sites have been nominated to protect a particularly species or type of vegetation; plant protection is generally achieved through protection of a general stretch of vegetation. In addition, there was no evidence of an extension of geographic coverage - sites remained exclusively on the coastal fringes, they were primarily clustered on and around the Antarctic Peninsula or around Ross Sea/Victoria Land regions, and no sites had been adopted in the Marie Byrd Land area of Western Antarctica. This reflects the inability of Treaty Parties to extend their thinking beyond interests or areas of specific national interest or the restrictive approaches applied to protected areas in some other parts of the world. The consensus decision approach has also not encouraged forward thinking.

New Zealand proposed several recommendations, many of which had been before the Parties before, sometimes repeatedly. For instance, they again called for active nomination of sites in underrepresented geographical areas and for underrepresented environmental values, as well as for a more systematic approach to the development of the protected areas network.

The exhortations in 2005 thus far appear to have had little impact on proposals for new designations of ASPAs. Three new ASPAs have been adopted since that meeting, totalling an area

55 SXII ATCM, Resolution 1 (2000), Guidelines for Implementation of the Framework for Protected Areas set forth in Article 3, Annex V of the Environmental Protocol. The Hague, 14-18 September 2000.

56 XXVIII ATCM, A Review of the Antarctic Protected Areas System (XXVIII ATCM/WP 11). Stockholm, 6-17 June 2005. 
of less than $8 \mathrm{~km}^{2}$, located similarly to other ASPAs on the coastal fringes, near other ASPAs, and protecting a colony of giant petrels, a terrestrial and freshwater habitat, and some historic buildings.

However, the study did open the way for a more focused debate on the importance of marine areas as part of the Treaty's development of a 'systematic environmental-geographic framework' for Antarctic Protected Areas. Few MPAs have been designated within the Antarctic Treaty area either as marine ASPAs or as part of ASMAs, and those that have been identified have occurred largely on an ad hoc basis. The United Kingdom introduced a position paper in 2006, noting that MPAs are considered increasingly important in other parts of the world as important tools for conservation of marine biodiversity and habitat, maintenance of healthy ecosystems in concert with sustainable fisheries, and co-ordination of activities in multiple-use areas; the paper suggested that MPAs would provide a useful means to provide scientific reference areas as well as protecting and conserving Antarctic marine areas of particularly high value or sensitivity. ${ }^{57}$

\subsubsection{Marine Protected Areas}

In 2005, with minimal debate, XXVIII ATCM in Stockholm, Sweden, passed Decision 9, giving CCAMLR an effective veto over protected areas that contain ocean marine areas. ${ }^{58}$ Any proposals with a marine component in which there is harvesting or 'potential' for harvesting or where CCAMLR activities might be restricted must first be approved by the CAMLR Commission prior to decision by an ATCM. This has led to further slowing of acceptance of protected areas with marine components.

The CAMLR Commission had already initiated its own focus on MPAs by agreeing in 2004 to convene a workshop to discuss how MPAs might usefully further CCAMLR's objectives and to review the types of scientific information that would be needed for the development of CCAMLR MPAs. The workshop was held in Silver Spring, Maryland, in the United States in late August 2005 and the report was submitted to the November 2005 XXIV CCAMLR meeting.

The CAMLR Commission had also earlier established the Ecosystem Monitoring Programme (CEMP) and associated CEMP sites (in 1995) to monitor the effects of fishing on both harvested species (target species) and dependent species (predators). Entry into CEMP sites is prohibited without a permit, and all CEMP sites have management plans. In 2004, the Commission adopted a conservation measure to establish a process for according specific protection measures to be applied to CEMP sites in order to ensure the site itself or its approved scientific activities are not significantly disturbed. The process requires advice from SCAR and consideration by ATCPs prior to formal adoption by CCAMLR. Fishing activity is not necessarily restricted in such sites.

In reviewing the outcomes of the Silver Spring workshop, the Scientific Committee of CCAMLR stated 'overall, when viewed in relation to the IUCN categories of protected areas [that] the Convention Area as a whole would qualify as Category IV (Habitat/Species Management Area:

57 XXIX ATCM, Marine Protected Areas (MPAs) - Tools for Protection and Management (XXIX ATCM/WP 4). Edinburgh, 12-23 June 2006.

58 ATCM XXVIII, Decision 9 (2005). Stockholm, 6-17 June 2005. 
protected area managed mainly for conservation through management intervention) ${ }^{59}$ Category IV is defined as an area of land and/or sea subject to active intervention for management purposes so as to ensure the maintenance of habitats and/or to meet the requirements of specific species. The Committee also noted that CCAMLR already uses a form of 'area management' via 'Fisheries Closed Areas' for individual fisheries based on advice from working groups on individual fisheries.

The 2005 CAMLR Commission endorsed the workshop's proposal to 'elaborate the principles, practical guidelines and scientific requirements for MPA development' ${ }^{60}$ and its proposed MPA definition as 'any area of intertidal or sub tidal terrain, together with its overlying water and associated flora, fauna, historical and cultural features, which has been reserved by law or other effective means to protect part or all of the enclosed environment'. ${ }^{61}$ It was generally acknowledged that MPAs could be a useful tool for furthering CCAMLR's objectives, particularly in relation to protection of ecosystem processes, habitats and biodiversity, and protection of species (including population and life history stages) ${ }^{62}$ and that there was a need to develop a strategic approach to MPA design and implementation for the Southern Ocean.

The 2005 CCAMLR meeting went on to agree on a process for the development of a system of protected areas, starting with broad-scale bioregionalization of the Southern Ocean, followed by fine-scale subdivision of biogeographic provinces, together with identification of areas that might be used to achieve the conservation objectives and determination of areas requiring interim protection. It established a Steering Committee, which includes members of the Scientific Committee and the CEP, and agreed to a further workshop to advise on a bioregionalization of the Southern Ocean, including, where possible, advice on smaller-scale delineation of provinces and potential areas for protection to further the conservation objectives of CCAMLR. This work plan is currently under way.

The XXIX ATCM in 2006 again acknowledged the urgent need for definition and designation of Antarctic MPAs and the need for work to start 'sooner rather than later'. ${ }^{63}$ Parties had previously recognized the importance of MPAs by committing to identify such areas within a systematic environmental-geographic framework and to include in the series of ASPAs representative examples of major marine ecosystems. The XXIX ATCM endorsed a proposal to co-operate with CCAMLR to develop a bioregionalization of the Southern Ocean as a first step towards the elaboration of a systematic environmental-geographic framework for protected areas. It is clear, however, that ongoing access to marine living resources is a significant barrier to the acceptance of any significant MPA designations in the short term, and several nations continually express the need for due consideration of alternative options for conserving the marine environment.

59 SC-CAMLR XXIV, Final Report of Scientific Committee (para 3.44-3.73) and Annex 7 (Report of the CCAMLR Workshop on Marine Protected Areas, Silver Spring, MD, USA, 29 August to 1 September 2005). Hobart, 24-28 October 2005.

60 Ibid. paras. 3.44-3.73.

61 Ibid. Annex 7, paragraph 1.

62 Ibid. Annex 7, paragraph 126.

63 XXIX ATCM, Final Report of the Twenty-ninth ATCM (para 80). Edinburgh, 12-23 June 2006. 


\subsection{Where are we now?}

The Antarctic Treaty Parties have adopted more than 85 recommendations dealing with area protection and management, accounting for more than a quarter of all their recommendations. By the end of 2006, the CEP had considered more than 130 Working Papers and over 70 Information Papers relating to matters concerning area protection and management. ${ }^{64}$

All existing protected areas have been amalgamated into ASPAs according to the Protocol. Any area may be nominated for ASPA status to protect outstanding environmental, scientific, historic, aesthetic, or wilderness values or any combination of those values or to protect ongoing or planned scientific research. There are currently 67 ASPAs, totalling less than $2,760 \mathrm{~km}^{2}$ total area. The six ASMAs provide a considerably larger area (in total, approximately $42,000 \mathrm{~km}^{2}$ ) with a lower level of protection, although three of the ASMAs also contain ASPAs. The purpose of an ASMA is to provide co-ordination of activities (to minimize physical disturbance or cumulative impact, for instance) rather than restriction or prohibition of activities.

Of the areas protected, six are fully marine ASPAs, a further nine ASPAs contain small marine components, and three ASMAs contain marine components, covering a total of $1,780 \mathrm{~km}^{2}$ or 0.012 per cent of the marine area south of $60^{\circ} \mathrm{S}$.

A list of all existing ASPAs and ASMAs can be found on the Web site of the Committee for Environmental Protection: http://cep.ats.aq/cep/.

Figure 7.1 identifies the location of protected areas as of the end of 2006.

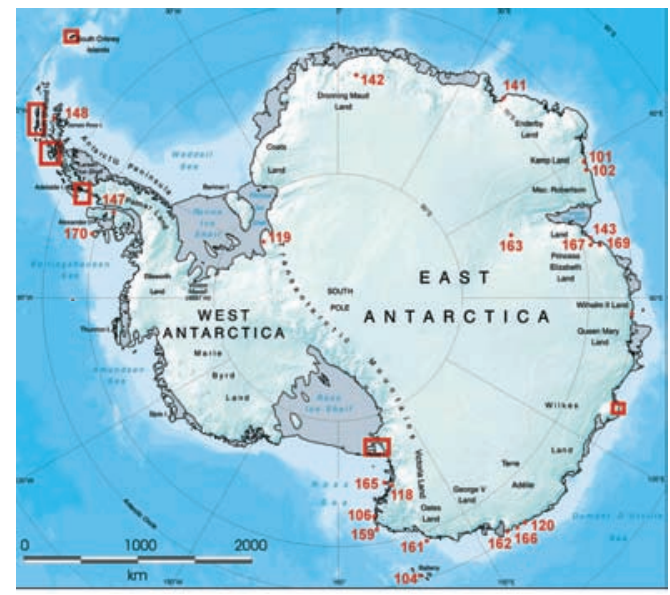

Photo: courtesy of British Antarctic Survey

All ASPAs and ASMAs must have a management plan, and all management plans must be reviewed by the CEP every five years. A permit, issued by the appropriate national authority, is required for entry into ASPAs. The Treaty Parties have developed guidelines for the development of

64 R.A. Sanchez and E. Mclvor, The Antarctic Committee for Environmental Protection: Past, Present, and Future. Polar Record, vol. 43 (2007), pp. 239-246. 
management plans for ASPAs, a standardised reporting format for visits to ASPAs, and procedures for considering new and revised draft management plans.

The Antarctic Treaty Parties have repeatedly committed themselves to develop a systematic framework of ASPAs, including a representative range of ecosystems and species; areas of particular scientific interest; areas representing the type of locality or only known habitat of any species; examples of outstanding geological, glaciological, or geomorphological features; areas of outstanding aesthetic and wilderness value; historic sites or monuments. While work has started, they appear to be many years - and designated areas - from meeting this commitment.

CCAMLR has established CEMP sites to monitor the effects of fishing on both harvested species (target species) and dependent species (predators). Entry to CEMP sites is prohibited without a permit, issued by the relevant national authority. CEMP sites also have Management Plans. Two of the CEMP sites have been afforded special protection:

1) Seal Islands (near Elephant Island) in the South Shetland Islands, previously an important ecosystem monitoring site and now used for census studies; and

2) Cape Shirreff and Telmo Island, South Shetland Islands (approximate area: $3.47 \mathrm{~km} 2$ ) (which is also designated as ASPA 149 under the Antarctic Treaty), an important ecosystem monitoring sites for the study of significant breeding colonies of Antarctic fur seals (Arctocephalus gazelle), Chinstrap penguins (Pygoscelis antarctica) and Gentoo penguins (Pygoscelis papua), whose foraging range overlaps with commercial krill fisheries.

CCAMLR has also initiated a process for consideration of designation of marine protected areas.

There are also three Seal Reserves under the Convention for the Conservation of Antarctic Seals, the purpose of which is to protect sites that are seal breeding areas or the sites of scientific research on seals. The killing or capturing of seals in these reserves is prohibited. The three Reserves are around the South Orkney Islands, (approximate area: 9,090.9 km2), the southwestern Ross Sea south of $76^{\circ} \mathrm{S}$ and west of $170^{\circ} \mathrm{E}$ (approximate area: $32,3630 \mathrm{~km} 2$ ), and Edisto Inlet south - Cape Hallett - Helm Point (approximate area: $230.5 \mathrm{~km}^{2}$ ). There is currently no commercial seal take in the Antarctic region.

The Madrid Protocol was a huge step forward for the protection of the Antarctic environment, but thus far it has failed to deliver a systematic and representative network of protected areas. Its Committee for Environmental Protection is a technical/advisory body with no real power to make this happen.

The effective management of the impacts of tourism is also becoming a major issue in terms of systematic or representative protection of values and areas in Antarctica. Tourism is growing in the Antarctic region, both in terms of the total numbers and the range of activities undertaken. ${ }^{65}$ The big questions to be tackled are how to minimize the cumulative impacts of tourist activity and to do this prior to disturbance or deterioration of areas that may qualify for protected status. The XXX

65 IAATO, IAATO Overview of Antarctic Tourism 2006-2007 Antarctic Season (XXX ATCM/IP 121). XXX ATCM, New Delhi, 30 April - 11 May 2007. 
ATCM adopted a voluntary Resolution endorsing the concept that all tourism activity should be guided by the principle that tourism should have no more than a minor or transitory impact on Antarctica. ${ }^{66}$ This may be seen as a useful 'first step' but alone will do little to limit the growth of tourism or regulate/guide its geographic spread and impact.

While much work has been done to develop standardized processes to apply to existing protected areas, tangible developments with respect to the creation of a logical and consistent network of protected areas have yet to emerge. The existing SPA sites have arisen primarily from national interests rather than any attempt to achieve systematic or representative coverage of Antarctic ecosystems. As a result, there are significant gaps in coverage, particularly with respect to MPAs and inland areas, and few areas are kept intentionally free of human activity.

Annex $\mathrm{V}$ of the Madrid Protocol also requires Treaty Parties to identify and designate marine areas, although as noted above, these must also be approved by CCAMLR. After multiple calls by IUCN, SCAR, and international environmental organizations to urgently address this singular gap in Antarctic area protection, the Antarctic Treaty and CCAMLR have finally begun to consider this issue in a serious way. In 2006 they acknowledged the urgent need for definition and designation of Antarctic MPAs. ${ }^{67}$ They have determined and initiated their first step - the development of a systematic environmental geographic framework for the offshore marine environment - which hopefully will lead to selection and designation of a network of Antarctic MPAs.

Antarctic area protection faces other difficulties, not from the Protocol itself but from the way in which it is implemented by Antarctic States, collectively and/or individually, as a result of questions of interpretation and a lack of resources or political will. There is no international organization to enforce ATS obligations. Each signatory nation writes and enforces its own laws and regulations to implement these treaties, which do not always view things the same way. There is a growing 'implementation gap' among Parties between those appropriately meeting Protocol obligations and those lagging significantly behind. For example, EIA is applied in widely different ways, with some countries literally never preparing one. Some nations make their assessments available to the ATCM, while others do not. This is resulting in lower environmental standards being accepted as the 'norm'. At the same time, improved technology and knowledge over the last 100 years have allowed greater access to the continent in terms of scale and scope of activities, scientific and private, that are able to penetrate further into wilderness areas. ${ }^{68}$

The Protocol also faces an increasing number of cross-cutting environmental issues and strategic environmental needs that challenge its ability to govern the Antarctic region effectively. The key environmental principles articulated in Articles 2 and 3 often become secondary to other interests that individual States have in the region, particularly with respect to the exploitation of the marine environment. Thus the area of application of the Protocol has retreated for the most part to the continent rather than applying to the entire Treaty area, as mandated by the Protocol, and much of the harvesting activities at sea are exempted from its implementation. For instance, the recently concluded Liability Annex does not apply to fishing vessels in the Southern Ocean (which

66 XXX ATCM, Resolution 5 (2007) Final Report of the Thirtieth ATCM. New Delhi, 30 April-11 May 2007.

67 XXIX ATCM, Final Report of the Twenty-ninth ATCM (para 80). Edinburgh, 12-23 June 2006.

68 ASOC, Strengthening the CEE Process, IP 84, XXX ATCM. New Delhi, 30 April-11 May 2007. 
constitute the majority of the vessels there) and it has proved extremely difficult to establish MPAs under Annex V of the Protocol. ${ }^{69}$

Treaty nations also have broader international obligations with respect to developing effective area protection for the Antarctic Treaty area. For instance, many Antarctic Treaty Parties participated in the agreement reached at the World Summit on Sustainable Development (Johannesburg, 2002) to implement representative networks of MPAs by 2012 with the aim of conserving marine biodiversity and allowing sustainable use of marine resources. Parties to the Convention on Biological Diversity (CBD) have also called for urgent action to address the underrepresentation of marine and coastal biodiversity in the global protected area system, particularly in areas beyond national jurisdiction. The Eighth Meeting of the Conference of the Parties to the CBD (Curitiba, Brazil, 2006) specifically considered MPA discussions and decisions in the CCAMLR context. Most recently, the G-8 2007 Environment Ministers' Meeting (Potsdam, Germany, 15-17 March 2007) agreed to 'intensify our research and enhance our cooperation regarding the high seas in order to identify those habitats that merit protection and to ensure their protection. ${ }^{70}$

\subsection{Conclusion}

The Antarctic Treaty system can reasonably claim to have been in the vanguard of international protected areas efforts in the 1960s, with initiatives based around the Agreed Measures. The system was refocused again in the early 1990s in Annex $V$ to the Protocol. The picture in CCAMLR has been less encouraging. With the exception of a few CEMP sites, the quarter-of-a-century lifetime of CCAMLR has not seen it designate a single protected area, an option plainly available to it through a conservation measure.

The expanded brief provided by Annex V of the Madrid Protocol has slowly changed the focus of protected areas designations on the continent and islands within the Antarctic Treaty area. There is evidence of a broadening of the criteria upon which designations are made, and there is some evidence of increasing size in designated areas. Protected areas are still proportionately more common in the peninsula and southern Ross Sea, but other focal areas are beginning to emerge. These areas, both old and new, seem to fairly coincide with areas of greatest human pressure, so the clustering has a rational basis. Happily, more States are proposing protected areas. Whilst Anglo-Saxon domination of proposals has not entirely disappeared, there has been a relative decline.

But there are some developments of a more questionable nature. The positive development of the ASMA category, which offered for the first time the mechanism to coordinate activities involving several States - a matter of some significance, given the clustering of national programme stations

69 Antarctic and Southern Ocean Coalition, ASOC Analysis of the First Antarctic Liability Regime, 3 August 2005; A.D. Hemmings, Agreement to a Liability Annex to the Protocol, Antarctic, vol. 23, no. 3 (2005), pp. 50-51. This analysis presents further examples of the positive and negative aspects of the new Liability Annex.

70 'Potsdam Initiative - Biological Diversity 2010', G8 2007 Environment Ministers Meeting, Potsdam, 15-17 March 2007, available at www.bmu.de/files/pdfs/allgemein/application/pdf/potsdam_initiative_en.pdf 
in several parts of the Antarctic, most notably King George Island, the Larsemann Hills, and McMurdo Sound - seems to be evolving in a different way. Whilst these are still early days, there is some reason to fear that ASMAs are being used in place of ASPAs because they impose less onerous duties.

The most problematical development however remains in relation to protected areas in the marine environment. There is substantial support for using Protocol Annex $V$ to designate marine protected areas as ASPAs (or ASMAs). But the ATCM (and to a degree this reflects concessions made within its advisory Committee for Environmental Protection) has allowed the emergence of a de facto veto on the designation of marine ASPAs/ASMAs by requiring CCAMLR's concurrence on any such proposals. This is plainly problematical, given that CCAMLR's conception of conservation includes 'rational use' and thus the restriction of harvesting (given that constraints on harvesting seem likely to be part of any proposal for a marine ASPA) can be expected to face resistance within its fora. Key fishing States within CCAMLR are quite clearly resistant to any constraints on access for harvesting, not only because they do not wish to see them in the Antarctic but because they fear the establishment of 'unfortunate precedents'. Whilst it may be quite difficult to too brutally block proposals when they arise in the CEP/ATCM, these States have no such difficulties in the much more aggressively pro-use fora of CCAMLR. The capacity of Antarctic States to wear quite different hats depending on whether they are in the CEP/ATCM or CCAMLR is significant.

A secondary facet of this is the procedural complexity of a discussion of an area moving back and forth between the ATCM/CEP and CCAMLR's Scientific Committee, the various subgroups reporting to the Scientific Committee, and (if it ever cleared the Scientific Committee) the Commission. The present CCAMLR focus on bioregionalization appears to have taken a useful component of a discussion about marine protected areas and established it as the sole focus of discussion without apparent end - a sort of sandpit wherein safe play is assured. As a result of these developments, no significant marine area has as yet been designated as an ASPA or ASMA and none look likely in the near term. Once again, consensus has its costs.

But, as the saying goes, 'wait, there's more'. Even if one sees a marine area designated as an ASPA or ASMA under the Protocol, the area need not be secure against activity conducted under CCAMLR. This arises because a) the membership of the two instruments is, whilst close, not identical and b) State Parties have generally implemented their Antarctic Treaty and Madrid Protocol obligations through different domestic legislation to that which implements their CCAMLR obligations. For many States, it may be necessary for there to be parallel legal obligations coming out of both the ATCM and CCAMLR Commission.

So, what is currently required by way of development of a truly effective Antarctic protected areas system?

1) A recognition that the historic remoteness of Antarctica and the general declaratory commitment towards the environment in the Antarctic Treaty, CCAMLR, and the Protocol are not enough. The Antarctic is not protected merely by the designation of Antarctica as a natural reserve. Some tangible further steps are now required, and these include various forms of area protection. Antarctica's marine environment is under increasing pressure from marine harvesting, possibly soon from bioprospecting, from tourism, from whaling, potentially 
from some sorts of research (such as iron-seeding and acoustic/air-gun equipment), and from the unfolding and profound consequences of climate change.

2) A real commitment to establish in the near term a set of marine protected areas in the Antarctic. It is always difficult to agree on MPAs anywhere in the world, but if we cannot agree to them in Antarctica, we are in serious trouble. It would be good to see CCAMLR designating some real protected areas on its own initiative, and not just playing the spoiler to proposals that arise through the Protocol's mechanisms.

3) The mechanisms for co-operation between the ATCM and CCAMLR in relation to MPAs need further development. ${ }^{71}$

4) A range of MPAs are required - from perhaps quite small and coastal areas (a continuation of established ATS practice) to large open ocean areas. Some progressive thinking needs to become evident in relation to open ocean MPAs globally, and the claims to innovative and co-operative ways on the part of the ATS could be usefully demonstrated if these were pioneered in Antarctica.

5) If these MPAs are to be effective they will inevitably constrain some activities. Those who practice these activities will, of course, resist this. We do nobody any favours by suggesting that the designation of MPAs (or indeed of any other sort of protected area) will necessarily be pain-free.

6) Whilst the subantarctic islands (most of which lay outside the area we have here construed as the Antarctic) are increasingly designated as protected areas under national legislation (in the case of the Australian, New Zealand, and South African islands, then also designated as World Heritage Sites), no equivalent island or archipelago protection (of land and its surrounding marine area) has yet been achieved in Antarctica. The New Zealand proposal for the Balleny Islands foundered on political problems and perceptions that it was in part at least tied in to New Zealand sovereignty interests. ${ }^{72}$ Objectively, groups such as the Ballenys, Peter I, the South Sandwich Islands, etc. warrant serious consideration.

7) Although the protected areas system ashore in Antarctica is less problematical - in terms of at least being accepted and the precedent of 40 years of practical deployment - it is still poorly developed. The underpinnings for the mandatory systemic environmental-geographic framework may have been provided by New Zealand (and particularly by Harry Keys) ${ }^{73}$ but we are still a long way off from realizing its potential.

8) There are, for instance, still no protected areas designated for that most typical Antarctic environment, the high polar plateau, 36 years after Patterson wondered whether we were

71 See S.M. Grant, Challenges of Marine Protected Area Development in Antarctica, Parks vol. 15 (2005), pp. $40-47$.

72 J. Burgess et al., Declaration of Marine Protected Areas - The Case of the Balleny Islands, Antarctica, in J.P. Breumer; A.Grant, and D.C. Smith (eds.), Aquatic Protected Areas: What Works Best and How Do We Know? Proceedings of the World Congress on Aquatic Protected Areas, Cairns, Australia - August 2002 (Gosford, NSW, Australia: Australian Society for Fish Biology, 2003), pp. 196-202.

73 New Zealand, Systematic Environmental Protection in Antarctica - First Progress Report, XXVII ATCM IP 24, 2004. 
dusting it with aviation fuel breakdown products. ${ }^{74}$ Are we now too late to address that? The distribution and size of designated areas are still issues, and the values recognized under the Protocol are not yet well represented in protected areas designated ashore in Antarctica.

These are significant tasks, and plainly they will not be accomplished overnight. It would be nice to think, however, that at least some progress would be evident before we all assemble at the XXXII ATCM in Baltimore, Maryland, in the northern summer of 2009 on the fiftieth anniversary of the adoption of the Antarctic Treaty.

74 C. Patterson, Limiting the Contamination of Virgin Surfaces of Firn by Engine Exhausts from Nearby Traverses and Overflights, in B.C. Parker (ed.), Conservation Problems in Antarctica (Blacksburg, VA: Virginia Polytechnic Institute and State University, 1972). 


\title{
8 Efectos Ambientales Transfronterizos del Proyecto Minero Binacional Pascua Lama: el conflicto analizado desde la perspectiva internacional
}

\author{
Marta Brunilda Rovere ${ }^{1}$
}

\subsection{Introducción}

El proyecto minero binacional Pascua Lama de la transnacional Barrick Gold ${ }^{2}$ consiste en la instalación y el funcionamiento de un emprendimiento minero en la cordillera de los Andes, que se ubicará sobre el límite internacional chileno-argentino. ${ }^{3}$ La explotación de los yacimientos mineros que se encuentran ubicados en forma contigua al emprendimiento Veladero, situado en la parte noroeste de Argentina, Provincia de San Juan en la Cordillera de los Andes cerca del límite con Chile, se hará a rajo abierto. ${ }^{4}$ Se extraerán minerales de oro, plata y cobre, y se hará un procesamiento para obtener metal doré (oro, plata) y concentrado de cobre. ${ }^{5}$

La futura instalación de este emprendimiento originó un conflicto, debido a las reacciones contrarias de diversos sectores de la comunidad argentina y chilena. ${ }^{6}$ Los afectados directos del proyecto en Chile son los agricultores del Valle del Huasco y la población de la Provincia de

1 Abogada, especializada en derecho ambiental y de aguas. Codirectora del Grupo de Expertos en Aguas y Humedales de la Comisión de Derecho Ambiental de UICN. Integrante del Consejo de Redacción del Suplemento de Derecho Ambiental, FARN, de la Revista Jurídica LA LEY.

2 Las empresas que desarrollan el proyecto son en Chile la Compañía Minera Nevada Limitada y en Argentina, Barrick Exploraciones Argentinas S.A. y Exploraciones Mineras Argentinas S.A. Las compañías son subsidiarias de la empresa canadiense Barrick Gold Corporation.

3 A aproximadamente $300 \mathrm{~km}$. al nororiente de la ciudad de San Juan, Departamento de Iglesia, Provincia de San Juan (Argentina), y $150 \mathrm{~km}$ al sureste de la ciudad de Vallenar, Comuna Alto del Carmen, Provincia del Huasco, III Región (Chile).

4 En el territorio chileno se desarrollará gran parte del rajo abierto y se construirá un basurero receptor de estéril, un chancador primario, un complejo de manutención de equipos de mina y polvorín para el almacenamiento de explosivos. Estas obras se ubicarán en la cabecera del Río del Estrecho, tributario del Río Chollay, sobre los 4.400 metros sobre el nivel del mar. En territorio argentino se desarrollará una porción menor del rajo y se construirá un basurero receptor de estéril, las instalaciones de la planta de procesos, un tranque de relaves, los campamentos de construcción y operación para aproximadamente 4.000 y 1.000 personas respectivamente, además de un aeródromo privado.

5 El mineral será extraído de la mina a razón de 15 millones de toneladas por año y enviado a un chancador primario ubicado en territorio chileno, para reducir su tamaño. Luego será transportado por medio de una correa hasta las instalaciones de proceso que se ubicarán en territorio argentino, traspasando la frontera a través de un túnel de $2.7 \mathrm{~km}$. de longitud. En la planta de procesos el mineral se someterá a operaciones de chancado secundario, molienda y lavado. Los relaves del lavado de los minerales y del circuito de lixiviación serán dispuestos en un tanque que se construirá en el valle del Arroyo Turbio, en Argentina.

6 Ver 'Argentina y Chile frente al conflicto ambiental suscitado por el Proyecto Minero Binacional Pascua Lama', Año XIV, № 1, Suplemento de Derecho Ambiental, FARN, LA LEY, por Marta B. Rovere. 
Vallenar (70.000 habitantes). Las asociaciones de agricultores y las comunidades cristianas inician diversas acciones contra el proyecto Pascua Lama. En Argentina se oponen al mismo los habitantes de las localidades de Calingasta, Iglesia y los viñateros de la Provincia de San Juan.

El conflicto abarca aspectos económicos, ${ }^{7}$ ambientales y sociales, y gira en torno a los potenciales efectos contaminantes que pueden producirse sobre el ambiente y los recursos naturales de ambos países, entre ellos el agua y los glaciares. Estos últimos se encuentran cerca del lugar donde se ubicarán las instalaciones mineras, y pueden sufrir los efectos propios de una actividad contaminante como la minería. En el Estudio de Impacto ambiental presentado por Minera Nevada (empresa subisidaria de Barrick Chile), se omitió la presencia de glaciares que serían removidos para construir el rajo de la mina. Por tal motivo ese mismo año agricultores de la región denuncian la existencia de tres glaciares que se verían afectados por la mina: Toro I, Toro II y Esperanza. En el 2001 COREMA de la Región de Atacama, aprobó el EIA condicionado a la presentación de un plan de manejo de glaciares, tres meses antes de la construcción de la mina. La situación de indefensión de los glaciares, independientemente de esta exigencia, se encuentra agravada por el vacío normativo existente en materia de glaciares en el nivel nacional en Argentina y Chile, y en el bilateral e internacional.

Las objeciones no refieren únicamente a los efectos contaminantes del proyecto, sino que también a los beneficios económicos que producirá. Los agricultores chilenos que utilizan el agua para sus cultivos y para consumo humano, tienen serias dudas respecto de los beneficios que el mismo podría tener para ellos. Argumentan que estarían subsidiando a una empresa minera multinacional que gana mucho dinero, mientras que ellos deben abonar impuestos muy elevados que luego son utilizados por el gobierno para facilitar la inversión a una empresa minera extranjera.

La demanda de agua del Proyecto Pascua-Lama será de aproximadamente $370 \mathrm{l} / \mathrm{s}$ en total, que provendrá del Río de Las Taguas ${ }^{8}$ en Argentina. También se contempla en Chile la extracción de agua para las operaciones de la mina y talleres, estimándose un requerimiento de hasta $42 \mathrm{~L} / \mathrm{s}$, que se obtendrán del Río del Estrecho y Río El Toro. Barrick solicitará los derechos de aprovechamiento correspondientes, de conformidad a la legislación de cada uno de los países. La empresa minera habría ofrecido en junio del 2005 la cancelación de más de 60 millones de dólares a los dueños de los derechos de aguas y a los agricultores, en concepto de los potenciales daños que pudiera sufrir la cuenca hidrográfica por la explotación minera.

El problema debe ser analizado en todos sus aspectos, y también desde la perspectiva del derecho internacional, dentro del contexto binacional. Para ello se tendrán en cuenta los principios

7 El monto de la inversión fue valorado en alrededor de US\$1.1380-1.500 millones de dólares y la vida útil del proyecto sería de 17 años. La producción anual se calcula en 5.000 toneladas de cobre contenido en concentrados, 615.000 onzas de oro y 30 millones de onzas de plata. Durante la construcción se ocupará un promedio de 3.000 trabajadores, alcanzándose un máximo de 6.000 en el período de punta. La operación dará empleo directo a 1.570 personas, incluyendo a los contratistas, y se calcula que el Proyecto generará entre 3.000 y 4.000 empleos indirectos.

8 El río de las Taguas es uno de los dos ríos principales del extenso sistema de la cuenca del Palca. El río Valle del Cura drena la parte suroeste de la cuenca y el río de las Taguas, en forma conjunta con el río de La Sal, drenan el escurrimiento del sector noroeste. 
del derecho internacional ambiental involucrados, los instrumentos económicos y ambientales bilaterales suscritos entre ambos países, y la normativa ambiental de cada uno de éstos.

\subsection{Efectos contaminantes sobre los recursos naturales: reclamos de los opositores al Proyecto}

El Proyecto fue aprobado en Chile por la Resolución Exenta No 39 de la Comisión Regional de Medio Ambiente (COREMA) de la Región de Atacama, de fecha 25 de abril de 2001. La empresa había presentado el Estudio de Impacto Ambiental (EIA) en agosto del 2000, y las modificaciones en diciembre del 2004. ${ }^{9}$ En febrero de 2005 la autoridad ambiental envía un consolidado de observaciones al proyecto de ampliación y en abril la empresa entrega las respuestas. En mayo envía nuevas observaciones, y propone a la empresa que estudie la factibilidad de hacer una exploración combinada de rajo abierto y subterránea. El junio la empresa solicita 90 días para presentar las repuestas a tales observaciones.

En Argentina, la Comisión Interdisciplinaria de Evaluación Ambiental Minera (CIEAM) de la Provincia San Juan, fue creada para analizar la Declaración de Impacto Ambiental que presentó Barrick respecto del Proyecto Pascua Lama. Le corresponde la evaluación y posterior aprobación del proyecto, si ello procediere. Esta comisión concedió a sus miembros una prórroga hasta la primer semana de octubre para que presenten sus informes técnicos definitivos. Ello obligó a la empresa canadiense a aplazar sus planes de obtención de los permisos necesarios para comenzar la construcción de la mina de oro y plata.

A la par del proceso de evaluación del proyecto, existe otro paralelo en ambos países, de movilizaciones y reclamos de la ciudadanía y de los opositores a aquel. Estos mencionan entre los efectos contaminantes que el emprendimiento producirá sobre el ambiente y los recursos naturales los siguientes:

- Producción de residuos provenientes de la lixiviación con cianuro de sodio: el mineral de oro y plata y otros metales no refractarios son sometidos a lixiviación con cianuro de sodio y luego pasan a un circuito de decantación para separar los minerales ricos, mientras que los sólidos residuales serán tratados con anhídrido sulfuroso y luego pasan al tanque de relaves. Los detractores del proyecto alegan que el proceso dejará un cóctel de residuos en las altas cumbres donde nacen las aguas de San Juan y que el concentrado de cobre generará relaves y tóxicos letales envenenando las cuencas del Pacífico y del Atlántico.

- Contaminación de cuerpos de agua y cuencas: los ríos sobre los que se construyeron las represas y embalses, nacen y transcurren en el área de aplicación del mismo, con peligro de

9 Se ampliaron las dimensiones industriales y de producción y se agregaron las siguientes actividades: explotación de un nuevo yacimiento denominado Penélope, ubicado $2,5 \mathrm{~km}$ al sureste del yacimiento principal, en territorio argentino; aumento del ritmo de extracción de mineral de 37.000 toneladas por día a 48.800 toneladas por día; aumento de la tasa de procesamiento a partir del cuarto año, de 33.000 toneladas por día a 44.000 toneladas por día; modificación del punto de captación de agua en el río del Estrecho; reubicación del sistema de manejo y tratamiento de drenajes del depósito de estéril para asegurar un flujo gravitacional y ampliación del campamento ubicado en Chile. 
contaminación de las cuencas y de los embalses, motivo por el se solicita la inclusión de cláusulas específicas que excluyan estas áreas.

- Generación de aguas ácidas: el drenaje ácido de minas pone en riesgo la calidad del agua que se utiliza para regar el valle.

- Demanda excesiva de agua: la demanda de agua del Proyecto Pascua-Lama será de aproximadamente $370 \mathrm{l} / \mathrm{s}$ en total, que provendrá del Río de Las Taguas en Argentina. También se contempla en Chile la extracción de agua para las operaciones de la mina y talleres, estimándose un requerimiento de hasta $42 \mathrm{~L} / \mathrm{s}$, que se obtendrán del Río del Estrecho y Río El Toro.

- Afectación de parques nacionales y provinciales, reservas, embalses y termas ${ }^{10}$

- Emisiones de material particulado a la atmósfera

- Perjuicio a los glaciares (véase lo expuesto en III)

Existen varios reclamos efectuados ante los organismos de gobierno. A continuación se enuncian algunos de ellos:

- Recurso de reclamación presentado por organizaciones sociales chilenas ${ }^{11}$ ante COREMA con el respaldo de un senador y un diputado, para revertir la resolución que aprueba la ejecución del proyecto Pascua Lama, y para que se ordene la realización de un nuevo Estudio de Impacto Ambiental.

- Acción judicial interpuesta por un empresario de la zona de Huasco, para impedir que la iniciativa comience sus operaciones. Esta apunta a obtener la nulidad de derecho público de la resolución número 39 del 2001 de la COREMA de la Tercera Región, que calificó favorablemente el proyecto Pascua Lama. ${ }^{12}$

- Demanda de nulidad de compraventa presentada ante el $14^{\circ}$ Juzgado Civil de Santiago por el dueño de los terrenos aledaños a aquellos en los que se desarrolla el proyecto minero Pascua Lama. En 1997 el titular cedió a la compañía las concesiones mineras sobre las que se trazaron los accesos al complejo. El tribunal hizo lugar a la demanda, determinó que el monto de venta no se ajusta al valor real de las 8.600 hectáreas de la Región de Atacama y dictaminó que el contrato es inconstitucional, ya que impide al demandante solicitar y constituir concesiones mineras en un extenso terreno colindante a Pascua Lama.

10 Entre otros se mencionan los siguientes: Parque Provincial y Reserva Nacional de Ischigualasto (San Juan) y de Talampaya (La Rioja); Reserva de Biósfera San Guillermo (San Juan); Parques Nacionales: Laguna Blanca (Neuquén), Lanín (Neuquén), Nahuel Huapi (Río Negro), Lago Puelo (Chubut), Los Alerces (Chubut), Perito Moreno (Norte de Santa Cruz); termas Fiambalá (Catamarca), Pismanta (San Juan), El Sosneado (Mendoza), Copahue y Caviavue (Neuquén); embalses: los Nihuiles I, II y III y Valle Grande sobre el río Atuel, Los Reyunos sobre el río Diamante, Agua del Toro, (Mendoza).

11 Dentro de las organizaciones se encontraban representantes de Oceana, del Consejo de Defensa del Valle del Huasco y de Olca.

12 La demanda de nulidad de derecho público fue interpuesta por el empresario ante la Corte de Apelaciones de Santiago de Chile el 27 de enero de este año contra la CONAMA, alegando el proyecto lesiona sus derechos de aprovechamiento de agua en la zona.

Fuente: www.olca.cl/oca/chile/region03/pascualama133.htm 
- Presentación realizada en septiembre del año 2005 por la Clínica de Acciones de Interés Público y Derechos Humanos de la Universidad Diego Portales, en representación de la Comunidad Diaguita de los Huascoaltinos. Solicitó a la Dirección General de Aguas (DGA) del Ministerio de Obras Públicas, que declare la ilegalidad del Protocolo de Mitigación de Impacto Ambiental firmado por el Directorio de la Junta de Vigilancia del Río Huasco y sus Afluentes con la Compañía Minera Nevada, filial de la multinacional canadiense Barrick Gold. La comunidad alega que el Protocolo es inválido, ya que lo suscribe únicamente el Directorio de la Junta de Vigilancia, sin que exista representación de la totalidad del organismo, y compromete derechos territoriales de todo el Valle del Huasco, cuyos titulares no han estado representados en el proceso de negociación. La DGA dictaminó que el directorio se excedió en sus facultades legales al suscribir un Protocolo, ${ }^{13}$ e interpretó que aquel no está autorizado para suscribir un acuerdo $^{14}$ de esas características, sin la aprobación de una asamblea general extraordinaria de sus miembros, hecho que no fue acreditado de acuerdo a los antecedentes presentados por la Junta a la DGA. Si bien la DGA denegó la solicitud presentada por corresponder a un acuerdo entre privados, y no a un acto administrativo del Estado, reconoce sus facultades fiscalizadoras sobre las juntas de vigilancia, de acuerdo a lo dispuesto por el Código de Aguas. En virtud de ellas emitió su pronunciamiento.

- Presentación ${ }^{15}$ de las organizaciones del Valle del Huasco ante la Comisión de Recursos Naturales y Medio Ambiente de la Cámara de Diputados (en virtud del rol fiscalizador de la Cámara) para solicitar la anulación de la Resolución Exenta N 39 del 25 de Abril de 2001 y de la Resolución Exenta 024 del 15 de febrero del año 2006. En la presentación se mencionan entre otras cuestiones irregularidades en el proceso de evaluación ambiental; y falta de consideración por el organismo ambiental de los informes y estudios de la DGA, y de las declaraciones de la empresa donde se constatan los daños que produjeron las labores de exploración del proyecto minero Pascua Lama sobre los glaciares del sector. Solicitan se forme una Comisión Investigadora de la Cámara de Diputados para que revise las irregularidades mencionadas en el informe, y se paralicen las resoluciones hasta que exista un pronunciamiento de la Cámara de Diputados que refiera a las investigaciones realizadas.

- Reclamos efectuados por los habitantes del valle del Huasco en Chile, para impedir la materialización del proyecto minero. Esta instancia de participación está contemplada en la ley

13 El Protocolo fue firmado el 30 de junio de 2005 y establece entre otras cuestiones, la transferencia de 60 millones de dólares en un plazo de 20 años para compensar los potenciales impactos y efectos adversos directos e indirectos, que pudieran resultar de la ejecución del proyecto Pascua Lama.

14 Alegan que el acuerdo habría sido unos de los principales antecedentes tomados en cuenta por la Comisión Regional de Medio Ambiente, COREMA, para dar su aprobación a la iniciativa.

15 Firmada por los siguientes: integrantes de la Delegación de las organizaciones del Valle del Huasco frente al proyecto Pascua Lama:Luis Faura, Concejal de Alto del Carmen; Jorge Pino, Concejal Vallenar y Presidente de los M unicipios Mineros; Iván Espinoza, Presidente Pirquineros de la Provincia del Huasco; Juan Peñaloza, Consejo de Defensa del Valle del Huasco; Hermana Sandra Segovia, Congregación Dominicas de la Presentación; Lucio Cuenca, Presidente OLCA; Daniela Escalona, Geógrafa OLCA; Javier Karmy, Periodista, Programa Semillas de Agua. 
ambiental chilena, y permite que sean los propios afectados quienes tengan influencia directa en el Estudio de Impacto Ambiental (EIA). ${ }^{16}$

- Manifestación de un grupo de madres de los Jachalleros Autoconvocados de San Juan, Argentina, apoyada por la organización no gubernamental FUNAM en 2004. Esta organización manifestó durante el Primer Congreso Argentino en Defensa de los Recursos Naturales realizado en Jáchal, que denunciaría al gobierno de la Provincia de San Juan y a la Secretaría Ambiental Nacional ante la UNESCO, por no proteger la Reserva de la Biósfera de San Guillermo. Más de 400 personas marcharon en aquel entonces en Jáchal alrededor de la plaza local para protestar contra la empresa Barrick Gold.

\subsection{Situación de los glaciares: vacíos legales}

Es indudable la estrecha relación que existe entre el Proyecto minero y los glaciares, ya que éste contempla la realización de la explotación minera en las cercanías de tres glaciares: Esperanza, Toro I y Toro II. El yacimiento se encuentra debajo de esos glaciares, que forman parte de la Cuenca hidrográfica del Huasco, que alimenta a gran parte de los ríos de la zona. En el sector de la naciente de la cuenca del Río El Toro existen varios glaciares además de los mencionados. Según el estudio presentado por la empresa, el rajo de la mina debería ocupar por lo menos 10 hectáreas de glaciares. El denominado 'Plan de Manejo de Glaciares' presentado por aquella, contempla su remoción (un total de 10 hectáreas de hielo), lo cual obliga a movilizar hacia el lugar los equipos mineros que realizarán el trabajo (bulldozer y/o cargador frontal). Los trozos de glaciar serán removidos con esa maquinaria hasta dejar despejada la superficie del terreno (principalmente roca), y trasladados hasta un sector adyacente cercano, fuera de los límites que serán intervenidos con el desarrollo del rajo. En el plan se indica que el titular desarrollará un programa de seguimiento de los glaciares removidos y relocalizados, a fin de verificar su evolución y evaluar si la medida de traslado de glaciares adoptada fue adecuada. Si ésta no arroja los resultados esperados y se demuestra que los glaciares tienden a desaparecer, aquel deberá proponer e implementar las medidas compensatorias que resulten pertinentes, que serán evaluadas previamente por la autoridad ambiental.

El 15 de febrero de 2006, la COREMA de la III Región chilena de Atacama aprobó en forma unánime la explotación aurífera de Pascua Lama en la frontera con Argentina, mediante Resolución Exenta $\mathrm{N}^{\circ}$ 024, en la cual establece como condición que 'el titular deberá acceder al recurso mineral y obras asociadas al desarrollo del proyecto en la zona de glaciares Toro 1, Toro 2 y Esperanza de manera tal que no se produzca remoción, traslado, destrucción o cualquier otra intervención física sobre ellos.' La imposibilidad de intervención material directa sobre los glaciares

16 Dentro de los argumentos esgrimidos en los reclamos se menciona que el proyecto no asegura que los glaciares no serán afectados negativamente por el material particulado que genere la minera, que al depositarse en la superficie del hielo produce un aumento de la temperatura que a su vez puede acelerar su derretimiento. También se menciona que las aguas subterráneas bajo la zona de influencia de la mina (debajo de los depósitos de estériles y del rajo) pueden verse seriamente afectados por elementos contaminantes como el mercurio y el arsénico, al filtrarse hacia la napa. Según ellos, el proyecto no aseguraría que materiales tóxicos como el cianuro no sean transportados por la ladera del río Huasco. 
implica en la práctica que la minera deberá proceder a efectuar minería subterránea o mixta para ejecutar su proyecto.

Para algunos ${ }^{17}$ la condición impuesta por la COREMA no es garantía de la conservación de los glaciares, ya que éstos ya presentan un evidente deterioro por el polvo procedente de las obras que Barrick realiza desde hace meses (por ejemplo la apertura de caminos).

Argentina ${ }^{18}$ y Chile no poseen normativa específica referida a la protección directa de glaciares. Son evidentes los vacíos normativos y de políticas existentes en la materia en ambos países, ${ }^{19}$ lo cual implica que su regulación dependerá en este caso y en lo sucesivo hasta que la cuestión sea normada, de lo que resuelvan las respectivas autoridades ambientales. Tampoco existen tratados o convenciones internacionales que los protejan en forma directa. ${ }^{20}$

Las posturas en torno a la reducción de la superficie de los glaciares son diversas. La primera hace responsable de esta situación a la intervención efectuada por la empresa en los terrenos cercanos a los glaciares durante 20 años en la etapa del anteproyecto. Afirma que si la minera continúa sus faenas podría producirse la extinción de otros glaciares próximos a los depósitos estériles del mineral (por ej. el glaciar Estrecho), y pronostica la tendencia hacia la extinción de los glaciares más expuestos a los trabajos futuros de la minera Barrick. ${ }^{21}$ La otra, ${ }^{22}$ si bien reconoce que 'hay tres glaciares pequeños que se afectan con el rajo de la mina y ya tienen una disminución en su superficie', asegura que es necesario consultar a dos glaciólogos del Centro de Investigación Científica de Valdivia, para obtener una evaluación acertada, 'quienes emitirán pronto los resultados de sus análisis'. La primera de las posturas descarta la teoría de la empresa, que alega

17 Por ej. el representante del Consejo de Defensa del Valle del Huasco.

Fuente: www.tierramerica.net/2006/0218/noticias2.shtml

18 La única referencia indirecta al tema puede encontrase cuando se hace referencia a los sistemas de montaña, en el documento de la Estrategia Nacional de Biodiversidad, aprobada por Resolución SAyDS $N^{\circ}$ 91/03. Allí, en la parte que refiere a la 'Planificación bioregional y del uso de la tierra', se establece como objetivo específico $\mathrm{N}^{\circ} 4$ '...lograr un planeamiento para el manejo integral de las zonas costeras y marinas, así como de alta montaña, del país'. Sin embargo, no se hace referencia específica tampoco aquí a los glaciares.

19 Según surge del libro en vías de publicación titulado 'Aspectos jurídicos de los glaciares', Centro de Derecho Ambiental de la UICN, UICN Serie de Política y Derecho Ambiental.

20 Cabe destacar, como instrumento bilateral, la Declaración de Calafate firmada en la Provincia de Santa Cruz entre los presidentes de la República Argentina y de la República de Chile el 29 de agosto del 2003, en la que se hace una mención a los glaciares cuando se alude a los efectos negativos que el deterioro de la capa de ozono y el cambio climático pueden causar en el extremo Sur del continente y en la Antártida y a las consecuencias adversas que el aumento de la radiación ultravioleta provoca en general. Se hace mención así a 'la inusitada intensidad del deshielo que reduce los glaciares y los témpanos'. Los mandatarios deciden dentro del marco de esta declaración, apoyar e impulsar estudios conjuntos de científicos argentinos y chilenos sobre los efectos del cambio climático y el deterioro de la capa de ozono en las zonas patagónicas y en la Antártida, con especial énfasis en la interrelación existente entre estos fenómenos, con la necesaria cooperación internacional adicional a los recursos y esfuerzos que realizan Argentina y Chile.

21 Según surge del resultado del estudio realizado por la Dirección General de Aguas del Ministerio de Obras Públicas, a cargo de un ingeniero experto en glaciares, quien junto a otros 14 especialistas fue convocado en enero por la COREMA de la Tercera Región, para realizar una visita de fiscalización a los trabajos que está realizando la compañía. La COREMA coordinó la visita con la Minera. Fuente: www.olca.cl/oca/chile/ region03/pascualama04.htm

22 Representada por el Director de la COREMA de la región de Atacama. 
que la disminución del volumen de los glaciares se debe al efecto climático, y la segunda sostiene que esta es sólo una de las hipótesis a considerar.

Los glaciares son reservorios y fuente de provisión de agua, y actúan como reguladores del balance hídrico en la cuenca. Estas funciones serán afectadas por la actividad minera y por la reducción de la superficie de los glaciares. También deben ser tenidos en cuenta los impactos sociales que se producirán para los lugareños, agricultores y regantes de Vallenar del Valle del Huasco en Chile, que usan el agua que surge de la fuente natural, para los cultivos de aceite de oliva, aceitunas y vinos, y para consumo humano.

En Argentina la Fundación Ciudadanos Independientes (FU.CI) inició en abril del año 2005 una acción legal, y denunció mediante sumario $N^{\circ} 32.688 / 05$ caratulado 'Villalonga, Silvia e Icazatti, Silvia C/ Motivo S/ Estado Provincial' que:

en el informe de la minera Barrick, no se detalló la existencia de glaciares de roca interiores (Permafrost, Capa Activa, etc.), los que constituyen la reserva hídrica de agua dulce de la zona, pues son los que aportan el agua por cauces subterráneos y superficiales, según las necesidades y condiciones imperantes, constituyendo las reservas hídricas, conforme lo expuesto por el glaciólogo ${ }^{23}$ en su informe titulado 'Las Reservas Hídricas Ocultas de Veladero.' 24

\subsection{Normativa nacional ambiental aplicable al Proyecto}

La normativa aplicable en materia ambiental en ambos países abarca desde leyes marco o generales del ambiente - ambas normas ${ }^{25}$ mencionadas en nota al pie contemplan como instrumento de gestión el EIA - hasta normas aplicables en materia de recursos naturales (agua, aire, suelo, áreas protegidas y reservas naturales, entre otras).

En Argentina la Ley General del Ambiente $N^{\circ} 25.675$, de presupuestos mínimos de protección ambiental, contiene aspectos de suma relevancia que sientan la base para la formulación de la política ambiental. A partir de la sanción de dicha norma, toda obra o actividad que se realice en el territorio de la Nación que sea susceptible de degradar el ambiente (art. 11) está sujeta a un procedimiento de EIA, en forma previa a su ejecución.

A través de la incorporación de un Título Complementario referido a la 'Protección ambiental para la actividad minera,' por medio de la ley 24.585, en el Código de Minería (texto ordenado por decreto 456/97), se exige la realización de un Informe de Impacto Ambiental. ${ }^{26}$ La realización del Informe de Impacto ambiental (IIA) para las etapas de prospección y exploración, debe sujetarse a lo dispuesto en los Anexos I y II de las Normas complementarias de la Ley 24.585. El Título

23 Refiere al experto en glaciología Lic. Pablo Milana.

24 Fuente: Primera nota, informe especial de las entrevistas e intercambios que sostuvo Javier Rodríguez Pardo, en San Juan con el investigador glaciólogo, Dr. Juan Pablo Milana y su cuestionamiento a los proyectos de Barrick Gold en la provincia de San Juan, colindantes con el mismo emprendimiento del lado chileno. Javier Rodríguez Pardo, San Juan 27 de julio de 2005.

25 Ley chilena sobre 'Bases Generales del Medio Ambiente' N 19.300 y Ley argentina 'General del Ambiente' $\mathrm{N}^{\circ} 25.675$.

26 Véase arts. 4 , inc. a), $8^{\circ}$ y 3. 
Complementario del Código de Minería fue reglamentado dentro del marco del COFEMIN, donde se confeccionaron las denominadas normas 'complementarias' o 'reglamentarias' de la Ley 24.585, aprobadas por dicho organismo a los efectos de su aplicación por parte de las autoridades provinciales pertinentes. De esta manera, se deja a cada Provincia la facultad de reglamentar la Ley 24.585 en sus respectivas jurisdicciones, sin que exista una intromisión en las facultades ambientales provinciales, que refleja una concertación interjurisdiccional de las políticas ambientales y mineras.

En la Provincia de San Juan, la ley $N^{\circ} 6.571$ establece en su art. $2^{\circ}$ que 'todos los proyectos de obras o actividades capaces de modificar directa o indirectamente el ambiente del territorio provincial, deberán obtener una Declaración de Impacto Ambiental (D.I.A) expedida por la Subsecretaría de Política Ambiental.' Los emprendimientos mineros deben someterse al proceso de evaluación de Impacto Ambiental efectuado por la autoridad Ambiental Provincial (art. 17). El Decreto 1426/96 de Protección Ambiental para la Actividad Minera, obliga a la presentación del Informe de Impacto Ambiental ante la autoridad de aplicación, para cada una de las etapas del procedimiento minero.

En Argentina las provincias dictan la normativa aplicable en materia de aguas: Códigos y leyes de agua; normas de vertidos a cuerpos de agua; leyes ambientales y normas de prestación del servicio de agua potable y cloacas. ${ }^{27}$ Los códigos de agua provinciales contemplan las formas de otorgar el uso especial de las aguas públicas (permiso de uso y concesión). La asignación de los derechos de uso del agua corresponde a las autoridades provinciales del agua, que los otorgan según lo previsto en legislación sobre agua.

La Provincia de San Juan tiene un Código de Aguas $^{28}$ que regula el uso del agua para las actividades mineras. El minero debe impedir la contaminación de los acuíferos e indicar como cualquier usuario, el volumen de la concesión de uso de agua solicitado y el destino de las aguas sobrantes y el modo de extracción.

Al sector minero son aplicables también las normas que rigen a la biodiversidad; parques y áreas protegidas; impacto ambiental; flora y fauna y paisaje. También el valor estético y paisajístico posee una importancia en sí misma, teniendo en cuenta que el art. 41 de la CN refiere a la preservación del patrimonio natural y cultural y de la diversidad biológica. La Ley 24.585 establece en el artículo 18 del Título Complementario que 'todo el que causare daño actual o residual al patrimonio ambiental, estará obligado a mitigarlo, rehabilitarlo, restaurarlo o recomponerlo según correspondiere.'

La labor minera genera como otros sectores productivos e industriales residuos peligrosos. Al respecto el Código de Minería dispone en su artículo 170 (Texto ordenado por Decreto 456/97), que 'Los establecimientos públicos de fundición y beneficio de minerales se sujetarán a las

27 Cabe señalar que la Ley 25.688 de presupuestos mínimos en materia de aguas, aplicable en todo el territorio del país, fija el Régimen de Gestión Ambiental de Aguas y establece 'los presupuestos mínimos ambientales, para la preservación de las aguas, su aprovechamiento y uso racional'. 
disposiciones que rigen las empresas industriales comunes.' Existe un debate no resuelto, en torno a la aplicabilidad de las normas generales en materia de residuos a la actividad minera. ${ }^{29}$

En Chile la ley 19.300 sobre 'Bases Generales del Medio Ambiente'30 contempla el Sistema de Evaluación de Impacto Ambiental (SEIA). Incluye como proyecto o actividades susceptibles de causar impacto ambiental, que debe someterse al SEIA a los Proyectos de desarrollo minero (art. 10, inc. i).

El Proyecto minero Pascua Lama considera la extracción de agua desde los Ríos del Estrecho y, en menor medida del Río El Toro para uso en las operaciones de la mina y talleres, para lo cual la empresa está tramitando la obtención de derechos de aprovechamiento del recurso. La cantidad de agua a extraer será de 42 l/s como máximo en el Río del Estrecho y un mínimo en el Río El Toro. En un escenario de año seco o muy seco (95\% de probabilidad de excedencia), las captaciones implicarán una reducción de hasta un 16\% en el caudal del Río del Estrecho, en los sectores donde existe captación para riego. En estos años secos el Proyecto se compromete a dejar un caudal en los puntos de captación, equivalente al caudal mínimo mensual de un año con 95\% de probabilidad de excedencia, de modo que no se interrumpirá el flujo aguas abajo.

En materia de recursos hídricos se aplica el Código de Aguas de 1981, ${ }^{31}$ modificado por ley posterior, que regula fundamentalmente los aspectos patrimoniales de agua, pero no los referidos a su conservación, preservación y contaminación. La modificación al Código de Aguas, realizada por la ley $20.017^{32}$ incluyó algunas normas de tipo ambiental, tales como aquellas que establecen un caudal ecológico mínimo para otorgar derechos de aguas (art. 129 bis 1). La Dirección General de Aguas (DGA) propuso establecer 'caudales ecológicos mínimos' (flujos mínimos para conservar las condiciones ecológicas del cauce) para tramos de un río determinado, que servirán como referencia para la concesión de nuevos derechos.

29 Algunos autores entienden que la aplicación de la normativa común (por ej. LRP 24.051) a la actividad minera iría contra la unidad del derecho minero (porque volúmenes de materia prima involucradas en la minería suelen ser mucho mayores a su equivalente en un proceso industrial típico y en los EE.UU la tendencia es favorable a exclusión de residuos mineros de la legislación sobre RP).

Si se considera aplicable la normativa común sobre RP, surge dilema a partir de la sanción de la Ley 25.612 de Gestión Integral de Residuos Industriales y Actividades de Servicio (art. 60 establece que queda derogada la ley 24.051 de Residuos Peligrosos; esto fue observado y vetado por el Decreto 1343/02). Se esgrimen 2 posturas: a) derogación tácita por incompatibilidades entre ley 24.051 y 25.612; ley posterior deroga a anterior; b) ley 24.051 continúa vigente hasta tanto no exista derogación expresa. No hay disenso en que la 24.051 continúa vigente respecto de las normas de responsabilidad penal respecto de delitos cometidos con residuos peligrosos, hasta tanto se sancione otra norma de presupuestos mínimos en esta última materia (ver artículo 60 de la Ley 25.612 y artículo 1 del Decreto 1343/2002 que veta el capítulo penal de la Ley 25.612).

Por otro lado el art. 60 de la ley 25.612 dispone que 'hasta tanto la reglamentación establezca la creación de los diferentes registros determinados por la presente, se mantendrán vigentes los anexos y registros contenidos en dicha ley ' (hace referencia a la 24.051).

30 En su art. $8^{\circ}$ establece que '...los proyectos o actividades señalados en el artículo 10 sólo podrán ejecutarse o modificarse previa evaluación de su impacto ambiental...'.

31 Contenido en el Decreto con Fuerza de Ley (DFL) $N^{\circ} 1.122$ promulgado el 13 de agosto de 1981 y publicado en el Diario Oficial el 29 de octubre de 1981.

32 Promulgada el 11 de mayo de 2005 y publicada en el Diario Oficial el 16 de junio de 2005. 
El titular del proyecto deberá cumplir la Norma técnica Chilena Oficial NCh.1333, que establece los 'Requisitos de Calidad del Agua para diferentes usos', y la Norma Chilena Oficial NCh. 409 de Agua Potable para las primeras captaciones para consumo humano que existan en el río, tanto en el Valle del Carmen como en el Valle del Chollay, aguas abajo del proyecto. Estas normas son técnicas y jurídicamente no obligatorias.

\subsection{Carácter binacional del Proyecto: tratados ambientales multilaterales y principios del derecho internacional ambiental}

\subsubsection{Consideraciones generales. Los tratados ambientales multilaterales como creadores de obligaciones para las partes}

Debido al carácter binacional del proyecto son aplicables varios tratados bilaterales firmados entre Chile y Argentina, que contemplan aspectos económicos, mineros y ambientales. Tanto Chile como Argentina suscribieron la mayoría de los tratados multilaterales ambientales, que integran su derecho interno. Ambos son parte a su vez de la Convención de Viena de Derecho de los Tratados de 1969, que dispone que 'un Estado parte en un tratado no podrá invocar las disposiciones de su derecho interno como justificación del incumplimiento del tratado' (art. 27, principio 1). Esta convención establece a su vez que las relaciones de los Estados parte de dicha Convención, en virtud de un tratado entre dos o más estados, se regirán por aquella (art. 73).

Además de la legislación local y los tratados bilaterales, se aplican los tratados ambientales multilaterales. Será necesario entonces determinar cual es el rango de los tratados internacionales en cada país, y cómo se incorporan éstos a su ordenamiento jurídico interno.

En Argentina, la Constitución Nacional prevé la jerarquía supralegal de los tratados en el art. 75, inc. 22, en forma concordante con lo establecido por el art. 27, Sección I de la Convención de Viena sobre el Derecho de los Tratados, que fue ratificada por la Argentina mediante Ley $N^{\circ} 23.782$ (B.O. 7.6.90). Los Tratados de Derechos Humanos enumerados taxativamente en el inciso 22 del art. 75 de la CN poseen jerarquía constitucional. En Chile, los tratados internacionales 'constituyen una jerarquía de normas que están por debajo de la Constitución, pero antes de la ley común y de todas las demás normas jurídicas que se dicten dentro del Estado. ${ }^{33}$ Ambos países coinciden en que los tratados poseen una jerarquía por encima de las leyes, de acuerdo a lo establecido por la Convención de Viena.

Siguiendo a Laciar, ${ }^{34}$ cabe señalar que el origen fundamental del derecho internacional ambiental se encuentra en las llamadas 'normas convencionales', dentro de cuya categoría se incluye a muchos de los tratados aún cuando contengan únicamente algunas disposiciones ambientales. Los tratados ambientales frecuentemente invaden áreas tradicionalmente específicas

33 Silva Bascuñan, A. 'Tratado de Derecho Constitucional'. Tomo IV, Editorial Jurídica de Chile, Segunda Edición, Santiago de Chile,1997, pág. 124.

34 Laciar, Mirta Elisabeth: Informe Final, Contribución al desarrollo y fortalecimiento de las capacidades de organización institucional para el desarrollo sustentable de la República Argentina, Programa Desarrollo Institucional Ambiental AR=0065/BID/SRNyAH, Componente Política Ambiental, Buenos Aires, julio de 1995. 
de los estados particulares, y fijan un marco de reglas internacionales que deben ser complementadas por normas del derecho interno, y adoptadas por el estado parte o firmante del convenio. Es una obligación fundamental en el ámbito del derecho internacional, observar de buena fe los tratados y sus obligaciones. Si bien los tratados y convenios son vistos como creadores de obligaciones para los estados parte, la naturaleza de los problemas ambientales muchas veces no hacen posible definir el contenido exacto de tales obligaciones. La autora mencionada precedentemente dice que éstos, más que fijar exigencias específicas, contienen cláusulas a las que deberán sujetarse las partes para cooperar en el logro de un programa de acción común, para obtener el cumplimiento de los objetivos de un tratado.

Estrada Oyuela ${ }^{35}$ explica que los convenios ambientales multilaterales pertenecen a la categoría más reciente de tratados desarrollados en siglo $\mathrm{XX}$, particularmente luego de la Primera Guerra Mundial, en los que se ve más claramente la decisión de los gobiernos de hacer esfuerzos conjuntos de cooperación para el bien común. Estos convenios crean secretarías permanentes y conferencias periódicas y suelen contemplar a modo de complemento mediante protocolos subsidiarios, que contienen disposiciones de implementación más especificas que los tratados. Este tipo de tratados crea regímenes jurídicos y son 'conjuntos de principios implícitos o explícitos, normas reglamentos y procedimientos para la adopción de decisiones. ${ }^{36}$ Estos regímenes imponen una interacción constante entre las partes, y en ellos se desarrollaron criterios de control de la observancia de los tratados. Generalmente solicitan a los gobiernos que presenten comunicaciones periódicas sobre el cumplimiento de sus obligaciones, o que informen cuando realicen actores restringidos o regulados por los tratados.

Siguiendo esta línea argumental, cabe hacer mención a ciertos principios del derecho internacional (generales y particulares ${ }^{37}$ ) que se aplican al caso Pascua Lama, debido a que están incluidos o subyacen a diversos tratados ambientales internacionales ratificados por ambos países. Éstos integran a su vez el grupo de las denominadas reglas consuetudinarias del derecho internacional, entendidas como normas derivadas de una práctica generalizada y aceptada como ley por los Estados. Existen varias normas consuetudinarias del derecho internacional ambiental que emergen de dicha práctica (por ej. la obligación de cooperar, contemplada por el Principio 24 de la Declaración de Estocolmo, que luego fue adoptada y reafirmada por varios instrumentos internacionales vinculantes y no vinculantes). Podemos hablar entonces de principios fundamentales subyacentes en el sistema internacional, aplicables a todas las materias ambientales.

Como dice Barboza, ${ }^{38}$ nos referimos a los principios jurídicos que merecieron alguna consagración en la práctica internacional, y que subyacen a un conjunto de normas particulares de derecho positivo.

35 Estrada Oyuela, Raúl 'El control de la observancia o cumplimiento de Iso acuerdos ambientales internacionales', en Revista Jurídica de Buenos Aires. Derecho Ambiental, Ed. Lexis Nexis, Abeledo Perrot, Buenos Aires, 2005.

36 Krasner, Stephen D. 'International Regimes', Cornell University Press, 1983.

37 Recordemos que existen principios generales del derecho internacional que son aplicables además a otros ámbitos además del ambiental.

38 Barboza, Julio: 'Derecho internacional público', Ed. Zavalía, Buenos Aires, 1999. 


\subsubsection{Principios del derecho ambiental internacional: su consideración en los tratados ambientales multilaterales y en los acuerdos bilaterales}

Rigen también en este caso los principios del derecho ambiental internacional consagrados por varios tratados internacionales ambientales, que integran el derecho interno de Argentina y Chile. Muchos de ellos son contemplados a su vez por los tratados bilaterales suscriptos entre ambos países. Haremos referencia a los siguientes principios: preventivo, precautorio, de cooperación y uso racional de los recursos dentro del marco del concepto del desarrollo sustentable.

Estos principios se convierten en obligatorios para los Estados a partir de su incorporación en tratados o normas de la costumbre internacional. El incumplimiento de aquellos por un Estado, lo hará responsable por las consecuencias dañosas. El Estado afectado estará entonces en condiciones de exigir una compensación, por soportar un mayor riesgo ambiental sobre su territorio. Las reglas elaboradas por la Comisión de Derecho Internacional sobre Responsabilidad Internacional ${ }^{39}$ consagran la responsabilidad internacional del Estado adopte una conducta que constituya una violación de una obligación internacional, que le sea atribuible según el derecho internacional. Sin embargo, esta obligatoriedad se ve frecuentemente 'suavizada' o 'desvirtuada' de su verdadero efecto en la práctica, ya que es muy difícil hacerla cumplir.

El proyecto Pascua Lama es un emprendimiento binacional situado en la frontera entre Chile y Argentina, que como tal posee un riesgo inherente desde el punto de vista ambiental para ambos países, y que es susceptible de producir efectos contaminantes transfronterizos. Los países involucrados se limitaron a recibir los respectivos estudios de impacto ambiental en cumplimiento de la legislación nacional, a través de los organismos ambientales administrativos pertinentes, que son evaluados por aquellos en forma individual. Sin embargo, no fueron implementados mecanismos conjuntos de evaluación y de consulta a las comunidades afectadas de ambos lados de la frontera, teniendo en cuenta que se trata de un proyecto binacional. La ausencia de tratados o instrumentos bilaterales que contemplen un sistema de evaluación de impacto ambiental transfronterizo, y de un sistema de consulta compartido para proyectos de estas características debidamente reglamentados, no favorecen un enfoque en conjunto.

\section{Principio preventivo}

El principio $N^{\circ} 21$ de la Declaración de Estocolmo, denominado 'preventivo', alude al derecho soberano de los Estados de explotar sus propios recursos en aplicación de su política ambiental. En contrapartida refiere a la obligación de asegurar que las actividades que se lleven a cabo dentro de su jurisdicción o bajo su control, no perjudiquen al medio de otros Estados. Siguiendo esta línea argumental, se mencionará el tema de la responsabilidad por las consecuencias perjudiciales de los actos no prohibidos por el derecho internacional. En el art. $3^{\circ}$ del Proyecto de la Comisión de Derecho Internacional ${ }^{40}$ se hace referencia a la 'libertad de acción y sus límites' (subtítulo), y se expresa que la libertad de los Estados para desarrollar actividades en su territorio no es ilimitada, sino que 'está supeditada a la obligación general de prevenir o minimizar el riesgo de causar un

39 Arts. 1,2 y 3 de las 'Drafts Articles on State Responsability adopted by the International Law Comission on 12 July 1996'. Informe de la CDI 1996, Capítulo 3.

40 Op. cit. (41). 
daño transfronterizo sensible y también a las obligaciones jurídicas concretas que se hayan asumido a ese respecto con otro Estado.'

Según menciona Barboza ${ }^{41}$ la cuestión enunciada encuadra dentro del principio jurídico del utere tuo et alienum non laedas, y debe ser analizada desde dos ángulos que deben hacerse compatibles. El primero refiere al ámbito de libertad interno, y se basa en la soberanía territorial de cada Estado, que posee un límite expresado en el segundo. Este último está dado por la obligación de no perjudicar el medio ambiente de otros Estados, como resultado de las actividades realizadas dentro del ámbito de su jurisdicción. Según expresa el autor, la soberanía territorial es dual, ya que afirma la libertad de acción en el propio territorio, pero rechaza cualquier efecto perjudicial venido de afuera. Esto confluye en el compromiso de cada Estado de hacer un uso inofensivo del territorio.

Varios tratados multilaterales y bilaterales hacen mención a este principio. El Tratado de Medio Ambiente suscripto entre Argentina y Chile, cuando alude al objetivo del tratado (art. $1^{\circ}$ ) establece claramente que 'cada una de las Partes se compromete a no realizar acciones unilaterales que pudieren causar perjuicio al medio ambiente de la otra'. También en su art. $2^{\circ}$ menciona reiteradamente el principio preventivo - que busca evitar la producción del daño empleando la debida diligencia y que se relaciona con el concepto de riesgo ambiental ${ }^{42}$ - cuando refiere a las acciones que las Partes deben efectuar en forma coordinada. Mencionada entre aquellas a la investigación, evaluación y prevención de la contaminación transfronteriza; protección y aprovechamiento racional de los recursos hídricos y de sus recursos vivos; y prevención de catástrofes naturales y ecológicas.

El principio preventivo también se traduce en los mecanismos o instrumentos previstos obligatoriamente en actividades calificadas como 'riesgosas', para prevenir el daño ambiental (por ej. Evaluación de Impacto Ambiental - $E A^{43}$ ). En el Tratado de Minería (art. 12) firmado entre ambos países, las partes se comprometen a someter las actividades mineras al Sistema de Evaluación de Impacto Ambiental en Chile, y a la Declaración de Impacto Ambiental en la Argentina (según la norma provincial).

\section{Principio precautorio}

Este principio dispone que frente a una amenaza de daño irreparable al medio ambiente, la falta de certidumbre científica sobre la producción de ese daño no debe demorar la adopción de medidas para prevenirlo. Su origen se remonta a Alemania en la década de los setenta, y tuvo su primer reconocimiento internacional a través de la Carta Mundial de la Naturaleza, aprobada por la Asamblea General de las Naciones Unidas en 1982. Luego fue adoptado por distintos convenios internacionales ambientales. En la Declaración de la Conferencia de las Naciones Unidas sobre

41 Op. cit (41).

$42 \mathrm{El}$ art. $4^{\circ}$ del Proyecto de la CDI subtitulado 'La prevención' establece que 'Los Estados adoptarán todas las medidas apropiadas par prevenir o minimizar el riesgo de causar un daño transfronterizo sensible y, cuando éste se haya producido, para minimizar sus efectos'.

43 Cabe señalar el caso de la obligación de realizar la EIA dentro del marco de la Convención de ESPOO de la Comisión Económica para Europa de 1991, sobre EIA en ámbito transfronterizo. 
Medio Ambiente y Desarrollo (ECO 92) celebrada en Río de Janeiro, se establece en el Principio 15 que:

Con el fin de proteger al ambiente, los estados deberán aplicar ampliamente el criterio de precaución conforme a sus capacidades. Cuando haya peligro de daño grave o irreversible, la falta de certeza científica absoluta no deberá utilizarse como razón para postergar la adopción de medidas eficaces en función de los costos para impedir la degradación del medio ambiente.

Si bien este principio no se enuncia expresamente en los tratados bilaterales firmados entre ambos países, recordemos que en el Tratado de Medio Ambiente las Partes acuerdan 'concertar sus posiciones en los procesos negociadores que se desarrollen en foros multilaterales sobre los temas objeto del presente Tratado.' Se interpreta aquí que ambos países, que ratificaron la mayoría de los tratados internacionales ambientales en los cuales se enuncia el principio precautorio, adhieren a este principio a través de aquellos. Recordemos que tanto Argentina como Chile adhirieron a la Declaración de la Conferencia de las Naciones Unidas sobre Medio Ambiente y Desarrollo (ECO 92), celebrada en Río de Janeiro. ${ }^{44}$

\section{Principio de cooperación}

El principio de 'cooperación internacional' obliga a la coordinación de políticas respecto de ciertas actividades; creación de organismos o comisiones conjuntas; e intercambio de información y procedimientos de emergencias. El mismo es enunciado tanto en el Tratado de Minería, cuando en el último párrafo del art. 12 establece que las Partes deben promover el intercambio de información relevante que tenga relación con los principales efectos ambientales de cada uno de los negocios mineros o actividades accesorias del tratado, como en el Tratado de Medio Ambiente, cuando en su art. $2^{\circ}$ refiere las acciones coordinadas o conjuntas que deben realizar las partes en los sectores allí enunciados. El tratado ambiental obliga a las Partes a través del art. $3^{\circ}$, a realizar las acciones conjuntas en las materias del tratado, a través de Protocolos específicos adicionales; intercambiar información sobre la legislación vigente y las instituciones y estructuras existentes en el campo de la protección del medio ambiente; formar bancos de datos sobre la base de recolección, análisis y procesamiento de información sobre el estado del medio ambiente, y realizar estudios de impacto ambiental.

\section{Principio de uso sustentable}

En cuanto al 'concepto de la sustentabilidad' (relacionado con el principio de 'uso sustentable de los recursos naturales'), el Informe Nuestro Futuro Común, elaborado por la Comisión Mundial sobre el Medio Ambiente y Desarrollo de Naciones Unidas (Comisión Brundtland) en 1987, define el desarrollo sustentable como aquel que 'debe asegurar que satisfaga las necesidades del presente sin comprometer la capacidad de las futuras generaciones para satisfacer las propias'.

44 Recordemos a Cano, cuando en su artículo 'La Agenda 21: América Latina y el Caribe' publicado en la Revista de Política y Derecho Ambientales en América Latina y el Caribe', Vol. I, № 1. Ed. Fundación Ambiente y Recursos Naturales, 1994, Buenos Aires, refiere a que los países que participaron de la CNUMAD de Río asumieron a través de la Agenda 21 un compromiso político, que si bien no obliga jurídicamente a los gobiernos, tiene un importante peso moral y político. 
Este concepto se refleja en varias convenciones internacionales y subsume a su vez el principio de equidad intergeneracional, según el cual cada generación tiene el deber de legar a las próximas generaciones, una naturaleza que se encuentre en un estado lo más cercano posible al recibido.

La Conferencia de las Naciones Unidas sobre Medio Ambiente realizada en Estocolmo en 1972, ya hacía alusión al derecho del hombre de vivir en un ambiente cuya calidad le permita vivir en dignidad y bienestar, y el consiguiente deber de protegerlo y mejorarlo para las generaciones presentes y futuras. Veinte años más tarde, la Declaración de la Conferencia de las Naciones Unidas sobre Medio Ambiente y Desarrollo (ECO 92) consagraba este concepto en varios de sus principios ( $\mathrm{N}^{\circ} 3$ y 10$)$.

El Tratado sobre Medio Ambiente argentino-chileno enuncia el concepto de desarrollo sustentable y el principio de principio de uso sustentable de los recursos naturales, cuando refiere a las acciones conjuntas entre las Partes, que 'deben impulsar la utilización racional y equilibrada de los recursos naturales, teniendo en cuenta el vínculo existente entre medio ambiente $y$ desarrollo' (art. $1^{\circ}$ ). Cuando enumera las acciones que deberán realizar en los distintos sectores, traduce claramente la idea de un uso racional de los recursos. Así por ejemplo, alude al aprovechamiento racional de los recursos hídricos y de sus recursos vivos; aprovechamiento ambientalmente racional de sus recursos hidrobiológicos y preservación de su diversidad genética; utilización sostenible del patrimonio fito y zoogenético; gestión y administración ecológicamente racional de los productos químicos tóxicos, otros productos nocivos y de los desechos peligrosos y prevención del tráfico internacional ilícito de los mismos, y utilización racional de los recursos energéticos y desarrollo de fuentes energéticas alternativas ambientalmente inocuas.

\subsubsection{Instrumentos bilaterales comerciales y ambientales aplicables al conflicto}

Debido a que se trata de un proyecto minero cuyo objetivo es económico, y que a su vez suscita un conflicto de naturaleza ambiental, deberá ser analizado a la luz de cuestiones tanto económicas, como ambientales y sociales. Nos situamos aquí dentro del concepto de desarrollo sustentable, que implica mucho más que agregar o superponer aspectos ambientales a modelos sociales o económicos preexistentes, y que exige integrar las relaciones entre los sistemas biológicos, económicos y sociales en su conjunto, independientemente del tratamiento de aquellos sistemas en forma aislada. ${ }^{45}$

Los aspectos económicos están contemplados por los tratados, acuerdos y protocolos referidos a las inversiones recíprocas entre ambos países, y por los instrumentos bilaterales que tratan el tema minero en general, y el Proyecto Pascua Lama en particular. Estos deberán integrarse con los aspectos ambientales incluidos en el Tratado de Medio Ambiente, y en el art. 12 del Tratado de Minería, sin olvidar los aspectos sociales que impregnan el conflicto. Chile y Argentina poseen normativa ambiental que deber ser cumplida obligatoriamente por la actividad minera, que además debe realizar los estudios de impacto ambiental en ambos lados de la frontera.

45 Walsh, Juan Rodrigo: 'El ambiente y el paradigma de la sustentabilidad', Capítulo 1, 'Ambiente, Derecho y Sustentabilidad' en coautoría con Gustavo Acosta, Daniel Ryan, Hernán López, Daniel Sabsay, Marta B. Rovere y María Eugenia Di Paola, editado por LA LEY, septiembre de 2000. 
Para una visión integral del problema debemos tener presente, que se trata de un proyecto en el cual están comprometidas inversiones de ambos países, ${ }^{46}$ que tiene una innegable connotación ambiental. La actividad minera es riesgosa en términos ambientales, ya que por sus características produce impactos ambientales cuyo potencial contaminante es de distinto tipo, ya que varía en cada una de las etapas que la integran (prospección, exploración y explotación). Las connotaciones sociales del proyecto están a la vista - según se refleja en los reclamos descriptos ut supra - y suscitan reacciones visibles en la zona afectada por el proyecto.

Si bien las inversiones involucradas en el Proyecto no podrían denominarse como estrictamente recíprocas, en el sentido literal estipulado en el art. $2^{\circ}$ del Tratado de Inversiones Recíprocas ${ }^{47}$ (este refiere a que 'cada una de las Partes Contratantes promoverá las inversiones dentro de su territorio de nacionales o sociedades de la otra Parte Contratante'), puede decirse que estamos frente a inversiones vinculadas ambas a un mismo emprendimiento, realizado en cada país por empresas que son subsidiarias de la misma 'Barrick Gold Corporation', y que por tal motivo dependen mutuamente una de la otra.

El Tratado dispone que las Partes promoverán dentro de su territorio las inversiones de nacionales o sociedades de la otra, y que tratará las inversiones en forma justa y equitativa. Aquellas que son realizadas de acuerdo con las disposiciones legales de una de las Partes Contratantes, gozarán de la plena protección del Tratado, y ninguna de ellas perjudicará en su territorio la administración, la utilización, el uso o el goce de las inversiones de nacionales o sociedades de la otra a través de medidas arbitrarias o discriminatorias.

Rigen en este caso también el Tratado sobre Integración y Complementación Minera ${ }^{48}$ y su Protocolo complementario. ${ }^{49}$ El Tratado sobre Minería constituye un marco jurídico que rige el negocio minero, que tiene por objeto permitir a los inversionistas de cada una de las Partes participar en el desarrollo de la integración minera, de acuerdo a lo establecido por los respectivos ordenamientos jurídicos. Contiene cláusulas ambientales, y establece que las Partes aplicarán sus respectivas legislaciones nacionales sobre protección del medio ambiente (art. 12), 'sometiendo las actividades mineras al Sistema de Evaluación de Impacto Ambiental en Chile y a la Declaración de Impacto Ambiental en la Argentina, según corresponda.' También deben promover el intercambio de información relevante, que tenga relación con los principales efectos ambientales de cada uno de los negocios mineros o actividades accesorias, comprendidas en el presente Tratado. En cuanto a los recursos hídricos compartidos (art. 14), dispone que su utilización 'deberá llevarse a cabo de conformidad con las normas de derecho internacional sobre la materia.' Cita en particular el 'Acta de Santiago sobre Cuencas Hidrológicas' del 26 de junio de 1971; 'Tratado sobre Medio

46 El monto total de la inversión es de 1.450 millones de dólares (950 millones para el Proyecto Pascua Lama más 500 millones para las Modificaciones al Proyecto (Véase: www.e-seia.cl/seia-web/ficha/ fichaPrincipal.php?id_expediente=1048260). El Proyecto tiene una vida útil de 20 años según las actuales reservas, y anualmente producirá unas 5.000 toneladas de cobre contenido en concentrados, 615.000 onzas de oro y 18,2 millones de onzas de plata.

47 Tratado sobre Promoción y Protección Recíproca de Inversiones (firmado el 2.08.91) aprobado en Argentina por Ley 24.342 de fecha 9.06.94.

48 Firmado el 29.12.97, aprobado en Argentina por Ley 25243, de fecha 23.03.00

49 Firmado el 20.08.99. Este Protocolo fue corregido por un Acuerdo del 31.08.99. 
Ambiente' entre la República Argentina y la República de Chile y el 'Protocolo Específico Adicional sobre Recursos Hídricos Compartidos entre la República Argentina y la República de Chile'.

El Acuerdo de Complementación Económica $N^{\circ} 16$ elaborado en forma conjunta por Chile y Argentina, derivado del Tratado de Montevideo de $1980^{50}$ por el cual se instituye a la ALADI (Asociación Latinoamericana de Integración), tiene entre sus objetivos facilitar y expandir el intercambio comercial entre ambos países, promover las inversiones recíprocas y facilitar el 'desarrollo de proyectos de interés común.' En esta última frase encuadra perfectamente el proyecto Pascua Lama, el cual a su vez es regido por los Protocolos adicionales del tratado en mención sobre Promoción e Integración Minera $\left(N^{\circ} 3\right)$, y los $N^{\circ} 20$ y 23, que refieren respectivamente a la facilitación del Proyecto minero Pascua Lama, y a la reglamentación y complemento de las facilitaciones establecidas para dicho Proyecto.

Las Partes suscribieron también el Protocolo Adicional Específico al Tratado sobre Integración y Complementación Minera para el Proyecto Minero 'Lama Pascua', para la adecuación del proyecto minero 'Pascua-Lama', con el objeto de facilitar su desarrollo. El mismo sustituye los Protocolos Vigésimo y Vigésimo Tercero del ACE $16 .^{51}$

El Tratado sobre Medio Ambiente ${ }^{52}$ obliga a las Partes a realizar acciones coordinadas 0 conjuntas en materia de protección, preservación, conservación y saneamiento del medio ambiente e impulsar la utilización racional y equilibrada de los recursos naturales, teniendo en cuenta el vínculo existente entre medio ambiente y desarrollo. Se menciona la prevención de catástrofes naturales y ecológicas (por medio del establecimiento de un sistema de alerta inmediato de las catástrofes naturales y ecológicas), y el análisis de sus causas y las formas de atenuar sus impactos; tratamiento de desechos y productos nocivos; efectos ambientalmente negativos de las Actividades Energéticas Mineras e Industriales y la gestión y administración ecológicamente racional de los productos químicos tóxicos.

A través del Acuerdo sobre Cooperación en Materia de Catástrofes, las partes acuerdan la cooperación mutua en las acciones que emprendan en sus respectivos territorios en caso de catástrofe, y contemplan el diseño y elaboración de Programas, Proyectos y Planes Conjuntos de contingencia.

\subsection{Colofón}

El conflicto debe ser analizado en todos sus aspectos - ambientales, sociales y económicos desde la perspectiva del derecho internacional, dentro del contexto binacional. En puntos precedentes fueron analizados los principios del derecho internacional ambiental, los instrumentos económicos y ambientales bilaterales suscritos entre ambos países, y la normativa ambiental de Chile y Argentina.

50 Aprobado en Argentina por ley $\mathrm{N}^{\circ} 22.354$.

51 www.mineria.gov.ar/planesnacionales/lama_pascua.asp?titpag=Protocolo+Lama+Pascua

52 En materia ambiental resulta aplicable el Tratado de Medio Ambiente (suscripto el 2.08.91) aprobado en Argentina por ley el 24.105 (1.07.92) y en Chile por Decreto Supremo $N^{\circ} 67$ del Ministerio de Relaciones Exteriores (16.01.92). 
La ausencia de tratados o instrumentos bilaterales que contemplen un sistema conjunto de evaluación de impacto ambiental transfronterizo, y de participación ciudadana y consulta, atenta contra la sustentabilidad del proyecto. La escasa participación que tuvieron las comunidades afectadas de ambos países en el proceso de evaluación del proyecto, generó reclamos interminables liderados por organizaciones sociales que vieron frustrada la posibilidad de emitir su opinión en un espacio de consulta formal, dentro del marco del proceso de toma de decisión gubernamental.

Esta ausencia se refleja desde los inicios. Tal es así, que en el año 2001 luego de un pobre proceso de participación ciudadana, las comunidades chilenas de Huasco y Alto del Carmen se enteran de la existencia del proyecto minero. Son los propios agricultores quienes dan la voz de alerta a la autoridad ambiental chilena, respecto de la existencia de glaciares en el lugar que abarca el rajo de la mina. Esta pide explicaciones a la empresa, que informa que trasladará los glaciares afectados hacia otro sector alejado del rajo. La autoridad exige información sobre las acciones del traslado de los glaciares, e incluye en la resolución ambiental de calificación del proyecto la exigencia de presentar un Plan de Manejo de glaciares. Una vez aprobado el proyecto la empresa decide suspender el inicio del proyecto, debido al bajo precio de los metales preciosos a explotar.

A pesar de la postergación del proyecto, la preocupación de las comunidades afectadas seguía vigente. Cuando la empresa anunció la reactivación del proyecto en el año 2004, aquellas fortalecieron sus organizaciones para evitar que el mismo se concretara.

Los reclamos y movilizaciones descriptos dan cuenta de las falencias en el proceso realizado por las autoridades públicas, que no tuvieron en cuenta en su justa medida a los directamente afectados por el proyecto.

Surge entonces el siguiente interrogante: teniendo en cuenta que se trata de un proyecto binacional, al que se aplican los principios del derecho internacional ambiental contemplados en los tratados ambientales multilaterales, ¿los estados parte tuvieron en cuenta las consecuencias del proyecto en toda su dimensión? ¿Existió un intercambio de información entre ambos países respecto de los posibles efectos ambientales y sociales del emprendimiento? Más allá de la respuesta, no cabe duda que es inminente la necesidad de formular un instrumento que contemple un sistema común de evaluación de impacto ambiental transfronterizo, y de consulta previa. Lo contrario contribuirá a acentuar las desavenencias y dificultades que por el momento parecieran tener un final incierto. 



\section{Successfully Managing Marine Fisheries in the Benguela Current Large Marine Ecosystem}

Shaheen Moolla

\subsection{Introduction}

Large Marine Ecosystems are regions of ocean space encompassing coastal areas from river basins and estuaries to the seaward boundaries of continental shelves, enclosed and semienclosed seas, and the outer margins of the major current systems.... They are relatively large regions, of the order of $200000 \mathrm{~km}^{2}$ or greater, characterized by distinct bathymetry, hydrography, productivity, and trophically dependent populations. Within the 64 LMEs, 95\% of the global marine capture fisheries are found as well as most of the ocean pollution and coastal habitat alteration. ${ }^{2}$

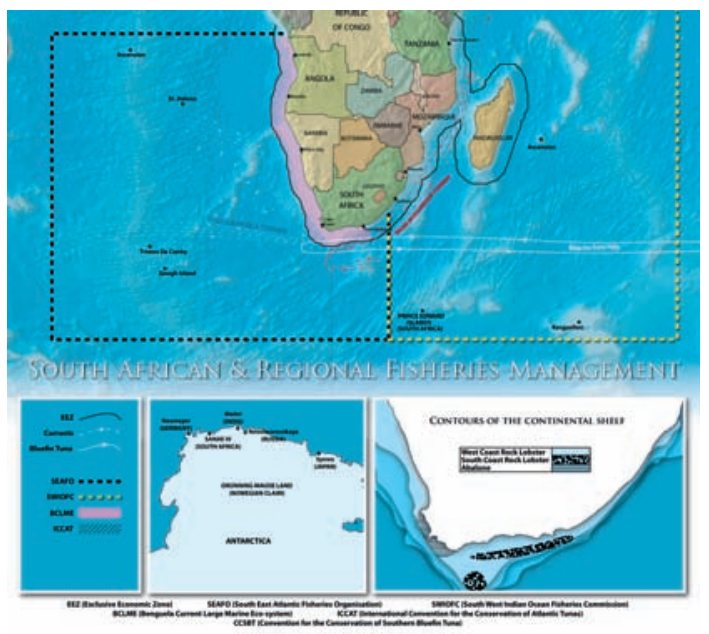

Map: courtesy of Feike Natural Resource Management Advisers

The Benguela Current Large Marine Ecosystem (BCLME) Programme is a trilateral country programme that involves Angola, Namibia, and South Africa. ${ }^{3}$ The bulk of financial support for the BCLME Programme has to date been provided by the Global Environment Facility (GEF) under its International Waters portfolio. Implementation of the BCLME Programme is undertaken by the

1 Director, Feike (Pty) Ltd (natural resources advisory firm), Cape Town, South Africa. Moolla is a member of IUCN's Commission on Environmental Law: Oceans, Coastal and Coral Reef Specialist Group.

2 D.A. Duda and K. Sherman, K., A New Imperative for Improving Management of Large Marine Ecosystems, Ocean \& Coastal Management, vol. 45, no. 11 (2002), p. 802.

3 Useful Internet resources on this issue include http://seis.sea.uct.ac.za/index.php; www.bclme.org; www.benefit.org.na; www.feike.co.za; www.mcm-deat.gov.za; and www.mfmr.gov.na 
United Nations Development Programme (UNDP). The three member countries provide financial and in-kind contributions. ${ }^{4}$

The BCLME is one of 64 large marine ecosystems that were identified in the years subsequent to the United Nations Conference on Environment and Development (UNCED) in 1992. It extends west of Port Elizabeth on the Cape south-east coast, covering the entire Exclusive Economic Zone (EEZ) of Namibia and continuing northwards to Cabinda in Angola. The BCLME region has been recognized as one of the most productive ocean areas in the world. ${ }^{5}$

The Benguela Current and region support a multitude of marine fish, mammals, and seabirds. The current has for centuries supported subsistence, small-scale commercial, recreational, and large-scale commercial fishing industries, which in turn has resulted in significant economic activity in the BCLME region. For example, South Africa's commercial fishing industry landed approximately R4.5 billion (US $\$ 640$ million) worth of fish in $2006 .{ }^{6}$ Approximately 70 per cent of this value would have been harvested and processed within the Western Cape and Northern Cape provinces, which are located within the BCLME region. In Namibia, the commercial fisheries sector supports more than 14,000 direct jobs and contributes approximately 7 per cent to that country's gross domestic product (GDP). ${ }^{7}$

Additionally, the BCLME region is increasingly becoming known for its vast mineral wealth, particularly oil deposits off the coast of Angola. Angola is the second largest oil producer in subSaharan Africa after Nigeria, with reserves estimated at 12.4 billion barrels. Oil currently accounts for 90 per cent of Angolan exports, 50 per cent of its GDP, and 80 per cent of its tax revenues. Crude oil production has increased 600 per cent since 1980. From the current oil production of around 1.5 million barrels a day, oil production in Angola is expected to reach 2 million barrels per day in 2007. It is anticipated that by 2012 over 80 per cent of the country's oil production will come from the deepwater and ultra-deepwater wells currently being developed. Gas production is expected to reach an average of 1.5 billion cubic feet a day during the period 2001-2007, resulting in substantial new opportunities for downstream industrial investment. ${ }^{8}$

However, by 1992 the cumulative impacts of commercial (over) fishing, unregulated artisanal fishing in Angola, and pollution from rapidly growing mining interests within the Benguela region, coupled with the human impacts of continued coastal migration, convinced South Africa, Namibia, and Angola, together with a number of coastal States, to take measures aimed at:

- Preventing, reducing, and controlling the degradation of the marine environment;

- Developing and increasing the potential of marine living resources to meet human nutritional needs as well as social, economic, and development goals; and

4 See www.bclme.org

5 lbid.

6 Feike (Pty) Ltd et al., Report on the Biological, Social and Economic Impact of Rights Allocations in the BCLME Region (Cape Town, South Africa: October 2006). Available at www.feike.co.za/frame_bclme.jsp or on request from smoolla@feike.co.za

7 lbid.

8 See http://seis.sea.uct.ac.za/php/pollution/angola/mining.php 
- Promoting the integrated management and sustainable development of coastal regions, including the marine environment.

To achieve the UNCED objectives, an ecological framework of management - the Large Marine Ecosystem (LME) concept - was proposed and adopted. An essential component of such a management regime is the inclusion of a scientifically based strategy to monitor and assess the changing states and health of the ecosystems by tracking key biological and environmental parameters. This management system includes regulatory, institutional, and decision-making aspects as well as the scientific information on conditions, contaminants, and resources at risk within the geographic extent of the ecosystem. ${ }^{9}$

\subsection{Establishment of the BCLME Programme}

\subsubsection{Phase 1: the Benguela Fisheries Interaction Training Programme}

In 1995, Angola, Namibia, and South Africa agreed to establish the Benguela Fisheries Interaction Training (BENEFIT) Programme. BENEFIT was originally conceived as a project of the Southern African Development Community (SADC) in 1996. Its principal objectives are to develop marine science and technology skills and capacity within the BCLME region and, in particular, in Namibia and Angola. ${ }^{10}$ The BENEFIT Programme was officially launched in May 1999. It is funded over a 10year cycle.

\subsubsection{Phase 2: establishment of the BCLME Programme}

The first steps towards the establishment of the BCLME Programme were taken in 1997 when funding for the programme was sought from UNDP. UNDP allocated the BCLME Programme US $\$ 344,000$ and in July 1998 the first BCLME regional workshop was held in Cape Town, South Africa. $^{11}$

The most significant outcome of the 1998 workshop was the development of six thematic reports on the BCLME region. ${ }^{12}$ The six themes covered fisheries, oceanography, coastal environments, mining, offshore oil and gas exploration, and socioeconomic impacts of economic activities in the BCLME region.

In April 1999, a second regional workshop was held in Windhoek, Namibia. The most significant outcome of this workshop was the development of a Transboundary Diagnostic Analysis (TDA). The TDA identified the most critical issues affecting the Benguela Current and the region; the three critical areas identified were the sustainable management and utilization of resources,

9 M.J. O'Toole et al., Integrated Management of the Benguela Current Region, in B. von Bodungen and R.K. Turner (eds.), Science and Integrated Coastal Management (Berlin: Dahlem University Press, 2001), pp. 231-253.

10 See www.benefit.org.na

11 See www.bclme.org

12 Ibid. 
environmental variability and predictability, and ecosystem health and the management of adverse impacts. $^{13}$

In February 2000, seven Ministers, representing the governments of Namibia, Angola, and South Africa, signed a Strategic Action Plan (SAP), which was to be the principal codification that would guide policy development for the sustainable management of the BCLME region. In addition, the SAP made provision for the first set of institutions to be established for the long-term management of the BCLME region. Perhaps the most important aspect of the SAP was that it set out a number of key policy actions that were required of the three governments. It also put in place a timetable for the achievement of these policy actions. The key policy actions codified were as follows:

- To endeavour to harmonize the management of shared stocks by 2005 ;

- To commit to compliance with the Food and Agriculture Organization (FAO) Code of Conduct for Responsible Fishing;

- To implement a regional framework for consultation to mitigate the negative impacts of seabed mining and oil/gas exploration and production activities by December 2002;

- To implement a regional Harmful Algal Blooms reporting network by 2001;

- To develop a regional aquaculture policy by December 2002;

- To develop a regional biodiversity conservation management plan and framework by December 2003;

- To develop a regional strategic programme for capacity development and maintenance of health of the BCLME by June 2001; and

- To encourage the three countries to address priority transboundary issues and enhance cooperation with other regional and international bodies such as SADC, the South East Atlantic Fisheries Organisation, FAO, and BENEFIT (which was considered to be an important stakeholder in the BCLME Programme that would undertake key transboundary marine science research and training within the framework of the SAP).

\subsubsection{Implementation of the BCLME Programme, 2002}

Phase 1 of a two-phase implementation timetable commenced in 2002. Phase 1 was scheduled to continue until 2006, after which the principal donors would review the progress made and consider funding of the second phase from 2007 until 2012. However, during Phase 2 each member State would have to start contributing to the funding of the programme's institutions and work. Upon commencement of the programme in 2002, country activity centres were set up in each member State; a Programme Co-ordination Unit (PCU) was established and operates from Windhoek, Namibia; and a Programme Steering Committee (PSC) was established and tasked with managing the BCLME Programme. The PSC comprises representatives of the three governments, SADC, UNDP-GEF, and BENEFIT. The BCLME Programme Chief Technical Adviser chairs the PSC.

13 lbid. 
Between 2002 and 2006 more than 70 projects were commissioned by the PCU with the aim of satisfying the policy actions codified in the SAP. Some of the more significant projects undertaken included:

- Scientific and biological studies on the relationship between South African and Namibian Hake stocks, led by BENEFIT and including fisheries scientists from Namibia and South Africa;

- Research on the socioeconomic impacts of regulated access to fisheries;

- Investigation of the possibility of harmonizing policy, legislation, and trade rules affecting fisheries in the three member States, with detailed conclusions and recommendations put forward in this regard;

- Development of a Web-based Benguela Ecosystem Information database, which provides managers in the region with accurate data pertaining to the BCLME region's oceanography, fisheries, pollution, and ecosystem health; ${ }^{14}$ and

- Development of an environmental early warning system, scheduled to have been completed by the end of 2007.

By the end of 2006, UNDP-GEF approved further funding for the second phase of the BCLME Programme to commence. In August 2006, Angola, Namibia, and South Africa agreed to the establishment of a Benguela Current Commission (BCC). An interim agreement establishing the BCC was signed by Namibia and South Africa on 29 August 2006 and by Angola on 31 January 2007.

\subsection{Institutional arrangements}

The SAP made provision for the establishment of an 'interim Benguela Current Commission'. The governments of Angola, South Africa, and Namibia instead agreed to bypass use of an interim commission and in August 2006 established the actual Benguela Current Commission. The BCC has two decision-making structures: an administrative secretariat and a strategic advisory body.

In terms of Article 6 of the Interim Agreement establishing the BCC, a Ministerial Conference shall be constituted. Article 6 provides that:

1) The Ministerial Conference consists of national delegations from each Contracting State, each led by a Minister authorised to represent that Contracting State.

2) The Ministerial Conference shall evaluate the implementation of this Agreement and in particular shall -

a. approve any changes to the Strategic Action Programme;

b. mandate the taking of whatever action may be necessary or appropriate to facilitate the effective implementation of the Strategic Action Programme; and

c. take all measures necessary to expedite the negotiation, conclusion, signature, ratification and implementation of a legal instrument to establish the Benguela Current Commission.

14 See http://seis.sea.uct.ac.za/index.php 
3) Meetings of the Ministerial Conference shall be chaired in rotation by the heads of delegation of each of the Contracting States, proceeding in the order that the Contracting States notify each other in accordance with paragraph 1 of Article 16 that they are bound by this Agreement.

4) Decisions of the Ministerial Conference shall be taken by consensus between the delegations of all the Contracting States except that in relation to any matter that only affects two Contracting States, the agreement of those Contracting States shall be sufficient for the Ministerial Conference to take a decision on that issue.

5) Meetings of the Ministerial Conference shall be convened by the Secretariat either in accordance with a decision of the Ministerial Conference, or at the written request of any Contracting States.

6) Any State which is not a party to this Agreement and any other body or agency, whether governmental or non-governmental, whose experience or expertise is relevant to the activities of the Interim Commission, the Secretariat, the Ecosystem Advisory Committee and any subsidiary bodies established in accordance with this Agreement, or any in relation to matters dealt with in the Strategic Action Programme, which has informed the Secretariat of its wish to be represented as an observer may be admitted to a meeting of the Ministerial Conference, unless one or more of the Contracting States present, object. The admission and participation of observers shall be subject to the rules of procedure adopted by the Ministerial Conference.

Article 7 makes provision for the establishment of the Benguela Current Commission.

1) The Commission comprises national delegations from each Contracting State, each led by a Director-General or permanent secretary, or his or her nominee.

2) The role of the Commission is to promote a co-ordinated regional approach to dealing with management issues concerning the Benguela Current Large Marine Ecosystem and its functions include -

a. coordinating the implementation by the Contracting States of the Strategic Action Programme and this Agreement; and

b. advancing and representing the common interests of the Contracting States in matters concerning the Benguela Current Large Marine Ecosystem.

3) The first meeting of the Commission shall be held within three months of this Agreement entering into force in accordance with Article 16 and at that meeting the Commission shall adopt rules and procedures for itself and determine the initial composition of the Ecosystem Advisory Committee and of the sub-committees referred to in paragraph 11(a).

4) Unless the Commission decides otherwise, each of its meetings shall be chaired in rotation by the head of a delegation, proceeding in the order that the Contracting States notify each other under paragraph 1 of Article 16 that they are bound by this Agreement.

5) Decisions of the Commission shall be taken by consensus between the delegations of the Contracting States except that in relation to any matter that only affects two Contracting 
States, the agreement of those Contracting States shall be sufficient for the Commission to take a decision on that matter.

6) If the Commission is unable to take a decision on a particular issue, it shall be reconsidered at the next meeting.

7) Meetings of the Commission shall be convened by the Secretariat, either in accordance with a decision of the Commission, or at the written request of any Contracting State.

8) The Commission shall adopt rules and procedures for itself and for any subsidiary body established by it under this Agreement.

9) The Commission shall -

a. interpret and apply the policy decisions of the Ministerial Conference;

b. develop and approve budgets, action plans and work programmes for the Commission, the Secretariat, the Ecosystem Advisory Committee and any subsidiary bodies established in accordance with this Agreement;

c. integrate the recommendations of the Ecosystem Advisory Committee and any subsidiary bodies established in accordance with this Agreement and resolve any conflicts between their recommendations;

d. oversee and direct the activities of the Secretariat and appoint the executive secretary of the Secretariat and the Ecosystem Advisory Committee co-ordinator;

e. co-ordinate the implementation of the Strategic Action Programme;

f. review periodically the effectiveness of the implementation of the Strategic Action Programme and where necessary make recommendations to the Ministerial Conference concerning amendments to the Strategic Action Programme;

g. establish mechanisms for interacting with the private sector, non-governmental organisations, and other stakeholders and communities; and

h. ensure that there is adequate consultation with stakeholders in relation to the development and amendment of the Strategic Action Programme and other action plans.

10) The Commission may make recommendations to the competent authorities of a Contracting State, on management issues relating to the protection, enhancement and ecologically sustainable use of the Benguela Current Large Marine Ecosystem and of any aspect of it, including recommendations in relation to any matter referred to in Annex 1.

11) The Commission -

a. shall at its first meeting establish the following sub-committees which shall continue to exist until the Commission decides otherwise:

i. a minerals and petroleum sub-committee;

ii. a marine living resources sub-committee; and

iii. an ecosystem health sub-committee; and 
b. may establish one or more additional working sub-committees or working groups to deal with specific issues of concern to two or more of the Contracting States.

12) Each sub-committee or working group shall determine its own rules of procedure to the extent that these have not been determined by the Commission.

13) Working groups may include any person with appropriate expertise or who represents a particular sector or group of people with an interest in the matter being dealt with by the working group.

Article 8 makes provision for the establishment of the Secretariat to the BCC.

1) The $[B C C]$ shall -

a. appoint and supervise an executive secretary who shall direct and manage the Secretariat; and

b. appoint a co-ordinator who shall co-ordinate the activities of the Ecosystem Advisory Committee and who is under the supervision of the executive secretary.

2) Unless the Commission decides otherwise, the Coordination Unit [PCU] of the BCLME Programme shall function as the Secretariat of the Commission and the Chief Technical Adviser of the BCLME Programme shall function as the executive secretary of the Secretariat until the persons referred to in paragraph 1 take up their positions, but the consent of the Steering Committee of the BCLME Programme shall be required for this arrangement to be continued after 31 December 2007.

3) The functions of the Secretariat are:

a. to facilitate the implementation and effective monitoring of the Strategic Action Programme;

b. to carry out the tasks assigned to it by the Commission;

c. to arrange and support meetings of the Ministerial Conference, the Commission, the Ecosystem Advisory Committee, and other subsidiary bodies established under this Agreement, including taking and keeping minutes of these meetings;

d. to negotiate with donors interested in supporting the implementation of the Strategic Action Programme;

e. to perform the financial and other administrative services required for the proper and efficient operation of the Commission, the Secretariat; the Ecosystem Advisory Committee and any subsidiary bodies established in accordance with this Agreement;

f. to formulate draft work programmes and prepare draft budgets for the Commission, the Secretariat, the Ecosystem Advisory Committee and any subsidiary bodies established in accordance with this Agreement;

g. to prepare plans, projects, assessments, reports and other documents required by the Commission and to assist the Ecosystem Advisory Committee and subsidiary bodies established under the Agreement to prepare such documents; 
h. to obtain and update regularly information required by the Contracting States for the implementation of this Agreement and of the Strategic Action Programme;

i. to facilitate the exchange of information in order to promote the objectives of this Agreement, including by ensuring that up-to-date information relevant to the implementation of this Agreement is disseminated to all Contracting States and to the public;

j. to prepare reports on its performance and on the performance of subsidiary bodies established in accordance with this Agreement and to present them to the Commission; and

k. to perform any other functions delegated to it by the Ministerial Conference or the Commission.

Article 9 establishes the principal advisory body to the BCC. Initial drafts spoke of a 'scientific committee' to be established to advise the BCC. The draft BCC Interim Agreement was amended and the establishment of an ecosystem advisory committee was provided for.

1) The Ecosystem Advisory Committee consists of experts nominated by each of the Contracting States.

2) The role of Ecosystem Advisory Committee is -

a. to support decision-making by the Commission, the Ministerial Conference and the Contracting States by providing them with the best available scientific, management, legal and other information, and expert advice concerning the conservation and ecologically sustainable use and development of the Benguela Current Large Marine Ecosystem; and

b. to build capacity within the Contracting States to generate and provide the information and expert advice referred to in (a) on a sustainable basis.

3) The Ecosystem Advisory Committee shall determine its composition and its rules of procedure to the extent that these have not been determined by the Commission.

4) The Ecosystem Advisory Committee may establish working groups or subcommittees to assist it in the performance of its functions.

5) Working groups may include any person with appropriate expertise or who represents a particular sector or group of people with an interest in the matter being dealt with by the working group.

6) The Ecosystem Advisory Committee shall meet at least once annually and shall make decisions by consensus.

7) The Secretariat shall convene the first meeting of the Ecosystem Advisory Committee within three months of the first meeting of the Commission convened in accordance with Article 7(3).

8) The Ecosystem Advisory Committee shall submit annually to the Interim Commission, a draft work plan and budget for the forthcoming two years and a draft annual report of its activities during the previous year. 
Although the BCC will be the principal vehicle charged with the sustainable management of the BCLME region, its policy positions and management recommendations should complement the policy and political commitments particularly of SADC, the Abuja Declaration, and the Pan African LME Forum with respect to fisheries and aquaculture.

The SADC Fisheries Desk today sadly only exists in name. The last time the SADC Fisheries Ministers met was in May 2002, when they agreed to hold an extraordinary meeting to address illegal, unreported, and unregulated (IUU) fishing in SADC members' EEZs. Although a draft declaration of measures to prevent, deter, and eliminate IUU fishing in the SADC region was circulated in January 2004, the declaration remains a draft. Nonetheless, the BCC would be wise to consider implementing the tenets of such documents, which were drafted for the SADC region and are therefore considered appropriate to the region's needs.

More recently, African Ministers and Heads of State met in Abuja in August 2005 and adopted the Abuja Declaration. This recognises, inter alia, the dependence of millions of Africans on fisheries and aquaculture for their livelihoods, for food and nutrition, and for economic well-being and commerce. In addition, the benefits of sustainable fisheries and aquaculture practices were accepted but noted with grave concern the depletion of fisheries resources, the degradation of aquatic environments, and the threats to sustainable fisheries and aquaculture on the African continent.

The Pan African LME Forum declared in November 2006 the commitment of the various African coastal states to, inter alia, the LME model of ecosystem management to recover fisheries and halt further degradation of marine and coastal environments and to seek to harmonize fisheries policies on the African continent.

\subsection{Evaluating the BCLME Programme: challenges and achievements}

In terms of Article 16 of the Interim Agreement that established the BCC, '[t]his Agreement shall enter into force on the thirtieth day after two or more Contracting States have notified the other States in writing of their consent to be bound by the provisions of this Agreement'. For the Interim Agreement to be enforceable, each member State must inform the other members of its intention to be bound by its provisions. It is understood that the country commitments to be bound by the provisions of the Interim Agreement were circulated in February and March 2007. The Interim Agreement is therefore enforceable between the BCLME member States.

Since the conceptualization of the BCLME Programme in 1995, it has had an inherent scientific bias. Much of its project budget and resources have been committed to scientific study of the marine ecosystem. Only since 2003 was there a realization that for the BCLME Programme to be politically palatable it would have to have some relevance and location within the socio-politicoeconomic agendas of the three member States. The political disinterest in the BCLME is starkly demonstrated by the fact that between 2000 and 2006 the Ministers responsible for fisheries in South Africa and Namibia met twice - once to sign the SAP in 2000 and again to sign the BCC 
Interim Agreement in August 2006. The first scheduled BCC Ministerial Conference occurred in July 2007.

The fact that the BCC Interim Agreement was signed by all three member States may very well have been the result of the sheer energy and commitment of the BCLME Programme's Chief Technical Advisor.

On paper, the BCLME Programme ought to be capable of sustainably managing the Benguela Current Large Marine Ecosystem. The BCC is a lean bureaucratic minimalist structure. It has a political head in the Ministerial Conference. Decision making and key recommendations for sustainable management of the region's ecosystem are to emanate from the BCC, which will be supported administratively by the Secretariat and strategically by the Ecosystem Advisory Committee. In addition, it ought to be sufficiently funded until at least 2012. Finally, the BCC should commence its duties on a foundation of significant fisheries science research, shared stock management analyses, policy, legislative and trade analyses, and socioeconomic data.

\subsubsection{Challenges}

So, how does reality change the theoretical success that the BCLME threatens to be? To answer this, it is important to consider the following factors:

- The changing Benguela Current;

- The socio-politico-economic realities that affect each sovereign member State;

- The challenges of shared stock management;

- Access to information held and owned by sovereign States; and

- The need to harmonize, where reasonably practicable, policy, legislation, and general management practices.

\section{The changing Benguela Current}

There is increasing scientific support for the notion that the Benguela Current is changing. A study of recent sea surface temperatures (SST) in the region indicates steady increases. ${ }^{15}$ Rising SSTs, increased fishing effort, and the impacts of years of overfishing and under-reporting of catches are resulting in substantial changes to the fishing economies of the region.

During 2004, Angola declared a zero catch allowance in its pelagic trawl fishery. Between 1990 and 2001, the average annual large pelagic catch fell from more than 10,000 tons to less than 4,000 tons. ${ }^{16}$ The most dramatic changes are occurring in Namibia and along South Africa's West Coast. Namibia's hake and small pelagic fisheries have all but collapsed. The Namibian government issued an emergency moratorium on hake fishing during October $2006 .{ }^{17}$ With regard to the small pelagic fishery, the total allowable catch (TAC) was set at 65,000 tons in 1998 , but by 2002 the Namibian government declared a zero catch limit. By 2005, the TAC was set at 25,000

15 See http://seis.sea.uct.ac.za/index.php

16 See http://seis.sea.uct.ac.za/php/fishResources/fishAngola.php

17 See www.mfmr.gov.na 
tons. The result of these collapses has been a number of fish factory closures, which have resulted in further unemployment in the Namibian fishing industry. In turn, key socioeconomic and biological objectives set in Namibia's National Development Plan have not been achieved. ${ }^{18}$

South Africa's West Coast has been witness to a dramatic migration of the staple West Coast fisheries over the past seven years. West Coast rock lobster has continued a steady migration further offshore and south-east, migrating to regions that never before had access to commercial quantities of lobster. Small pelagics, and in particular pilchards, have migrated further eastward, threatening the continued economic viability of the largest processing facilities on South Africa's West Coast. South Africa's pilchard TAC collapsed by 48 per cent between 2005 and 2006 to approximately 210,000 tons. Hake stocks have been overfished, with trawlers reportedly catching a predominance of 'baby' or undersized hake. A number of trawlers have consequently engaged in large-scale dumping of up to 50 per cent of their catches and targeting of already pressured line fish stocks, such as snoek (Thyrsites atun).

\section{Socio-politico-economic realities}

The socio-politico-economic realities that exist in each of the three member States differ significantly in certain respects, yet are similar in others. To date, the BCLME Programme has not received the levels of public, economic, and political interest it ought to have received. The principal political driver of the BCLME Programme has been the Namibian Ministry of Fisheries and Marine Resources.

Fisheries rank second in perceived importance to mining, whether marine diamond mining, gas exploration, or offshore oil drilling in each of the three member States. Diamond mining along the South African and Namibian coasts, as well as oil drilling in Angola's EEZ, has had an adverse impact on the marine ecosystem, but more often than not, mining interests trump sustainable ecosystem management requirements. A good example is South Africa's failure to declare a marine protected area along its west coast to protect hake stocks because of concerns raised by a single mining company that has an exploration permit in the vicinity of the proposed marine protected area. In this example, just the potential use of a mining exploration permit allocated to a single entity derailed a marine protected area aimed at protecting South Africa's commercially most important fish stock - hake.

Large-scale commercial fishing enterprises are non-existent in Angola (although a number of large fishing vessels fish in Angolan waters), increasingly few in Namibia, and relatively abundant in South Africa. More than 95 per cent of Angola's total fish landings are utilized for domestic consumption. The mainstay of the Angolan fishery is its artisanal sector, which remains unregulated with no obligation on fishers to record or report catches. Offshore oil and gas mining, on the other hand, contributes more than 80 per cent to Angola's tax revenue and accounts for more than 90 per cent of all exports.

Although fisheries contribute some 7 per cent to Namibia's GDP and employ some 14,000 people directly, the recent collapses in its small pelagic and hake fisheries threaten the long-term

18 See, for example, Feike (Pty) Ltd et al., supra note 6, pp. 34-37. 
economic sustainability of the Namibian fishery. Diamond mining in Namibia contributes approximately 20 per cent to GDP. The same threats apply to South Africa. South African hake and pelagic fisheries are increasingly under biological and ecological pressures. Both fisheries are managed conservatively and have faced substantial cuts in the total allowable catches over the past two years. The most significant difference is that in South Africa, the commercial fisheries contribute no more than 1 per cent to GDP and have therefore failed to attract significant political interest in the management of the fisheries. The commercial fisheries do, however, directly employ some 45,000 people, mainly in the Northern Cape, Western Cape, and Eastern Cape provinces.

While political, social, and economic concerns for sustainable fisheries in the three BCLME member States may be hard to elevate, the economic and social concerns about the possible impacts of climate change and biodiversity loss have attracted the attention of entire populations and not just those residing along the coasts of the BCLME member States. The BCLME Programme would accordingly do well to shift its focus from the narrower area of sustainable fisheries and marine ecosystem management to the impacts of climate change on the economies of Angola, South Africa, and Namibia. In this way greater levels of political interest and support would be achieved.

In addition to mining, sustainable fisheries management in the BCLME region faces a number of further socio-politico-economic challenges. The most significant challenge has been social, political, and economic transformation. ${ }^{19}$ Angola's transition from war to peace resulted in the implementation of an 'Angolans First' policy that also applied to the fisheries sector. Essentially, this policy forced the numerous foreign nationals fishing involved in harvesting Angolan marine resources to partner with Angolan nationals. In addition, artisanal Angolan fishers were granted access to a host of inshore fisheries. In Namibia, the post-Apartheid Namibian government introduced its Namibianisation Policy (as part of the National Development Plan), which sought to affirm Namibian access to fish resources. In South Africa, the post-Apartheid government introduced a policy of granting commercial fishing rights to 'new entrants' or black South African persons who were denied access to these resources under the Apartheid regime. Under all three policies, the number of participants increased dramatically across the commercial fisheries. For example, between 1993 and 2004, South Africa's commercial fisheries witnessed a tenfold increase in the number of commercial right holders.

A further challenge to the sustainable management of fisheries that is shared by all three member States is the adverse ecological impacts caused by population migration to coastal regions. It is estimated that approximately 30 per cent of Angola's entire population lives in Luanda. $^{20}$ The result has been a combination of unregulated access to inshore fish stocks for subsistence and local trade purposes, as well as uncontrolled dumping of sewerage and other

19 See further a report drafted by Feike (Pty) Ltd et al. for the BCLME PCU: Transformation in the Marine Fisheries of the BCLME Countries, 1 October 2005, available at www.feike.co.za/library.html. See also S. Moolla, H.G. H. Kleinschmidt, and M. Diemont, A New Chapter in South African Fisheries Management, in Ship Year, 2005, pp.116-122.

20 Interview by the Author with the Director General of the Institute of Marine Fisheries, INIP, Angola, July 2006. 
pollutants into the Bay of Luanda. ${ }^{21}$ In Namibia and South Africa, population migration to the coast, coupled with rapidly increasing domestic and foreign tourism, has placed significant pressure on coastal resources in both countries. Coastal zone management has to date been very poor in Namibia and South Africa.

The reason for poor to non-existent management may very well emanate from the fact that in each country three spheres of government assume jurisdiction over different aspects and parts of the coastal zone. In addition, much of the coastal development that has occurred, regardless of its ecological impact, has been justified as being necessary because of the jobs it will provide, the investments that have been committed to a local region, and the fact that the development supports Namibianisation or South African black economic empowerment. Fortunately, Namibia and South Africa are in the process of designing legislation aimed at closing the loopholes that have historically permitted degradation of the coastal zone.

\section{Shared stock management}

A core objective of the BCLME Programme is the sharing of management, research, and compliance obligations with respect to the various shared stocks of the BCLME region.

Shared fish stocks as such have not been legally defined. Neither the United Nations Law of the Sea Convention nor the 1995 Agreement for the Implementation of the Provisions of UNCLOS relating to the Conservation and Management of Straddling Fish Stocks and Highly Migratory Fish Stocks (1995 Fish Stocks Agreement) provides a legal definition. A definition proposed by Hayashi in 1993 and subsequently adopted by Caddy and others in 1998 has since been used to refer specifically to transboundary stocks that do not extend to the high seas:

A group of commercially exploitable organisms distributed over, or migrating across, a maritime boundary between two or more national jurisdictions, whose exploitations can only be managed effectively by cooperation between the States concerned, but where emigration to or immigration from other jurisdictions need not be taken into account. ${ }^{22}$ [emphasis added]

The major shared, commercially important fish stocks of the BCLME region include:

- Large pelagics (swordfish and tuna),

- Hakes,

- Small pelagics (sardines and anchovies),

- Horse mackerel,

- Crustaceans (red crab and rock lobster), and

- Traditional line fish species. ${ }^{23}$

21 Visit by the Author to Luanda during July 2006.

22 See further a report drafted by Feike (Pty) Ltd et al. for the BCLME PCU: Comparative Legal Analysis and Law Reform, 21 April 2006, available at www.feike.co.za/library.html

23 For more information on the traditional line fisheries in South Africa and Namibia, see www.feike.co.za/library.html 
The management of shared fish stocks presents one of the greatest challenges to the achievement of long-term, sustainable fisheries. Legal, biological, socio-politico-economic, and financial drivers all form an essential part of shared fish stock management. Where the harvesting activities of one State may well affect the harvesting opportunities of another country due to the sharing of resources, a prima facie case for the establishment of a co-operative management institution does exist. ${ }^{24}$

Within the BCLME, there are many such examples, involving small pelagics, line fish, crabs, lobsters, tunas, horse mackerel, and hake. At least two levels of co-operation are currently recognized in such situations. ${ }^{25}$ The so-called primary level of co-operation exists in terms of shared and coordinated research programmes and activities. In the context of the BCLME, BENEFIT provides a well-known and ideal example. Simultaneously this provides the suitable and requisite platform from which to move to the next, secondary level of co-operation, that of active or shared management. Current expert opinion is that this form of co-management requires (almost by definition) the establishment of co-ordinated, joint management programmes. Should this premise be accepted (which it appears is the case within the BCLME, with the establishment of the $\mathrm{BCC})$, this then in turn requires the following commitments ${ }^{26}$ :

- The determination of optimal global harvests over time, which must feed into the application of a so-called optimal management strategy through time;

- The implementation and enforcement of coordinated management agreements; and

- The allocation of harvest shares among participating states.

To achieve the above-mentioned commitments the following would be necessary ${ }^{27}$ :

- A co-operative management authority (such as the BCC);

- Detailed, joint management plans;

- A set of agreed, common objectives;

- Agreed management tools, which include reference points and indicators for monitoring performance levels;

- A joint ecosystems management forum to provide strategic advice; and

- Proof that co-management of shared resources within an ecosystem is beneficial to the member States in order to make it 'worth their while'.

Shared management of shared stocks is a prerequisite from a scientific, socioeconomic, and fisheries management perspective. The mandate for the development of measures for the

24 G. Munro, A. Van Houtte, and R. Willmann, The Conservation and Management of Shared Fish Stocks: Legal and Economic Aspects, FAO Fisheries Technical Paper No. 465 (Rome: Food and Agriculture Organization, 2004), p. 5.

25 See further Feike (Pty) Ltd et al., supra note 23.

26 lbid.

27 lbid. 
transboundary management of shared stocks in the region clearly exists. ${ }^{28}$ The common, stated objective of all the applicable regional and international legal and policy frameworks is to promote the 'responsible and sustainable' use of marine resources. In the case of shared stocks, this can only be attained through negotiated, co-operative agreements between the member States.

\section{Access to information}

The ability to successfully manage shared stocks will depend extensively on the ability and desire of member States to share information and to provide the BCC (and the advisory structures) with access to reliable, accurate, and most recent data. To date, experience has shown a worrying degree of reluctance by member States to share data. Even more concerning is the reliability and accuracy of much of the data that is accessible.

Accordingly, an urgent prerogative of the BCC should be to develop at least two protocols pertaining to access to information. The first protocol ought to provide an agreed methodology for collating and analysing data. The second one ought to provide a list of data categorized by degree of confidentiality and the conditions for the release of that data to either officials of other member States (only) and/or the public in general.

\section{Harmonization}

The effective management of shared stocks by entities such as the BCC will depend significantly on whether the laws, policies, and management practices in each of the BCLME member States are complementary. It is important to note that although harmonization of laws, policies, and management practices is strongly advocated, what is not advocated at all is that these laws, policies, and management practices must be the same regardless of national circumstances.

Although each member State has overarching, complementary national fisheries laws in place aimed at ensuring sustainable use of the fisheries, substantial gaps have been identified when it comes to implementation. ${ }^{29}$ Broadly, these gaps include the following:

- The lack of complementary or joint fisheries science, management, and compliance methodologies. These gaps continue to place substantial strain on shared stocks such as hakes and small pelagics.

- The lack of complementary and effective administrative systems aimed at recovering the costs of fisheries management, compliance, and research. This precludes holistic, regular, and effective fisheries management.

- Varying degrees of codified policy and regulations pertaining to access to commercial fisheries, as well as managing effort, which result in economic uncertainty, an unwillingness to commit to long-term investment programmes, and general sector instability.

28 R.U. Sumaila, C. Ninnes, B. and Oelofsen, Management of Shared Hake Stocks in the Benguela Current Large Marine Ecosystem, presented at the Norway-FAO Expert Consultation on the Management of Shared Fish Stocks, Bergen, Norway, 7-10 October 2002, p. 16.

29 See further Feike (Pty) Ltd et al., supra note 23. 
- A lack or shortage of fisheries managers and scientists, as well as training and mentoring programmes for fisheries managers. This threatens the achievement of long-term fisheries sustainability and the attainment of socioeconomic and political objectives.

- Of the three member States of the BCLME, Angola is the only one that has to date neither signed nor acceded to or ratified the 1995 Fish Stocks Agreement. Angola should ratify this Agreement as a matter of urgency.

- With respect to fisheries policy, the three countries need to urgently develop a single policy with respect to foreign (i.e., non-BCLME) flagged vessels, operational management procedures for shared stocks (such as hakes and pelagics), foreign fishing in BCLME EEZs, European Union fish processing investments in the BCLME. and marine protected areas.

- With respect to fisheries research policy and rules, the BCLME countries need to design shared or complementary research methodologies, scientific expert exchange programmes, complementary gear utilization rules (such as mesh sizes, trawl, and purse-seine nets), complementary rules to implement the ecosystems approach to fisheries management, and, importantly, a way to effectively harness and incorporate indigenous knowledge systems into fisheries science.

- With respect to fisheries compliance, the BCLME countries must each draft and thereafter implement National Plans of Action (NPOAs) to prevent, deter, and eliminate IUU fishing within their EEZs. These NPOAs should necessarily be complementary and may even be drafted as a regional plan of action as opposed to three separate NPOAs. In addition, joint compliance initiatives undertaken under the SADC-European Union Monitoring Control and Surveillance Programme proved tremendously successful. Joint compliance initiatives that are permanently in place would significantly bolster the fight against IUU fishing in the BCLME EEZ. This in turn will require complementary regulatory and policy provisions pertaining to fines, arrest, seizure, detention, cancellation and suspension of rights/quotas, vessel monitoring systems on vessels and the sharing of the systems' information amongst BCLME members ${ }^{30}$, and the powers of fishery control officers along with the ability of such officers from one BCLME country to enforce the laws of another BCLME country while in its waters.

\subsubsection{Achievements}

The success of the first phase of the BCLME Programme is perhaps most clearly defined by the financial commitments made by the GEF/UNDP that allowed Phase 2 of the BCLME Programme to commence, entitled the SAP Implementation Phase during the last quarter of 2007. The BCLME Programme achieved a number of successes in the areas of fisheries research, management, compliance, and governance during Phase 1. Outlined below is a brief description of the most impressive achievements of the BCLME Programme to date.

Since the 1990s, South Africa, Namibia, and Angola have been sharing research expertise and have undertaken numerous research cruises under the auspices of BENEFIT with the financial

30 It is important to note that as members of SADC, South Africa, Angola, and Namibia have agreed to share vessel monitoring system data of vessels authorized to fish in their respective EEZs. This agreement was concluded in 2004. 
assistance of, inter alia, the Norwegian government. The result of the early investment in fisheries research in the Benguela region is that there has been significant fisheries science research and shared stock management analyses.

During the latter period of Phase 1, the BCLME Programme wisely committed significantly more resources than before to investigating the compatibility of management and legal fisheries systems in each member State. Between 2004 and 2007, a substantial programme was established to determine the fisheries management and legal systems in existence in member States and how these systems could be harmonized to increase management, research, and administration efficiencies. ${ }^{31}$ Between 1998 and 2004, South Africa, Namibia, and Angola each introduced new fisheries legislation that is broadly complementary and that gave effect to a number of the most important international fisheries management instruments, such as FAO's Compliance Agreement. Although there are number of gaps in the fisheries management spheres of the member States, the fundamental fisheries laws in each country are complementary and share the vision of the BCLME Programme's commitment to sustainable fisheries management.

Between 2002 and 2006, South African-Namibian and Namibian-Angolan fishery control officers undertook a number of joint fisheries patrol and training exercises. The most tangible outcome of the joint exercises was the conclusion in 2004 of an agreement between the three member States and the other six SADC coastal states to share all vessel monitoring data so as to increase the monitoring and co-operation capacities of the SADC coastal States.

Finally, during 2006 the BCLME Programme procured the development of an ecosystem information system aimed at providing managers, policy advisers, and fisheries scientists in each member State with reliable and up-to-date data on the region's oceanography, marine resources, pollution events and sources, and ecosystem indicators. The development of the information system commenced in May 2006 and was completed by November 2006. The intention is that the data from this site will be used, together with other real-time data sources, to implement an environmental early warning system programme, which commenced in March 2006 and was completed by the end of 2007. The State of the Ecosystem Information System site may be viewed at http://seis.sea.uct.ac.za/index.php.

\subsection{Conclusion}

The successful implementation of the BCC Interim Agreement will depend on the level of political commitment shown by the respective member State Ministers in the Ministerial Conference. Phase 2 will require substantial political, human, and financial resource commitments to the BCC, the Secretariat, and the various advisory committees that may be established.

Angola, Namibia, and South Africa simply cannot afford to have the BCC fail or stutter in the fulfilment of its mandate. The BCC is no longer a fisheries research vehicle that may or may not produce an answer on whether there is any relationship between South African hake and Namibian

31 On 26-27 February 2007, representatives from Angola, Namibia, and South Africa met in Windhoek, Namibia, to analyse and evaluate the findings and recommendations of the harmonization programme, which was led by the consulting firms Enviro-Fish Africa (Pty) and Feike (Pty) Ltd. 
hake. The BCC has quickly evolved into an institution that should be capable of creatively and efficiently mitigating the adverse impacts that will result from the changes being played out in the Benguela Current Large Marine Ecosystem. The economies of an entire region depend on it. 



\title{
1 The North Atlantic Salmon Conservation Organization (NASCO): Nearing a 25 Year Voyage in Transboundary Co-operation but Still Confronting a Sea of Challenges
}

\author{
David L. VanderZwaag and Emily Pudden ${ }^{1}$
}

\subsection{Introduction}

The North Atlantic Salmon Conservation Organization (NASCO) was established in 1984 under the authority of the Convention for the Conservation of Salmon in the North Atlantic Ocean ${ }^{2}$ (Salmon Convention) to promote the conservation, restoration, enhancement, and rational management of North Atlantic salmon stocks. ${ }^{3}$ NASCO serves as a forum for co-operation, consultation, and information sharing among participating States and organizations. Members include Canada, the United States, the European Union (EU), Iceland, Norway, Denmark (in respect of Greenland and the Faroe Islands), and the Russian Federation. In addition, five intergovernmental organizations and 34 nongovernmental organizations (NGOs) participate in NASCO as observers. ${ }^{4}$

Several factors combined to create a climate ripe for the development of an international management structure for Atlantic salmon. In the 1960s and 1970s, the harvesting of salmon in the international waters of the North Atlantic increased dramatically, with the result that domestic management initiatives were no longer sufficient to regulate the exploitation of this highly mobile species. $^{5}$

1 Professor VanderZwaag is Canada Research Chair in Ocean Law and Governance at the Marine \& Environmental Law Institute (MELI), Dalhousie University and co-chairs the IUCN Commission on Environmental Law's Specialist Group on Oceans, Coasts and Coral Reefs. Emily Pudden is a Research Assistant at MELI. The research support of the Social Sciences and Humanities Research Council of Canada through the project "Strengthening Canada's Regional Fisheries Management Arrangements in Light of Sustainability Principles" is gratefully acknowledged. This chapter attempts to be accurate as of 1 January 2008.

2 Convention for the Conservation of Salmon in the North Atlantic Ocean (adopted 2 March 1982, entered into force 1 October 1983) CTS 1983/11 (Salmon Convention).

3 North Atlantic Salmon Conservation Organization (NASCO), Report of the North Atlantic Salmon Conservation Organization 2002-2003 (Edinburgh: NASCO, 2003), p. 4.

4 For a complete list of NASCO-accredited observer groups, see the NASCO Web site, at www.nasco.int, accessed 18 April 2007.

5 M.L. Windsor and P. Hutchinson, International Management of Atlantic Salmon, Salmo salar L., by the North Atlantic Salmon Conservation Organization, 1984-1994, Fisheries Management and Ecology, vol. 1 (1994), p. 31 at 31-32. 
Overfishing, particularly on the high seas, was considered the primary reason for a decline in Atlantic salmon stocks, and States in whose rivers the salmon originated were particularly concerned about the impacts of these distant-water commercial fisheries. ${ }^{6}$ Discussions at the 1978 Atlantic Salmon Symposium identified the need for an international agreement to regulate salmon catch levels, and work began on developing a draft treaty. ${ }^{7}$

The early 1980s marked a period of growing international co-operation in the management of ocean resources. The 1982 United Nations Convention on the Law of the Sea expanded coastal States' fisheries jurisdictions ${ }^{8}$ and encouraged Parties to co-operate in managing anadromous fish stocks through regional organizations. ${ }^{9}$ In light of these developments, a group of States with interests in the salmon fisheries of the North Atlantic signed the Salmon Convention in 1982, laying the foundation for the establishment of NASCO.

After first providing a brief overview of the Salmon Convention and NASCO's administrative workings, this chapter highlights NASCO's actual voyaging in transboundary resource management and then proceeds to summarize key challenges still facing NASCO as it nears the 25-year milestone. Five components of NASCO's transboundary co-operative 'voyage' are described: addressing fisheries management, adopting the precautionary approach, broadening the NASCO net to cover aquaculture and other issues, encouraging scientific research, and reviewing NASCO's effectiveness. Following this, the chapter summarizes 10 key challenges still confronting NASCO: putting precaution into practice, embracing the ecosystem approach, enhancing public participation, considering indigenous participation and rights, getting better grips on unreported catches, bringing the St. Pierre and Miquelon fishery into the NASCO fold, preventing escape of farmed salmon, ensuring implementation of existing commitments, reaching agreement on a performance review, and addressing dispute resolution. ${ }^{10}$

\subsection{The Salmon Convention and NASCO administration}

The 1982 Salmon Convention was signed by Canada, the United States, the European Economic Community, Sweden, Iceland, Norway, and Denmark (in respect of Greenland and the Faroe Islands) and came into force in October 1983. ${ }^{11}$ The Russian Federation acceded to the convention in $1986 .{ }^{12}$

6 NASCO, Twenty-Year Milestones and Next Steps - A Vision for the Future (Edinburgh: NASCO, 2004), p. 3.

7 Ibid.

8 United Nations Convention on the Law of the Sea (adopted 10 December 1982, entered into force 16 November 1994), 1833 UNTS 3, Arts. 56-57.

9 Ibid., Art. 66.

10 The 'top 10 list' provided is, of course, not exhaustive. For example, how to control the spread of the parasite Gyrodactylus salaris and sorting out the role for hatcheries in restoring threatened and endangered salmon populations are ongoing challenges. On the latter issue, see R.A. Myers et al., Hatcheries and Endangered Salmon, Science vol. 303, no. 5666 (2004), p. 1, 980.

11 Salmon Convention, supra note 2.

12 Internet Guide to International Fisheries Law, International Organizations Compendium: North Atlantic Salmon Conservation Organization online, at www.intfish.net/orgs/fisheries/nasco.htm, accessed 20 April 2007. 
The Salmon Convention was envisioned as a tool for addressing the overexploitation of salmon stocks whose migratory range includes the high seas area of the Atlantic Ocean, north of $36^{\circ} \mathrm{N}$ latitude. ${ }^{13}$ The convention bans the harvest of salmon in waters beyond the 12-mile territorial sea of the Contracting Parties, with the exception of an area off the west coast of Greenland, outwards to a distance of 40 nautical miles, and waters under the fisheries jurisdiction of the Faroe Islands. ${ }^{14}$ The convention also establishes NASCO ${ }^{15}$ and sets out the memberships, functions, administrative structure, and procedures of the organization's Council ${ }^{16}$, regional Commissions, ${ }^{17}$ and Secretariat. ${ }^{18}$

Under Articles 14 and 15, the Parties are required to provide NASCO with regular reports outlining salmon catch statistics, scientific information on stocks, and details of domestic management initiatives and regulatory measures they have implemented. The provision of this information assists NASCO fulfill its mandate to promote and facilitate the dissemination of information on Atlantic salmon. ${ }^{19}$

NASCO activities are overseen by the NASCO Council, which is supported by a Secretariat and three regional Commissions. The Council is responsible for supervising and co-ordinating the organization's internal and external relations by facilitating co-operation and communications among NASCO members, and between members and non-signatory States, on issues affecting the salmon stocks subject to the convention. ${ }^{20}$ The Council also makes recommendations to NASCO members and to other scientific and fisheries organizations regarding scientific research. ${ }^{21} \mathrm{Up}$ to three representatives from each Party to the Salmon Convention serve on the Council, with each Party being accorded one vote. ${ }^{22}$ The Secretariat is responsible for all administrative functions of the Council. ${ }^{23}$

The North American, West Greenland, and North-East Atlantic Commissions serve as regional forums for co-operation and consultation among member States in addressing the management of transboundary salmon resources. Each Commission holds regular meetings and submits reports on its activities to the NASCO Council. ${ }^{24}$ The Commissions may develop regulatory measures for the harvest of transboundary salmon stocks within their areas of responsibility and make recommendations to the NASCO Council on scientific research. ${ }^{25}$

13 Salmon Convention, supra note 2, Art. 1.

14 Ibid., Art. 2.

15 Ibid., Art. 3.

16 Ibid., Arts. 4-6.

17 Ibid., Arts. 7-11.

18 Ibid., Art. 12.

19 Ibid., Art. 4(1)(a).

20 Ibid., Art. 4.

21 Ibid.

22 Ibid., Arts. 5(1), 6(2).

23 Ibid., Art. 12.

24 Ibid., Art. 10(7)(8).

25 Ibid., Arts. 7-8. 
The North American Commission (NAC) is composed of representatives from Canada and the United States. The Commission addresses salmon-related issues within the fisheries jurisdictions of its members off the east coast of North America. ${ }^{26}$ (See Figure 10.1.)

The West Greenland Commission (WGC) includes Canada, the United States, the EU, and Denmark (in respect of Greenland and the Faroe Islands). ${ }^{27}$ This body deals with a designated area of fisheries jurisdiction off the west coast of Greenland. ${ }^{28}$

The North-East Atlantic Commission (NEAC) is composed of Denmark (in respect of Greenland and the Faroe Islands), the EU, Iceland, Norway, and the Russian Federation. ${ }^{29}$ The NEAC is responsible for the maritime waters to the east of the WGC's area. ${ }^{30}$

\section{Figure 10.1. Map of NASCO Regional Commission Areas}

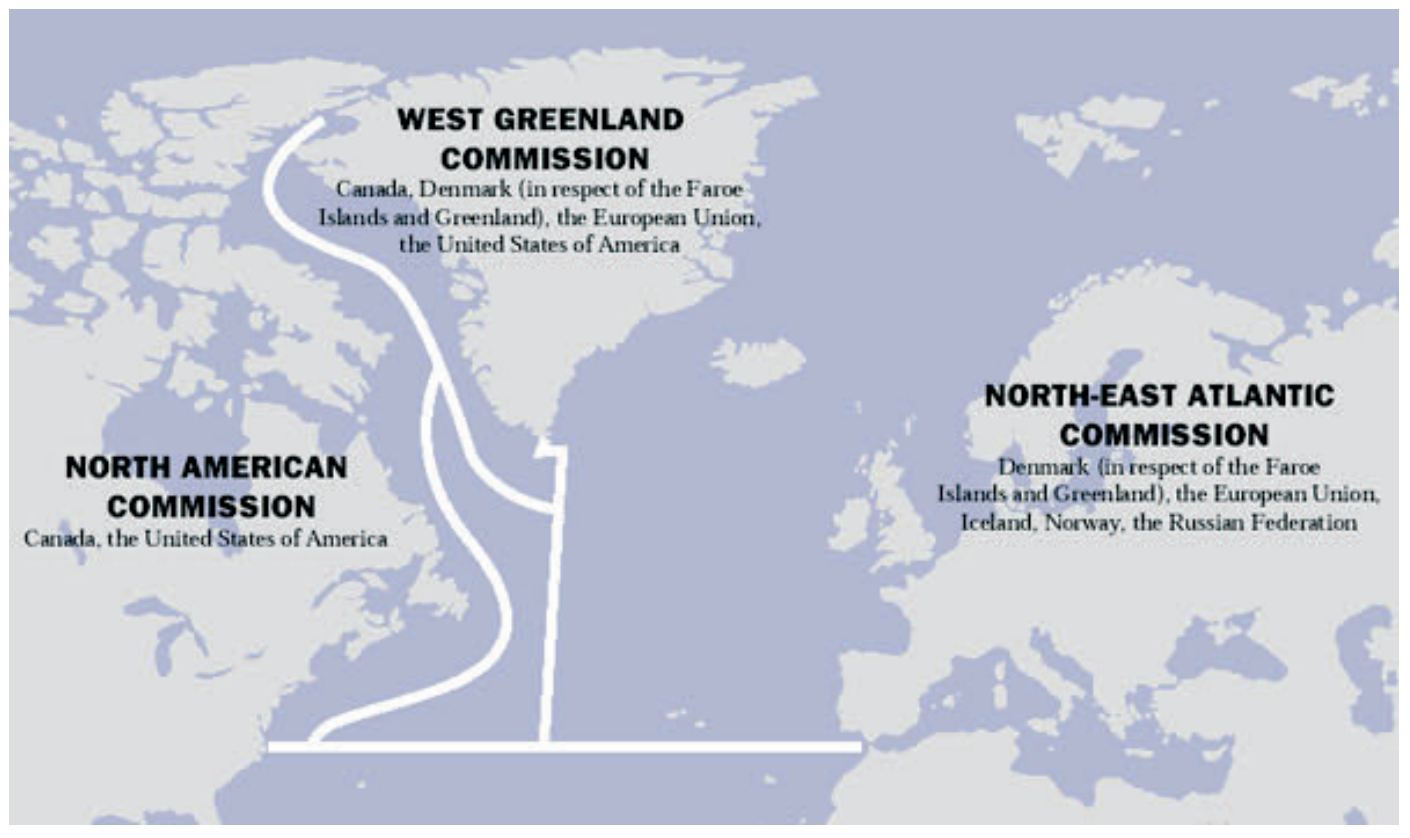

Source: <www.nasco.int> [Accessed 12 May 2007]

The regulatory measure power of Commissions is substantially constrained. Commissions may only propose regulatory measures for salmon fisheries under the jurisdiction of a member that involves harvesting of salmon originating from rivers of another Party. ${ }^{31} \mathrm{~A}$ Party in whose waters a

26 Ibid., Arts. 3(4)(a), 10(1)(a).

27 NASCO, About NASCO: Structure, supra note 4.

28 Salmon Convention, supra note 2, Art. 3(4)(b).

29 NASCO, About NASCO: Structure, supra note 4.

30 Salmon Convention, supra note 2, Art. 3(4)(c).

31 Ibid., Arts. 7(1)(c) and 8(b). 
proposed regulatory measures would apply has the option of lodging an objection to the regulatory measure within 60 days. ${ }^{32}$

Unanimous agreement among voting members is required for a Commission to determine regulatory measures affecting salmon fisheries within their respective areas. ${ }^{33}$ In addition to the regular members of each commission, the EU is entitled to propose and vote on regulatory measures affecting the NAC area where those measures concern stocks originating in EU countries. Likewise, Canada and the United States have the right to propose and vote on regulatory measures decided by the NEAC where they affect salmon stocks originating within their respective territories. ${ }^{34}$

\subsection{NASCO's voyage in transboundary co-operation}

\subsubsection{Addressing fisheries management}

Besides its primary function as a consultation forum where Parties can share information and views on management of transboundary salmon stocks, NASCO has played a limited role in developing regulatory measures for fisheries off West Greenland and the Faroe Islands. NASCO has also attempted to reduce high-seas salmon fishing by non-Parties, through the development of the 1992 Protocol to the Salmon Convention and the promotion of a more co-operative relationship with the French islands of St. Pierre and Miquelon.

\section{Regulatory measures}

The West Greenland salmon fishery has been restricted to one of domestic subsistence since 2002. ${ }^{35}$ The restriction followed a conservation agreement negotiated by the North Atlantic Salmon Fund, and other non-government interests, with the Organization of Fishermen and Hunters in Greenland to compensate local fishers for relinquishing their stake in the annual commercial salmon quota set by the WGC. ${ }^{36}$ As a result of this agreement, commercial salmon fishing has ceased, the WGC no longer sets commercial quotas, and harvest levels have been restricted to the amount required for domestic subsistence consumption, estimated at 20 tons. $^{37}$

32 Ibid., Art. 13. The opt-out procedure has not been used to date. Malcolm Windsor, Secretary, NASCO, Personal communication, 23 May 2007.

33 Ibid., Art. 11(3).

34 Ibid., Art. 11(2).

35 See further, S. Chase, Closing the North American Mixed-Stock Commercial Fishery for Wild Atlantic Salmon, in Derek Mills (ed.), Salmon at the Edge (Oxford: Blackwell, 2003), pp. 84-92.

36 Ibid., p. 91. A new Greenland Conservation Agreement continuing the commercial salmon moratorium was concluded in June 2007. See Atlantic Salmon Federation, New Atlantic Salmon Conservation Agreement Safer Ocean Migration Ensured, online at htpp://www.asf.ca/news.php?id=99 (accessed 30 December 2007).

37 West Greenland Commission (WGC), Regulatory Measure for the Fishing for Salmon at West Greenland for 2006, with possible application in 2007 and 2008, WGC(06)6, in NASCO, Report of the Twenty-Third Annual Meeting of the Commissions (Saariselkä, Finland, 5-9 June 2006); NASCO, Regulatory Measures - West Greenland Salmon Fishery online, at www.nasco.int/greenlandmeasures.htm, accessed 17 December 2007. 
No commercial salmon fishery as been carried out in the Faroe Islands since 1991. Although the NEAC continued to negotiate significant annual quotas until 2000, catch levels were restricted through the use of private-sector compensation agreements and other short-term management initiatives. ${ }^{38}$ In 2001, the Faroese Home Government resolved to apply the precautionary approach in managing the fishery, taking into account yearly scientific advice provided by the International Council for the Exploration of the Sea (ICES) on stock status. ${ }^{39}$ As a result of this decision, the NEAC no longer sets annual quotas and the commercial fishery remains closed. The Commission continues to monitor the status of salmon stocks in the area through annual reports provided by ICES, and Faroese authorities reserve the right to reopen the salmon fishery should stock conditions change. ${ }^{40}$

As neither Canada nor the United States has a commercial Atlantic salmon fishery, the development of regulatory measures by the NAC is unnecessary, although the Commission continues to review management initiatives implemented by both Parties. ${ }^{41}$ Under the terms of the Convention, NAC members have the added responsibility of reducing catches and bycatches of salmon originating in one another's rivers and obtaining consent from the State of origin before increasing harvest levels. ${ }^{42}$

In determining appropriate management measures for salmon stocks under their jurisdictions, NASCO's regional Commissions have had to balance the interests of member States in whose rivers salmon originate with those of members traditionally supporting interceptory fisheries, such as Greenland and the Faroe Islands. The Salmon Convention attempts to create an equitable solution by requiring Commissions to take into account relevant domestic salmon management initiatives, the potential impacts of contemplated exploitation options, and the interests of communities dependent on salmon fisheries in setting regulatory measures. ${ }^{43}$

To ensure that any regulatory measures developed are not detrimental to the long-term health of Atlantic salmon stocks, the Salmon Convention further directs the Commissions to rely on the best available information. ${ }^{44}$ Each year, the Council's Standing Scientific Committee prepares a formal request for advice from ICES on issues such as stock assessments and conservation limits, catch options, and management and research recommendations. ${ }^{45}$

As a result of the regulatory measures developed under the authority of the Salmon Convention, commercial salmon fishing in the international waters of the North Atlantic has largely ceased.

38 See further, National Marine Fisheries Service (NMFS), Convention for the Conservation of Salmon in the North Atlantic Ocean (Basic Instrument for the North Atlantic Salmon Conservation Organization) (CK Washington, DC: NMFS, 2005), pp. 11-12, online at www.nmfs.noaa.gov/ia/intlagree/docs/NASCO\%20\%2005.doc, accessed 9 May 2007.

39 NASCO, supra note 3, 12.

40 North-East Atlantic Commission, Decision regarding the Salmon Fishery in Faroese Waters 2007, with Possible Application in 2008 and 2009, NEA(06)6, in NASCO, Report, supra note 37.

41 NASCO, supra note 3, 12.

42 Salmon Convention, supra note 2, Art. 7.

43 Ibid., Art. 9.

44 Ibid., Art. 9(a).

45 See for example, NASCO, Request for Scientific Advice from ICES, CNL(05)12, Annex 13 of Report of the Twenty-Second Annual Meeting of the Council (Vichy, France, 6-10 June 2005) CNL(05)50. 
Atlantic salmon caught outside the fisheries jurisdiction of the State in whose rivers they originate accounted for 30 per cent of the annual harvest prior to 1984 and only 1 per cent by $2004 .^{46}$ Although catch levels were reduced, Atlantic salmon stocks have continued to decline in abundance and mortality at sea remains high, affecting the numbers of fish returning to their home rivers to spawn. ${ }^{47}$

\section{Salmon fishing by non-contracting Parties}

1992 Protocol

Despite progress made in reducing salmon catches among NASCO members, a number of States not party to the Convention continued to exploit the resource. In an effort to combat high-seas salmon fishing by non-Party States, the NASCO Council established a Protocol to the Salmon Convention in $1992 .{ }^{48}$ Under the terms of the protocol, signatory States would agree to implement the fisheries management provisions of the Convention.

The NASCO Council also resolved to gather data on high-seas salmon fishing by non-Parties, including vessel, catch, and transhipment information, and share information with other international organizations, such as the North-East Atlantic Fisheries Commission (NEAFC), on this issue. ${ }^{49}$ In addition, NASCO members are directed to report any observances of salmon harvesting on the high seas to the Secretariat and to encourage non-contracting Parties to adopt the protocol. ${ }^{50}$ NASCO Parties are further obliged to implement measures preventing their nationals from registering fishing vessels in non-contracting States as a means of circumventing the provisions of the convention. ${ }^{51}$

Although no States adopted the protocol, diplomatic negotiations by NASCO and its members had some measure of success. There have been no recorded observances of high-seas salmon fishing in the North Atlantic since $1994,{ }^{52}$ and NASCO no longer considers this issue to be a significant problem. ${ }^{53}$ Furthermore, non-contracting Parties, such as Poland and Panama, have taken steps to address salmon fishing in international waters by vessels flying their flags. ${ }^{54}$

\section{St. Pierre and Miquelon Fishery}

The mixed-stock salmon fishery carried out from the French islands of St. Pierre and Miquelon has been a cause of concern for NASCO, as catch levels threaten North American salmon conservation initiatives. In 2000 and 2002, NASCO adopted resolutions calling on Contracting Parties to

46 NASCO, supra note 6, p. 5.

47 NASCO, NASCO - The Past, Present, and Future (tabled by the United States) CNL(04)35, Annex 31 of Report of the Twenty-First Annual Meeting of the Council (Reykjavik, Iceland, 7-11 June 2004) CNL(04)50.

48 NASCO, Protocol Open for Signature by States Not Parties to the Convention for the Conservation of Salmon in the North Atlantic Ocean (1992) CNL(92)53.

49 NASCO. Resolution of the Council of NASCO at its Ninth Annual Meeting, Washington DC, 9-12 June 1992: Fishing for Salmon on the High Seas (1992), CNL(92)54, s. 5.

50 lbid., ss. 2, 4.

51 Ibid., s. 3.

52 NMFS, supra note 38, p. 5.

53 Twenty-Year Milestones, supra note 6, p. 5.

54 NMFS, supra note 38 , p. 5. 
encourage France, in respect of St. Pierre and Miquelon, to co-operate with NASCO's conservation and management measures and implement ICES recommendations to reduce salmon harvest levels. ${ }^{55}$ France was requested to provide NASCO with information on the fishery, including management measures, catch data, and unreported catch estimates. The 2002 resolution further requested NASCO Parties to pressure France to participate in a scientific sampling programme for the fishery.

In recent years, co-operation between France and NASCO in respect of the St. Pierre and Miquelon salmon fishery has increased. A biometric, genetic, and pathological scientific sampling programme has been developed to gather scientific information on the St. Pierre and Miquelon salmon stocks. Annual biometric assessments have been carried out since 2003, while tissue and scale samples, collected since 2004, are undergoing genetic analysis as part of an ongoing joint initiative with Canada. The pathological component of the sampling programme, testing for the presence of diseases and parasites, has not yet been initiated. ${ }^{56}$

Since 2004, France has presented a report on the sampling programme and the regulatory framework in place for managing the islands' fishery, including details on licensing provisions and reported catches, at NASCO's Annual Meetings. ${ }^{57}$ Although France considers the St. Pierre and Miquelon fishery to be a traditional subsistence fishery, the country stated its intention to reduce catch levels by limiting the number of permits issued in the coming years. ${ }^{58}$

\subsubsection{Adopting the precautionary approach}

Over the last 10 years, NASCO has emphasised the importance of adopting a precautionary approach in the conservation, management, and exploitation of Atlantic salmon. The exercise of precaution in the face of uncertainty or inadequate information is a fundamental component of modern sustainable development practices. ${ }^{59}$ NASCO's 1998 Agreement on Adoption of a Precautionary Approach ${ }^{60}$ and the accompanying 1999 Action Plan for Application of the Precautionary Approach ${ }^{61}$ serve as guidance documents for the organization and its Parties in incorporating precaution into management decisions.

For NASCO, the precautionary approach includes:

- Giving priority to conserving salmon stocks in the face of uncertainties regarding resource use;

55 NASCO, Resolution by the Contracting Parties to the Convention for the Conservation of Salmon in the North Atlantic Ocean Concerning St. Pierre and Miquelon (2000), CNL(00)59; NASCO, Resolution Concerning Cooperation with St. Pierre and Miquelon (2002), CNL(02)47.

56 NASCO, St. Pierre and Miquelon Salmon Fishery, CNL(06)23, Annex 24 of NASCO, Report, supra note 37, CNL(06)46; NASCO, St. Pierre and Miquelon Salmon Fishery, CNL(07)20.

57 See, for example, NASCO, Report, supra note 37.

58 Ibid. For a further discussion, see notes 201-204 and accompanying text.

59 See, e.g., D. VanderZwaag, The Precautionary Principle and Marine Environmental Protection: Slippery Shores, Rough Seas, and Rising Normative Tides, Ocean Development \& International Law, vol. 33 issue 2 (2002) p. 165; S. Marr, The Precautionary Principle in the Law of the Sea: Modern Decision Making in International Law (The Hague: Martinus Nijhoff, 2003).

60 NASCO, Agreement on Adoption of a Precautionary Approach (1998), CNL(98)46.

61 NASCO, Action Plan for Application of the Precautionary Approach (1999), CNL(99)48. 
- The prior identification of undesirable outcomes and the actions necessary to correct or avoid them;

- Implementing corrective measures immediately when required; and

- Demonstrating consideration of the needs of future generations by avoiding potentially irreversible changes. ${ }^{62}$

In 2002, NASCO adopted a model decision structure to assist Parties in consistently applying the precautionary approach to the management of single- and mixed-stock salmon fisheries. ${ }^{63}$ NASCO has also sought to improve catch reporting mechanisms in an effort to address high unreported catch values and to promote research initiatives evaluating the risk and impact of salmon bycatch in pelagic fisheries. NASCO's guidelines on stock rebuilding set out a multi-stage process for developing and implementing remedial programmes in the context of the precautionary approach. NASCO has also adopted guidelines in incorporating social and economic factors in reaching precautionary decisions.

\section{Fisheries management decision structure}

The decision structure is intended to help managers ensure that salmon harvest levels do not exceed the resource's exploitable surplus and that effective monitoring, control, and enforcement measures are developed and implemented. ${ }^{64}$ The model sets out a uniform process for recording the status of local salmon stocks, serving to both guide management decisions and record actions taken. ${ }^{65}$

Managers are encouraged to use reference points, such as conservation limits ${ }^{66}$ and management targets, to monitor and assess the abundance and diversity of local salmon stocks. Pre-agreed management actions can then be triggered when a stock reaches or falls below its conservation limit. The decision structure further emphasizes precaution by encouraging managers to assess the risks of various management actions to stock abundance and diversity before decisions are made, in order to help ensure a high probability of success in achieving management goals.

Although NASCO does not have the authority to enforce the use of the decision structure among member States, Parties agreed to evaluate the model's effectiveness and its adaptability to the unique requirements of particular rivers or stocks. ${ }^{67}$ In advance of the 2005 Annual Meeting, the Council asked Parties to submit assessment reports, along with an example of the decision structure's implementation. Responses revealed that Denmark, Spain, Sweden, Scotland, and Iceland had not applied the guidelines to any domestic salmon management programmes.

62 NASCO, supra note 60, s.2.

63 NASCO, Decision Structure for Management of North Atlantic Salmon Fisheries (2002), CNL31.332.

64 NASCO, supra note 3, p. 6.

65 Ibid.

66 NASCO defines a conservation limit as 'the spawning stock level that produces maximum sustainable yield'; see NASCO, supra note 60 , s.6.

67 NASCO, Progress with Application of the Decision Structure for Management of North Atlantic Salmon Fisheries - Returns by the Parties, CNL(05)16, Annex 23 of NASCO, supra note 45. 
Furthermore, only the United Kingdom (England and Wales) and the Russian Federation provided an example of the structure's application. ${ }^{68}$

\section{Unreported catches}

In 2004, unreported catch values were estimated at 593-791 tonnes, equal to 28-36 per cent of the total reported Atlantic salmon catch. ${ }^{69}$ A major focus for NASCO in addressing this problem has been improving the clarity and transparency of catch reporting mechanisms in accordance with NASCO guidelines on the precautionary approach. ${ }^{70}$

Since introducing minimum standards for catch statistics in $1993,{ }^{71}$ NASCO has continued to refine its guidelines for estimating and recounting unreported catch data. ${ }^{72}$ Parties provide NASCO with annual accounts of the number, weight, and age-class of fish caught in all components of the salmon fisheries ${ }^{73}$ along with estimates for recreational catch and release fisheries. ${ }^{74}$

From 1985 to 1998, ICES provided NASCO with yearly estimates of unreported catches for each of the three regional Commission areas based on numbers submitted by individual countries. However, the methods by which each State determined unreported catch values were not always explained. Under NASCO's revised guidelines, Parties are obliged to break down annual unreported catch estimates on a stock complex basis and provide an explanation as to how these values have been determined. ${ }^{75}$

NASCO has also encouraged its members to implement measures to address unreported catches and report the results of such initiatives. ${ }^{76}$ Recent actions taken by NASCO Parties include seasonal fishing restrictions (Iceland), enforcement actions (Canada), public education initiatives (Greenland and United States), and improvements to catch reporting systems (Norway). ${ }^{77}$

Although progress has been made in the way of improved reporting mechanisms and management initiatives, unreported salmon catches remain a concern for NASCO, and a Special Session on this topic was scheduled for the 2007 Annual Meeting. ${ }^{78}$

\section{Salmon bycatch in pelagic fisheries}

The bycatch of salmon in the herring and mackerel fisheries of the northeast Atlantic has the potential to detrimentally affect the health of Atlantic salmon stocks. ${ }^{79}$ As such, NASCO has

68 Ibid.

69 NASCO, Unreported Catches - Returns by the Parties, CNL(05)22, Annex 30 of NASCO, supra note 45 (Unreported Catches), p. 512.

70 NASCO, supra note 61, s. 4 .

71 NASCO, Minimum Standard for Catch Statistics Adopted by the Council at its Tenth Annual Meeting, 7-11 June 1993, Edinburgh, UK (1993), CNL(93)51.

72 NMFS, supra note $38,5$.

73 NASCO, supra note 71.

74 NASCO, supra note 61, s. 4 .

75 Ibid.

76 Ibid.

77 NASCO, supra note 69.

78 NASCO, Report, supra note 37, s.5.5. For a further discussion, see notes 197-200 and accompanying text.

79 NMFS, supra note $38,9$. 
emphasized the importance of adopting a precautionary approach in the management of any fisheries with the potential for salmon bycatch, and Parties are directed to consider this issue when developing fisheries management measures. ${ }^{80}$ NASCO has further requested its members to encourage non-contracting Parties engaging in such fisheries to implement actions to minimize bycatches. $^{81}$

One of NASCO's current priorities is the promotion of research initiatives evaluating the risk and impact of salmon bycatch in pelagic fisheries. The NASCO Council has encouraged studies on the distribution of salmon at sea, including their spatial and temporal overlap with commercial pelagic fish stocks. ${ }^{82}$ The organization has also promoted a series of pilot projects studying the effects of technical modifications to pelagic fisheries gear, and its deployment methods, in minimizing the bycatch of salmon. ${ }^{83}$ Finally, NASCO has sought information from ICES and the NEAFC on the risks of salmon bycatch in other fisheries and its effect on Atlantic salmon stocks. ${ }^{84}$

\section{Stock rebuilding programmes}

NASCO's Agreement on the Adoption of Precaution calls for the use of rebuilding programmes to maintain salmon stocks above conservation limits. ${ }^{85}$ To assist managers in developing and implementing remedial measures, such as restricting catches, restocking threatened populations, and habitat improvement projects, NASCO issued multi-stage guidelines on stock rebuilding programmes. $^{86}$

The guidelines state that management measures should be determined based on the results of assessments examining stock abundance, decline, and population diversity. ${ }^{87}$ Managers are also directed to evaluate potential natural and cultural threats, including environmental change, habitat degradation, interactions among different species, and human exploitation. ${ }^{88}$ Management actions should be developed and prioritized based on identified biological characteristics of the stock and the potential threats to its survival. ${ }^{89}$ Finally, recommendations for monitoring and evaluating the effectiveness of rebuilding measures are provided. ${ }^{90}$

The guidelines specify that all stock rebuilding activities should comply with the precautionary approach. ${ }^{91}$ This includes taking into account uncertainties in stock assessment data and further research to address existing knowledge gaps. The guidelines further recommend that managers

80 NASCO, supra note 61 , s.9.

81 Ibid.

82 NASCO, supra note $3,8$.

83 NASCO, supra note 45, s.6.6.

84 NMFS, supra note 38, p. 9.

85 NASCO, supra note $60, \mathrm{~s} .7(\mathrm{a}),(\mathrm{g})$.

86 NASCO, NASCO Guidelines on the Use of Stock Rebuilding Programmes in the Context of the Precautionary Management of Salmon Stocks (2004), CNL(04)55.

87 Ibid., ss.3-4.

88 Ibid., s.4.

89 Ibid., s.6.

90 Ibid., s.9.

91 Ibid., s.6. 
consider potential social and economic impacts when determining stock rebuilding options. ${ }^{92}$ The value of stakeholder consultation and involvement, from the earliest possible stage, is also highlighted. ${ }^{93}$

\section{Incorporating social and economic factors under the precautionary approach}

In 2004 NASCO adopted guidelines for incorporating social and economic factors in decisions under the precautionary approach. ${ }^{94}$ Meant to apply to all decisions where proposals may affect wild Atlantic salmon and their environment, the guidelines urge Parties to subject proposals to socioeconomic impact assessment. Management options with the highest social, economic, and environmental benefits are encouraged. ${ }^{95}$

To further develop social and economic valuation approaches, NASCO's Council decided at its Twenty-Fourth Annual meeting in June 2007 to establish a Working Group on Socio-Economics with a mandate to meet at least once before the 2008 NASCO meeting. ${ }^{96}$

\subsubsection{Broadening the scope of NASCO}

With Atlantic salmon stocks continuing to decline, NASCO expanded the scope of its work to tackle a broader range of threats. The Williamsburg Resolution pledges NASCO Parties to cooperate in minimizing adverse effects to wild salmon stocks from aquaculture, introductions and transfers, and transgenics. ${ }^{97}$ NASCO has also addressed salmon habitat protection and restoration through the development of a Habitat Action Plan and the promotion of information-sharing on the impacts of acid rain and mitigation techniques.

\section{Aquaculture, introductions and transfers, and transgenics: the Williamsburg Resolution}

Adopted in 2003, the Williamsburg Resolution consolidates various guidance documents on aquaculture, introductions and transfers, and transgenics, some of which go back to the 1990 s. $^{98}$ Co-operative guidance is set out in the main text of the resolution followed by seven annexes and two appendices.

\section{Resolution text}

Application of the precautionary approach is urged. Article 3 recommends that each Party place the burden of proof on proponents of activities, such as proposed aquaculture operations, to

92 Ibid., s.8.

93 Ibid., s.5.

94 NASCO, Guidelines for Incorporating Social and Economic Factors in Decisions under the Precautionary Approach (2004), CNL(04)57, s.4.

95 Ibid., s.7.

96 NASCO, Report of the Twenty-Fourth Annual Meeting of the Council, Bar Harbor, Maine, USA, 4-8 June 2007, CNL(07)58, s.6.4.

97 NASCO, Resolution by the Parties to the Convention for the Conservation of Salmon in the North Atlantic Ocean to Minimise Impacts from Aquaculture, Introductions and Transfers, and Transgenics on the Wild Salmon Stocks: The Williamsburg Resolution (adopted June 2003, amended June 2004 and June 2006), CNL(06)48.

98 For example, Resolution to Minimize Impact from Salmon Aquaculture on the Wild Salmon Stocks, CNL(94)53 and Guidelines for Actions on Transgenic Salmon, CNL(97)48. 
demonstrate the activities will not have a significant adverse impact on wild salmon stocks or lead to irreversible change. Article 4 encourages Parties to develop and apply risk assessment methodologies as an integral component of precaution. Article 7 suggests the use of transgenic salmonids should be considered a high-risk activity in light of the lack of scientific knowledge and advocates a strong presumption against any such use.

Various measures to minimize impacts of aquaculture and introductions or transfers are called for. For example, Parties are urged to minimize the escape of farmed salmon to a level as close as practicable to zero through the development and implementation of action plans. ${ }^{99}$ Introduction of non-indigenous fish into a river containing Atlantic salmon is frowned upon unless a thorough examination of the potential adverse impacts on the Atlantic salmon populations indicates there is no unacceptable risk of adverse ecological effects. ${ }^{100}$

\section{Annexes}

Annex 1 provides definitions of key terms. For example, the meaning of the words "introductions and transfers," two activities the Williamsburg Resolution aims to address, is clarified.

Annex 2 sets out further guidance on how Parties might minimize the impacts on wild salmon stocks of salmon aquaculture and introductions or transfers. Among other measures, Parties are urged to consider establishing 'wild salmon protection areas' where salmon aquaculture would be prohibited or restricted as well as 'aquaculture regions' where fish farming would be concentrated. ${ }^{101}$

Guidelines on Containment of Farm Salmon, set out in Annex 3, were adopted in $2001^{102}$ and provide very general directions on how escapes of farmed salmon to freshwater and marine environments might be prevented. Siting of aquaculture operations in areas where weather and environmental conditions are not harsh on nets and moorings is encouraged. ${ }^{103}$ Aquaculturalists are urged to adopt preventative inspection and repair procedures and to undertake regular stress testing of all nets in use. ${ }^{104}$ Operators are advised to report significant escapes immediately to authorities and to develop site-specific contingency plans where recapture details would be spelled out. ${ }^{105}$ Each jurisdiction is encouraged to draw up a national action plan (or regional plans) for minimizing escapes and to report annually on implementation progress. ${ }^{106}$

Guidelines for stocking Atlantic salmon, for example, from hatcheries for enhancement, restoration, or ranching purposes, are contained in Annex 4. Parties are urged to apply the precautionary approach to stocking proposals, whereby proponents would have to provide all information necessary to demonstrate that stocking would not have a significant adverse impact on

99 NASCO, supra note 97, Art. 5.

100 Ibid., Art. 6.

101 NASCO, General Measures to Minimise Impacts, Annex 2 of NASCO, supra note 97, ss.1.2-1.3.

102 NASCO, Guidelines on Containment of Farm Salmon, CNL(01)53, Annex 3 of NASCO, supra note 97.

103 Ibid., s.3.1.

104 Ibid., ss.5.3-5.4.

105 lbid., ss.6.2-6.3.

106 Ibid., ss.7-8. 
wild salmon populations or an unacceptable impact on the ecosystem. ${ }^{107}$ The guidelines urge prohibition of the release of Atlantic salmon of European, including Icelandic, origin in the NAC area and of Atlantic salmon of North American origin in the NEAC area. ${ }^{108}$

Annex 5 includes NASCO Guidelines for Action on Transgenic Salmonids. To counter the potential risks raised by genetically modified salmon to wild stocks, the guidelines call upon Parties to confine the use of transgenic salmonids to 'secure, self-contained, land-based facilities'. ${ }^{109}$ Parties are also asked to advise the NASCO Council of any proposal to permit the rearing of transgenics. Details regarding containment and safeguard measures are also to be provided. ${ }^{110}$

Annex 6 encourages Parties to classify and zone their Atlantic salmon rivers. For example, some areas may be designated as off limits for salmon enhancement efforts or aquaculture operations.

Annex 7 lists research priorities to support the Williamsburg Resolution. Parties agree to encourage research relating to sterile fish, tagging and making farmed salmon, production methods and technologies, aquaculture broodstocks, genetics, diseases and parasites, interaction of wild and farmed salmon, risk assessment frameworks, and escape prevention.

\section{Appendices}

Appendix 1 to the Williamsburg Resolution includes NAC Protocols for Introduction and Transfer of Salmonids. ${ }^{111}$ The NAC area is divided into three zones based upon the degree of degradation or manipulation of wild Atlantic salmon populations, with Zone I being least affected. ${ }^{112}$ Management approaches in relation to introduction or transfers, aquaculture, and commercial ranching are established for each zone, with the most stringent restrictions applying within Zone I. For all three zones, reproductively viable strains of Atlantic salmon of European origin, including Icelandic origin, are not to be released or used. ${ }^{113}$ Government agencies are called upon to establish a permit system for all introductions and transfer of fishes and to enact regulations to control introductions and transfers in accord with the agreed approaches. ${ }^{114}$

Appendix 2 includes a memorandum of understanding between Canada and the United States, adopted in 2005, that seeks to reconcile differing methods within the two countries for authorization of introductions and transfers. The Parties agree to consult with each other over introduction or transfer proposals that may have an impact on the other and any proposal that would be inconsistent with the NAC protocols. ${ }^{115}$

107 NASCO, Guidelines for Stocking Atlantic Salmon, Annex 4 of NASCO, supra note 97, s.2.

108 Ibid., s.3(B)(1).

109 NASCO, NASCO Guidelines for Action on Transgenic Salmonids, CNL(04)41, Annex 5 of NASCO, supra note 97.

110 lbid.

111 NASCO, North American Commission Protocols for the Introduction and Transfer of Salmonids: Summary of Protocols by Zone, NAC(94)14, Appendix 1 of NASCO, supra note 97.

112 lbid., s.1.

113 Ibid., s.3.1.1.

114 lbid., s.4.2.

115 NASCO, Memorandum of Understanding between Canada and USA, NAC(05)7, Appendix 2 of NASCO, supra note 97 , s.C. 


\section{Habitat protection and restoration}

Recognizing the numerous local activities affecting salmon habitat, such as hydroelectric development, irrigation projects, forestry, land drainage, and pollution, the Parties in 2001 adopted the NASCO Plan of Action for the Application of the Precautionary Approach to the Protection and Restoration of Atlantic Salmon Habitat. ${ }^{116}$ NASCO has also promoted information sharing on the impacts of acid rain and potential mitigation measures to protect salmon habitat.

\section{Habitat Plan of Action}

The Habitat Plan of Action sets out two overarching commitments: the need by each Party and its relevant jurisdictions to establish salmon river inventories and the need to develop national salmon habitat protection and restoration plans. ${ }^{117}$

Detailed guidance is given in Annex 2 of the Plan as to what information should be included for country inventories of salmon rivers. Besides basic information like river names, lengths, and locations, inventories should also provide salmon production data, such as historic and current levels of wild salmon smolts, proportion of adult salmon comprising reared fish, and critical habitat areas. Inclusion of habitat impact data is also encouraged. ${ }^{118}$

The Plan of Action also provides a checklist of what national habitat protection and restoration plans should address. Plans should among other things contain strategies for habitat protection and restoration, be co-ordinated with catchment area or watershed planning processes, and introduce habitat evaluation and monitoring systems. ${ }^{119}$ Each relevant jurisdiction is urged to apply the precautionary approach through habitat plan implementation by placing the burden of proof on proponents of potential activities that have an impact on habitat. ${ }^{120}$ Co-ordination of national habitat plans to deal with transboundary issues is also urged. ${ }^{121}$

To help measure how the objective of maintaining and where possible increasing the current productive capacity of Atlantic salmon habitat, the NASCO Plan of Action encourages national reporting. Contracting Parties are asked to regularly report on and update (perhaps every five years) their salmon river inventories. ${ }^{122}$ Parties are requested to report to NASCO on progress towards implementation of habitat plans 'on an ongoing basis'. ${ }^{123}$

116 NASCO, NASCO Plan of Action for the Application of the Precautionary Approach to the Protection and Restoration of Atlantic Salmon Habitat (2001), CNL(01)51.

117 Ibid., s.3.

118 The Atlantic Salmon Rivers Database is available on the NASCO Web site at: <www.nasco.int/asd/> [accessed 2 May 2007].

119 NASCO, supra note 116 , s.5.

120 lbid., s.3.

121 Ibid., s.5.

122 NASCO, Use of an Inventory of Salmon Rivers in the Protection and Restoration of Salmon Habitat, Annex 2 of NASCO, supra note 116 .

123 NASCO, supra note 116 , s.5. 


\section{Air pollution and acid rain}

The threats posed to wild salmon by acid rain and related leaching of toxic aluminium ${ }^{124}$ have been a concern of NASCO Parties, but NASCO has shied away from taking an advocacy role towards further reduction in fossil fuel emissions. NASCO has instead served as an information-sharing forum on the impacts of acid rain and mitigation techniques. The impact of acid rain on Atlantic salmon was included as an agenda item for the 2005 and 2006 Annual Meetings of the Council. At the 2005 meeting, Canada tabled a report on impacts of acid rain that highlighted that acid rain still affects a large area of south-eastern Canada (equal to the size of France), suggesting the need for reduction of acid rain contributing emissions from both the United States and Canada by 75 per cent and noting the initiation of a liming project for a river in eastern Nova Scotia to improve the habitat and survival of salmon. ${ }^{125}$ At the 2006 meeting, Norway reported annual expenditures associated with liming 22 acidified salmon rivers as being around $£ 4$ million. ${ }^{126}$ The representative of the NGOs lamented the lack of progress in Canada and the United States in developing and applying mitigation strategies for rivers affected by acid rain in Nova Scotia and Maine. ${ }^{127}$

Although NASCO's Habitat Plan of Action draws attention to the threats of industrial air pollution and acid rain, the plan indicates that addressing transboundary air pollution should be dealt with in other international fora. ${ }^{128}$ Such fora are not specified but would clearly include efforts under the UN Economic Commission for Europe to address long-range transport of air pollutants ${ }^{129}$ and Canadian-US initiatives on air quality. ${ }^{130}$

\subsubsection{Encouraging scientific research}

The absence of reliable scientific information on which to base management decisions represents a significant challenge for NASCO Parties in conserving salmon populations. To address this problem, NASCO members formed the International Atlantic Salmon Research Board in 2001. ${ }^{131}$ The Board's current priority is the Salmon at Sea (SALSEA) Programme, studying factors affecting the migration and distribution of salmon at sea.

124 Aluminum's solubility increases exponentially as $\mathrm{pH}$ declines below 7.0 and exposure to $\mathrm{pH}$ less than 4.5 can cause plasma ion loss and death of Atlantic salmon in freshwater. See NMFS and U.S. Fish and Wildlife Service, Recovery Plan for the Gulf of Maine Distinct Population Segment of Atlantic Salmon (Salmo salar) (Silver Spring, MD: NMFS, 2005) pp. 1-29-1-32.

125 NASCO, Impacts of Acid Rain - 2005 Report (tabled by Canada), CNL(05)47, Annex 34 of NASCO, supra note 45.

126 NASCO, Report, supra note 37, s.7.8.

127 Ibid.

128 NASCO, supra note 116 , s.2.

129 Pursuant to the 1979 Convention on Long-range Transboundary Air Pollution, eight protocols that identify measures for cutting air pollution emissions have been negotiated under UNECE auspices. See UNECE, History of the Convention, online at www.unece.org/env//rtap/Irtap_h1.htm, accessed 24 May 2007.

130 For example, the Agreement between Canada and the United States on air quality (adopted and entered into force 13 March 1991) CTS 1991/3 as amended by the Protocol (adopted and in force 7 December 2000) CTS 2000/26.

131 NASCO, Research Board, online at: <www.nasco.int/> [accessed 14 June 2007]. 


\section{International Atlantic Salmon Research Board}

The Research Board was established to encourage and facilitate co-operation and collaboration on research related to marine mortality in salmon. ${ }^{132}$ Board members include both NASCO Parties and accredited NGO representatives. ${ }^{133}$ The Board's Scientific Advisory Group evaluates ongoing and proposed research projects and provides Board members with recommendations regarding priorities for future research, submitted project proposals, and the co-ordination of research results and activities. ${ }^{134}$

In addition to promoting new research, the Board helps co-ordinate existing research by maintaining an international inventory, accessible through the Board's Web site, of completed, current, and planned research on salmon mortality at sea. ${ }^{135}$ The inventory is a valuable tool for sharing information on current and past salmon research projects and helping to identify priorities for future research. ${ }^{136}$ Projects are classified under five headings: life history and biological processes, specific natural and anthropogenic factors, long-term monitoring, development of methods, and distribution/migration at sea.

Fundraising to help offset the prohibitive costs of ocean-based research is another important function of the Research Board, which has sought to partner with organizations and interested individuals in supporting large-scale projects. ${ }^{137}$ These partnerships mark an innovative approach, unique among international fisheries organizations, to facilitating research initiatives. ${ }^{138}$ NASCO Parties and their partners have spent approximately UK£6 million annually on sea-based salmon research. $^{139}$

\section{SALSEA Programme}

The Research Board initiated the SALSEA Programme to address its current priority - the migration and distribution of salmon at sea with particular reference to feeding patterns and predation - in order to better understand factors contributing to salmon marine mortality. ${ }^{140}$ SALSEA is a broad, multiyear programme involving the co-ordination of existing research as well as the development and implementation of new studies. Scientists representing all NASCO Parties contributed to the development of this international co-operative venture. ${ }^{141}$

132 NASCO, Rules of Procedure for the International Atlantic Salmon Research Board, ICR(06)10, Annex 6 of Annex 12 of NASCO, Report, supra note 37.

133 lbid.

134 Ibid.

135 International Atlantic Salmon Research Board (IASRB), Inventory of Research Relating to Salmon Mortality in the Sea, online at www.nasco.int/sas/research.htm, accessed 2 May 2007.

136 NASCO, Report of the Fifth Meeting of the International Atlantic Salmon Research Board, CNL(06)11, Annex 12 of NASCO, Report, supra note 37, s.3.

137 NASCO, supra note 3, p. 11.

138 lbid.

139 NASCO, supra note 6, p. 10.

140 IASRB, SALSEA: An International Cooperative Research Programme on Salmon at Sea, SAL(04)5,1 online at www.nasco.int/sas/pdf/salsea_programme.pdf, accessed 9 May 2007.

141 lbid. 
The SALSEA Programme is organized into a series of four Work Packages. ${ }^{142}$ The first focuses on the development of technologies to support the implementation of the programme, including sampling gear, stock identification methods, migration models, and analytical techniques for assessing salmon populations.

Work Package 2 studies salmon migration through the inshore zone, from rivers and estuaries to coastal waters. Information gathered during these projects will help identify the effects of factors operating in the inshore zone that ultimately affect salmon mortality at sea. To date, funding for this part of the programme has been largely confined to national agencies and their partners.

Work Package 3 evaluates the distribution and migration of salmon at sea through a survey of post-smolts in the North Atlantic. As this phase will entail considerable research costs, the Board has developed a detailed implementation plan, including proposed public-private funding partnerships.

Work Package 4 addresses the communications necessary to implement SALSEA, including developing a fundraising strategy, facilitating information exchange among scientists and managers, and increasing public awareness.

\subsubsection{Reviewing NASCO's effectiveness}

To mark its twentieth anniversary, in 2004 NASCO members undertook a comprehensive review of the organization's effectiveness in meeting salmon conservation and management objectives. A working group was established to review NASCO's structure and procedural aspects and provide recommendations for addressing management challenges. The group examined the results of two public stakeholder consultation meetings, along with a number of discussion documents prepared by NASCO Parties and NGOs, and developed a vision statement and strategic approach to guide NASCO's future actions. ${ }^{143}$ While most of the working group's recommendations were approved for immediate implementation at NASCO's 2005 Annual Meeting, a task force was established to further develop recommendations for improving commitment to NASCO agreements and increasing transparency and inclusivity in NASCO decisions. ${ }^{144}$ The resultant suggestions were approved at the 2006 Annual Meeting. ${ }^{145}$

NASCO's newly adopted vision is "to pursue the restoration of abundant Atlantic salmon stocks throughout the species' range with the aim of providing the greatest possible benefits to society and individuals". ${ }^{146}$ The strategic approach, to guide NASCO's actions in achieving this vision, is comprised of four key goals: ensuring members' commitment to, and accountability for, implementing NASCO measures and agreements; increasing the organization's effectiveness and efficiency; ensuring transparency and inclusivity in NASCO processes; and, raising NASCO's public profile.

142 For a detailed account of the Work Packages, see ibid.

143 NASCO, Report of the 'Next Steps for NASCO' Working Group, CNL(05)14, Annex 15 of NASCO, supra note 45

144 NASCO, Report of the 'Next Steps for NASCO' Task Force, CNL(06)16, Annex 15 of NASCO, Report, supra note 37 .

145 NASCO, Report, supra note 37, s.6.2.

146 NASCO, Strategic Approach for NASCO's 'Next Steps', CNL(05)49, Annex 16 of NASCO, supra note 45, p. 292. 


\section{Implementation commitment and accountability}

Among the most notable recommendations adopted by NASCO are those geared towards improving the Parties' commitment to, and accountability for, implementing NASCO guidelines and agreements. In response to NGO concerns regarding NASCO's inability to ensure compliance among Parties in implementing management measures and agreements, the working group recommended that each NASCO jurisdiction be required to develop an Implementation Plan outlining its actions for achieving NASCO management objectives. In addition, the group set out provisions for regular reporting on, and review of, any actions taken. ${ }^{147}$

The Next Steps Task Force drafted guidelines for the Parties to follow in preparing their Implementation Plans. The plans are to outline the actions taken or planned by each Party to achieve NASCO's objectives in relation to salmon fisheries management; aquaculture, introductions, transfers, and transgenics; and habitat protection and restoration. The plans are also to include measurable outputs and timelines and to take into account NASCO guidelines on incorporating socioeconomic factors into decision making. ${ }^{148}$ Draft Implementation Plans were submitted to NASCO by each jurisdiction in October 2006.

A Review Committee was established to study the draft plans and provide critical analysis. The Committee included one representative each from Denmark, in respect of Greenland and the Faroe Islands (but not both); a European Party to NASCO; a North American Party to NASCO; NASCO's Standing Scientific Committee; a North American NASCO-accredited NGO; and a European NASCO-accredited NGO. The Committee presented its findings at NASCO's 2007 Annual Meeting. ${ }^{149}$

A key component of NASCO's new commitment to ensuring the implementation of its guidelines and agreements is its attempt to increase accountability through improved reporting mechanisms. Parties are to prepare regular reports outlining which actions have been implemented and whether expected objectives have been achieved. In addition, each jurisdiction is obliged to present oral progress reports on specific aspects of their Implementation Plans during open special sessions at NASCO Annual Meetings as of 2007..$^{150}$

\section{Increasing effectiveness and efficiency}

Recommendations for improving the effectiveness and efficiency of NASCO operations were adopted at NASCO's 2005 Annual Meeting. The topic 'new or emerging opportunities for, or threats to, salmon conservation and management' has been added to the agendas of NASCO Annual Meetings to help ensure that NASCO is prepared to respond to new developments.

147 NASCO, supra note 143 , ss.4.12-4.13.

148 NASCO, supra note 144, Annex 3.

149 NASCO, Terms of Reference for the 2006/2007 Ad Hoc Review Group, CNL(06)39, Annex 16 of NASCO, Report, supra note 37. For a further discussion, see notes 205-208 and accompanying text.

150 NASCO, supra note 144, Annex 5. 
NASCO-accredited NGOs and ICES are also encouraged to supply the Council with information on this topic. ${ }^{151}$

The Council agreed that the regional Commissions would discuss the feasibility of requesting scientific advice from ICES on a multiyear basis and using multiyear regulatory measures for the West Greenland and Faroese salmon fisheries. The Council requested ICES to provide catch advice for the 2006-2008 period. In 2006 ICES provided multiannual management advice for all the NASCO Commission Areas and presented a preliminary Framework of Indicators that would gauge whether any significant changes in previously multiannual advice had occurred in subsequent years. ${ }^{152}$ Three-year regulatory measures were agreed upon in the West Greenland and North-East Atlantic Commissions, with the second and third year of regulatory measures being dependant on ICES providing a finalized Framework of Indicators and the Parties to each Commission Area accepting that submission. ${ }^{153}$

\section{Ensuring transparency and inclusivity}

To address concerns raised by NGO representatives, the NASCO Council agreed to adopt several recommendations for improving stakeholder participation and increasing transparency in NASCO decisions. In 2006, the Council amended its Conditions for Attendance by Observers at NASCO. The conditions allow the accredited NGO chairperson and/or designee to make interventions on behalf of NGOs during regular meetings of the Council and Commissions. During sessions designated as Special Sessions, any NGO representative may make interventions. ${ }^{154}$

The Council has indicated a willingness to consider holding further public consultation meetings in 2008 or 2009 to promote public education and outreach initiatives and to receive feedback on suggestions for improving NASCO and its work. ${ }^{155}$ Accredited NGOs have also been encouraged to continue providing NASCO with their recommendations for improving the inclusiveness of the organization.

At its 2005 Annual Meeting, the Council agreed to seek stakeholder input for NASCO working groups, as appropriate, and to support NGO participation in the Aquaculture Liaison Group between NASCO and the North Atlantic salmon farming industry. While representatives of the salmon farming industry initially resisted NGO participation in the Liaison Group, agreement was reached prior to the Boston meeting of the North Atlantic Salmon Farming Industry and the NASCO Liaison Group in March 2007, to allow the chairperson of NASCO's accredited NGOs and/or his/her designate to participate in meetings. ${ }^{156}$.

151 NASCO, Report on Progress with Implementing the Strategic Approach for NASCO's Next Steps (2006), CNL(06)14.

152 NASCO, Report of the ICES Advisory Committee on Fishery Management, CNL(07)7, p. 11.

153 Ibid.

154 NASCO, Revised Conditions for Attendance by Observers at NASCO Meetings following amendment at the Twenty-Third Annual Meeting in June 2006, CNL(06)49.

155 NASCO, supra note 151.

156 Conditions for Attendance by Observers for NASCO's Accredited Non-Government Organizations at meetings of the NASCO/North Atlantic Salmon Farming Industry Liaison Group, SLG(07)12. The observer status will apply for a trial period of two years. 
To help ensure transparency in NASCO decisions and processes, the Council agreed that any new issues for discussion would be introduced during the annual Council or Commission meetings. In this way, NASCO observers are kept informed of new agendas and can participate in discussions through interventions when required. It was further determined that decisions reached during closed Heads of Delegations meetings would be presented, along with the rationale behind the decision and information on any debates related to the issue, at a subsequent Commission or Council meeting. ${ }^{157}$

\section{Raising NASCO's profile}

Among the conclusions reached during the Next Steps public consultation meetings is that NASCO is not well known among many stakeholders with interests in Atlantic salmon. To address this problem, the Council is working towards raising NASCO's public profile and improving cooperation with compatible international organizations.

The Council has agreed to establish a Public Relations Group to develop and implement a programme to promote the organization's objectives, actions, and achievements as a way of gaining public and political support for salmon conservation and management initiatives. Professional media consultants are to be retained to produce media products and enhance the NASCO Web site to make it more user-friendly. NASCO members also resolved to consult their NGO affiliates for advice in developing a media strategy. ${ }^{158}$

The Secretariat prepared a report on enhancing co-operation with other international organizations for discussion at the 2006 Annual Meeting. ${ }^{159}$ Although the report provides a series of recommendations for strengthening links with compatible groups, the actions necessary to achieve them have yet to be implemented.

\subsection{Confronting a sea of challenges}

While some challenges facing NASCO were already touched upon above, including the bycatch of salmon in other fisheries, this section briefly describes 10 issue areas confronting NASCO.

\subsubsection{Putting precaution into practice}

Application of the precautionary approach to fisheries management continues to be a challenge on many fronts. The ideal of having precautionary conservation limits and management targets for each salmon river $^{160}$ is still far from realization. For example, among European countries, only France, Ireland, and the United Kingdom (England \& Wales) have fully implemented river-specific conservation limits, according to ICES. ${ }^{161}$ Although ICES has expressed concern over fisheries on mixed stocks occurring either in coastal waters or on the high seas, since such fisheries cannot

157 NASCO, supra note 151.

158 NASCO, supra note 146, p. 298.

159 NASCO, Cooperation with Other International Organizations on Issues of Mutual Interest (2006), CNL(06)11.

160 NASCO, supra note 60 , s. 7(b).

161 NASCO, supra note $152,32$. 
target only these stocks with precautionary limits, ICES's precautionary recommendations for the complete cessation of fishing mixed stocks off West Greenland have not been followed. ${ }^{162}$ Getting a clear picture on how countries are implementing precaution in fishing management remains difficult due to the lack of specific and detailed reporting by jurisdictions on how the Agreement on Adoption of a Precautionary Approach is being put into practice. ${ }^{163}$

Precaution appears to be largely a paper exercise in its application to aquaculture and habitat protection and restoration. While the Williamsburg Resolution calls for placing the burden of proof on proponents of aquaculture activities to demonstrate proposed activities will not have a significant adverse impact on wild salmon or lead to irreversible change, ${ }^{164}$ and while the Habitat Plan of Action contains similar urging, ${ }^{165}$ the admonitions are not legally binding. Reports on implementation of NASCO agreements and guidance documents submitted by 15 jurisdictions in October 2006 did not indicate how the precautionary onus of proof is being applied in domestic decision-making processes relating to aquaculture or biodiversity conservation.

A recent review of Canadian aquaculture regulations raises serious doubts about how seriously precaution is being implemented. ${ }^{166}$ For example, no provincial aquaculture legislation explicitly requires a precautionary approach to aquaculture licensing. ${ }^{167}$ While commercial finfish mariculture proposals generally require environmental assessment under the Canadian Environmental Assessment Act, ${ }^{168}$ the legislation only gives a limited embrace to the precautionary approach in the purpose section, ${ }^{169}$ and the screening reviews usually applied to proposals have been limited in public participation and consideration of precaution. ${ }^{170}$

\subsubsection{Embracing the ecosystem approach}

While the ecosystem approach is still subject to considerable debate over terminology and management implications, ${ }^{171}$ a number of key directions are emerging. They include the need to protect ecosystems on which fish stocks depend; spur regional fisheries management organizations (RFMOs) to consider the impacts of fisheries on marine biodiversity health; promote co-ordination among the RFMOs having overlapping fisheries management jurisdictions; and foster

162 Ibid., pp. 61-62.

163 See Section 4.6 of this chapter.

164 NASCO, supra note 97, Art.. 3.

165 NASCO, supra note 116 , s. 3.

166 D.L. VanderZwaag, G. Chao, and C. Covan, Canadian Aquaculture and the Principles of Sustainable Development: Gauging the Law and Policy Tides and Charting a Course, in D.L. VanderZwaag and Gloria Chao (eds.), Aquaculture Law and Policy: Towards principled Access and Operations (London: Routledge, 2006) 49.

167 Ibid., p. 80.

168 S.C. 1992 , c. 37.

169 Section 4 of the Act was amended in 2003 to include as one of the purposes to 'ensure that projects are considered in a careful and precautionary manner before federal authorities take action in connection with them, in order to ensure such projects do not cause significant adverse environmental effects'. An Act to Amend the Canadian Environmental Assessment Act, S.C. 2003, c. 9, s. 2(1).

170 VanderZwaag, Chao, and Covan, supra note 166, pp. 82-83.

171 See D.R. Rothwell and D.L. VanderZwaag, The Sea Change Towards Principled Oceans Governance, in D.R. Rothwell and D.L. VanderZwaag (eds.), Towards Principled Oceans Governance: Australian and Canadian Approaches and Challenges (London: Routledge, 2006), p. 3 at 6. 
co-operation between RFMOs and regional marine environmental conservation programmes and initiatives. $^{172}$

NASCO might be described as "sputtering along" on the path to implementing the ecosystem approach. The Convention for the Conservation of North Atlantic Salmon, preceding the fast-paced international acceptance of the ecosystem approach, ${ }^{173}$ does not establish a firm foundation for implementing the approach. The convention is largely focused on protecting Atlantic salmon from high-seas targeted fisheries and ensuring salmon catches primarily occur within the 12-nauticalmile territorial seas. ${ }^{174}$ Contracting Parties have certainly devoted more emphasis to implementing the precautionary approach than the 'come lately' ecosystem approach. Protection and restoration of wild salmon habitats remains a 'soft law' obligation. Recovery of endangered salmon populations has been left mainly to coastal states. ${ }^{175}$

Co-operation with other international organizations having potential impacts on wild salmon has yet to be fully worked out. The NASCO Secretariat has invited representatives from various international organizations to attend annual meetings ${ }^{176}$ and has occasionally attended annual meetings of other regional fisheries organizations such as the North Pacific Anadromous Fisheries Commission. ${ }^{177}$ The Secretariats of the North Atlantic Regional Fisheries Management Organizations have also met from time to time, ${ }^{178}$ and every second year NASCO has participated in the meeting of Secretariats of Regional Fisheries Bodies from around the globe under the auspices of the Food and Agriculture Organization and its Committee on Fisheries. ${ }^{179}$ While a Memorandum of Understanding has been entered into with ICES, no formal co-operation agreements have been forged with other organizations. ${ }^{180}$

172 For discussion on the multiple implications of an ecosystem approach, see Report of the SecretaryGeneral, Oceans and the Law of the Sea, UNGA A/61/63 (9 March 2006), pp. 38-45, and Report on the Work of the United Nations Open-ended Informal Consultative Process on Oceans and the Law of the Sea at its seventh meeting, UNGA A/61/156 (17 July 2006).

173 For a review of the fast evolutions, see S.M. Garcia et al., The Ecosystem Approach to Fisheries: Issues, Terminology, Principles, Institutional Foundations, Implementation and Outlook, FAO Fisheries Technical Paper No. 443 (Rome: UN Food and Agriculture Organization, 2003).

174 Salmon Convention, supra note 2, Art. 2.

175 On the need for NASCO to develop a special initiative focusing political and financial attention towards endangered Atlantic salmon populations, see W. Carter et al., NASCO's Future: A Vision Statement (Atlantic Salmon Federation and World Wildlife Fund: St. Andrews, New Brunswick, and Washington, DC, 2004), pp. 16-17.

176 For example, at the 2005 Twenty-Second Annual Meeting of NASCO in Vichy, France, representatives of ICES, the International Baltic Sea Fishery Commission (IBSFC), the North Pacific Anadromous Fish Commission (NPAFC), and the North Atlantic Marine Mammal Commission (NAMMC) participated. NASCO, supra note 159, p. 1.

177 Ibid.

178 That is, North East Atlantic Fisheries Commission, IBSFC, NASCO, Northwest Atlantic Fisheries Organization, NAMMCO, and the International Commission for the Conservation of Atlantic Tunas. NASCO, supra note 159 .

179 lbid., pp. 1-2.

180 Ibid., p. 2. 


\subsubsection{Enhancing public participation}

Although NASCO stands out as one of the more progressive RFMOs in encouraging NGO and intergovernment organizational involvements ${ }^{181}$ in annual meetings and other processes, such as implementation reviews, participation issues still loom in the horizon. Beyond the question of whether entities other than national governments should have voting powers, the issues include whether financial support should be offered for NGO participation in NASCO meetings, ${ }^{182}$ what the appropriate number of nongovernmental representatives should be in liaison and review committees and the representational adequacy, and whether NGOs, individuals, or other groups should be empowered to lodge complaints and ask for investigations for lack of implementation of convention obligations and subsidiary agreements by Parties. ${ }^{183}$

\subsubsection{Considering indigenous participation and rights}

While indigenous communities around the North Atlantic may have special cultural, economic, and historical connections with the harvesting of wild salmon, ${ }^{184}$ the Salmon Convention is silent on the topics of indigenous participation and rights. The convention emphasizes fishery management cooperation among State Parties and defers to each Party to decide the details regarding access rights and allocation priorities at the national level.

Although NASCO has not specifically addressed issues of indigenous rights to date, future challenges cannot be ruled out in light of the evolving nature of indigenous rights in international law and practice. ${ }^{185}$ Special participation status might be argued for beyond the observer

181 For example, NASCO is quite liberal in the time within which an NGO must apply to attend meetings (no less than 15 days before the meeting of the Council), and the NASCO Secretary is granted discretion to decide whether the objectives of the organization are compatible with those of NASCO. NASCO, supra note 154. For a review of participation approaches in other regional fisheries organizations, see G.M. Wiser, Transparency in 21st Century Fisheries Management: Options for Public Participation to Enhance Conservation and Management of International Fish Stocks, Journal of International Wildlife Law and Policy, vol. 4, issue 2 (2001), p. 95.

182 The possible need to provide resources in order to facilitate meaningful and equitable participation in international forums is raised by the Almaty Guidelines on Promoting the Application of the Principles of the Aarhus Convention in International Forums. See Report of the Second Meeting of the Parties to the Convention on Access to Information, Public Participation in Decision-making and Access to Justice in Environmental Matters, ECE/MP.PP/2005/2/Add.5 (20 June 2005), Annex , para. 18.

183 For a review of some environmental regimes permitting NGOs and individuals to make formal complaints and trigger review procedures through, for example, compliance committees, see J. Ebbesson, Public Participation, in D. Bodansky, J. Brunee, and E Hey (eds.) The Oxford Handbook of International Environmental Law (Oxford: Oxford University Press, 2007), pp. 693-696.

184 For example, more than 40 First Nations and other Aboriginal organizations fish for Atlantic salmon in eastern Canada. See Canada - NASCO Implementation Plan (2006) in NASCO, Compilation of Implementation Plans, CNL(07)22, p. 187.

185 For reviews, see D. Sanders, Indigenous Rights: Implications for Aquaculture, in VanderZwaag and Chao, supra note 166, and Russell Lawrence Barsh, Indigenous Peoples, in Bodansky, Brunee, and Hey, supra note 183. 
category. ${ }^{186}$ Specific requirements that future fisheries, aquaculture, and potential habitat degradation activities fully consider the impacts on North Atlantic indigenous communities and cultural values might also be considered.

\subsubsection{Getting better grips on unreported catches}

The Special Session on Unreported Catches at the 2007 Annual Meeting highlighted the ongoing problem of unreported catches in many jurisdictions. In 2006, between 534 and 767 tonnes were estimated to be unreported out of a provisional declared catch of 2,001 tonnes, making the unreported catch 27-38 per cent of the reported catch. ${ }^{187}$ Limited reporting in Greenland, which is in the process of being addressed through media efforts to educate the public on the need to report all salmon catches, was especially worrisome - with ICES estimating around 10 tonnes of unreported catches in recent years, quite a large quantity in light of the total 22.8 tonnes reported caught in $2006 .^{188}$

While the 2007 Special Session provided a useful forum for sharing national approaches and challenges in documenting and addressing unreported catches, how exactly to tackle the unreporting issue was left unresolved. Various ideas were floated in the Special Session, including adoption of a catch documentation scheme, tagging of salmon carcasses, and the establishment of a NASCO working group to suggest ways forward in documenting and solving unreported catches. ${ }^{189}$ NASCO's Council did not adopt specific actions but decided the issue of unreported catches would remain on the Council's agenda for its Twenty-Fifth Annual Meeting in 2008. ${ }^{190}$

\subsubsection{Bringing the St. Pierre and Miquelon fishery into the NASCO fold}

At the 2007 Annual Meeting, serious concerns over the mixed-stock fishery for salmon at St. Pierre and Miquelon were again raised. Despite the reduction of licences issued in 2006 (62, down from 66 in 2005), the catch in 2006 of 3,555 kilograms was the highest for the period 1998-2006 and about 8 per cent higher than in $2005 .{ }^{191}$

NASCO's Council devoted considerable attention to addressing the challenge. The Council noted the unfortunate reality that while France is a member State and participates in the EU delegation to NASCO in relation to its domestic salmon fishery, the government has not chosen to become a Party to NASCO on behalf of its overseas territory. ${ }^{192}$ The President of NASCO expressed concern that France in respect to St. Pierre and Miquelon had not participated in the

186 For example, within the regional Arctic Council, indigenous organizations have been granted the status of Permanent Participants to ensure full participation but stopping short of voting rights. See T. Koivurova and L. Heinämäki, The participation of indigenous peoples in international norm-making in the Arctic, Polar Record, vol. 42, no. 221 (2006), p. 101. Involvement of Greenland's Home Rule Government, of course, does represent indigenous interests in Greenland.

187 NASCO, Unreported Catches - Returns by the Parties, CNL(07)10, p. 1.

188 NASCO, Special Session on Unreported Catches Tabled by Denmark (in respect of the Faroe Islands and Greenland), CNL(07)49.

189 Personal notes by Professor VanderZwaag, who attended the 2007 Annual Meeting.

190 NASCO, supra note 96, s. 4.6.

191 NASCO, St. Pierre and Miquelon Salmon Fishery, CNL(07)20, 1.

192 NASCO, supra note 96, s. 6.6. 
Twenty-Fourth Annual Meeting. ${ }^{193}$ The Council authorized the President of NASCO to invite France (in respect of St. Pierre and Miquelon) to accede to the Salmon Convention. ${ }^{194}$

\subsubsection{Preventing escape of farmed salmon}

While NASCO has developed Guidelines on Containment of Farm Salmon ${ }^{195}$ and has fostered dialogues between those interested in wild salmon conservation and those in the aquaculture industry, ${ }^{196}$ the number of escapes from aquaculture operations still tends to be substantial - at least in some jurisdictions. For example, Norway has reported that escaped farmed salmon averaged about 417,000 a year for the period 1994-2004, while over 700,000 salmon and rainbow trout escaped annually in 2005 and 2006. ${ }^{197}$ In 2005, four acts of vandalism in Canada resulted in the release of approximately 150,000 farmed fish. ${ }^{198}$ In recent years, escaped aquaculture fish have accounted for anywhere from 2 per cent to 100 per cent of total salmon returns to some Maine rivers in the United States. ${ }^{199}$

Challenging questions still face NASCO in relation to escape prevention. ${ }^{200}$ How might the existing Guidelines on Containment of Farm Salmon be clarified and tightened? ${ }^{201}$ What policy approach should be favoured to control escapes - for example, a ban or phaseout for marine-cage farming, a prohibition on escapes backed up with potential fines, or imposition of cage construction and operational standards? ${ }^{202}$ Is it feasible to consider a multilateral aquaculture agreement or inter-regional guidelines where the problem of escapes might be addressed on a broader geographical basis, such as escape of farmed salmon into the Pacific and possibly the Southern Ocean. ${ }^{203}$

193 lbid.

194 Ibid.

195 NASCO, supra note 97, Annex 3.

196 See note 156 and accompanying text.

197 Implementation Plan Norway, in NASCO, supra note 184, pp. 238-239.

198 NASCO, Report, supra note 37, 210.

199 NMFS and U.S. Fish and Wildlife Service, supra note 124, pp. 1-80.

200 Escape prevention, of course, is not the only challenge surrounding aquaculture, with other concerns beingparasite and disease spread from farmed salmon to wild stocks and the potential use of transgenic fish in aquaculture production. NASCO, supra note 6, p. 11. See also L.P. Hansen and M. Windsor, Interactions Between Aquaculture and Wild Stocks of Atlantic Salmon and Other Diadromous Fish Species: Science and Management, Challenges and Solutions, Special Report 34 (CITY: Norwegian Institute for Nature Research, 2006).

201 For example, among other strengthenings, the guidelines might set out more specific guidance on technical standards for net pens as well as training requirements for escape prevention and installation of security systems and could urge the third-party audits to verify escape preparedness. See T.K. Barry and D.L. VanderZwaag, Preventing Salmon Escapes from Aquaculture in Canada and the USA: Limited International Coordinates, Divergent Regulatory Currents and Possible Future Courses, RECIEL, vol. 16, no. 1 (2007), p. 58 at 73.

202 Although NASCO has favoured the latter policy approach through its Guidelines, the state of Washington has embraced a prohibition-on-escapes approach and Alaska has banned marine-cage farming of salmon. See Barry and VanderZwaag, ibid. 201, pp. 69-71.

203 NASCO itself has identified the need to determine whether internationally agreed regulations or standards should be pursued for aquaculture, introductions and transfers, and transgenics. NASCO, supra note 6, 15 . 
To further consider how to better address escapes and other impacts of salmon farming on wild stocks, NASCO's Council at its June 2007 meeting agreed to establish a Joint Technical Task Force involving industry and NASCO representatives. The representative of an NGO offered to provide a technical expert to the proposed Task Force. The Task Force is requested to develop best practice recommendations and to meet before the next Annual Meeting of NASCO. ${ }^{204}$

\subsubsection{Ensuring implementation of existing commitments}

NASCO's attempt to bolster implementation by Parties of its three main agreements and guidelines addressing fisheries management, aquaculture and associated activities, and habitat protection and restoration has met with only partial success. While 15 Implementation Plans were submitted for consideration at the 24th Annual Meeting in June 2007, the majority of them failed to make any reference to NASCO's agreements, resolutions, and guidelines and most plans failed to identify specific implementation actions. ${ }^{205}$ France and Germany submitted plans late and Portugal did not submit an Implementation Plan. The Ad Hoc Review Group tasked with assessing the plans simply evaluated their structure and content and did not investigate the adequacy of each jurisdiction's record in salmon management. ${ }^{206}$

The 24th Annual Meeting of NASCO's Council decided on the focus of the first reports by Parties under their Implementation Plans to be made in 2008 and the terms of reference and composition of a further Ad Hoc Review Group. The Council agreed that each Party or jurisdiction would prepare a Fisheries Management Focus Area Report for the 2008 Annual Meeting. ${ }^{207}$ The representational composition of the Review Group evaluating implementation reports was agreed to remain essentially the same as the first Group ${ }^{208}$ but with individuals possibly varying.

\subsubsection{Reaching agreement on a performance review}

The EU proposal for a NASCO performance review involving both internal and external reviewers, ${ }^{209}$ tabled at NASCO's Annual Meeting in June 2007, proved to be very contentious. The suggestion that the performance review be completed by 2010 was opposed by a number of Parties. While some Parties thought a performance review should be initiated on an urgent basis in light of UN Resolution 61/105, ${ }^{210}$ others felt NASCO's Next Steps Process, viewed as a form of internal review, should first be allowed to complete its course.

A compromise was finally reached. The Council decided that it would in the future undertake an additional external review, involving an experienced team of external and internal reviewers.

\footnotetext{
204 NASCO, supra note 96, s. 6.2(b).

205 Report of the Ad Hoc Review Group on Implementation Plans, IP(07)4, 7.

206 Report of the Ad Hoc Review Group on the Parties' Implementation Plans, CNL(07)15, para. 3.

207 NASCO, Fisheries Management Focus Areas, CNL(07)47.

208 See note 149 and accompanying text.

209 NASCO, EU Proposal for a Performance Review, CNL(07)43.

210 Paragraph 73 of the 2006 UN Resolution 61/105 on Sustainable Fisheries urges states to undertake performance reviews of regional fisheries management organizations and arrangements 'on an urgent basis'. NASCO, Information Note from the European Union, Extract from UN Resolution 61/105, adopted on 8 December 2006 Regarding Performance Review, CNL(07)41.
} 
Decisions on the timing and terms of reference for such a review were deferred to the 2008 Annual Meeting. ${ }^{211}$

\subsubsection{Addressing dispute resolution}

Given NASCO's soft law approach in promoting the conservation and management of Atlantic salmon, formal dispute resolution procedures have been deemed unnecessary. The issue was raised by the Next Steps Working Group, which recommended that the Secretariat review dispute resolution arrangements used by other organizations with a view to determining their applicability to NASCO. ${ }^{212}$

\subsection{Conclusion}

As NASCO nears the 25-year milestone, the organization can be praised for voyaging beyond the constraints imposed by the dated Salmon Convention adopted in 1982. NASCO has urged Contracting Parties to implement the precautionary approach in the areas of fisheries management, aquaculture, and habitat protection and restoration. It has also encouraged critical review of its operations and has moved to strengthen approaches to implementation, NGO participation, and media communications.

However, a sea of challenges still confronts NASCO. Key challenges include putting precaution into practice, embracing the ecosystem approach, enhancing public participation, considering indigenous participation and rights, getting better grips on unreported catches, bringing St. Pierre and Miquelon into the NASCO fold, preventing escape of farmed salmon, ensuring implementation of existing commitments, reaching agreement on a performance review, and addressing dispute resolution.

Various trends in transboundary resource management stand out from the NASCO experience. They include a preference for moving incrementally and softly to adopt a principled approach, a hesitancy to amend the founding convention, a continuing tension between national sovereign interests and the appropriate functions and powers of a regional organization, and a growing recognition of the complex array of human uses beyond fisheries that need to be addressed.

The effectiveness of NASCO may be questioned for not stemming during its watch the serious decline of many North Atlantic salmon stocks. Wild salmon have disappeared from at least 209 river systems in Europe and North America since NASCO's establishment. ${ }^{213}$ Atlantic salmon in 32 rivers of the inner Bay of Fundy in Canada have been listed as endangered. ${ }^{214}$ In the United States, the Gulf of Maine Distinct Population Segment of Atlantic salmon was listed as endangered in December 2000, and total adult returns in 2004 to the eight rivers still supporting wild salmon populations were estimated to range from 60 to 113 individuals. ${ }^{215}$

211 NASCO, supra note 96, s. 5.3.

212 NASCO, supra note 143.

213 Carter et al., supra note 175, p. 16.

214 NASCO, supra note 184, p. 184.

215 NMFS and U.S. Fish and Wildlife Service, supra note 124, p. ix. 
The ultimate litmus test for gauging NASCO's effectiveness may prove to be whether NASCO succeeds in achieving wild salmon population recoveries. Regaining sustainable salmon populations across their North Atlantic range remains a distant shore. Rough voyaging likely lies ahead for NASCO in light of its limited abilities to counter the powerful political and economic currents surrounding aquacultural and coastal developments within national jurisdictions. The treacherous shoals of climate change and land-based pollution and activities threaten to damage or sink even the most valiant fisheries conservation measures. The retrofitting of NASCO from a transboundary fisheries management fixation to a broader ecosystem approach continues, but whether NASCO will be able to orchestrate 'saving the salmon' has yet to be answered. 



\section{Management of Tuna Fisheries in the Western and Central Pacific}

\section{Pepe Clarke}

\subsection{Introduction}

The Western and Central Pacific region is home to the world's most important tuna fisheries, ${ }^{2}$ accounting for approximately 50 per cent of the world's 4-million-tonne annual catch of tuna. ${ }^{3}$ The primary tuna species in the region - skipjack (Katsuwonus pelamis), yellowfin (Thunnus albacares), bigeye (Thunnus obesus), and albacore (Thunnus alalunga) - are highly migratory, moving between the exclusive economic zones (EEZs) of Pacific island countries and the high seas, making them a shared and transboundary resource. ${ }^{4}$

The region encompasses 24 States and Territories, including Australia, New Zealand, and the Pacific island countries. ${ }^{5}$ Pacific island States and Territories have very small terrestrial areas relative to their exclusive economic zones, which extend 200 nautical miles from land and collectively represent a huge area of the Pacific Ocean. Island States in the region also have small populations - only Papua New Guinea has a population greater than 1 million - and face daunting development challenges. ${ }^{6}$

The sustainable management of tuna resources to ensure conservation of the resource and to maximize economic benefits for developing island states is a key issue for development in the region. The migratory nature of the species, combined with certain political and economic factors, limits the ability of individual countries to achieve optimal conservation and development outcomes within their marine territories. Regional collaboration has been, and will continue to be, crucial for the sustainable management of this rich transboundary resource.

This chapter critically reviews existing legal and institutional arrangements for management of tuna fisheries in the region and explores emerging opportunities for enhanced regional cooperation.

1 Legal Advisor, IUCN Regional Office for Oceania, Suva, Fiji.

2 E. H. Petersen (ed.), Institutional Economics and Fisheries Management: The Case of Pacific Tuna Cheltenham, UK: Edward Elgar Publishing, 2006), p. 25; G. Munro, The Management of Tropical Tuna Resources in the Western Pacific: Trans-Regional Cooperation and Second Tier Diplomacy, in G. Blake et al. (eds.), The Peaceful Management of Transboundary Resources (London: Graham \& Trotman, 1995), p. 475.

3 A. Langley, P. Williams, and J. Hampton, The Western and Central Pacific Tuna Fishery 2005: Overview and Status of Stocks (Noumea, New Caledonia: Oceanic Fisheries Programme, Secretariat of the Pacific Community, 2006).

4 H. Parris and R.Q. Grafton, Can Tuna Promote Sustainable Development in the Pacific? The Journal of Environment and Development, vol. 15, no. 3 (2006), pp. 270-272.

5 American Samoa, Australia, Cook Islands, Fiji, French Polynesia, Guam, Kiribati, Marshall Islands, Federated States of Micronesia, Nauru, New Caledonia, New Zealand, Niue, Northern Mariana Islands, Palau, Papua New Guinea, Pitcairn Islands, Samoa, Solomon Islands, Tokelau, Tonga, Tuvalu, Vanuatu, and Wallis and Futuna.

6 Parris and Grafton, supra note 4, p. 270. 
In particular, the chapter provides a critical analysis of: a) key resource management challenges; b) the legal framework, including key international and regional agreements; and c) the institutional framework, with an emphasis on the respective roles and achievements of the Forum Fisheries Agency (FFA) and the Western and Central Pacific Fisheries Commission (WCPFC).

Over the last 30 years the States and Territories of the region have made substantial progress in the establishment of an effective legal and institutional framework for the sustainable management of tuna resources. Nonetheless, resource conservation challenges remain, and these will become more urgent as fishing pressures in the region increase. A robust and responsive decision-making framework, together with the political will to adopt and implement effective conservation and management measures, will be essential to the long-term conservation of the resource and the sustainable development of the region.

\subsection{Regional overview}

The Western and Central Pacific is a vast region, covering an area of roughly 30 million square kilometres. The 24 States and Territories in the region are American Samoa, Australia, Cook Islands, Fiji, French Polynesia, Guam, Kiribati, Marshall Islands, Federated States of Micronesia, Nauru, New Caledonia, New Zealand, Niue, Northern Mariana Islands, Palau, Papua New Guinea, Pitcairn Islands, Samoa, Solomon Islands, Tokelau, Tonga, Tuvalu, Vanuatu, and Wallis and Futuna.

The island States and Territories of the region, with the exception of Papua New Guinea, have very small land areas: 11 of the island countries have a land area of less than 500 square kilometres, and 4 have a land area of less than 30 square kilometres. The land-to-sea ratio of most Pacific island countries is very high. Kiribati, for example, has a land-to-sea ratio of 1:5,000, with 33 small islands, all of which are atolls, and an EEZ covering 3.5 million square kilometres. ${ }^{7}$ The great majority of the Western and Central Pacific region falls within the EEZs of the Pacific islands States.

The total population of the Pacific islands is approximately 9 million. Papua New Guinea accounts for almost two-thirds of this figure, with a population approaching 6 million. By contrast, Niue and Tokelau each have a population of about 1,500 people. ${ }^{8}$ Pacific island countries are home to a rich diversity of cultures, languages and traditions relating to the use and conservation of natural resources. For centuries, traditional systems have successfully regulated individual and communal resource use. However, rapid population growth and economic development have placed considerable pressure on natural ecosystems. ${ }^{9}$

7 B. Boer, Environmental Law and the South Pacific: Law of the Sea Issues, in J. Crawford and D.R. Rothwell (eds.), The Law of the Sea in the Asian Pacific Region (Dordrecht, Netherlands: Nijhoff, 1994), p. 67.

8 Secretariat of the Pacific Community, Pacific Island Populations 2004, at www.spc.int/demog/en/index.html, accessed 22 February 2007.

9 B. Richardson, A Study of the Response of Transnational Environmental Law and Policy to the Environmental Problems of East Asia and the South Pacific, Environmental and Planning Law Journal, vol. 7 , no. 3 (1990), p. 219. 
Most countries in the region have a narrow resource base and small domestic markets, resulting in heavy dependence on a small number of export commodities. ${ }^{10}$ Sustainable natural resource management is central to long-term development prospects in the region:

The development challenges facing the countries of the western and central Pacific ... are daunting, despite substantial in-flows of development assistance. Commonly recognised problems include high rates of unemployment and underemployment, low levels of economic growth, and, in some countries, political unrest and instability. Regional governments generally see themselves as having a limited range of resources and opportunities for sustainable development and consequently place considerable importance on obtaining economic benefits from their natural resources. ${ }^{11}$

For communities throughout the Pacific islands, 'the ocean has immense value to their traditional way of life and their hopes for future economic development'. ${ }^{2}$ Small-scale coastal fisheries play an integral role in local subsistence economies, supporting local livelihoods and village-level food security..$^{13}$ However, it is large-scale, high-value, offshore fisheries - in particular, tuna fisheries - that have the greatest potential to support long-term economic development in many countries across the region:

Given the limited economic development options available, the importance of tuna resources and their exploitation to the economic security and sustainable development of Pacific island countries are considerable and cannot be overstated. ${ }^{14}$

\subsection{Resource overview}

As noted, the Western and Central Pacific region is home to four main tuna species: skipjack, yellowfin, bigeye, and albacore. These species are highly migratory, moving between the exclusive economic zones of Pacific island countries and the high seas: ${ }^{15}$

[S]chools of tuna cross oceans in months and national boundaries in hours. Their migration routes, areas of abundance, and commercial availability vary significantly from year to year, with the only boundaries established by the ocean environment, temperature gradations, and the availability of food. As a transboundary resource, conservation and management on a national or local basis will not guarantee the preservation of the resource at a sustainable level. ${ }^{16}$

10 Petersen, supra note 2, p. 37.

11 Parris and Grafton, supra note 4, p. 269.

12 L.K. Bostwick, Empowering South Pacific Fishmongers: A New Framework for Preferential Access Agreements in the South Pacific Tuna Industry, Law and Policy in International Business, vol. 26, no. 3 (1995), p. 897.

13 I. Novaczek (ed.), Pacific Voices: Equity and Sustainability in Pacific Island Fisheries (Suva, Fiji: Institute of Pacific Studies, University of the South Pacific, 2005); Bostwick, supra note 12, p. 907.

14 L. Cordonnery, L., Implementing the Pacific Islands Regional Ocean Policy: How Difficult Is It Going to Be? Victoria University of Wellington Law Review, no. 32 (2005).

15 Parris and Grafton, supra note 4, pp. 270-272.

16 Bostwick, supra note 12, p. 903. 
The total annual catch of the four main tuna species in the Western and Central Pacific Ocean remained relatively stable during the early and mid-1990s, at about 1.5 million tonnes. In subsequent years, the catch increased significantly. In 2005, the total tuna catch for the Western and Central Pacific region was estimated at 2,145,367 tonnes, the highest annual catch recorded and an increase of about 5 per cent over the record in $2004 .{ }^{17}$

The fishery is diverse, ranging from small-scale artisanal fishing in coastal waters to large-scale industrial operations both in the exclusive economic zones of Pacific States and on the high seas. ${ }^{18}$ Only a small percentage of the region's fishing catch is taken in the high seas, with the EEZs accounting for 80-90 per cent of total fisheries production.

The three main fishing methods used in the region are: purse-seining, which targets skipjack and yellowfin; pole-and-lining, which targets skipjack and to a smaller extent yellowfin; and longlining, which targets yellowfin, bigeye, and albacore. ${ }^{19}$ The purse-seine fishery accounted for an estimated 71 per cent of the total catch, pole-and-line 10 per cent, and longline 11 per cent, with the remaining 7 per cent taken by troll gear and artisanal gear. The catch was dominated by skipjack ( 67 per cent), followed by yellowfin ( 20 per cent), bigeye ( 8 per cent), and albacore ( 5 per cent). ${ }^{20}$

\subsubsection{Conservation status}

The status of tuna stocks is the subject of significant research effort in the region. In 2005, the Scientific Committee of the Western and Central Pacific Fisheries Commission concluded that skipjack tuna was not overfished, and exploitation levels were considered to be modest relative to the stock's biological potential. However, it was noted that any increases in purse-seine catches of skipjack may result in a corresponding increase in fishing mortality for yellowfin and bigeye tunas. ${ }^{21}$

Over the last 50 years, the catch per unit of effort for yellowfin tuna has declined by 70 per cent. $^{22}$ Since 1990, the biomass of yellowfin in the region has steadily declined. Although the stock is not yet in an overfished state, continued fishing at current levels of effort will move the stock to an overfished state. In 2005, the WCPFC Scientific Committee recommended that the catch levels for yellowfin be reduced by 10 per cent and noted that more urgent action may be required in the western equatorial region. ${ }^{23}$

The 2005 regional assessment for bigeye tuna found that the stock is not yet in an overfished state but that overfishing is occurring. Recent catch levels have been sustained by above average levels of recruitment. Future levels of recruitment are highly uncertain, and a return to long-term average levels of recruitment is predicted to result in a rapid decline in biomass. Based on the results of the assessment, the WCPFC Scientific Committee recommended that catch levels for

17 Langley, Williams, and Hampton, supra note 3.

18 Ibid.

19 Petersen, supra note 2, p. 27.

20 Langley, Williams, and Hampton, supra note 3.

21 Ibid.

22 Parris and Grafton, supra note 4, pp. 272-273.

23 Langley, Williams, and Hampton, supra note 3. Note: Overfishing occurs when fishing mortality rates exceed the overfishing benchmark. A stock is considered overfished when its biomass falls below the relevant overfishing benchmark. 
bigeye tuna be reduced by 25 per cent of recent levels and noted that urgent management actions may be required in the equatorial region. Higher reductions in catch levels would be required to achieve long-term sustainability. ${ }^{24}$ The 2006 IUCN Red List lists the Pacific stock of bigeye tuna as endangered, based on current abundance and exploitation levels. ${ }^{25}$

Biomass levels for albacore have declined over the last decade, due to low recruitment. However, in 2005 catch levels were considered to be sustainable, as exploitation was very low relative to the total biomass. The WCPFC Scientific Committee noted that the longline fleet was having a considerably higher impact on albacore age-classes vulnerable to longlining and that any significant increase in longlining would produce only moderate increases in yields. ${ }^{26}$

By global standards, the tuna fisheries of the Western and Central Pacific are relatively healthy. However, historical experience suggests that it would be prudent to adopt a conservative management approach:

The fisheries literature is replete with examples of failed fisheries management, and the majority of the world's fisheries are being harvested at, or above, the maximum sustainable yield.... It is imperative that governance of the [Western and Central Pacific] fishery is strengthened to prevent continued over-fishing of bigeye tuna, and before the other species start to be over-exploited. ${ }^{27}$

\subsubsection{Economic significance}

The importance of tuna fisheries for the economic development of the region should not be underestimated. The landed value of the total tuna catch for the region is approximately US\$2.2 billion per annum. ${ }^{28}$ Scharmann has described tuna as 'the single most valuable resource available in this vast area', ${ }^{29}$ while the South Pacific Forum Fisheries Agency has argued that 'tuna represents the [region]'s most valuable renewable resource, and, in the long term, probably its most valuable asset overall' ${ }^{30}$

Historically, about 90 per cent of the total tuna catch in the Western and Central Pacific has been harvested by four distant-water fishing nations: Japan, Taiwan, South Korea, and the United States of America. ${ }^{31}$ Effective management of tuna stocks requires recognition of the global reach of the tuna industry:

24 Langley, Williams, and Hampton, supra note 3.

25 Y. Uozumi, Thunnus obesus (Pacific stock), 1996, in World Conservation Union-IUCN, 2006 IUCN Red List of Threatened Species, at www.iucnredlist.org, downloaded 23 February 2007.

26 Langley, Williams, and Hampton, supra note 3.

27 Petersen, supra note 2, p. 30.

28 Ibid., p. 31.

29 L. Scharmann, The UN Convention on the Law of the Sea and Its Implications for Third World Countries: The Case of the Tuna Fishery in South Pacific Countries, 17 Ocean \& Shoreline Management, no. 309 (1991), p. 312.

30 Forum Fisheries Agency, Sustainable Development and the Ocean Environment: The Role of the Forum Fisheries Agency and the Need for Institutional Reform in the South Pacific, FFA Report 92/5 (Honiara, Solomon Islands: 1992), p. 4.

31 Petersen, supra note 2, p. 26. 
The tuna industry is itself transboundary: the vertical structure crosses many boundaries from the location of the actual fishing, the registration of the vessel, initial investment in the equipment, transshipment, processing, packaging, marketing and end-product markets. As fishing areas are depleted, the fleets move easily from ocean to another. ${ }^{32}$

On average, distant-water fishing nations pay access fees amounting to approximately 3-4 per cent of gross revenue, although the percentage varies across distant-water fishing nations. ${ }^{33}$ Based on current access arrangements, Pacific island countries receive total access fees of about US $\$ 60$ 80 million per annum. ${ }^{34}$ Low access fees, combined with limited participation in the fishery by coastal States, mean that Pacific island countries receive only a small fraction of the total benefits from the fisheries found in their territories: ${ }^{35}$

At present, the very substantial benefits flowing from the resource accrue mainly to distant water fishing nations. The harnessing of this resource for the benefit of island countries represents perhaps their greatest opportunity to achieve economic self-reliance. For some it may represent the only hope of achieving this goal. ${ }^{36}$

In order to increase economic benefits from their tuna fisheries, Pacific island countries have sought to encourage the development of domestic harvesting or processing operations. These efforts have generally relied on public investment in domestic enterprises and the inclusion of industry development conditions in access agreements with distant-water fishing nations. Unfortunately, these strategies have largely failed, ${ }^{37}$ prompting some analysts to argue that national governments would secure greater economic benefits by focusing their efforts on negotiating higher access fees for distant-water fishing fleets. ${ }^{38}$

Even at current levels, tuna access fees form a major component of national revenue for many countries in the region - particularly those with small populations, large marine territories, and rich tuna resources, such as Kiribati and the Federated States of Micronesia. ${ }^{39}$ As Petersen observes,

32 Bostwick, supra note 12, p. 904. See also, Greenpeace International, In the Race for Tuna, Dolphins Aren't the Only Sacrifice: The Impact of Commercial Tuna Fishing on Oceans, Marine Life and Human Communities. (Amsterdam: 1993).

33 Petersen, supra note 2, p. 31.

34 R. Gillett et al., Tuna: A Key Economic Resource in the Pacific (Manila, Philippines: Asian Development Bank, 2001).

35 Parris and Grafton, supra note 4, p. 273.

36 Forum Fisheries Agency, supra note 30, p. 4.

37 Parris and Grafton, supra note 4, pp. 275-276. See also, S.G. Chand, R.Q. Grafton, and E. Petersen, Multilateral Governance of Fisheries: Management and Cooperation in the Western and Central Pacific Tuna Fisheries, Marine Resource Economics, vol. 18, no. 4 (2003), p. 329; E.H. Petersen, Economic Policy, Institutions and Fisheries Development in the Pacific, Marine Policy, vol. 26, no. 5 (2002), p. 315; R.A. Schurmann, Tuna Dreams: Resource Nationalism and the Pacific Islands' Tuna Industry, Development and Change, vol. 29, no. 1 (1998), p. 107.

38 Gillett, Preston and Associates, A Financial and Economic Review of the PNG Tuna Fishery, Fisheries Development Project, ADB Loan No. 1656-PNG, 2000: 'Quite often high access fees paid by foreign fishng fleets deliver a higher level of domestic value added at less risk to an economy than costly attempts to establish a local fleet'. See also Petersen, supra note 2; G. van Santen et al., Working Apart or Together: The Case for a Common Approach to Management of Tuna Resources in Exclusive Economic Zones of Pacific Island Countries (Washington DC: World Bank, 2000).

39 Parris and Grafton, supra note 4, p. 270. 
'dependence on tuna is already unmatched elsewhere in the world and is likely to increase, causing the ownership of tuna, and the right to harvest it, to be sensitive political issues in Pacific island countries'. 40

\subsection{Legal framework}

The legal framework governing the management of tuna resources in the Western and Central Pacific region comprises a combination of international agreements - including global, regional, and bilateral treaties - and national legislation. This chapter focuses primarily on relevant global and regional treaties, but it is important to note that the primary mechanism for implementing these treaties at the domestic level is national fisheries legislation. The extent to which international agreements have been implemented at a national level varies from country to country, although most countries in the region have at least partially implemented the provisions of relevant treaties in their national fisheries legislation. ${ }^{41}$

\subsubsection{Global treaties}

The two key global agreements relevant to the management of tuna resources are the 1982 UN Convention on the Law of the Sea (UNCLOS) and the 1994 UN Fish Stocks Agreement (UNFSA).

\section{United Nations Convention on the Law of the Sea}

The 1982 United Nations Convention on the Law of the Sea is a global convention that has had a sweeping impact upon the Western and Central Pacific. ${ }^{42}$ UNCLOS provides, inter alia, for the establishment of an EEZ extending up to 200 nautical miles from the coastlines of coastal and island States. ${ }^{43}$ This legal development has had profound implications for the economic and political landscape of the region, allowing each small island State to exercise control over an EEZ many times the size of its terrestrial territory:

Without doubt, the global adoption of the 200-mile-zone regime has created new opportunities. However, it is important to note that while the declaration of an extended fisheries jurisdiction may provide the framework for rational exploitation and development of these resources, to the ultimate benefit of the coastal state, the magnitude of such benefits

40 Petersen, supra note 2, p. 37.

41 For example: Fisheries Act (Marshall Islands), Fisheries Act (Fiji), Fisheries Act 1988 (Samoa), Fisheries Act 1997 (Nauru), Fisheries Act 2005 (Vanuatu), Fisheries Management Act 1998 (Papua New Guinea), Fisheries Management Act 2002 (Tonga), Fisheries Ordinance (Kiribati), Fisheries Ordinance (Tuvalu), Marine Resources Act 1989 (Cook Islands), Marine Resources Act 2002 (Federated States of Micronesia).

42 B. Boer, R. Ramsay, and D. Rothwell, Regional Environment Issues and Responses, in International Environmental Law in the Asia-Pacific (London: Kluwer Law International, 1998), p. 58. Regional membership of the Convention, as of 5 March 2007, included Australia, Cook Islands, Fiji, France, Kiribati, Marshall Islands, Federated States of Micronesia, Nauru, New Zealand, Niue, Palau, Papua New Guinea, Samoa, Solomon Islands, Tonga, Tuvalu, and Vanuatu. Source: www.un.org/Depts/los/reference_files/ status2006.pdf

43 United Nations Convention on the Law of the Sea, Art. 55-75. 
and the form that accrue to each country will depend not only on the nature and extent of the resources but also on the utilization and development strategy adopted. ${ }^{44}$

Within its EEZ, each coastal State has the sovereign right to exploit, conserve, and manage living marine resources and an obligation to ensure the conservation of living marine resources. ${ }^{45}$ Coastal States are empowered to take such measures, including boarding, inspection, arrest, and judicial proceedings, as may be necessary to ensure compliance with laws adopted by it in conformity with the convention. ${ }^{46}$

UNCLOS requires coastal States to ensure that marine living resources within the EEZ are not endangered by overexploitation and to promote optimum utilization of those resources. ${ }^{47}$ In order to fulfil these responsibilities, coastal States are empowered to determine and prescribe the total allowable catch within their EEZ, the harvestable resources allocable to the fishing fleets of the coastal State, and foreign fishing fleets' access to the surplus catch. ${ }^{48}$ The power to control access to fisheries resources within the EEZ is particularly important for small developing States:

For developing states lacking the economic assets to directly and immediately make use of the resources in their EEZ, the effectiveness of their management and control efforts in their fisheries is largely dependent on their ability to strategically allocate their surplus to other foreign countries. Coastal states use their 'access' powers to negotiate with those states that possess the economic and technical resources to help them exploit their fisheries. ${ }^{49}$

UNCLOS encourages State Parties to co-operate, on an international or regional basis, for the protection and preservation of the marine environment, taking into account characteristic regional features. ${ }^{50}$ The treaty requires State Parties to establish, either directly or through appropriate regional organizations, measures necessary for the conservation and utilization of straddling and highly migratory fish stocks. ${ }^{51}$ These provisions, which are particularly relevant for the transboundary management of tuna stocks, have been elaborated upon in the 1995 United Nations Fish Stocks Agreement.

\section{United Nations Fish Stocks Agreement ${ }^{52}$}

One of the most contentious problems in fisheries management has been the management of straddling and highly migratory fish stocks. ${ }^{53}$ The 1995 United Nations Fish Stocks Agreement is a

44 Scharmann, supra note 29, p. 313.

45 United Nations Convention on the Law of the Sea, Art. 56, 61-2.

46 Ibid., Art. 73.

47 Ibid., Art. 61-2.

48 M.J. Picard, International Law of Fisheries and Small Developing States: A Call for the Recognition of Regional Hegemony, Texas International Law Journal, vol. 31, no. 2 (1996), p. 323.

49 lbid.

50 United Nations Convention on the Law of the Sea, Art. 197.

51 Ibid., Art. 63-4.

52 Agreement for the Implementation of the Provisions of the United Nations Convention on the Law of the Sea of 10 December 1982 relating to the Conservation and Management of Straddling Fish Stocks and Highly Migratory Fish Stocks, opened for signature 4 December 1995, UN Doc. A/CONF. 164/33 (1995) 34 International Legal Materials 1542. 
subsidiary agreement under UNCLOS that seeks to implement UNCLOS provisions dealing with conservation and management of straddling and highly migratory fish stocks.

The aim of the agreement is to ensure the long-term conservation and sustainable use of straddling and highly migratory fish species. ${ }^{54}$ The large majority of Pacific island States and Territories are parties to the agreement. ${ }^{55}$

The agreement sets out general principles, requiring Parties to, inter alia: adopt measures to ensure the long-term sustainability of straddling and highly migratory fish stocks; ensure that such measures are based on the best available scientific evidence, taking into account the interdependence of stocks; apply the precautionary principle; protect marine biodiversity; take measures to prevent or eliminate overfishing; take into account the interests of artisanal and subsistence fishers; and implement and enforce conservation and management measures through effective monitoring, control, and surveillance. ${ }^{56}$

The UNFSA provides a framework for international cooperation with particular emphasis on the role of regional fisheries management organizations. ${ }^{57}$ In each region where a competent fisheries management organization exists, State Parties fishing in that region and relevant coastal States are required to join that organization or, at a minimum, to ensure that their fishing vessels comply with any conservation and management measures adopted by that body. ${ }^{58}$ State Parties that do not comply with this requirement must not authorize their vessels to fish for stocks covered by regional conservation and management measures. ${ }^{59}$

In each region where there is no competent regional fisheries management organization, State Parties fishing on the high seas in that region and relevant coastal States are required to cooperate to establish such an organization or enter into other appropriate arrangements to ensure the conservation and management of straddling and highly migratory fish stocks in that region. ${ }^{60}$

The agreement sets out detailed provisions on the establishment, functions, and membership of fisheries management organizations and provides for international co-operation in compliance and enforcement activities, including the enforcement of regional conservation and management measures. ${ }^{61}$

Parties to the agreement are required to co-operate to prevent disputes and, where disputes arise, to settle them by peaceful means. The UNFSA adopts the dispute mechanisms established

53 K. Hopfl, Go Fish! Individual Transferable Quotas and International Possibilities in the South Pacific, Colorado Journal of International Environmental Law and Policy, vol. 8, no. 1 (1997), p. 155.

54 UN Fish Stocks Agreement, Art. 2.

55 Regional membership of the agreement, as at 24 April 2008, included Australia, Cook Islands, Fij, France, Kiribati, Marshall Islands, Federated States of Micronesia, Nauru, New Zealand, Niue, Palau, Papua New Guinea, Samoa, Solomon Islands, Tonga. See www.un.org/depts/los/reference_files/status2008.pdf. Tuvalu and Vanuatu had not yet ratified the agreement.

56 UN Fish Stocks Agreement, Art. 5.

57 Ibid., Art. 8. See Picard, supra note 48, p. 340.

58 UN Fish Stocks Agreement, Art. 8.

59 Ibid., Art. 17.

60 Ibid., Art. 8.

61 Ibid., Art. 9-12, 17, 19-23. 
under UNCLOS and encourages parties to resolve technical disputes by establishing an ad hoc expert panel. The establishment of effective decision-making arrangements within regional fisheries management organizations is explicitly identified in the UNFSA as a primary mechanism for the avoidance of disputes. ${ }^{62}$

The agreement represents a major landmark in international fisheries management and a significant step towards sustainable management of transboundary fisheries resources. Its emphasis on international co-operation via regional fisheries management organizations has had significant implications for the management of tuna resources in the Western and Central Pacific, in particular, by acting as a catalyst for the formation of the Western and Central Pacific Fisheries Commission.

\subsubsection{Regional agreements}

Pacific island countries have a strongly developed practice of regional co-operation across a wide range of areas, including the management of transboundary fishery resources:

Regional cooperation has been firmly established in the South Pacific since the island states began to achieve independence or self-government in the 1970s. In terms of fisheries management, they have made considerable gains through pursuing policies of cooperation. ${ }^{63}$

Over the last 30 years, the States and Territories of the Western and Central Pacific have made substantial progress in the development of a robust legal and institutional framework for the management of the region's tuna resources.

Regional agreements relevant to management of tuna resources in the Western and Central Pacific include:

- 1979 South Pacific Forum Fisheries Agency Convention

- 1982 Nauru Agreement Concerning Cooperation in the Management of Fisheries of Common Interest

- 1987 Treaty on Fisheries between certain Pacific Island States and the United States of America

- 1989 Wellington Convention for the Prohibition of Fishing with Long Driftnets in the South Pacific

- 1992 Niue Treaty on Cooperation in Fisheries Surveillance and Law Enforcement in the South Pacific

- 2000 Convention on the Conservation and Management of Highly Migratory Fish Stocks in the Western and Central Pacific Ocean.

The objectives and key features of a number of these agreements are reviewed below. Institutional arrangements for the management of tuna stocks in the region are discussed later in the chapter.

62 Ibid., Art. 27-30.

63 M. Lodge, New Approaches to Fisheries Enforcement, Review of European Community and International Environmental Law, vol. 2, no. 3 (1993), p. 278. 


\section{South Pacific Forum Fisheries Agency Convention ${ }^{64}$}

During the Third United Nations Law of the Sea Conference, which ran from 1973 to 1982, an emerging global consensus on the establishment of a 200-nautical-mile EEZ prompted the South Pacific Forum to call for increased regional co-operation in fisheries management via the establishment of a regional fisheries agency for the South Pacific. ${ }^{65}$

In 1979, the member States of the South Pacific Forum signed the South Pacific Forum Fisheries Agency Convention, establishing the South Pacific Forum Fisheries Agency. ${ }^{66}$ The objectives of the treaty are to support the conservation and optimum utilization of the living marine resources of the region; to secure maximum benefit from those living marine resources, particularly for the benefit of the developing countries in the region; to promote regional co-operation and coordination in respect of fisheries policies; and to facilitate the collection, analysis, evaluation, and dissemination of relevant statistical, scientific, and economic information about the living marine resources of the region. ${ }^{67}$ The treaty makes specific reference to the importance of regional cooperation in the management of highly migratory fish species, ${ }^{68}$ reflecting the Parties' paramount concern: effective management of the region's rich tuna resources.

The agency's governing body, the Forum Fisheries Committee, is charged with promoting regional co-operation in relation to, inter alia, harmonization of national fisheries management policies, co-ordination of fisheries surveillance and enforcement, and collective bargaining with distant-water fishing nations. ${ }^{69}$ Distant-water fishing nations, such as Japan and the United States, were deliberately excluded from the Committee, consistent with the Parties' intention of presenting a common front to such nations seeking access to tuna resources in the Parties' EEZs. ${ }^{70}$

Subject to direction by the Committee, the FFA Secretariat carries out the following functions for the benefit of member States: monitoring regional fisheries; providing technical advice and information; assisting with the development of fisheries policies; and assisting with licensing, surveillance, and enforcement of national fisheries legislation. ${ }^{71}$ The FFA functions as a consultative and advisory body rather than a management organization and does not exercise any regulatory powers. Nonetheless, the FFA has made an enormous contribution to the development of fisheries management law and policy in the region, not least through its co-ordinating role in the negotiation

64 Opened for signature 10 July 1979 in Honiara, Solomon Islands. Entered into force 9 August 1979.

65 Declaration on the Law of the Sea and a Regional Fisheries Agency, 8th South Pacific Forum, Port Moresby, August 1977. The South Pacific Forum comprises the Heads of Government of the independent states in the South Pacific. Membership of the Forum has expanded from 12 to 17 since its establishment in 1971 and now includes Australia, Cook Islands, Federated States of Micronesia, Fiji, Kiribati, Marshall Islands, Nauru, New Zealand, Niue, Palau, Papua New Guinea, Samoa, Solomon Islands, Tokelau, Tonga, Tuvalu, and Vanuatu.

66 F. Gubon, History and Role of the Forum Fisheries Agency, in D.J. Doulman (ed.), Tuna Issues and Perspectives in the Pacific Islands Region (Honolulu: East-West Centre, 1987).

67 South Pacific Forum Fisheries Agency Convention, Preamble.

68 Ibid., Preamble, Art. III, VII.

69 Ibid., Art. V.

70 Hopfl, supra note 53, p. 156; C. Hedley, Forum Fisheries Agency, Guide to International Fisheries Law, 2001, at www.oceanlaw.net/orgs/ffa.htm, accessed 28 February 2007.

71 South Pacific Forum Fisheries Agency Convention, Art. VII. For information about the Forum Fisheries Agency, see www.ffa.int 
of regional and subregional fisheries management agreements. ${ }^{72}$ The institutional structure of the FFA, and its achievements to date, are discussed in more detail below.

\section{Treaty on Fisheries between certain Pacific Island States and the United States of America}

Following the conclusion of UNCLOS, most coastal States - including the Pacific island States claimed sovereignty over fisheries stocks within their EEZs, including highly migratory species. However, the United States opposed coastal State jurisdiction over highly migratory species, excluding them from its own jurisdiction under national legislation. The rationale for the US position was that because highly migratory species travel through the waters of numerous countries, they would be better managed by an international body. Critics argue, however, that the real reason for the US policy was to justify its position of refusing to recognize the jurisdiction of other coastal States over valuable tuna stocks: ${ }^{73}$

The aim of the US was to insulate tuna fisheries from coastal state jurisdiction as a means of maintaining the bargaining power of its tuna harvesting industry. This power consisted of provisions of US law which threatened economic sanctions against nations which seize US tuna fishing vessels for violations of their claims to national jurisdiction. ${ }^{74}$

Consistent with its denial of State sovereignty over highly migratory species, the United States refused to respect the power of Pacific island States to control access to their tuna stocks. The Magnuson-Stevens Fisheries Management and Conservation Act allowed the United States to impose an embargo on the importation of any fisheries products from any country that seizes a US vessel for fishing for highly migratory species without a licence. The Fishermen's Protective Act provided for compensation from the US government to any US tuna fishers whose vessels were seized for illegally fishing in the EEZ of another state. This legislation allowed, if not encouraged, US vessels to blatantly violate the laws of coastal States. ${ }^{75}$

The continuation of tuna fishing by US vessels within the EEZs of Pacific island States became a significant source of conflict and resulted in boat seizures and sanctions. In 1982, Papua New Guinea seized the US purse seine vessel Danica. This was followed by the Solomon Islands' seizure of the Jeanette Diana in 1984, which resulted in a seven-month embargo on imports of fish products from the Solomon Islands to the United States and a ban on US vessels entering the waters of the Solomon Islands. ${ }^{76}$ The increasing acrimony encouraged some Pacific island States to enter into fishing agreements with the USSR, fuelling US concerns about increasing Soviet influence in the region. ${ }^{77}$

72 Lodge, supra note 63, p. 278.

73 Hopfl, supra note 53, p. 157. See also B.M. Tsamenyi, The South Pacific States, the USA and Sovereignty Over Highly Migratory Species, Marine Policy, vol. 10, no. 1 (1986), p. 30.

74 W. Burke, The New International Law of Fisheries: UNCLOS 1982 and Beyond, Oxford Monographs in International Law (New York: Oxford University Press USA, 1994), p. 205.

75 Hopfl, supra note 53, p. 157.

76 G. Waugh, Development, Economics and Fishing Rights in the South Pacific Tuna Fishery, in P. Neher, R. Arnason, and N. Mollet (eds.), Rights Based Fishing (New York: Springer-Verlag, 1989), p. 323. The Federated States of Micronesia also seized two US vessels, the Ocean Pearl and Pracilla $M$.

77 Hopfl, supra note 53, p. 157. 
In 1987, the FFA member States entered into an agreement with the United States to resolve the escalating conflict. The Treaty on Fisheries between the Governments of certain Pacific Island States and the Government of the United States of America (known as the US Fisheries Treaty) seeks to maximize the benefits flowing from the development of fisheries resources within the fisheries jurisdiction of the Pacific island Parties. ${ }^{78}$ Key features of the treaty include: an undertaking by the United States to provide technical and economic assistance; establishment of licensing and access fee arrangements for US vessels; acceptance of flag State responsibility by the United States, including an undertaking to enforce the terms of the treaty against US vessels; acknowledgment of the compliance powers of the coastal States; and a procedure for resolving disputes arising under the treaty. ${ }^{79}$

The licensing fees and assistance packages negotiated under the treaty provide a return of about 9-10 per cent of the value of the landed catch, compared with the 2-4 per cent access fees negotiated by individual Pacific island States in bilateral negotiations with other distant-water fishing nations. Under the treaty, US vessels receive regional licences at a price indexed to the market price of tuna, subject to a minimum base price. Once administrative costs have been met, licence fees are distributed to the coastal State Parties in proportion to the amount of tuna caught in each State's EEZ. The US tuna industry and the federal government contribute to a substantial technical and economic assistance package, which is divided among the Pacific island Parties at predetermined ratios. ${ }^{80}$ The treaty has been extended twice, in 1993 and 2003, with successive increases in total payments to coastal States and adjustments in the allocation of payments between them.

The US Fisheries Treaty is a testament to the strength of a co-ordinated regional approach to access negotiations: 'In addition to easing tensions, the Treaty is considered a success for the South Pacific island nations and a model for other international access agreements. ${ }^{81}$ Bergin argues that 'this treaty was undoubtedly the [Pacific island countries] most successful venture into fisheries diplomacy'. ${ }^{2}$ By working together, with the co-ordinating support of the FFA, Pacific island States were able to secure significantly higher financial returns as well as the implementation of most of the minimum terms and conditions that other distant-water fishing nations were resisting. Furthermore, by agreeing to implement these minimum terms and conditions, the United States strengthened the hand of the Pacific island countries in their negotiations with other distantwater fishing nations. ${ }^{83}$

78 US Fisheries Treaty, Preamble.

79 Ibid., Arts. 2-6.

80 Bostwick, supra note 12, pp. 911-912.

81 Ibid., p. 911. See also: Forum Fisheries Agency, Pacific Islands Treaty on Fisheries with USA, South Pacific Forum Fisheries Agency News Digest, May-June 1992, p. 1.

82 A. Bergin, Political and Legal Control over Marine Living Resources - Recent Developments in South Pacific Distant Water Fishing, The International Journal of Marine and Coastal Law, vol. 9, no. 3 (1994), pp. 297-298.

83 Ibid., pp. 297-298. 


\section{Convention on the Conservation and Management of Highly Migratory Fish Stocks}

The negotiation of agreements between Pacific island States has played an important role in improving the management of tuna stocks in the Western and Central Pacific. However, these agreements do not entirely fulfil obligations arising under UNCLOS and the UNFSA, which require the establishment of regional fisheries management organizations, comprising both coastal States and distant-water fishing nations, to provide for management of highly migratory species across their entire range, including the high seas. ${ }^{84}$

The 1979 Forum Fisheries Agency Convention reflects the (then draft) provisions of UNCLOS in relation to highly migratory fish stocks, recognizing that:

effective cooperation for the conservation and optimum utilisation of the highly migratory species of the region will require the establishment of additional international machinery to provide for cooperation between all coastal states in the region and all states involved in the harvesting of such resources. ${ }^{85}$

This ambition was fulfilled two decades later, with the adoption of the Convention on the Conservation and Management of Highly Migratory Fish Stocks in the Western and Central Pacific Ocean (the WCPO Convention). The convention was opened for signature in September 2000, after four years of complex negotiations between the coastal States of the Western and Central Pacific and States fishing in the region, and it entered into force on 19 June $2004{ }^{86}$ The convention is 'a remarkable political, diplomatic and legal achievement', covering the largest area of any fisheries commission in the world and including among its members the largest and most powerful countries in the world as well as the smallest. ${ }^{87}$

The WCPO Convention aims 'to ensure, through effective management, the long-term conservation and sustainable use of highly migratory fish stocks in the western and central Pacific Ocean'. ${ }^{88}$ To support this aim, it provides for the establishment of the Western and Central Pacific Fisheries Commission (WCPF Commission) - a regional fisheries management organization (RFMO)

84 T. Aqorau, Tuna Fisheries Management in the Western and Central Pacific Ocean: A Critical Analysis of the Convention for the Conservation and Management of Highly Migratory Fish Stocks in the Western and Central Pacific Ocean and Its Implications for the Pacific Island States, The International Journal of Marine and Coastal Law, vol. 16, no. 3 (2001), p. 397; United Nations Convention on the Law of the Sea, Art. 63-4; UN Fish Stocks Agreement, Art. 8.

85 South Pacific Forum Fisheries Agency Convention, Art. III.

86 Internet Guide to International Fisheries Law, www.intfish.net/treaties/summaries/3141.htm, accessed 5 January 2007. See also: L. Cordonnery, A Note on the 2000 Convention for the Conservation and Management of Tuna in the Western and Central Pacific Ocean, Ocean Development and International Law, vol. 33, no. 1 (2002), pp. 3-4.

87 M. Lodge, The Practice of Fishing Entities in Regional Fisheries Management Organizations: The Case of the Commission for the Conservation and Management of Highly Migratory Fish Stocks in the Western and Central Pacific Ocean, Ocean Development and International Law, vol. 37, no. 2 (2006), p. 186.

WCPO Convention, Art. 2. 
composed of both coastal States and distant-water fishing nations. ${ }^{89}$ The Commission is empowered, inter alia, to adopt binding conservation and management measures for highly migratory fish stocks, including setting the total allowable catch or level of fishing effort for highly migratory fish stocks in the convention area. ${ }^{90}$

The WCPO Convention is the first regional agreement for the management of highly migratory fish stocks to fully reflect the provisions of UNCLOS and the UNFSA. ${ }^{91}$ The agreement presents an important example for older regional fisheries management organizations - including the InterAmerican Tropical Tuna Commission, ${ }^{92}$ the International Commission for the Conservation of Atlantic Tunas, ${ }^{93}$ the Commission for the Conservation of Bluefin Tuna, ${ }^{94}$ and the Indian Ocean Tuna Commission ${ }^{95}$ - to consider when assessing whether their existing arrangements meet the benchmarks established by the UNFSA. ${ }^{96}$

The convention sets out a range of conservation and management principles, modelled closely on the principles set out in the UNFSA. In particular, the convention requires Parties to:

- Adopt measures to ensure the long-term sustainability of highly migratory fish stocks in the Western and Central Pacific Ocean, and to promote their optimum use;

- Ensure that such measures are based on the best scientific evidence available and are designed to maintain or restore stocks at levels capable of producing maximum sustainable yield, taking into account certain environmental and economic factors, including the special needs of developing states;

- Apply the precautionary approach, consistent with international standards (including the guidelines annexed to the UNFSA) and based on the best scientific evidence available;

- Adopt measures to minimize unnecessary impacts on target and non-target species and to promote the development and use of selective, environmentally safe, and cost-effective fishing gear and techniques;

- Adopt measures to prevent or eliminate overfishing and excess fishing capacity and to ensure that levels of fishing effort are consistent with the sustainable use of fisheries resources;

89 As at 18 November 2005, state parties included Australia, Canada, China, Cook Islands, European Community, Federated States of Micronesia, Fiji, France (inc. French Polynesia, New Caledonia, and Wallis and Futuna), Indonesia, Japan, Kiribati, South Korea, Marshall Islands, Nauru, New Zealand (inc. Tokelau), Niue, Palau, Papua New Guinea, Philippines, Samoa, Tonga, Tuvalu, United Kingdom (inc. Pitcairn Island), the United States, and Vanuatu. Taiwan entered into the agreement as a 'participating fishing entity' at the insistence of China. Indonesia is involved as a co-operating non-party.

90 WCPO Convention, Art. 10. The functions of the Commission are discussed in more detail below.

91 Lodge, supra note 87, p.196. See also: WCPF Convention, Art. 2, 4.

92 Convention for the Establishment of an Inter-American Tropical Tuna Commission, 31 May 1949. In force 3 March 1950.

93 International Convention for the Conservation and Management of Atlantic Tunas, 14 May 1966. In force 21 March 1969.

94 Convention for the Conservation of Southern Bluefin Tuna, 10 May 1993. In force 20 May 1994.

95 Agreement for the Establishment of the Indian Ocean Tuna Commission, 20 November 1993. In force 27 March 1996.

96 Lodge, supra note 87, p. 186. 
- Protect biological diversity in the marine environment;

- Take into account the interests of artisanal and subsistence fishers; and

- Implement and enforce conservation and management measures through effective monitoring, control, and surveillance. ${ }^{97}$

The convention requires Parties to co-operate to ensure that conservation and management measures adopted for the high seas and for areas under national jurisdiction are compatible. Furthermore, coastal States are obliged to ensure that measures adopted by them for areas within national jurisdiction do not undermine the effectiveness of measures adopted by the Commission. ${ }^{98}$

Under the convention, each flag State Party is required to: a) ensure that its fishing vessels comply with the convention and any measures adopted under the convention and do not engage in any activities that undermine the effectiveness of such measures; $b$ ) ensure that its fishing vessels refrain from unauthorized fishing activities in waters within the national jurisdiction of the coastal State Parties; c) only authorize its fishing vessels to operate on the high seas if the flag State is able to effectively exercise its responsibilities in relation to those vessels; d) maintain a record of its fishing vessels; and e) ensure that its fishing vessels use satellite-based position transmitters for the purposes of a regional vessel monitoring system. ${ }^{99}$

The convention allows for enforcement by both flag States and coastal States and encourages co-operation in relation to investigation and prosecution of fisheries offences. To improve monitoring of fishing activities, the convention establishes a regional observer programme and discourages transshipment at sea. ${ }^{100}$ The convention adopts the dispute resolution procedures set out in UNCLOS and the UNFSA. ${ }^{101}$ Intergovernmental organizations and non-government organizations are entitled to participate in the Commission and its subsidiary bodies as observers. ${ }^{102}$ The institutional structure of the Commission, and its achievements to date, are discussed in detail below.

\subsubsection{Bilateral agreements}

The developments in global and regional fisheries law described above have fundamentally reshaped the context in which fisheries access arrangements are negotiated in the Western and Central Pacific region. Nonetheless, bilateral agreements remain the most common form of such arrangement. Pacific island countries have entered into bilateral agreements with a range of distant-water fishing nations, including Japan, South Korea, the former Soviet Union, Taiwan, the Philippines, and Indonesia.

Bilateral access agreements in the region typically run for a one-year term (rolled over annually), set a limit on the number of vessels entitled to operate in the fishery for that period, and impose

97 WCPO Convention, Art. 5. See also Art. 6 re application of precautionary approach.

98 Ibid., Art. 8.

99 Ibid., Art. 24.

100 Ibid., Art. 25, 28, 29.

101 lbid., Art. 31.

102 Ibid., Art. 21. See also Rule 36, Western and Central Pacific Fisheries Commission (WCPFC) Rules of Procedure. 
minimum terms and conditions of access but do not generally set any limits on catch volumes. ${ }^{103}$ Overall, the access or licensing fees of the region's bilateral arrangements have averaged around 2 per cent of the value of the total landed catch, although a goal of 4 per cent had been set by the FFA as the minimal rate of return. ${ }^{104}$

Historically, attempts by coastal states in the region to unilaterally increase access fees have met with limited success. According to Petersen:

In the late 1980s, Papua New Guinea tried to raise the value of access fees to a minimum of six per cent. In reaction, Japan ceased fishing in Papua New Guinea's EEZ, fishing instead in other countries' EEZs at lower cost. This reflects the problems Pacific island countries have when they negotiate bilaterally with distant water fishing nations, competing with one another to provide access. Distant water fishing nations realise this and encourage bilateral treaties. The success of Pacific island countries in attracting higher access fees will depend on their success in working collectively in allocating access rights. ${ }^{105}$

Bostwick is similarly critical of the widespread use of bilateral access agreements in the region:

Bilateral agreements among powerful distant water fishing nations and individual island states dilute the negotiating strength of the small island states across the region. Japan, for example, has been accused on numerous occasions of playing the South Pacific nations off each other to these nations' detriment. Distant water fishing nations are able to tie fishing access to aid packages in other areas of the islands' public expenditures, further diminishing their bargaining power.

[M]ultilateral negotiations increase the bargaining power of the island states and reduce detrimental competition for agreements among them. The transboundary nature of the tuna resource necessitates regional coordination for the conservation of the resource, which is imperative for sustainable development.... The multilateral approach should be strengthened by a commitment by all FFA members to end bilateral agreement negotiations. ${ }^{106}$

The challenges faced by Pacific island States in bilateral negotiations highlight the need for institutional structures that support collective bargaining and informed, equitable negotiation of fisheries conservation and management measures.

\subsection{Institutional framework}

Regional co-operation is well established in the Western and Central Pacific region. Regional intergovernmental organizations play a key role in political and economic affairs in the region, including the management of fisheries resources. Regional co-operation in fisheries management

103 M. Hyndman, South Pacific Forum Fisheries Agency: Benefits and Costs, Working Paper No. 4, in R. Grynberg et al., Toward a New Pacific Regionalism (Manila, Philippines: Asian Development BankCommonwealth Secretariat, 2005), p. 5.

104 Bostwick, supra note 12, p. 910.

105 Petersen, supra note 2, pp. 133-134.

106 Bostwick, supra note 12, pp. 910, 912-913. 
has been both a strategic political response - 'the small island nations were quick to realise that their interests ... could best be protected through cooperative and collective effort' - and a pragmatic response in the face of limited institutional resources - 'regional co-operation contributes significantly ... through the sharing of expertise, experience, facilities and infrastructure, and the pooling of resources and markets'. ${ }^{107}$

Two key fisheries management institutions are discussed in detail below - the Forum Fisheries Agency and the Western and Central Pacific Fisheries Commission. However, it is important to note that institutional arrangements for fisheries management in the region are complex and multilayered, involving national governments - of both coastal States and flag States - and a variety of other regional organizations:

- The Secretariat of the Pacific Community (SPC) Oceanic Fisheries Programme is a key source of scientific advice on the management of oceanic fisheries, including tuna stocks.

- The Secretariat of the Pacific Regional Environment Programme runs training programmes and provides technical assistance to support the conservation of marine biodiversity.

- The South Pacific Applied Geoscience Commission provides technical assistance on maritime boundary delimitation and acts as the depository for marine scientific research data.

- The University of the South Pacific is the primary source of tertiary education in the fields of fisheries management and marine conservation in the region. ${ }^{108}$

\subsubsection{Forum Fisheries Agency}

The Forum Fisheries Agency consists of the Forum Fisheries Committee and a Secretariat, based in Honiara, Solomon Islands. The Committee is charged with promoting regional cooperation in relation to, inter alia, harmonization of national fisheries management policies, co-ordination of fisheries surveillance and enforcement, and collective bargaining with distant-water fishing nations. ${ }^{109}$ The Committee provides strategic policy direction and administrative guidance to the Secretariat and provides a forum for Parties to consult on matters of common concern in the field of fisheries management. ${ }^{110}$ The Committee includes one representative from each of the State Parties to the FFA Convention. Decisions of the Committee are usually made by consensus. If consensus is not reached, decisions are taken on a two-thirds majority of the members present and voting. The exclusion of distant-water fishing nations from membership of the Committee has greatly enhanced the capacity of coastal States in the region to develop consensus on key issues and to establish collaborative management initiatives. ${ }^{111}$

Subject to direction by the Committee, the Secretariat monitors regional fisheries, provides technical advice and information to FFA member States, assists with the development of fisheries

107 J. Veitayaki, The Peaceful Management of Transboundary Resources in the South Pacific, in Blake et al., supra note 2, p. 497.

108 Cordonnery, supra note 14. See also SPC Web site, at www.spc.int; SPREP Web site, at www.sprep.org; SOPAC Web site, at www.sopac.org; and USP Web site, at www.usp.ac.fj

109 South Pacific Forum Fisheries Agency Convention, Art. V.

110 Aqorau, supra note 84, p. 396.

111 Bostwick, supra note 12, p. 903. 
policies, and helps with licensing, surveillance, and enforcement of national fisheries legislation. ${ }^{112}$ The Secretariat employs about 50 professional and support staff and has an annual budget of approximately US $\$ 4$ million. Key sources of funding include: a) member contributions, prescribed by a formula set by the Committee, which typically provide about 20 per cent of total funding; b) donor support, on a bilateral and multilateral basis, which provides the majority of funding; and c) fees charged by the FFA on a partial cost-recovery basis (for example, vessel registration fees), which provide a very small proportion of total funding. ${ }^{113}$

The FFA provides a cost-effective mechanism for developing and implementing regional fisheries policy and programmes. According to a recent cost-benefit analysis of the FFA:

Its creation has led to the concentration within it of a critical mass of expertise in many aspects of fisheries management and conservation, as well as effective coordination of their use. This concentration of resources and coordination of effort has yielded obvious economies of scale and scope in terms of securing for member countries a cost-effective dedicated supply of expert information gathering, analysis, advice and support on fisheries issues. $^{114}$

The FFA has made an enormous contribution to the development of fisheries management law and policy in the region, not least through its co-ordinating role in the negotiation of regional and subregional fisheries management agreements. The involvement of the FFA in bilateral and multilateral negotiations has played a key role in securing improved economic returns from tuna fisheries through increased access fees and in improving management of those fisheries via the imposition of minimum terms and conditions of access. The FFA actively fosters fisheries management expertise amongst its member States. Since its inception, the FFA has provided regional- and national-level training for government officers in a variety of fisheries management disciplines, including workshops on international fisheries law for policy officers and monitoring, surveillance, and compliance training for observers and enforcement officers.

The FFA has played a pivotal role in the development and coordination of regional fisheries monitoring, surveillance, and compliance programmes: 'Control and effective monitoring of the fisheries is extremely difficult for Pacific island nations. To monitor effectively millions of square miles of ocean is expensive and requires support, equipment, and enforcement strength. ${ }^{115}$ In particular, the FFA has been responsible for: a) establishing and maintaining databases covering fisheries agreements, legislation, licences, violations, and prosecutions; b) co-ordinating aerial surveillance by Australia, France, New Zealand, and the United States; and c) establishing and administering a regional register of foreign fishing vessels, a regional observer programme, and a regional vessel monitoring system. The FFA has also worked closely with the government of Australia to facilitate the supply of fisheries patrol boats for Pacific island countries.

112 South Pacific Forum Fisheries Agency Convention, Art. VII. See also: Forum Fisheries Agency website, www.ffa.int

113 Hyndman, supra note 103, p. 3.

114 Ibid., p. 4.

115 Bostwick, supra note 12, p. 908. 
The regional register of foreign fishing vessels was established by the FFA in 1984. The register contains comprehensive details for foreign fishing vessels that may wish to apply for licences to fish in the region. Before any foreign fishing vessel may be licensed to fish in the region, it must be in good standing on the regional register. Vessels must apply annually for registration. Good standing is automatically conferred on a vessel upon registration. This status may be withdrawn in certain circumstances, including where a vessel has committed a serious fisheries offence. Once good standing is withdrawn, the vessel is effectively prohibited from fishing in the region. ${ }^{116}$ The withdrawal of good standing has been rare, but the threat of withdrawal has been used to good effect on a number of occasions. ${ }^{117}$

In 1998, the FFA established a satellite-based vessel monitoring system (VMS) to provide FFA member countries with real-time information about the position, speed, and direction of registered fishing vessels. The establishment of the VMS presents an opportunity to greatly improve the compliance and enforcement programmes of FFA member States by increasing their capacity to monitor vessel movements over large tracts of ocean. Prior to the establishment of the VMS, member countries were reliant on reports from fisheries observers, which only cover a small portion of licensed fishing fleets, and occasional aerial surveillance reports. Realization of the system's potential requires passage of empowering national legislation and installation and activation of suitable automatic location communicators (ALC) on fishing vessels. Most FFA member States have now enacted legislation requiring vessels to fit an ALC as a condition of their fishing licence, and vessels are now required to install an ALC as a condition of entry on the regional register. The number of vessels registered on the VMS has grown substantially, from only two in the first year of its operation, to more than 1,000 vessels by 2007 .

The contribution of the FFA to management of tuna resources in the Western and Central Pacific is indisputable. Collaboration between coastal States, to the exclusion of distant-water fishing nations, has provided an efficient and effective mechanism for developing and implementing innovative fisheries policies and programmes and has led to significant improvements in the management of tuna harvesting operations within the jurisdiction of its member states. However, as Cordonnery notes:

Despite some impressive achievements, it is important to recognise the limitations of the FFA insofar as conservation and management of tuna stocks is concerned. The limitations of the FFA arise from its functions being administrative, facilitative and advisory, rather than decision-making, which prevents it from becoming a management agency. ${ }^{118}$

116 Lodge, supra note 63, p. 280.

117 Bergin, supra note 82 , p. 304 . For example, 12 vessels from Japan, South Korea, and Taiwan were removed from the register in 1992, and two Japanese longliners were suspended at the request of Australia, pending the outcome of court proceedings. In the same year, Nauru received a US\$1 million settlement from a Korean firm to reinstate six Korean vessels and US\$150,000 to reinstate two Taiwanese vessels, all observed fishing unlawfully within Nauru's EEZ.

118 Cordonnery, supra note 86, p. 3. 
The FFA is subject to a further, more fundamental, limitation: 'It does not adequately address the fact that because tuna are subject to harvest in both EEZs and the high seas, single coastal states cannot exercise sufficient control over the industry to properly manage tuna populations.'119

\subsubsection{Western and Central Pacific Fisheries Commission}

The establishment of the WCPF Commission in June 2004 marked a new chapter in the management and conservation of tuna resources in the region. The functions of the Commission include: a) adopting conservation and management measures and recommendations for highly migratory fish stocks, including setting total allowable catch and level of fishing effort; b) promoting co-ordination among Commission members to ensure that conservation and management measures for highly migratory fish stocks within national jurisdiction and the high seas are compatible; c) adopting conservation and management measures and recommendations for nontarget species and species dependent on or associated with target stocks; d) establishing appropriate co-operative mechanisms for effective monitoring, control, surveillance, and enforcement, including a vessel monitoring system; e) adopting standards for collection, verification, exchange, and reporting of data; and f) promoting the peaceful settlement of disputes. $^{120}$

The decision-making processes of the Commission reflect a delicate compromise between the interests of the coastal States and those of distant-water fishing nations. Generally, decision making in the Commission is by consensus. In certain cases - for example, setting total allowable catch or total level of fishing effort - this is a mandatory requirement. In other cases, the decision may be put to a vote if all efforts to reach consensus have been exhausted. If a decision of substance is put to a vote, parties are divided into two chambers, consisting of FFA members and FFA non-members respectively. The decision must be adopted by a three-quarters majority of the Commission and a three-quarters majority in each chamber. No proposal may be defeated by two or fewer votes in either chamber. The Convention establishes a conciliation and review process and adopts the dispute resolution process established under UNCLOS and the UNFSA. ${ }^{121}$

The Commission is supported by a Secretariat and two subsidiary bodies: a Scientific Committee and a Technical and Compliance Committee. The Scientific Committee is responsible for ensuring that the Commission obtains for its consideration the best available scientific information. ${ }^{122}$ The Technical and Compliance Committee is charged with providing technical advice and recommendations to the Commission on implementation of, and compliance with, conservation and management measures. ${ }^{123}$ Intergovernmental and nongovernment organizations may also play a constructive role as observers to the Commission's deliberations, by enhancing

119 Hopfl, supra note 53, p. 143.

120 Ibid., Art. 10.

121 Ibid., Art. 20, 31

122 Ibid., Art. 12.

123 Ibid., Art. 14. 
transparency, engaging the broader community in regional fisheries management, and providing input on key technical issues. ${ }^{124}$

Commission members are required to ensure that conservation and management measures are based on the best scientific evidence available and to adopt the precautionary approach when making conservation and management decisions. ${ }^{125}$ The establishment of the Scientific Committee, combined with the ongoing involvement of the FFA and SPC Oceanic Fisheries Programme, provides a robust basis for data collection, research, and stock assessment. ${ }^{126}$ However, the Commission's responses to the recommendations of its own Scientific Committee have tended to reflect short-term political and economic considerations rather than a commitment to long-term sustainable management of the region's tuna stocks.

In August 2005, the first regular meeting of the Scientific Committee concluded that it was likely that bigeye and yellowfin tuna were both subject to overfishing and recommended a reduction in fishing mortality for both species to avoid moving the species into an overfished state. ${ }^{127}$ In December 2005, the second session of the Commission adopted a conservation and management measure for bigeye and yellowfin tuna requiring members to not increase total catch effort beyond current levels. ${ }^{128}$ The decision to adopt this measure represents a missed opportunity for decisive action, based on sound scientific advice, to reduce fishing effort for bigeye and yellowfin tuna. At the conclusion of the meeting, the Commission Chair acknowledged that: 'scientists have stated that yellowfin and bigeye tuna stocks cannot sustain this level of fishing and there is a need for a reduction in both effort and catch'. ${ }^{129}$

In August 2006, the second regular meeting of the Scientific Committee found that there was a high probability (>99 per cent) that bigeye tuna was subject to overfishing. In order to maintain the

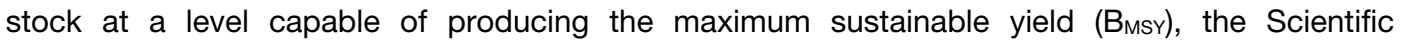
Committee recommended a 25 per cent reduction in fishing mortality from the average levels for 2001-2004. The Scientific Committee also found that it was likely (73 per cent) that yellowfin tuna was subject to overfishing and recommended a 10 per cent reduction in fishing mortality from the average levels for 2001-2004 in order to maintain the stock at a level capable of producing the maximum sustainable yield (BMsY). For both species, the Committee noted that further reductions would be required to maintain equilibrium average biomass above $\mathrm{B}_{\mathrm{MSY}}{ }^{130}$ Despite these strong

124 Q. Hanich, Western and Central Pacific Fisheries Commission: Roles, Functions, Committees, Working Groups and Observers, NGO and Civil Society Workshop on Oceanic Fisheries Management, Suva, Fiji, 24-25 April 2007.

125 WCPO Convention, Art. 5.

126 P. Ward et al., Science Arrangements for the Regional Management of Tuna Fisheries, Marine Policy, vol. 24, no. 2 (2000), p. 93.

127 WCPFC, Report of the First Regular Session of the Scientific Committee, Noumea, New Caledonia, 8-19 August 2005, pp. 33-34.

128 WCPFC, Conservation and Management Measures for Bigeye and Yellowfin Tuna, 2005, CCM 2005-01.

129 WCPFC, Press Release: Major Tuna Conference Concludes in Pohnpei, 16 December 2005, at www.wcpfc.int/press/Comm2_press_release.pdf

130 WCPFC, Report of the Second Regular Session of the Scientific Committee, Manila, Philippines, 7-18 August 2006, pp. 3,7. Maintaining biomass above BMSY would be consistent with the Commission members' obligation to apply the precautionary approach to conservation and management decisions: WCPO Convention, Art. 5. 
findings, the third session of the Commission adopted a conservation and management measure that failed to require any reduction in the level of effort or catch for bigeye or yellowfin tuna from 2001-2004 levels. ${ }^{131}$

To its credit, the Commission has adopted a number of conservation and management measures aimed at reducing the environmental impact of fishing operations in the region including measures dealing with non-target fish species, sea turtles, sea birds, swordfish, striped marlin, and sharks. The Commission has also adopted measures to support monitoring, control, and surveillance - including measures establishing a regional vessel monitoring system, a regional observer programme, boarding and inspection procedures, and an illegal, unregulated, and unreported fishing vessel register. However, the unwillingness of Commission members to adopt binding targets for reduction in effort and catch for bigeye and yellowfin tuna reflects a disturbing failure to fulfil the primary objectives of its governing convention.

Regional fisheries management organizations around the world have been strongly criticized for their failure to prevent overexploitation of highly migratory fish stocks:

RFMOs have generally failed to prevent over-exploitation of straddling and highly migratory fish stocks, to rebuild overexploited stocks and to prevent degradation of the marine ecosystems in which fishing occurs. Not only have broader, international expectations not been met but RFMOs have also largely failed to meet the objectives of their own governing conventions, generally characterized as conservation and sustainable utilization of target stocks under their mandate. It is difficult to identify examples of sustainable management of target stocks by RFMOs. ${ }^{132}$

Establishment of a regional fisheries management organization for the Western and Central Pacific is a necessary precondition for the sustainable management of the region's highly migratory tuna resources but is not sufficient in its own right. Sadly, the first three years of the Commission's operation have mirrored the experience of other regional fisheries management organizations, in which short-term political and economic expediency has taken precedence over scientifically sound fisheries management. By deferring decisive management action, Commission members are reducing the range of options available for future management of regional tuna resources:

[T] he WCPFC is at a watershed. In common with most other RFMOs, the WCPFC is now faced with overcapacity and overfishing. Other than the recently agreed conservation and management measures, comprehensive management, including allocation, appears to be some way off. Faced with increasingly strong warnings about the biological status of the stock from scientific advisors, as well as continuing investment and increasing capacity, the window of opportunity to take effective action is closing fast. ${ }^{133}$

131 WCPFC, supra note 128.

132 A. Willock and M. Lack, Follow the Leader: Learning from Experience and Best Practice in Regional Fisheries Management Organizations (Gland, Switzerland, and Sydney, Australia: WWF International and TRAFFIC International, 2006).

133 A. Willock and I. Cartwright, Conservation Implications of Allocation under the Western and Central Pacific Fisheries Commission (Sydney, Australia: WWF Australia and TRAFFIC Oceania, 2006), p. 8. 
The relative health of the region's tuna stocks to date has largely been a product of the robustness of the resource rather than sound management. Until recently, there has been little pressure on States to limit fishing effort or to clearly allocate fishing rights. Experience worldwide, however, has shown that uncontrolled fishing inevitably results in overfishing. There is an urgent need for the Commission to rise to this challenge: 'With so much at stake, it must quickly begin to work. The Commission has the best opportunity of all the world's regional fisheries management organizations to successfully manage its fish stocks; it must not fail. ${ }^{134}$

Pacific island countries, due to their dependence on tuna fisheries, have a strong incentive to ensure the long-term viability of the stocks by reducing total allowable catch. According to Willock and Cartwright, FFA member States may hold the key to a successful conservation and management outcome: 'One of the major features of the region is the FFA group, which, if choosing to display cohesion and strength and adopt its often advocated stewardship role, could be the factor that turns the tide in the Commission. ${ }^{135}$

\subsection{Conclusion}

The sustainable management of tuna resources, to ensure conservation of the resource and to maximize economic benefits for developing island States, is a key issue for development in the Western and Central Pacific region. The migratory nature of the species, combined with certain political and economic factors, have limited the ability of individual countries to achieve optimal conservation and development outcomes within their marine territories. Regional collaboration has been, and will continue to be, crucial for the sustainable management of this rich transboundary resource.

Over the last 30 years, the States and Territories of the region have made substantial progress in the establishment of an effective legal and institutional framework for the sustainable management of tuna resources. Nonetheless, resource conservation challenges remain and will become more urgent as fishing pressures in the region increase. A robust and responsive decision-making framework, together with the political will to adopt and implement effective conservation and management measures, will be essential to the long-term conservation of the resource and the sustainable development of the region.

The Forum Fisheries Agency has played a central role in the development of fisheries management across the region. The contribution of the FFA is indisputable. Collaboration between coastal States, to the exclusion of distant-water fishing nations, has provided an efficient and effective mechanism for developing and implementing innovative fisheries policies and programmes and has led to significant improvements in the management of tuna resources within the jurisdiction of its member States.

The establishment of the Western and Central Pacific Fisheries Commission presents an important opportunity for sustainable transboundary management of tuna resources in the region. The Commission provides a forum for coastal States and distant-water fishing nations to enter into 
multilateral negotiations for the purpose of adopting binding conservation and management measures for highly migratory fish stocks, including setting the total allowable catch or level of fishing effort in the Convention area.

The first three years of the Commission's operation have revealed a lack of political will to adopt binding measures to prevent continued overfishing of bigeye and yellowfin tuna, despite increasingly urgent warnings from the Commission's own Scientific Committee. The working relationship developed between FFA member States in recent decades may present the best hope of advancing the collective interest of the coastal states in the sustainable and equitable management of the region's rich tuna resources.

Regional management of tuna resources in the Western and Central Pacific Ocean is a living example of transboundary resource management in evolution. The stakes are high, but the countries concerned have made substantial progress in the development of a legal and institutional framework to support rational and equitable use of the resources in future decades. The actions of these nations over the next few years will determine, in large part, the future of this vast and precious resource. 



\title{
12 A Breakthrough in Solving the Indonesian Haze?
}

\author{
Koh Kheng-Lian ${ }^{1}$
}

\subsection{Introduction}

Established in 1967, ${ }^{2}$ ASEAN - the Association of Southeast Asian Nations - consists of 10 member States: Brunei, Cambodia, Indonesia, Laos, Malaysia, Myanmar, the Philippines, Singapore, Thailand, and Vietnam.

Under the ASEAN Agreement on Transboundary Haze Pollution, 2002 (ATHP), 'haze pollution' is defined in Article 1 (6) as: ${ }^{3}$

smoke resulting from land and/or forest fire which causes deleterious effects of such a nature as to endanger human health, harm living resources and ecosystems and material property and impair or interfere with amenities and other legitimate uses of the environment. ${ }^{4}$

In Indonesia, haze was the result of land-clearing fires for oil palm plantations; also, Indonesia farmers have practised swidden agriculture for thousands of years. ${ }^{5}$ Burning is the cheapest way to clear land. At times, the fires were exacerbated by El Niños. It should also be mentioned that in the mid-1990s, former President Suharto's Mega Rice Project to turn 1 million hectares of peat land in Central Kalimantan into rice cropland was a complete ecological disaster and the source of the haze that blanketed Singapore and Malaysia in July 1997 to May $1998 .{ }^{6}$

I might add that the term 'haze' was used by ASEAN as a euphemism to play down the impact of the Indonesian fires even though they had wrought disaster on health, transportation, construction, tourism, forestry, and agriculture, not to mention having an economic impact. For example, during one of the worst episodes in 1997-1998, damage to regional economies affected by the haze was US $\$ 9$ billion, according to the ASEAN Secretariat. ${ }^{7}$ Also, during this episode about 2.5 million tonnes of carbon dioxide were pumped into the atmosphere. 'Playing down' the

1 Emeritus Professor, Faculty of Law, National University of Singapore and Director, Asia- Pacific Centre for Environmental Law.

2 The ASEAN Declaration (Bangkok Declaration), Bangkok, 8 August 1967, see K.L. Koh (complier), Selected ASEAN Documents on the Environment (APCEL Document Series: 1996), pp. ii-iv; www.aseansec.org/1212.htm, accessed 1 March 2007.

3 Agreement on Transboundary Haze Pollution (ATHP), at www.fire.uni-freiburg.de/se_asia/ projects/ASEAN Agreement.pdf, accessed 1 March 2007.

4 Ed., in Fire, Smoke, and Haze: The ASEAN Response Strategy (Association of Southeast Asian Nations (ASEAN) and Asian Development Bank (ADB): 2001), p. 61. Before the ATHP, the term 'haze' was described by S Tahir Qadri as 'the 'dirty cloud of haze' that gives the fire a regional or transboundary dimension and brings in the social dimension of health and safety.'

5 Ibid at xiii-xvi.

6 John McBeth, Suharto's Mega Rice Project: A Fertile Seed Springs from a Barren Plan, The Straits Times, Review, 12 April 2007.

7 Why Jakarta Should Accept International Help, The Straits Times, 4 November 2006.

8 lbid. 
problem at the initial stages of the haze was consistent with the ASEAN Way of doing things (discussed in the next section). However, after over 12 years of almost annual recurrence, ${ }^{9}$ ASEAN's patience has worn thin. ${ }^{10}$

Much ink has flowed on the haze. This chapter will not deal with what has been written except give excerpts of the publications in relevant sections. Rather, the chapter will assess the progressive development of the role of ASEAN in dealing with the haze from the 1990s when it spilled into Indonesia's neighbouring countries - Malaysia and Singapore, the two worst hit areas. The haze had at times also affected Brunei Darussalam, Thailand, and the Philippines. The chapter will also consider the renewed vigour ASEAN in solving the haze following recurrence of the haze in 2006.

This is a timely chapter as a 'breakthrough' (or at least a potential breakthrough) seems to be on the horizon. Moreover, ASEAN member States, particularly those affected, are making concerted efforts with Indonesia.

\subsection{Setting the stage}

In understanding the approach that has so far been undertaken by ASEAN, we need to examine the ASEAN Way of doing things - or ASEAN governance. The crux of the ASEAN Way is agreement by consensus - musyawarah. It is nonconfrontational and generally typified by soft laws rather than hard laws. Of course, there are other reasons why many environmental instruments take the form of soft laws, and one might say that the ASEAN Way is no different. ${ }^{11}$ However, in the ASEAN Way, even if there is a hard law instrument, such as the ASEAN Agreement on Transboundary Haze Pollution, 2002 (ATHP), the burden of implementation, compliance, and enforcement rests with the member States, as there is no central ASEAN bureaucracy and no ASEAN judiciary to enforce the laws. There are no sanctions imposed by ASEAN should a member State fail to abide by its responsibilities under the ATHP, nor are there any monitoring mechanisms. Thus, much is left to the national level to implement the ASEAN environmental instruments.

While the ASEAN Way has served its purpose to build confidence (although at times such confidence may wane, as described later), it needs to be reviewed in light of many complicated problems that require more cohesion and legal teeth to deal with. ${ }^{12}$ The ASEAN Way is now ready to move forward to the next stage under the forthcoming ASEAN Charter. Ong Keng Yong,

9 Third ASEAN State of the Environment Report 2006, Chapter 7: Atmosphere, p. 87.

10 See, for example, The Haze: Shut Up and Don't Speak Out, at http://kitana.wordpress.com/2006/10/15/ the-haze-shut-up-and-dont-speak-out/, accessed 1 March 2007.

11 Edith Brown Weiss (ed.), International Compliance with Nonbinding Accords (Washington, DC: American Society of International Law, 1997), 1; Weiss notes that soft laws are flexible and can set standards and behaviour of states and non-state actors.

12 Koh Kheng-Lian and N.A. Robinson, Strengthening Sustainable Development in Regional InterGovernmental Governance: Lessons from the 'ASEAN Way', Singapore Journal of International and Comparative Law, 2002, pp. 640-682; Koh Kheng-Lian and N.A. Robinson, Regional Environmental Governance: Examining the Association of Southeast Asian Nations (ASEAN) Model, in Daniel C. Esty and Maria H Ivanova (eds.), Global Environmental Governance - Options \& Opportunities (New Haven, CT: Yale School of Forestry and Environmental Studies: 2002), pp. 101-120; Review of ASEAN's Practice of Consensus, The Straits Times, 19 April 2006. 
Secretary General of ASEAN said that 'a certain formality based on a more legal regime will help ASEAN grow into a more effective regional organization'. ${ }^{13}$

It has been suggested by the Eminent Persons Group that for a more effective decision-making process, ASEAN would as a general rule proceed on consultation and consensus, especially in 'sensitive areas'. ${ }^{14}$ In other areas, if consensus cannot be achieved, decisions may be based on a simple two-thirds or three-quarters majority. Would the haze be a sensitive area, as it may involve questions of corruption, current land use, and concessions given by the Indonesian government to palm oil companies that slash and burn the forest to make way for palm oil plantations? If it is a sensitive area, it would mean that ASEAN is not able go ahead with decisions on a majority vote to deal with such issues. Yet this is an area in which ASEAN should push ahead, particularly in compliance and enforcement, and also in persuading Indonesia to ratify the ATHP.

More recently, Singapore's Deputy Prime Minister, S. Jayakumar, ${ }^{15}$ envisaged that there will be sweeping reforms in the forthcoming charter. These would include recommendations that could overcome current problems of implementation and compliance. He said there could also be 'sanctions', although the word itself may not be used. He also said that 'while consensus can be retained for more critical, sensitive areas like the foreign policy and security areas,' ASEAN must be prepared to 'take votes by majority' in other cases. He added that the principle of non-interference 'should not impede ASEAN's ability to respond to major transnational events which require concerted regional efforts' and 'may have to be adjusted where the occasion arises.'

\subsection{Evaluation of ASEAN's and Indonesia's roles in dealing with the haze from the 1990s to August 2006}

Transboundary pollution was one of the common concerns of ASEAN in the 1990s, and when the haze began to spread to some of the member countries, it became the focus of some ASEAN environmental instruments. This section looks at the relevant ASEAN instruments.

\subsubsection{ASEAN soft law environmental instruments relating to the haze}

\section{The Kuala Lumpur Accord on Environment and Development, 1990 ${ }^{16}$}

There were a number of fire episodes not only in Indonesia but also in other parts of Southeast Asia in the 1980s and 1990s that led to a number of ASEAN meetings and regional workshops on transboundary pollution. The issue was first brought up in the 1990 Kuala Lumpur Accord on Environment and Development at the 4th meeting of the ASEAN Ministers Meeting on the Environment (AMME). The meeting agreed to initiate efforts leading towards concrete steps

13 The Straits Times, 13 December 2005.

14 Report of the Eminent Persons Group on the ASEAN Charter (ASEAN: 2006) -Chap 5: Decision-Making Process, para. 63; ASEAN Reforms Required Political Will: Jaya, The Straits Times, 24 March 2007.

15 ASEAN Reforms Require Political Will: Jaya, supra note 14.

16 The Kuala Lumpur Accord on Environment and Development, at www.aseansec.org/6082.htm, accessed 1 March 2007. 
pertaining to the harmonization of transboundary pollution prevention and abatement practices. The Accord was adopted by the ASEAN Ministers for the Environment on 19 June 1990.

\section{Singapore Resolution on Environment and Development, $1992^{17}$}

The next significant policy harmonization on forest fires was reiterated in the Singapore Summit under the 18 February 1992 Singapore Resolution on Environment and Development, where it was mentioned that to promote regional co-operation towards sustainable development, the members agreed to harmonize policy directions and step up operational and technical co-operation on environmental matters such as transboundary air pollution and forest fires. ${ }^{18}$

\section{ASEAN Cooperation Plan on Transboundary Pollution, 1995}

The haze recurred in 2004 with worsening effects and for the first time spread to Malaysia, Singapore, and the Philippines. An AMME meeting was held on 26 April 2004 at Bandar Seri Begawan, Brunei. The Bandar Seri Begawan Resolution on Environment and Development, 1994 was adopted. Several subsequent meetings were held.

In Singapore, on 27 September 1994, the then all-time high of 153 on the Pollutant Standards Index was recorded due to the haze. ${ }^{19}$ This was the worst in Singapore, and it led to the establishment of an interministrial task force on the haze. The experience of the other ASEAN countries affected by the haze had earlier led to the ASEAN Meeting on the Management of Transboundary Pollution in Kuala Lumpur from 14 to 17 June $1995 .{ }^{20}$ Canada, one of the Dialogue partners, also presented a Country Report on Canada, as it has a history of managing transboundary air pollution issues on a bilateral and global level. ${ }^{21}$

It is in the nature of things that it takes a real or impending disaster for countries to react. So ASEAN took the first step in drafting the Cooperation Plan on Transboundary Atmospheric Pollution (ACPTP) after the September 1994 fire episode. At this meeting, a number of ASEAN member States - namely, Indonesia, Malaysia Thailand, Singapore, and the Philippines - presented their country reports on the subject, and the ACPTP was drafted. It reflected a significant milestone in ASEAN environmental cooperation and a common resolve to address the problem. The following were the objectives and strategies:

- To discover the origin and cause (s), nature, and extent of local and regional haze incidents;

- To prevent and control the sources of haze at both national and regional levels by applying environmentally sound technologies and by strengthening both national and regional capabilities in the assessment, mitigation, and management of haze; and

- To develop and implement national and regional emergency response plans.

The strategies that were recommended were both short-term and long-term.

17 Koh, supra note 2.

18 Ibid., pp. 70-71.

19 C.Rpt. No 5, Country Report: Singapore.

20 See also country reports on Thailand (C. Rpt. No.6 - A) and the Philippines (C. Rpt. No. 4).

21 C. Rpt. N0.8 - A. 
The best short-term strategy was to prevent anthropogencially induced forest fires, especially in land-clearing activities in timber and agricultural estates and transmigration projects. The following measures should be undertaken:

- Timely detection and prevention of forest fires through early warning systems, the deployment of ground forces, and preparedness of local communities;

- A ban on burning of biomass generated largely by development projects during dry periods, particularly in the region affected by dry weather;

- During haze episode, minimization of any generation of pollution from local sources, activation of a communication network for the sharing of information, and activation of relevant joint activities; and

- Promotion of investments in alternative uses of biomass.

As a long-term strategy, zero-burning practices and technologies that would result in pollution reduction should be promoted in all economic sectors through attractive financing by lending agencies. The longer-term measures also included awareness-building efforts to eliminate the use of fire in land-clearing activities, as well as introducing improvement of land-clearing activities through economically sound and environmentally friendly methods in agriculture. Areas susceptible to spontaneous outbreaks of fire, such as coal beds and peat fields, should be developed to enable investments in appropriate activities.

The ACPTP recommended the following activities be undertaken:

- Establish National Focal Points in each country with, inter alia, the following functions:

- make an inventory of existing resources;

- establish a regional information dissemination mechanism;

- identify types of information to be shared/disseminated;

- Expand the role of the ASEAN Specialized Meteorological Centre to develop an atmospheric transport model in order to predict the tracts and spread of smoke haze;

- Establish procedures for reporting/alerting of fires by Forestry and other relevant agencies;

- Develop a common air quality index and harmonize air quality sampling techniques;

- Develop a regional fire danger rating system;

- Share knowledge and technology in the prevention and mitigation of forest fire and other emission sources;

- Establish a mechanism for co-operation in combating forest fires and other emission sources and their points of activation;

- Expand the role of the ASEAN Institute of Forest Management to strengthen national capacity through training in forest fire management; and

- Enhance national and regional capabilities to deal with forest fires and other emission sources 
Under the ACPTP, the National Focal points consisted of the various environment agencies of the then six ASEAN member countries. It also consisted of regional institutions such as the ASEAN Specialized Meteorological Centre, the ASEAN Institute of Forest Management, the ASEAN Working Group on Forestry, the ASEAN-EC Joint Consultative Committee's Sub-Committee on Forest, and the Brunei-Indonesia-Malaysia-Philippines East ASEAN Growth Areas Sub-Committee.

In September 1995, during the Sixth Meeting of the ASEAN Senior Officials on the Environment, the Haze Technical Task Force was established to operationalize and implement the measures recommended in the ACPTP. Its tasks included demarcation of critical areas of land and forest fires, identification of critical periods for occurrence of smoke haze, monitoring and reporting on the status of projects relating to the management, and control of transboundary haze pollution involving international and developed countries. ${ }^{22}$ The haze is a sub-regional issue within ASEAN, involving only some member States. It was handled, therefore, by a Task Force rather than through the ASEAN-wide working group format. The format took some time to evolve. Forest fire management and abatement of air pollution resulting from these forest fires requires co-operation from Indonesia, Malaysia, Singapore, Brunei, the Philippines, and others. Success in co-operation can only be achieved if Indonesia does not deem it as interference in its domestic affairs.

\subsubsection{ASEAN Regional Haze Action Plan, $1997^{23}$}

In 1997, there was a severe recurrence of the haze. The ASEAN member countries decided to take more effective and concerted action to prevent and mitigate such disasters, given the significance of the social, economic and environmental impacts of transboundary atmospheric pollution in the region. The Haze Technical Task Force undertook concerted efforts to finalize a response strategy in the form of the Regional Haze Action Plan (RHAP). The RHAP was completed in December 1997 and endorsed by the ASEAN Ministerial Meeting on Haze held in Singapore from 22 to 23 December $1997 .^{24}$

The main objectives of the RHAP are to:

- Prevent forest fires through improved natural resources management policies and enforcement of relevant legislation;

- Establish operational procedures for monitoring land and forest fires; and

- Strengthen regional firefighting capabilities as well as other mitigation measures.

22 See Hazeonline Action, at www.haze-online.or.id, accessed 1 March 2007.

23 HazeOnline Action, at www.haze-online.or.id/help/rhap.php, accessed 1 March 2007.

24 ADB Support to ASEAN via a Regional Technical Assistance (RETA) 'Strengthening ASEAN's Capacity to Prevent and Mitigate Transboundary Atmospheric Pollution Resulting from Forest Fires (RETA 5778-REG)' (IFFN No. 19 - September 1998, 13-15), at www.fire.uni-freiburg.de/iffn/country/asean/ase_1.htm; Regional Haze Action, at www.aseansec.org/9059.htm, accessed 1 March 2007; see also S Tahir Qadri, Fire, Smoke, and Haze: The ASEAN Response Strategy (ASEAN and ADB: 2001); Ebinezer R Florano, Regional Environmental Cooperation without Tears or Fear: The Case of the ASEAN Regional Haze Action Plan, International Environmental Governance, Conference, Paris, 15-16 March 2004 (unpublished); Ebinezer R Florano, Regional Environmental Governance: A Study on the ASEAN Regional Haze Action Plan (RHAP) (unpublished). 
To achieve these objectives, RHAP sets out co-operative measures at national and regional levels to combat the haze. The national plans recommended include:

- Policies and strategies to curb activities that may lead to land and forest fires and control emissions from mobile and stationary sources;

- Formulation of air quality management legislation to prohibit open burning, along with strict enforcement of laws and legislation;

- Implementation of air quality monitoring and reporting regimes and surveillance of local sources of emissions, both mobile and stationary;

- Establishment of a national task force/committee to develop strategies and response plans to deal with fires and smoke haze; and

- Utilization of information technology to provide haze-related information to relevant agencies to prevent and control spread of fire and to enhance public awareness of the haze situation.

Other action plans recommended by RHAP included monitoring mechanisms by relevant ASEAN meteorological service and environmental agencies to improve communications and enhance the effectiveness of existing early warning and monitoring system. Also, national and regional land and forest firefighting capability would be strengthened.

The ASEAN Ministers requested the Asian Development Bank (ADB) to finance the RHAP. The implementation of the RHAP had the support of some 26 international organizations. The ADB responded by providing an ADB Regional Technical Assistance grant for strengthening ASEAN's capacity to prevent and mitigate transboundary atmospheric pollution. ADB and ASEAN arranged co-operation and assistance with many international and regional organizations as well. ${ }^{25}$

\subsubsection{ASEAN Agreement on Transboundary Haze Pollution, 2002}

The next step ASEAN took was to develop a hard law instrument: on 10 June 2002, the ASEAN member States adopted the Agreement on Transboundary Haze Pollution. ${ }^{26}$ The ATHP was specifically targeted at the haze in Indonesia, even though it was for general application in all

25 These include: Australian Agency for International Development, Canadian International Development Agency, European Community, Gesellschaft fuer Technische Zusammenarbeit (German Government Agency for Technical Cooperation), Hanns Seidel Foundation, Impacts Centre for South East Asia, Japan International Cooperation Agency, Singapore Environment Council, South East Asia Fire Monitoring Centre, United Nations Environment Programme, UN-FAO/ECE/ILO Team of Specialists on Forest Fire, UNDP Asia Pacific Development Information Programme, US Agency for International Development, US Centers for Disease Control and Prevention, US Environmental Protection Agency, US Forest Service, US National Oceanic and Atmospheric Administration, WALHI (an NGO umbrella organization that coordinates work with a large number of NGOs operating out of Indonesia), World Bank, World Conservation UnionIUCN, World Health Organization, World Meteorological Organization, and World Wide Fund for Nature.

26 The Agreement can be found at www.fire.uni-freiburg.de/se_asia/ projects/ASEAN-Agreement.pdf, accessed 1 March 2007; see Vientiane Action Plan (VAP) - www.aseansec.org/VAP-10th\%20ASEAN\%20Summit.pdf, accessed 1 March 2007; VAP 3.3.2, 'Land and Forest Fires and Transboundary Haze Pollution'; under 3.3.2.2, it calls for the operationalization of the ASEAN Coordinating Centre for Transboundary Haze Pollution Control to effectively implement the provisions of the ASEAN Agreement on Transboundary Haze Pollution, and in 3.3.2.3, calls on the ASEAN Transboundary Haze Pollution Control Fund to provide the required resources for regional and national level action. 
ASEAN States. It entered into force in 25 November 2003 with the ratification of seven ASEAN member States, (Brunei, Laos, Myanmar, Malaysia, Singapore, Thailand, and Vietnam). Indonesia, which has caused the forest fires, has not as yet ratified the ATHP, nor have Cambodia and the Philippines. The ATHP is a back-to-back environmental instrument with RHAP and provides a mechanism for its implementation.

Under the ATHP, each State agrees to undertake individual and joint action to assess the origin, causes, nature, and extent of land and/or forest fires and the resulting haze. They also undertake to prevent and control the sources of such land and/or forest fires and the resulting haze by applying environmentally sound policies, practices, and technologies and to strengthen national and regional capabilities and co-operation in the assessment, prevention, mitigation, and management of land and/or forest fires and the resulting haze.

Article 7 requires each Party to take appropriate measures to monitor all fire-prone areas, all land and/or forest fires, the environmental conditions conducive to such land and/or forest fires, and haze pollution arising from such land and/or forest fires.

Parties must also develop strategies and identify, manage, and control risks to human health and also national emergency response by developing legislative, administrative, and financial resources to mobilize equipment, materials, and human resources.

Article 9 requires each Party to undertake measures to prevent and control activities that may lead to transboundary haze pollution.

An ASEAN Co-ordinating Centre for Transboundary Haze Pollution Control is to be established under Article 5 to monitor, assess, prevent, and put in place national emergency plans. Each Party must designate one or more bodies to function as National Monitoring Centres to undertake monitoring and to communicate to the Co-ordinating Centre. In the event of emergency, each Party must initiate immediate action to control or put out the fires.

Like most global and regional environmental treaties, the ATHP is a framework agreement. It provides only general principles and guidelines. The Parties are under an obligation to develop their legislative, administrative, and financial resources. Parties are also to provide sanctions under Article 9, which deals with 'prevention'. At the subregional level, however, ASEAN cannot sanction Parties if they fail to comply with its provisions. Perhaps the forthcoming ASEAN Charter ${ }^{27}$ may provide for some of the current gaps in ATHP and give it more teeth to strengthen its role in solving the haze.

\subsection{An evaluation - the ASEAN and Indonesian levels}

Before discussing the potential 'breakthrough' in solving the haze, let us note the progressive efforts ASEAN made. These include plans, programmes, strategies, resolutions, and declarations to keep up with the progress and, finally, the development of a hard law instrument, the ATHP. Was the progress too slow? For progress to be made, it is vital that Indonesia's efforts are in sync with

27 Report of the Eminent Persons Group on the ASEAN Charter (ASEAN: 2006), Chapter 6: Dispute Settlement Mechanisms, para. 64. 
those of ASEAN and vice versa. Indonesia has not even ratified the ATHP for which it was formulated. While ASEAN's efforts could have been more effective in terms of the scoping of the ATHP, nonetheless, the haze issues are very complex and involve a mix of political, economic, and sociocultural dimensions. While it was clear that cooperation was needed, it was not clear how this could best be done the ASEAN Way.

Criticisms of the ASEAN Way are not altogether justified. As earlier noted, it had a positive role to play in confidence building in its formative years and thus applies throughout the other 'pillars' of ASEAN - namely, the security community (political), the economic community, and the sociocultural community (which includes the environment). This is vital even before ASEAN could cooperate or collaborate. Its usefulness in formulating policies, plans of action, programmes, and strategies across the region should not be overlooked. ${ }^{28}$

In the future, things will not remain the same, as ASEAN is now developing an ASEAN Charter that will give more legal teeth to implementation and compliance. Having said that, and until the next major change in ASEAN's governance, it did not help that there is no central bureaucracy to impose sanctions on a member State that fails to meet its obligations, even though the ATHP is a hard law instrument. (In any case, Indonesia has not ratified it.) Some critics pointed to the inefficacy of soft laws over the ATHP to deal with the haze. It is submitted that the dichotomy between soft and hard laws is not always critical to implementation and compliance. As pointed out by Edith Brown Weiss in her Introduction to International Compliance with Nonbinding Accords, '[w]hile countries have long relied on binding legal instruments or binding rules of international law, nonbinding legal instruments are an increasingly important source of international law'. ${ }^{29}$ In an earlier article, Weiss observed: ${ }^{30}$

How we make, implement, and comply with international law has been changing ...traditional model centers on states, relies on legal instruments to provide fixed solutions to clearly defined problems in a world that changes slowly,... The line between international and national law is sharply drawn, and there is a strong preference for binding agreements. But the world is moving to a dynamic, more open and complex system. ...

The new model is a network of states, intergovernmental organizations... intricately connected through binding and nonbinding or incompletely binding instruments and associated institutions. [emphasis added]

I would add that implementation of and compliance with international law or, in our case, the implementation and compliance of ASEAN (subregional) soft and hard law instruments by a member State may depend on other factors, as will be seen in the latter part of this chapter. In our case study, these have included the dynamics between Indonesia and Singapore relating to a

28 Koh and Robinson, Strengthening Sustainable Development, supra note 12; Koh and Robinson, Regional Environmental Governance, supra note 12.

29 Weiss, supra note 11, p. 1.

30 New Directions in International Environmental Law, in United Nations Congress on Public International Law (New York: 1995) reproduced in D.G. Craig, N.A. Robinson, and K.-L. Koh, Capacity Building for Environmental Law in the Asian and Pacific Region: Approaches and Resources, Vol I, 2nd ed. (ADB: 2003), p. 9. 
'package deal' of issues that may not be related to the haze problem; funding to carry out the implementation; and manageable schemes, such as 'adopting a district' by a particular member country for ground-level performance.

All in all, implementation and compliance are complex and involve a network of players such as States, international organizations, the private sectors, nongovernmental organizations (NGOs), and others. These players are dynamic and have blurred the demarcation between soft and hard laws that Weiss observed. It also requires confidence building if member States are to deal with one another - in the case of ASEAN, the fragile relationship of member States has reared its ugly head from time to time. This has taken quite a toll in finding solutions for the haze problem. To top it all off, misunderstandings, inadequate knowledge of the implications of environmental instruments such as the doctrine of sovereignty, and 'non-interference of domestic affairs' have added to finding a solution to the haze problem. However, after over a decade, a breakthrough seems to be on the horizon.

In the meantime, the internal problems of Indonesia that have hitherto stood in the way of a solution will be listed, as they are well documented and so will not be dealt with here. These include: ${ }^{31}$

- Little or no political will;

- Weak environmental governance and management;

- Continued use of fires to clear land for oil palm plantations and swidden agriculture;

- Economic reasons for continued burning to clear land for palm oil industry and agriculture;

- Indonesia's lack of capacity both in terms of technical and financial terms to deal with the haze and find alternative means of livelihood to firefighting;

- Endemic corruption in the system;

- Overlapping jurisdiction between the central and provincial agencies, with no clear demarcation of powers;

- Inappropriate land use - short-term land use that encourages a rapid conversion rate of land from forest to plantation using fires; use of virgin land; lack of incentives to practice sustainable forestry;

31 Kheng Lian Koh, ASEAN Air Plan: Up in Smoke, The Environmental Forum, vol. 15, no. 1 (Jan/Feb 1998), pp. 50-51; Simon S.C. Tay, The South-East Asian Fires and Sustainable Development: What Should be Done About the Haze? Indonesian Quarterly, vol. xxvi, no. 2, pp.99-117; N.A. Robinson, 'Forest Fires as a Common International Concern: Precedents for the Progressive Development of International Environmental Law, Pace Environmental Law Review, vol. 18 (2000); S Tahir Qadri (ed.), in Fire, Smoke, and Haze: The ASEAN Response Strategy (ASEAN \& ADB: 2001); Ebinezer R. Florano, Assessment of the 'Strengths' of the New ASEAN Agreement on Transboundary Haze Pollution, International Review for Environmental Strategies, vo1. 4, no. 1 (2003), pp. 127-147; Florano, Regional Environmental Cooperation, supra note 24; Florano, Regional Environmental Governance, supra note 24; Alan K.J. Tan, The ASEAN Agreement on Transboundary Haze Pollution: Prospects for Compliance and Effectiveness in Post-Suharto Indonesia, New York University Environmental Law Journal, vol. 13, no. 3 (2005), p. 647; Ednardo Araral, The Fire and Haze Problem: Causes, Consequences and Long Term Solutions, October 2006 (unpublished). 
- Misguided development of environmental and development policies;

- Indonesian laws dealing with forest fires inadequate to prosecute culprits; ${ }^{32}$

- Since 2000, out of dozens of companies investigated, only 11 had been brought to trial. The most severe punishments meted out were a two-year jail sentence, and some sentences were later reduced to eight months. The most difficult issue is a question of proofing that the accused started the fires. The cases were classified as criminal law cases rather than corruption. ${ }^{33}$ Also, many of the prosecutions involved the 'small' offenders and not the big companies;

- There are a number of laws in Indonesia dealing with forest fines but they are not adequately compiled with or enforced; ${ }^{34}$

- Impoverished farmers need to clear land cheaply;

- El Niño drought cycle (natural cause);

- Farmers do not have alternative means of livelihood at the moment;

- Burning is the cheapest way to clear land;

- Farmers do not have security of tenure over their farms so they do not have long-term incentives to employ sustainability principles;

- Concessions decisions tainted with lack of transparency and corruption;

- Weak regulations;

- Indonesia perceived as not serious about fighting haze; ${ }^{35}$

- Lack of funding;

- Ineffective compliance and enforcement of laws; and

- Conversion of peat swamp forests into concessions for palm oil and pulp plantations.

At the bottom line is hard economics - there is a global demand for palm oil products from the world community. Unless the buying stops, the palm oil industry will continue. It is not realistic to stop the sale of palm oil products. The reality is therefore to have a sustainable palm oil industry. One way is to have eco-labelling of products. This was not addressed in the ADHP or other instruments.

32 No Bite to Jakarta's Laws on Forest Burning, The Straits Times, 4 November 2006; Indonesia Must Manage Environment Better: Don, The Straits Times, 27 October 2006.

33 Indonesia Must Manage Environment Better, supra note 32.

34 The Environmental Management Act, 1997 No. 23/1997 requires a licence for an activity that has significant impact on the environment - an ElA must be obtained. The Forestry Act 1999, No. 41, Article 49 stipulates that the licence holder in the field of forestry and plantation is responsible for the occurrence of the forest fires in his jurisdiction, and Article 50 provides that every person is prohibited from burning the forest unless he has an authorized licence for special or limited purposes. There are loopholes in these laws. See No Bite to Jakarta's Laws, supra note 32. See also Tan, supra note 31, p. 686 et seq. where he discusses in detail the relevant Indonesian laws and the inadequacies as well as poor compliance and enforcement.

The Straits Times, 28 October 2006. 


\subsection{Breakthrough in solving the haze: from August 2006?}

The recurrence of the haze from August to November 2006 seems to have worn out the patience of ASEAN and the member States affected by its yearly recurrence over the last 15 years. There has been a renewed and vigorous attempt on the part of ASEAN and even Indonesia to take positive steps to deal with the haze. Indonesia's President Susilo Bambang Yudhoyono apologized and assured ASEAN that it would soon ratify the ATHP. ${ }^{36}$ In the meanwhile, he said that Indonesia has taken and would also be taking the following steps: ${ }^{37}$

- It has now empowered police to seize land without having first to prove culpability. Difficulty and failure of proving who had started the fire had for too long bred defiance and indifference towards the law;

- Environment Minister Rachmat Witoelar is now determined to deal with the hitherto weak enforcement, which has been the singular problem in the prevention of burning; ${ }^{38}$

- Comprehensive data on local and foreign companies in the plantation business will be compiled; ${ }^{39}$ and

- Small farmers will be encouraged to abandon slash-and-burn agriculture and use other greener methods to clear land.

Other measures suggested by the Environment Minister, include:

- Land will be confiscated where suspicious fires have broken out, and plantation owners will be prevented from extending their land holdings illegally;

- Control of peat fires (e.g. the water level in peat areas will be raised to reduce the fire hazards under the ASEAN Peatland Management Strategy (2006-2020); ${ }^{40}$ and

- Plantation owners will be held responsible if fires occur near their plantations without having to prove that they started the fire. In other words, strict liability will be imposed. Their land cannot then be cultivated.

Environment Minister Witoelar stated: 'Indonesia hopes to end haze within two years: We expect to have a decrease of 30 per cent to 40 per cent of happenings there. ${ }^{41}$ For 2007 , he said that Indonesia hoped to reduce the annual incidence of forest fire by half. ${ }^{42}$ It was also reported by Singapore's Minister of the Environment and Water Resources, Dr Yaacob Ibrahim, that Indonesia had budgeted 700 billion rupiah (S\$110 million) a year for its national fire plan. He said its plan to halve the number of hotspots was commendable. ${ }^{43}$

36 Sorry for the Haze, Says Indonesian President SBY, Today, 12 October 2006; Nearly All Fires Are Out, Says Indonesia: ASEAN Ministers in Jakarta to Hammer Out Haze Action Plan, Today, 3 November 2006.

37 Light through the Haze, The Straits Times, 6 December 2006.

38 Ibid.

39 lbid.

40 http://www.haze-online.or.id/misc/apmi/index.php?PG=APMS, accessed 1 March 2007.

41 The Straits Times, 5 December 2006.

42 Indonesia Aims to Cut Forest Fires by Half This Year, Today, 1 March 2007.

43 S'pore, Indonesia Working on Plan to Prevent Fires at Hotspot, The Straits Times, 7 March 2007. 
Despite President Susilo Bambang Yudhoyono's assurance, the Indonesian Forum for the Environment (WALHI), an NGO, is of the view that the government does not have the political will to stop companies from exploiting the country's national resources. ${ }^{44}$ So much for the dynamics of politics, which can be unpredictable!

\subsubsection{Cebu Resolution on Sustainable Development, 2006: Haze}

At the 11th ASEAN Ministers of the Environment meeting in Cebu held from 9 to 11 November 2006, the haze was discussed extensively. ${ }^{45}$ The Preamble to the Resolution was emphatic in dealing with the haze:

- Express our serious concern over the recurring transboundary haze pollution which was aggravated by the extended drier weather condition during El Nino years, and resolve to further enhance preventive, monitoring and mitigation efforts to address land and forest fires;

- Commit to continue assisting member countries affected by land and forest fires within the framework of the ASEAN Agreement on Transboundary Haze Pollution, and for this purpose encourage the remaining member countries to quickly ratify the Agreement; and

- Establish the Sub-regional Ministerial Steering Committee consisting of Ministers from the 5 most affected countries, namely, Brunei Darussalam, Indonesia, Malaysia, Singapore and Thailand to oversee the implementation of concrete actions to address land and forest fires and the resulting transboundary haze pollution.

At the Cebu meeting, Environment Minister Witoelar discussed an action plan for Indonesia that would include the following:

- Create more effective enforcement against plantation companies and forest concessionaries caught violating laws against indiscriminate burning to clear land;

- Make it mandatory for plantations and companies to comply with firefighting regulations and help pay for firefighting equipment and personnel in their regions;

- Establish a panel of experts;

- Conduct water bombing and cloud-seeding operations when they are most effective, during the early stages of the fires;

- Develop an emergency response system;

- Form the ASEAN Haze Fund and hold joint taskforces in fire prevention and suppression, with plantation owners made to contribute to a regional fund to fight the haze; and

- Make plantation conglomerates that are granted tree-cutting rights foot part of the expenses for firefighting and control measures.

44 Indonesia Facing Ecological Disaster, Today, 6 March 2007.

45 The Cebu Resolution on Sustainable Development called for greater collaboration to address issues of the haze; see www.aseansec.org/18915.htm, accessed 1 March 2007; Today, Nearly All Fires Are Out, supra note 36; Five ASEAN Countries Approve Anti-haze Plan, The Straits Times, 10 November 2006. 
Dr Raman Letchumanan, head of ASEAN Secretariat's Environment and Disaster Management Unit, said, 'it's very clear from the presentation and their action points that they have a very targeted immediate goal - certainly there is a greater commitment here'. But what remains to be seen is how the plan translates into action, he added. Lee Yuen Hee, chief executive officer of Singapore's National Environment Agency, described the discussions as comprehensive and noted that the plans were a good basis to solve the problem. ${ }^{46}$

\subsubsection{Action plans for 'fire-prone' districts}

Following the November Cebu meeting, which discussed adopting fire-prone districts, ${ }^{47}$ the 12 th AMME on haze held at Bandar Seri Begawan from 28 February - 1 March 2007 in Brunei further developed the concept.

At this meeting, it was noted that Indonesia had made great progress and had drawn up a comprehensive Plan of Action to deal with land and forest fires, which included actions at the national level and local level. The meeting also expressed satisfaction at the highest level of support shown nationally and the significant progress made in implementing the Plan of Action, which included: 48

- The 35 fire-prone districts are currently developing their respective action plans, in line with Indonesia's Plan of Action;

- The relevant national agencies have allocated budget to support the implementation of Indonesia's Plan of Action and identified experts for the Plan of Action and the Panel of ASEAN Experts;

- A monitoring and law enforcement system has been put in place in Riau Province that proved effective in reducing the number of hotspots in February 2007;

- Stringent law enforcement is being implemented in the fire-prone areas as a deterrent for both individuals and plantation companies;

- Task forces have been set up in Kalimantan (based in Balikpapan, East Kalimantan) and in Sumatra (based in Pekanbaru, Riau) to closely monitor the fire and haze situation and give reports directly to the Minister and subsequently to the President;

- the Minister of Environment, the Minister of Forestry, and the Minister of Agriculture of Indonesia were scheduled to meet with timber processing estate, logging, and plantation companies to develop a comprehensive strategy and seek their cooperation in preventing and suppressing fires in the next dry season; and

46 See SIIA Web site, at www.siiaonline.org/news_highlights? func=viewSubmission\&sid=990\&wid=171, accessed 1 March 2007.

47 ASEAN Ministers to Flesh Out Haze Action Plan at Meeting, The Straits Times, 9 November 2006; Five ASEAN Countries Approve Anti-Haze Plan, supra note 45; Battling the Haze, One District at a Time, The Straits Times, 22 November 2006.

48 S'pore, Indonesia Working on Plan, supra note 43. 
- A Presidential Decree was being drafted to implement the national action plan on sustainable management of peatlands, with efforts focusing on rehabilitation of degraded peatlands and water management.

The Ministers also noted that Indonesia had set a target to reduce the number of hotspots by 50 per cent in 2007 in forested areas. In addition, Indonesia mobilized about 700 billion Rupiah to implement its Plan of Action especially for prevention and suppression.

The Ministers demonstrated full commitment to assist Indonesia in the implementation of its Plan of Action. In particular, Singapore is working with the Ministry of Environment of Indonesia and the Provincial Government of Jambi to develop and implement a Master Plan for the Muaro Jambi Regency. ${ }^{49}$ The plan includes a series of programmes such as fire prevention and suppression; legislation and enforcement; early warning and monitoring; regional and international collaboration; and training farmers not to use slash-and-burn. It also provides farmers with water pumps and other equipment, implementing a fire danger warning system. It will reward farmers who do not practise slash-and-burn with free fertilizers and seeds. This self-help system involving farmers and other members of the community can be very effective in forest fire management. ${ }^{50}$ If the plan is successful, it will be replicated elsewhere. Malaysia indicated that it will assist Indonesia with capacity building by undertaking a number of projects, including working with plantation companies to implement zero burning practices and other preventive measures.

Singapore will work in tandem with Indonesia's national fire plan. The measures will be managed by the Jambi government together with the 'plantation owners and the kampungs'. ${ }^{51}$ The plan was expected to be in place by the second half of 2007.

The number of meetings held over the last few months to discuss the Plan of Action bear testimony to a concerted effort to make a breakthrough. Also, dividing fire-prone areas into 35 districts for action plans and the adoption of each district by various member States or organizations make it more manageable to deal with the situation.

\subsubsection{ASEAN Haze Fund}

In the past, combating the haze has been much hampered by the lack of funds. One of the areas discussed at the 11th ASEAN Meeting in Cebu was the ASEAN Haze Fund. At its 12th AMME meeting, in Bandar Seri Begawan, Brunei, from 27 February to 6 March 2007, the Ministers discussed strategies to encourage contributions to the fund from other countries, organizations, and the private sector. At the 2nd ATHP COP meeting, the Ministers adopted the Financial Rules for the ASEAN Transboundary Haze Pollution Control Fund and agreed to establish the fund by providing an initial target amount of US $\$ 500,000$.

Indonesia, Brunei, Singapore, Malaysia, and Thailand kick-started the establishment of the haze fund, with Indonesia and Singapore committing an initial US\$50,000 each. ${ }^{52}$ These contributions

49 Spore, Indonesia Collaborate on Master Plan to Fight Haze Problem, Channelnewsasia, at www.channelnewsasia.com/stories/singaporelocalnews/view/263051/1/.html, accessed 1 March 2007.

50 See Robinson, supra note 31.

51 S'pore, Indonesia working on plan, supra note 43.

52 S'pore among First to Give to Haze Fund, The Sunday Times, 12 November 2006. 
are on a voluntary basis. Other ASEAN countries are also expected to make contributions. ADB estimated around US\$60 million a year will be needed for fire prevention and control, including providing incentives to farmers to abandon slash-and-burn land clearing. ${ }^{53}$ But with the current US $\$ 150$ million plan, it expected to halve the incidence of forest fires in $2007 .{ }^{54}$ It is significant that although Indonesia has not ratified the ATHP, the other member States have raised funds under the ATHP to deal with the haze.

\subsubsection{Establishment of an ASEAN Environmental Taskforce?}

During the Cebu meeting, a subregional ministerial steering committee made up of ministers from the five affected countries was created to oversee the implementation of concrete actions to address land and forest fires that resulted in transboundary haze pollution and to work together in enforcing environmental laws in the region. The Philippines introduced the idea of setting up a network among ASEAN member-countries for a more effective implementation of environmental laws at both the national and regional level. Should a Southeast Asian regional environmental task force be established? This question was mooted. Such a task force could establish a system of collaboration and capacity building, as well as exchange of technology, experts, training, information, and data. ${ }^{55}$ This will consolidate the earlier Taskforce on Haze. ${ }^{56}$

\subsubsection{The 'Heart of Borneo Forests' transboundary collaboration: keeping the haze at bay}

Three ASEAN member States - Indonesia, Malaysia, and Brunei - share the natural resources from Kinabatangan to Sebuku Sembakung, covering some 2.5 million hectares. These include palm oil plantations. These member States have initiated the Heart of Borneo (HOB) Conservation Plan, which was endorsed by ASEAN at the 11th ASEAN Summit, held in Kuala Lumpur on 12 December $2005 .{ }^{57}$ The plan is to protect biodiversity in the HOB, linking five protected areas and six forest reserves (each of the three states owns parts of the area). The WWF-Indonesia and the International Tropical Wildlife Organization are providing technical assistance at the national level to support the protection and sustainable development of the forest under this plan. The United States donated US\$100,000 for the project (as that country is one of the Dialogue Partners of

53 Make Plantations Pay for Haze Fund: ADB, The Straits Times, 11 November 2006; see also S'pore among First, supra note 52.

54 HazeOnline Action, at www.haze-online.or.id/news.php/ID=20070305102033, accessed 1 March 2007.

55 Asean sets up anti-haze fund, at www.sunstar.com.ph/static/ceb/2006/11/12/news/asean.sets.up.anti. haze.fund.html, accessed 1 March 2007; see also SIIA Stopping the Haze: Indonesian and ASEAN Credibility, at www.siiaonline.org/asean_must_mind_the_credibility_gap, accessed 1 March 2007; SIIA, at www.siiaonline.org/home; Programme on Transboundary Haze Prevention in Southeast Asia, at www.siiaonline.org/hazewatch, accessed 1 March 2007.

56 Indonesian and Regional Initiatives in Fire and Smoke Management and Policy Development, at www.fire.uni-freiburg.de/iffn/country/id/id_11.htm, accessed 1 March 2007.

57 Heart of Borneo, at www.panda.org/about_wwf/where_we_work/asia_pacific/our_solutions/borneo_forests/ borneo_rainforest_conservation/transboundary_collaboration/index.cfm>, accessed 1 March 2007. 
ASEAN). ${ }^{58}$ The plan would help to keep the Indonesia haze at bay or prevent it from worsening. It was signed by the three countries as the Heart of Borneo Declaration on 12 February $2007 .^{59}$

\subsubsection{A Turn of Events Affecting Solution of Haze?}

On 20 October 2006, the Prime Minister of Singapore, Lee Hsien Loong, decided to raise the haze issue at the United Nations General Assembly in order to seek assistance, as resources were needed and also enforcement. ${ }^{60} \mathrm{He}$ approached the Indonesian representatives to issue an ASEAN statement on the haze in order to get assistance from the UN family. However, Indonesia's representative, Adiyatwidi Adiwoso Asmady, stated that the haze was a domestic problem and Indonesia did not want any interference with its domestic affairs. Asmady characterized Singapore's call for international assistance as 'badgering.' She said: 61 'It is tantamount to interference in the domestic affairs of Indonesians'. She even suggested that there might be 'some malice' behind Singapore's statement to the UN. She then mentioned that there were other 'issues related to environmental degradation that also needed to be addressed - such as sand mining'. She went on to say that Singapore should 'cease to give protection, safety and sanctuary for corruptors and their ill-gotten wealth'.

Many regarded these remarks as quite a 'startling reaction', viewed objectively. In an article entitled 'Haze: Why Jakarta should accept international help', Janadas Devan, ${ }^{62}$ after recounting what was said by Asmady, said, 'All this merely for suggesting that the haze is a staggering problem, that Indonesia and ASEAN cannot cope with it themselves, and that international assistance is urgently needed?' Devan compared the tsunami disaster, when Indonesia had no difficulty accepting assistance from the international community. He pointed out: 'The haze is a man-made catastrophe, for which many Indonesians can be blamed. Though its 'scale and severity' are such that Jakarta cannot solve the problem without international help, some Indonesians find it difficult to accept that fact.' Subsequently, on 23 January 2007 Indonesia banned the export of sand to Singapore. It will be recalled that 'sand mining' was mentioned at the UN by Asmady.

Subsequently, it became clear that Indonesia was using the ban to put pressure on Singapore to sign an extradition treaty to bring to justice Indonesians who were smuggling sand into Singapore

58 'Heart of Borneo' Conservation Initiative to Receive US Fund, at http://usinfo.state.gov/ xarchives/display.html?p=washfile-english\&y=2006\&m=August\&x=20060802180241ASesuarK0.1152002;

Transboundary collaboration, at www.panda.org/about_wwf/where_we_work/asia_pacific/our_solutions/ borneo_forests/index.cfm; see also www.panda.org/news_facts/newsroom/index.cfm?uNewsID=67180, accessed 1 March 2007; Guardians of the Region's Greenery, Today, 29 November 2006.

59 Successes: A Third of Borneo to be Conserved under New Rainforest Declaration, at www.panda.org/news_facts/newsroom/index.cfm?uNewsID=93980, 1 March 2007.

60 Haze: Balls on UN Table, Indonesia Upset, at www.jeffooi.com/2006/11/haze_balls_on_un_table_ sand_ind.php, 1 March 2007.

61 The Straits Times, 4 November 2006; see also, ASEAN Needs Help to Tackle Haze: PM: International Expertise Needed to Help Nip Problem in the Bud, The Straits Times, 6 November 2006; Embassy: Jakarta Prefers to Solve Haze within ASEAN, The Straits Times, 9 November 2006.

62 Jakarta Using Sand Ban to Put Pressure on Spore, The Straits Times, 17 February 2007; Ministers Set Record Straight, Call for Calm as Neighbours Blow Hot and Cold, Today, 13 February 2007. 
and also seeking the return of some of its citizens for tax evasion and fraud. ${ }^{63}$ Indonesia again emphasized that sand mining in Indonesian islands had caused environmental degradation and also affected its maritime boundaries. Singapore's response was that the price of sand had been factored such that some proceeds of sale were ploughed back into environmental reconstruction. As to maritime boundaries, Singapore assured Indonesia that its reclamation works (using Indonesian sand) would not affect the boundaries. It also said that the extradition treaty was being worked out.

This controversy underlines the fact that solving the haze problem is not easy and may be linked with other issues that have nothing to do with the haze but that have to be dealt with as a package deal. Subsequently, it was reported in The Straits Times on 21 February 2007 that Indonesia backtracked on the claim that the ban on sand exports to Singapore was linked to the extradition treaty but maintained that the reason was to prevent future damage to the environment. However, it is not altogether clear whether this is the real reason. ${ }^{64}$ Was it Singapore's delay on the extradition treaty? ${ }^{65}$ The controversy is still continuing at the time of writing.

It should be noted that the Singapore Prime Minister's call for assistance from the UN family is not out of turn, as Article 2 of the ATHP specifically mentions that the objective is to prevent and monitor the 'transboundary haze pollution' through 'concerted national efforts and intensified regional and international co-operation'. ${ }^{66}$ Below are further remarks on the incident.

According to the discussion blog Lushhome ${ }^{67}$ :

Singapore is disappointed with Indonesia's decision. Singapore ministers had earlier raised this issue with their Indonesian counterparts, and expressed Singapore's preparedness to work with Indonesia to address their concerns. We regret that Indonesia did not take up our offer to address those concerns.

The Indonesian stance has come as a surprise.

63 Jakarta's Anti-graft Battle: Is an Extradition Treaty with Singapore the Magic Bullet, The Straits Times, 7 March 2007.

64 Ministers Set Record Straight, supra note 62; A Need to Temper those Tantrums..., The Straits Times, 20 February 2007; Jakarta Backs Down from Tough Stand, The Straits Times, 21 February 2007; Land Sand Ban Hits Riau Mining Companies Hard, and Jakarta Minister Says Foreigners Stealing Resources, The Straits Times, 5 March 2007; Singapore 'Baffled' by Report on Jakarta's Granite Export Ban, The Straits Times, 10 March 2007; The Straits Times, No Plans to Ban Granite, 14 March 2007; S'pore-bound Granite Barges Still Being Held ..., The Straits Times, 14 March 2007; Jakarta Using Spore, KL as Bogeyman? The Straits Times, 17 March 2007; Land Reclamation Not Factor in Talks with Jakarta-Spore, The Straits Times, 18 March 2007; Sand Ban Hurts Both Sides: PM, The Straits Times, 18 March 2007; Granite Supply Still Not Back to Normal, The Straits Times, 21 March 2007; Jakarta Debate Continues in S'pore Reclamation, The Straits Times, 24 March 2007; Detention of Barges: Riau Granite Miners Seek Jakarta's Help, The Straits Times, 24 March 2007; Indonesia Sand Ban: S'pore Vulnerable Side Exposed, The Straits Times, 6 April 2007; Granite Quarry Blasts 'Business' Related: Attack Was Well-Planned, Say Police, No Suspects Identified Yet, The Straits Times, 7 April 2007.

65 Jakarta's anti-graft battle, supra note 63.

66 See also VAP, para 3.3 (ii), where it is envisaged that environmental management of the haze must be intensified though, inter alia, 'international cooperation.'

67 Indonesia Bans Sand Export, Lushhome: Singapore Real Estate/Property Sharing \& Discussion Blog, at http://lushhome.wordpress.com/2007/01/25/indonesia-bans-sand-export, accessed 1 March 2007. 
This is because Singapore, which is almost entirely dependent on land sand imports from Indonesia, is one of the biggest foreign investors in Indonesia. As part of the warm bilateral ties, the Singapore government has led efforts to help set up Special Economic Zones in the Indonesian Riau region to help Indonesia woo other foreign investors.

The ban came at a time when Singapore's construction industry is booming. This has led to some thinking that the politics of envy may be behind the reason, as Singapore is forging ahead with its construction industry, including its integrated resorts. Singapore's PM Lee Hsien Loong remarked: 'Our integrated resorts won't look as beautiful as they ought to. '68

Indonesia's displeasure was also voiced by its Industry Minister, Fahmi Idris: ${ }^{69}$

Indonesia's Industry Minister Fahmi Idris is still upset at Singapore's decision to raise the haze issue at the United Nations General Assembly last month.... To register his protest at the move, Mr Fahmi boycotted a meeting of the Indonesia-Singapore joint steering committee on the Batam, Bintan and Karimun special economic zones, 'according to Antara news agency. .' I did not attend the meeting in protest of Singapore's step to table the haze issue at the UN General Assembly, though Singapore has previously agreed to tackle the problem at ASEAN (Association of 'South-east Asian Nations) level,' said Mr Fahmi, who stayed away from last Friday's meeting.

The Indonesian Minister accused Singapore of not upholding the spirit of cooperation among ASEAN member countries. He said: ${ }^{70}$

As a Cabinet minister, I also feel offended by Singapore's statement at the General Assembly that the (Indonesian) President, his ministers, the House of Representatives and the provincial administrations are not solid in tackling the spread of the haze.

If Indonesia's banning of sand to Singapore is connected with the Singapore Prime Minister's call for international assistance in solving the haze, this may have wide implications on the haze breakthrough. It puts a damper at the dawn of a breakthrough in solving the haze. In environmental law, much depends on political will, and the law is on the back burner if political sensitivities rule the day. The call for internationalizing was not intended to put the blame on Indonesia for the haze. The Second Foreign Minister of Singapore, Raymond Lim, had earlier stressed that there is 'no reason for the haze problem to affect relations between the two countries'. ${ }^{71}$ Lim explained that Singapore had to make a statement at the UN because the haze problem had global implications. It was driving away foreign investors and contributing significantly to global greenhouse emissions. Singapore had urged ASEAN to make a joint statement, but the Indonesian representative in the UN did not want the haze issue mentioned at all, added Lim. He said:

We made a factual statement which acknowledged the commitments and efforts made by Indonesia and other countries: Our statement also aimed to present a comprehensive and

68 ASEAN needs help, supra note 61.

69 Haze: Balls on UN Table, supra note 60.

70 Ibid.

71 Ministers Set Record Straight, supra note 62. 
balanced appraisal of the issue, including pointing out some of the more problematic issues that remain. ${ }^{72}$

However, Indonesia's Asmady point was that '[w]here there is already a bilateral and regional arrangement for addressing a problem, let us make full use of them instead of misusing the UN forum in a frenzy of naming and shaming'. Singapore assured Indonesia that Singapore raised the matter at the UN not to shame its neighbour but to mobilize international support that was needed. Also, the matter could not be glossed over in a debate on environmental issues at the United Nations without a serious loss of credibility to ASEAN.

Singapore felt strongly that the ASEAN countries had to identify and address this serious, longterm environmental problem in Southeast Asia. In the past, many international organizations have contributed to various initiatives on the haze ${ }^{73}$ and Singapore's attempted call for international assistance was not out of line. Indeed, as pointed out earlier, the ATHP calls for international cooperation, which includes the UN and other international organizations.

The ongoing spats do not seem to have affected the cooperation of Singapore and Indonesia on Singapore's role in the fire-prone area of Mauro, Jambi - at least for now.

\subsection{Conclusion}

Given the complexity and magnitude of the problem, which straddles not only law and policy but also the changing dynamics of politics, economics, and sociocultural dimensions, little wonder that it has taken over a decade to see a glimpse of a breakthrough. This glimmer has come about because the haze had gone beyond the limits of tolerance. Now there is a determination by ASEAN, followed by an apparent political will in Indonesia.

However, the coast is not altogether clear, as there may still be some storms to overcome. This is seen in the negative response of some Indonesians when Singapore tried to issue a strong ASEAN Statement at the United Nations to garner assistance from the UN family. Such unintended consequences can occur to thwart efforts. What followed from this incident was very surprising and puzzling, as witnessed by the current 'sandstorm' - that is, the spat over Indonesian's sale of sand to Singapore ${ }^{74}$ and the unrelated issue of the Singapore-Indonesia extradition treaty. One could say that these issues have nothing to do with Singapore trying to get assistance from the world community. However, in today's politics (including world politics), everything can be connected - national, bilateral, regional, and international relations can come in a 'package deal'.

Be that as it may, there is reason to believe that there is a sliver lining in solving or mitigating the haze problem, as Indonesia is a member of ASEAN. Under the ASEAN Vision 2020 of 1997, the member States envision 'clean and green environment ASEAN... sustainable development to

72 Spore Jakarta Ties Not Clouded by Haze, The Straits Times, 15 November 2006.

73 For example, the International Tropical Timber Organization sponsored the development of National Guidelines on Protection of Forests against fire; see IFFN No. 18, January 1998, pp. 33-36; Indonesia \& Regional Initiatives in Fire and Smoke Management and Policy Development, at www.fire.unifreiburg.de/iffn/country/id/id_11.htm, accessed 1 March 2007.

74 Indonesia Acts to Curb Smuggling of Sand to Singapore, The Sunday Times, 18 February 2007; The Shifting Sands of Statesmanship, Today, 8 March 2007. 
ensure the protection of the region's environment, the sustainability of its natural resources, and the high quality of life of its people'. ${ }^{75}$

\section{Postscript}

(1) Letter Of Intent (LOI) for the Joint Development of a Master Plan and the Implementation of Agreed Activities to deal with Land and Forest Fires in Muaro Jambi Regency, Jambi: Singapore, 7 November 2007 (http://app.mewr.gov.sg/view.asp?id=CDS5838)

- Under the LOI, a Master Plan was formulated providing an overarching framework for land clearing without the use of fire, and prevention and mitigation of peatland fires, covering the following 5 areas:
a) Fire prevention
b) Fire suppression
c) Legislation and Enforcement
d) Early Warning and Monitoring
e) International and Regional Assistance and Collaboration

- The Master Plan also seeks to establish Jambi as a model for sustainable "land clearing" practices in Indonesia, which could be replicated in other regencies or sub-districts in Jambi and other fire-prone districts. The Jambi Provincial Government will own the Master Plan. The Master Plan, if successfully implemented, can be used as a model for other fire-prone districts in Indonesia.

- Under the LOI, Singapore will offer technical assistance to implement some specific action programmes. Some programmes are long-term, while others may be implemented within 1-2 years. Singapore will implement selected action programmes jointly with Jambi. A sum of about S\$1 million has also been set aside for the implementation of these action programmes. Among the action programmes identified for joint implementation by Jambi and Singapore are two programmes on the "Development of a Fire-Danger Rating System (FDRS) for Muaro Jambi Regency" and "Developing the Capacity of Jambi Officers in Reading and Interpreting Satellite Pictures for Hotspot Information".

(2) Charter of the Association of Southeast Asian Nations (established on 20 November 2007 at the 13th ASEAN Summit, Singapore) (www.13thaseansummit.org.sg/asean/index.php/web/documents/agreements/charter_of_the_as sociation_of_southeast_asian_nations_1)

Chapter VII: Decision-Making (Article 20: Consultation and Consensus). It provides:

1. As a basic principle, decision-making in ASEAN shall be based on consultation and consensus.

2. Where consensus cannot be achieved, the ASEAN Summit may decide how a specific decision can be made. 
3. Nothing in paragraphs 1 and 2 of this Article shall affect the modes of decision-making as contained in the relevant ASEAN legal instruments.

4. In the case of a serious breach of the Charter or non-compliance, the matter shall be referred to the ASEAN Summit for decision.

[Note: Some of the recommendations of the Eminent Persons Group on the ASEAN Charter relating to decision making, such as when consensus cannot be achieved, recommended that the decision be based on a simple two-thirds or three-quarters majority (see section 12.2). These were not accepted.] 


\section{Acronyms and Abbreviations}

ACPTP Cooperation Plan on Transboundary Atmospheric Pollution (of ASEAN)

ADB Asian Development Bank

ALC automatic location communicators

AMME Ministers Meeting on the Environment (of ASEAN)

ASEAN Association of Southeast Asian Nations

ASMA Antarctic Specially Managed Area

ASPA Antarctic Specially Protected Areas

ASTI Area of Special Tourist Interest

ATCM Antarctic Treaty Consultative Meeting

ATCP Antarctic Treaty Consultative Party

ATHP Agreement on Transboundary Haze Pollution (of ASEAN)

ATS Antarctic Treaty System

BCC Benguela Current Commission

BCLME Benguela Current Large Marine Ecosystem

BENEFIT Benguela Fisheries Interaction Training Programme

BP Bank Procedure

CAS country assistance strategy (World Bank)

CBD Convention on Biological Diversity

CCAMLR Convention for the Conservation of Antarctic Marine Living Resources

CCAS Convention for the Conservation of Antarctic Seals

CEMP Ecosystem Monitoring Programme (of CAMLR Commission)

CEP Committee for Environmental Protection (Madrid Protocol)

CITES Convention on the International Trade in Endangered Species of Wild Fauna and Flora

CRAMRA Convention on the Regulation of Antarctic Mineral Resource Activities

CSO civil society organization

DRC Democratic Republic of Congo

EA environmental assessment

EEZ Exclusive Economic Zone

EIA environmental impact assessment 


\begin{tabular}{|c|c|}
\hline EU & European Union \\
\hline FAO & Food and Agriculture Organization of the United Nations \\
\hline FFA & Forum Fisheries Agency \\
\hline GDP & gross domestic product \\
\hline GEF & Global Environment Facility \\
\hline $\mathrm{HOB}$ & Heart of Borneo \\
\hline HSM & Historic Sites and Monument \\
\hline ICES & International Council for the Exploration of the Sea \\
\hline ICZM & Integrated Coastal Zone Management \\
\hline IUCN & International Union for Conservation of Nature \\
\hline IUU & illegal, unreported, and unregulated fishing \\
\hline LME & large marine ecosystem \\
\hline LOI & Letter of Intent \\
\hline MPA & Marine Protected Area; Multiple Use Planning Area \\
\hline MSSSI & Marine SSSIs \\
\hline NAC & North American Commission (of NASCO) \\
\hline NASCO & North Atlantic Salmon Conservation Organization \\
\hline NEAC & North-East Atlantic Commission (of NASCO) \\
\hline NEAFC & North-East Atlantic Fisheries Commission \\
\hline NEMA & National Environmental Management Act (South Africa) \\
\hline NGO & nongovernmental organization \\
\hline NPOA & National Plan of Action \\
\hline NWA & National Water Act (South Africa) \\
\hline ÖNB & Österreichischer Naturschutzbund (Austrian Nature Conservation Association) \\
\hline OP & Operational Policy (World Bank) \\
\hline PC & public consultation \\
\hline PCU & Programme Co-ordination Unit (of BCLME Programme) \\
\hline PIC & prior informed consent \\
\hline PSC & Programme Steering Committee (of BCLME Programme) \\
\hline RFMO & regional fisheries management organization \\
\hline RHAP & Regional Haze Action Plan (of ASEAN) \\
\hline SADC & Southern African Development Community \\
\hline
\end{tabular}


SALSEA Salmon at Sea Programme

SAP Strategic Action Plan

SCAR Scientific Committee on Antarctic Research

SPA SADC Programme of Action; Specially Protected Areas

SPC Secretariat of the Pacific Community (of the Oceanic Fisheries Programme)

SRA Specially Reserved Areas

SSSI Sites of Special Scientific Interest

SST sea surface temperature

SWA Shared Watercourse Agreements

TAC total allowable catch

TDA Transboundary Diagnostic Analysis

UNCED United Nations Conference on Environment and Development

UNCLOS United Nations Convention on the Law of the Sea

UNDP United Nations Development Programme

UNEP United Nations Environment Programme

UNFSA UN Fish Stocks Agreement

VMS vessel monitoring system

WCPFC Western and Central Pacific Fisheries Commission

WCPO Convention on the Conservation and Management of Highly Migratory Fish Stocks in the Western and Central Pacific Ocean

WGC West Greenland Commission (of NASCO)

WWF World Wildlife Fund 




IUCN Environmental Law Programme

Environmental Law Centre

Godesbergerallee 108-112

53175 Bonn, Germany

Phone: ++ 49228 / 2692231

Fax: $\quad++49228 / 2692250$

elcsecretariat@iucn.org

www.iucn.org/law 